Prepared for the U.S. Department of Energy

under Contract DE-AC05-76RL01830

\title{
Supplemental Immobilization Cast Stone Technology Development and Waste Form Qualification Testing Plan
}

JH Westsik, Jr.

RJ Serne

EM Pierce

AD Cozzi

C Chung

DJ Swanberg

May 2013

Pacific Northwest

NATIONAL LABORATORY

Proudly Operated by Battelle Since 1965 


\title{
DISCLAIMER
}

This report was prepared as an account of work sponsored by an agency of the United States Government. Neither the United States Government nor any agency thereof, nor Battelle Memorial Institute, nor any of their employees, makes any warranty, express or implied, or assumes any legal liability or responsibility for the accuracy, completeness, or usefulness of any information, apparatus, product, or process disclosed, or represents that its use would not infringe privately owned rights. Reference herein to any specific commercial product, process, or service by trade name, trademark, manufacturer, or otherwise does not necessarily constitute or imply its endorsement, recommendation, or favoring by the United States Government or any agency thereof, or Battelle Memorial Institute. The views and opinions of authors expressed herein do not necessarily state or reflect those of the United States Government or any agency thereof.

\author{
PACIFIC NORTHWEST NATIONAL LABORATORY \\ operated by \\ BATTELLE \\ for the \\ UNITED STATES DEPARTMENT OF ENERGY \\ under Contract DE-AC05-76RL01830 \\ Printed in the United States of America \\ Available to DOE and DOE contractors from the \\ Office of Scientific and Technical Information, \\ P.O. Box 62, Oak Ridge, TN 37831-0062; \\ ph: (865) 576-8401 \\ fax: $(865) 576-5728$ \\ email: reports@adonis.osti.gov \\ Available to the public from the National Technical Information Service \\ 5301 Shawnee Rd., Alexandria, VA 22312 \\ ph: (800) 553-NTIS (6847) \\ email: orders@ntis.gov <http://www.ntis.gov/about/form.aspx> \\ Online ordering: http://www.ntis.gov
}




\title{
Supplemental Immobilization Cast Stone Technology Development and Waste Form Qualification Testing Plan
}

\author{
JH Westsik, Jr. \\ RJ Serne \\ EM Pierce ${ }^{1}$ \\ AD Cozzi ${ }^{2}$ \\ C Chung \\ DJ Swanberg ${ }^{3}$
}

May 2013

Prepared for

the U.S. Department of Energy

under Contract DE-AC05-76RL01830

Pacific Northwest National Laboratory

Richland, Washington 99352

\footnotetext{
${ }^{1}$ Oak Ridge National Laboratory, Oak Ridge, Tennessee.

${ }^{2}$ Savannah River National Laboratory, Savannah River Site, Aiken, South Carolina.

${ }^{3}$ Washington River Protection Solutions, Richland, Washington.
} 


\section{Summary}

The Hanford Tank Waste Treatment and Immobilization Plant (WTP) is being constructed to treat the 56 million gallons of radioactive waste stored in 177 underground tanks at the Hanford Site. The WTP includes a pretreatment facility to separate the wastes into high-level waste (HLW) and low-activity waste (LAW) fractions for vitrification and disposal. The LAW will be converted to glass for final disposal at the Integrated Disposal Facility (IDF). The pretreatment facility will have the capacity to separate all of the tank wastes into the HLW and LAW fractions, and the HLW Vitrification Facility will have the capacity to vitrify all of the HLW. However, a second immobilization facility will be needed for the expected volume of LAW requiring immobilization. A number of alternatives, including Cast Stone-a cementitious waste form - are being considered to provide the additional LAW immobilization capacity.

The supplemental immobilization waste form must be acceptable for disposal in the IDF. This supplemental immobilization waste form testing plan outlines the testing of the waste form and immobilization process to demonstrate that the Cast Stone waste form can comply with the disposal requirements.

Specifications for the supplemental immobilization waste form have not been established. For this testing plan, Cast Stone specifications are derived from specifications for the immobilized LAW glass in the WTP contract, the waste acceptance criteria for the IDF, and the waste acceptance criteria in the IDF

portion of the Hanford Facility Resource and Recovery Act (RCRA) Permit issued by the State of Washington. This testing plan outlines the testing needed to demonstrate that the waste form can comply with these waste form specifications and acceptance criteria. The testing program must also demonstrate that the immobilization process can be controlled to consistently provide an acceptable waste form product. This testing plan also outlines the testing needed to provide the technical basis for understanding the long-term performance of the waste form in the disposal environment. These waste form performance data will be needed to support performance assessment analyses of the long-term environmental impact of immobilized LAW in the IDF. 


\section{Acronyms and Abbreviations}

3-D

ANS

ANSI

ASTM

BET

BJH

CBP

CFR

COC

DET

DOE

ECKEChem

Ecology

EDS

EPA

ERT

EXAFS

FTIR

FY

HLVIT

HLW

HTWOS

ICP

IDF

IDFWAC

ILAW

ISO

$\mathrm{L} / \mathrm{S}$

LAW

LDR

LI

$\mathrm{MCC}$

MDL

ML

MS

NMR

three-dimensional

American Nuclear Society

American National Standards Institute

ASTM International, a consensus standards organization

Brunauer-Emmett-Teller

Barret-Joyner-Halenda

Cementitious Barriers Partnership

Code of Federal Regulations

constituent of concern

determination of equivalent treatment

U.S. Department of Energy

Equilibrium-Conservation-Kinetic Equation Chemistry

Washington State Department of Ecology

energy dispersive spectroscopy

U.S. Environmental Protection Agency

electrical resistance tomography

extended X-ray absorption fine structure

Fourier transform infrared

fiscal year

land disposal restriction treatment standard for high-level waste

high-level waste

Hanford Tank Waste Operations Simulator

inductively coupled plasma

Integrated Disposal Facility

Integrated Disposal Facility Waste Acceptance Criteria

immobilized low-activity waste

International Organization for Standardization

liquid-solid ratio

low-activity waste

land disposal restriction

leachability index

Materials Characterization Center

method detection limit

minimum level of quantitation

mass spectroscopy

nuclear magnetic resonance 
$\mathrm{NRC}$

OES

ORCHESTRA

ORP

PA

PCT

PNNL

psi

PUF

QA

QAP

RCRA

RPP

SBS

SEM

SPFT

SRNL

STADIUM

STEM

STOMP

STORM

TCLP

TEM

THAMES

TOC

TPA

TRU

UTS

VHT

VSI

WAC

WFQ

WTP

XAFS

XANES

XAS

XMT

XPS
U.S. Nuclear Regulatory Commission

optical emission spectroscopy

Objects Representing CHEmical Speciation and TRAnsport models

U.S. Department of Energy Office of River Protection

performance assessment

Product Consistency Test

Pacific Northwest National Laboratory

pounds per square inch

pressurized unsaturated flow

quality assurance

Quality Assurance Program

Resource Conservation and Recovery Act

River Protection Project

submerged bed scrubber

scanning electron microscopy

single-pass flow-through

Savannah River National Laboratory

Software for Transport and Degradation in Unsaturated Materials

scanning transmission electron microscopy

Subsurface Transport Over Multiple Phases

Subsurface Transport Over Reactive Multiphases

Toxicity Characteristic Leaching Procedure

transmission electron microscopy

Thermodynamic Hydration And Microstructure Evolution Simulator total organic carbon

Tri-Party Agreement

transuranic

Universal Treatment Standard

Vapor Hydration Test

vertical scanning interferometry

Washington Administrative Code

waste form qualification

Hanford Tank Waste Treatment and Immobilization Plant

X-ray absorption fine structure

X-ray absorption near-edge structure

X-ray absorption spectroscopy

$\mathrm{X}$-ray microtomography

$\mathrm{X}$-ray photoelectron spectroscopy 
XRD

XRF
X-ray diffraction

$\mathrm{X}$-ray fluorescence 


\section{Acknowledgements}

The authors thank Dave Swanberg at Washington River Protection Solutions for project funding and programmatic guidance. We acknowledge the technical review provided by Wooyong Um, Larry

Ulbricht, Fred Mann, and Rose Russell. The efforts of Maura Zimmerschied and Susan Tackett in editing and preparing the document are greatly appreciated. 


\section{Contents}

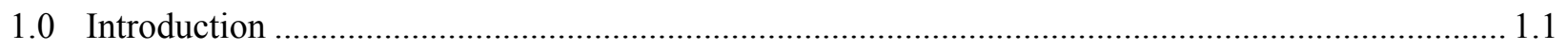

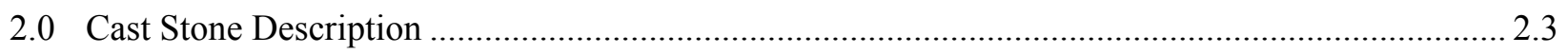

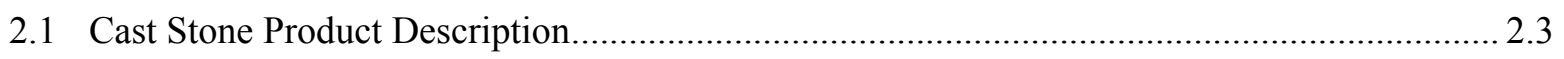

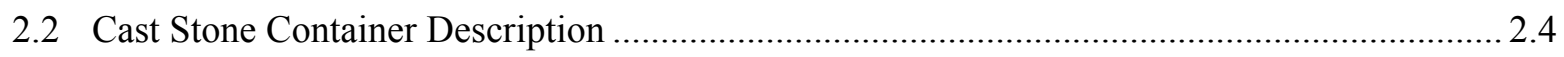

2.3 Cast Stone Process Description............................................................................................... 2.5

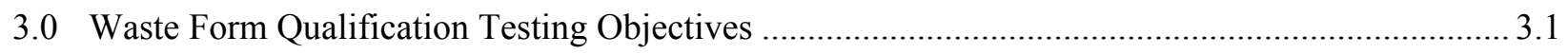

3.1 Provide for Acceptance of Waste Form at Integrated Disposal Facility .................................. 3.1

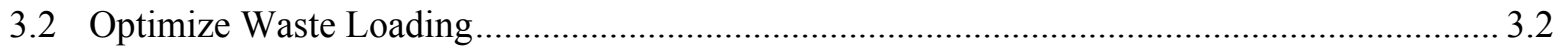

3.3 Demonstrate Waste Form Over Expected Range of Wastes ................................................. 3.2

3.4 Define and Demonstrate Product Control Strategy .............................................................. 3.2

3.5 Provide Data to Support Risk and Performance Assessments .............................................. 3.2

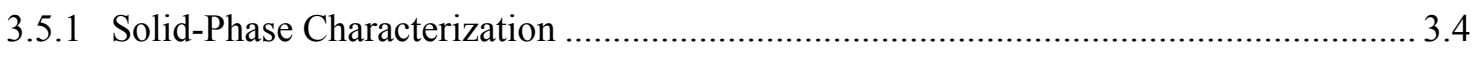

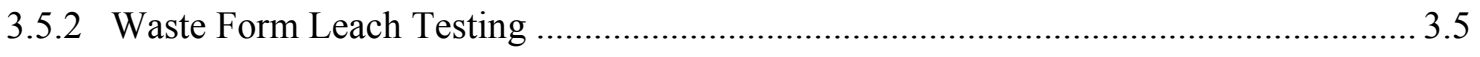

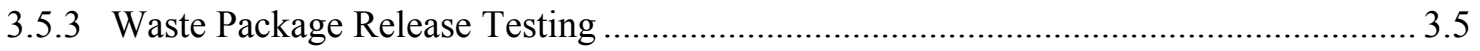

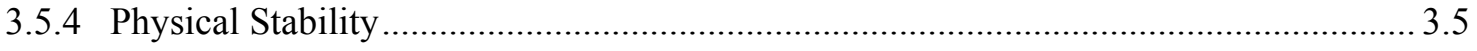

3.5.5 Update Waste Form Release Conceptual Model and Code........................................ 3.6

3.5.6 Adsorption Tests with Waste Form Leachates and Hanford Formation

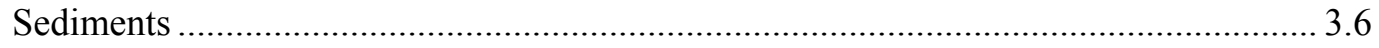

3.5.7 Performance Assessment Model Validation .............................................................. 3.6

4.0 Cast Stone Waste Form Qualification Testing Elements........................................................... 4.1

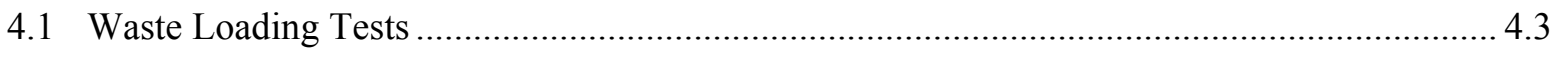

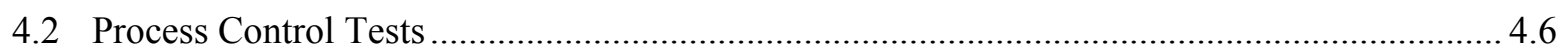

4.3 Full-Scale Waste Form Package Tests .......................................................................... 4.7

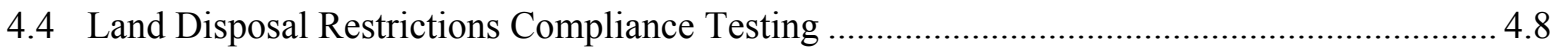

4.5 Cast Stone Physical and Chemical Properties (Laboratory Scale) ........................................ 4.10

4.5.1 Cast Stone Processing Properties .......................................................................... 4.10

4.5.2 Cast Stone Waste Form Properties ....................................................................... 4.11

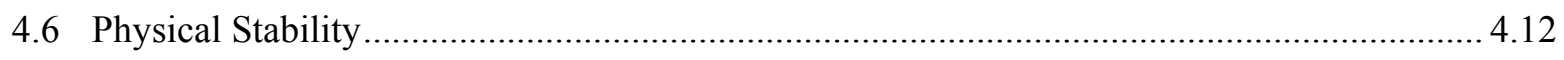

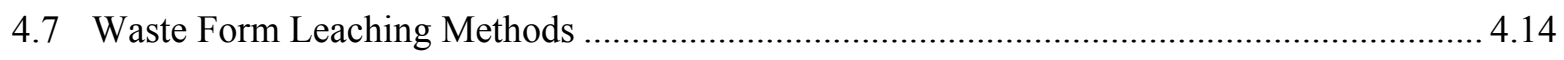

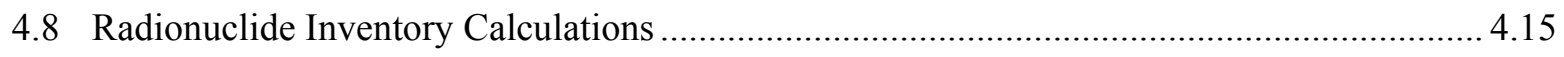

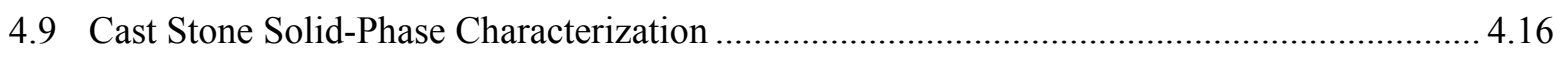

4.10 Waste Form Leach Testing —PA Support........................................................................ 4.18

4.10.1 Cast Stone Monolith Leach Testing ........................................................................... 4.19 
4.10.2 EPA 1313 and 1316 Batch Leach Tests Using Crushed LAW Cast Stone Waste Forms

4.10.3 EPA 1314 Flow-Through Leach Tests Using Crushed LAW Cast Stone Waste Forms 4.24

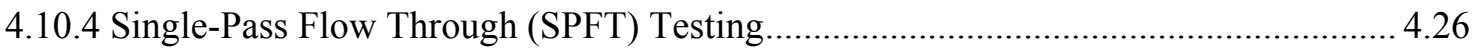

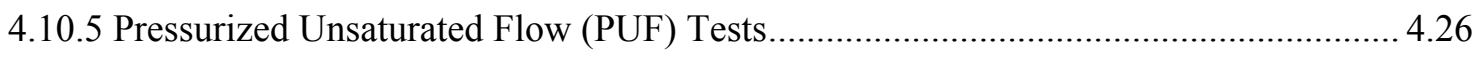

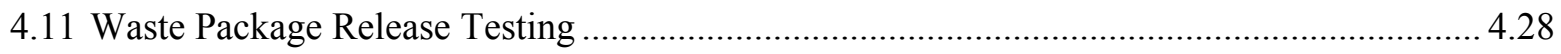

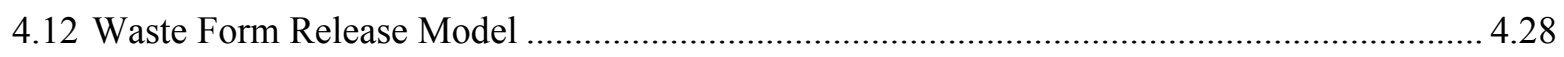

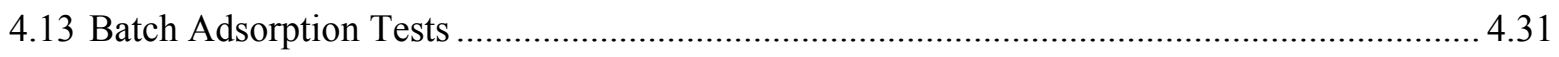

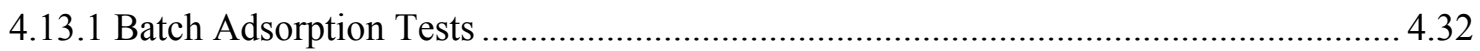

4.13.2 Saturated and Unsaturated Column Tests on LAW Cast Stone Waste Form Solids Embedded in Sediments

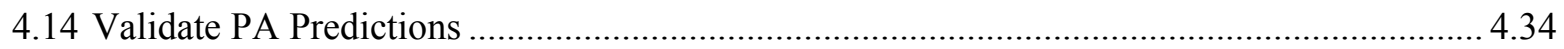

4.14.1 Reactive Transport Simulators for the Waste Form Calculations .............................. 4.37

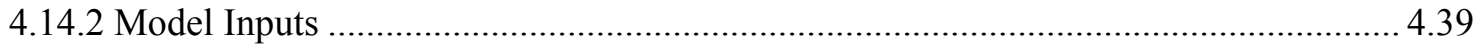

4.14.3 Cementitious Barriers Partnership Modeling Suite ..................................................... 4.39

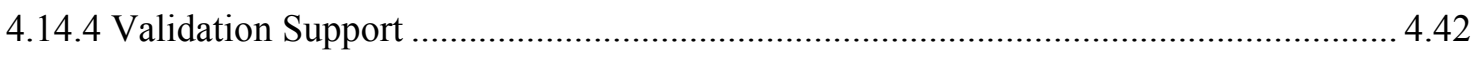

5.0 Hanford Tank Waste Simulants for Cast Stone Tests............................................................... 5.1

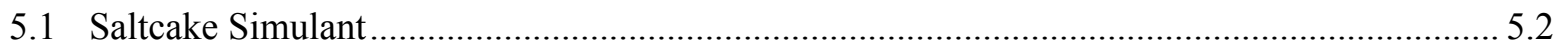

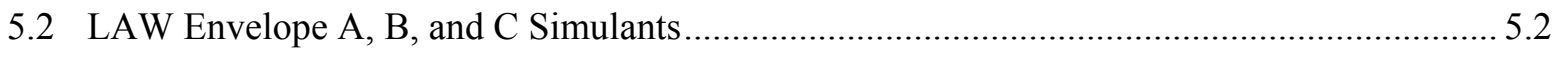

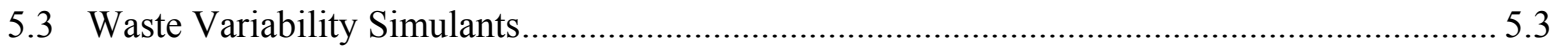

5.4 Simulants Based on System Plan 6 HTWOS Modeling ........................................................5.5

6.0 Near-Term Testing to Support TPA Milestone M-062-40ZZ …............................................... 6.1

6.1 Cast Stone Formulation Screening Tests............................................................................ 6.1

6.2 Cast Stone Waste Loading and Waste Form Qualification Testing ...................................... 6.2

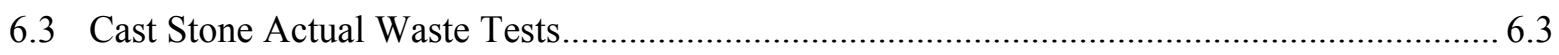

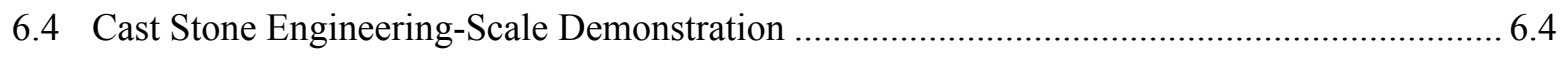

6.5 Risk Assessment and Performance Assessment Support ..................................................... 6.5

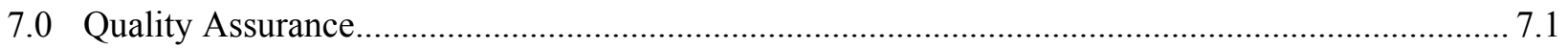

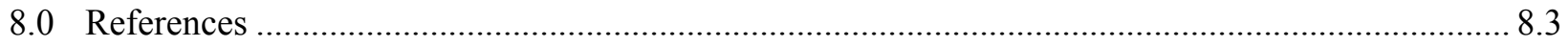

Appendix A - Comparison of Specifications Relevant to Low-Activity Waste Cast Stone Waste

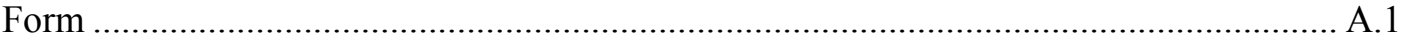

Appendix B - Low-Activity Waste Cast Stone Waste Form Testing Objectives and Approach

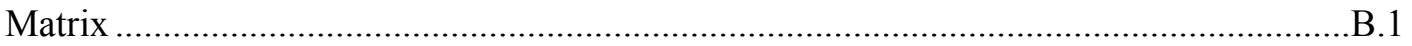

Appendix C - Solution and Solid-Phase Analysis Techniques ........................................................... 


\section{Figures}

2.1. Schematic of a Cast Stone Process Flowsheet (from Ramsey and Robbins 2012) ......................... 2.6

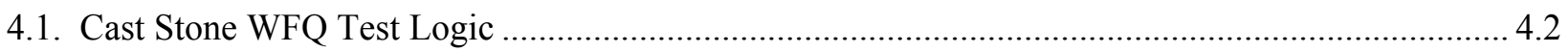

4.2. Schematic of Intermittent Solution-Exchange Leach Test Methods Such as ANSI 16.1,

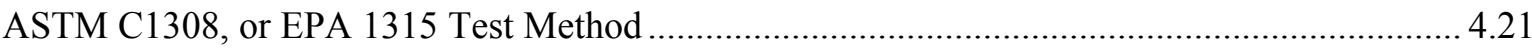

4.3. Schematic of Batch Test EPA Method 1313 and Method 1316 ................................................... 4.22

4.4. Example Plot of Data Generated from EPA 1313 Method ............................................................. 4.23

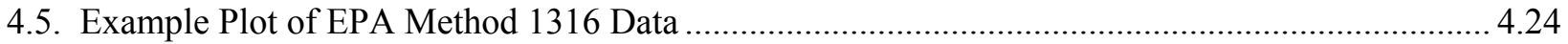

4.6. Schematic of the EPA Method 1314 Up-Flow Column Test........................................................ 4.25

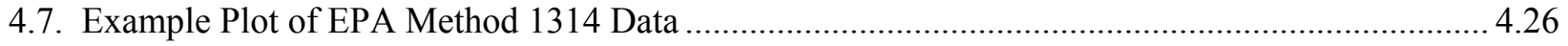

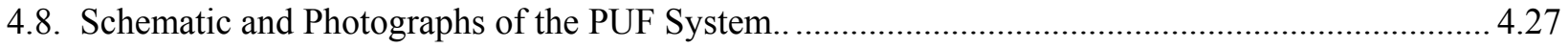

4.9. Schematic of a Hanging Water Column System. ...................................................................... 4.33

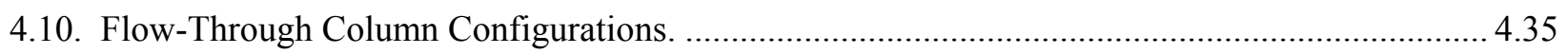

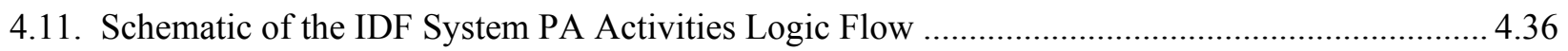

4.12. Schematic Showing Relationship Between Characterization and Testing Methods and the STORM/STOMP-W-R Simulators

4.13 Schematic Showing Relationship Between Characterization and Testing Methods and the CBP Suite of Codes.

\section{Tables}

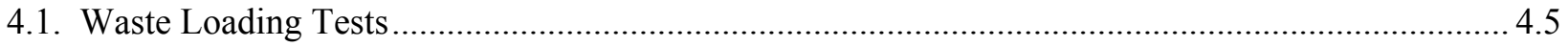

4.2. Cast Stone Process-Control Tests on Pilot-Scale Tests ................................................................ 4.7

4.3. Full-Scale Waste Form Package Testing ................................................................................. 4.9

4.4. Test Conditions for Cast Stone LDR Compliance Testing ........................................................ 4.10

4.5. Cast Stone Chemical and Physical Properties Testing.............................................................. 4.12

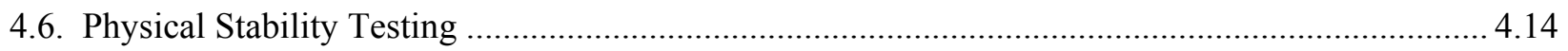

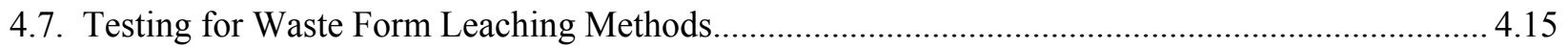

4.8. Testing for Waste Acceptance Criteria Base on Radionuclide Inventory..................................... 4.16

4.9. Composition of and Chemicals Used to Create IDF Vadose Zone Pore Water and LAW

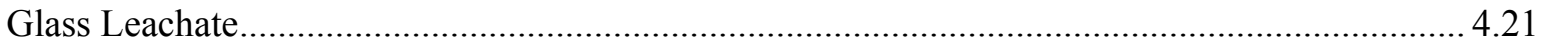

5.1. Nonradioactive Dissolved Saltcake Solution Simulant Composition (Rassat et al. 2003) ............... 5.3

5.2. LAW Envelope A, B, and C Simulants Used in Glass Formulation and Melter Tests ..................... 5.4

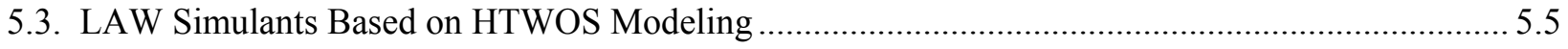

5.4. Spike Levels for Hazardous Constituents and Radionuclides for HTWOS Simulants ...................... 5.6 


\subsection{Introduction}

More than 56 million gallons of radioactive and hazardous waste are stored in 177 underground storage tanks at the U.S. Department of Energy's (DOE's) Hanford Site in southeastern Washington State. The Hanford Tank Waste Treatment and Immobilization Plant (WTP) is being constructed to treat the wastes and immobilize them in a glass waste form. The WTP includes a pretreatment facility to separate the wastes into a small volume of high-level waste (HLW) containing most of the radioactivity and a larger volume of low-activity waste (LAW) containing most of the nonradioactive chemicals. The HLW will be converted to glass in the HLW Vitrification Facility for ultimate disposal at an offsite federal repository. At least a portion (35\%) of the LAW will be converted to glass in the LAW vitrification facility and will be disposed of onsite at the Integrated Disposal Facility (IDF). The pretreatment and HLW vitrification facilities will have the capacity to treat and immobilize the wastes destined for each facility. However, a second facility will be needed for the expected volume of LAW requiring immobilization.

A cementitious waste form known as Cast Stone is being considered to provide the required additional LAW immobilization capacity. The Cast Stone waste form must be acceptable for disposal in the IDF. The Cast Stone waste form and immobilization process must be tested to demonstrate that the final Cast Stone waste form can comply with the waste acceptance criteria for the disposal facility and that the immobilization processes can be controlled to consistently provide an acceptable waste form product. Further, the waste form must be tested to provide the technical basis for understanding the longterm performance of the waste form in the disposal environment. These waste form performance data are needed to support risk assessment and performance assessment (PA) analyses of the long-term environmental impact of the waste disposal in the IDF.

This Cast Stone technology development and waste form qualification (WFQ) testing plan lays out the experimental work to be conducted to mature the Cast Stone waste form and immobilization process for Hanford LAW and to qualify the waste form for disposal on site at the IDF. The Cast Stone technology maturation and WFQ testing will include 1) refinement and optimization of the Cast Stone formulation for LAW, 2) demonstration of the flexibility and robustness of the Cast Stone process to handle the range in composition of the tank wastes to be immobilized, 3) engineering- and pilot-scale tests to demonstrate the integration of the Cast Stone immobilization system components, 4) resolution of design issues such that a detailed design can begin, and 5) measuring contaminant release rates and evaluating the long-term weathering of Cast Stone in the disposal environment. As appropriate, the WFQ testing will be conducted in conjunction with the technology maturation testing.

As the Cast Stone technology for treating and immobilizing the low-activity fraction of the Hanford tank wastes matures, the approach to qualifying the Cast Stone waste form will be refined. The final WFQ approach will be documented in a formal LAW Cast Stone Waste Form Qualification Plan. This Cast Stone supplemental immobilization testing plan anticipates the general approach and outlines the testing to be conducted to demonstrate that the Cast Stone waste form meets the IDF waste acceptance criteria (IDFWAC) and that the Cast Stone immobilization process can be controlled to consistently

produce an acceptable waste form. Further, the testing plan addresses the testing needs to demonstrate that the Cast Stone product meets land disposal restrictions in Title 40 of the Code of Federal Regulations (CFR) Part 268 (40 CFR 268) and Washington Administrative Code (WAC) 173-303-140, including the need for a determination of equivalent treatment (DET) to show that Cast Stone is equivalent to the 
HLVIT $^{1}$ treatment standard for HLW. This testing plan also describes the data and modeling needs to support risk assessments and PAs for the IDF.

In the sections that follow, the Cast Stone immobilization process and the resulting waste form are described in Section 2. Section 3 describes the specific WFQ testing objectives to be addressed. Section 4 outlines the specific elements of the testing program to complete the WFQ objectives. Section 5 describes Hanford LAW simulants that have been used for LAW waste form and immobilization process testing. Section 6 describes near-term testing planned to support a Tri-Party Agreement $^{2}$ (TPA) milestone for a One-Time Hanford Tank Waste Supplemental Treatment Technologies Report by October 2014. Section 7 lists the general quality assurance (QA) requirements. Section 8 provides references.

\footnotetext{
${ }^{1}$ HLVIT is the technology-based treatment standard in 40 CFR 268.42 for vitrification of high-level mixed radioactive waste.

${ }^{2}$ The Hanford Federal Facility Agreement and Consent Order, or Tri-Party Agreement, is an agreement for achieving compliance with the Comprehensive Environmental Response Compensation and Liability Act remedial action provisions and with the Resource Conservation and Recovery Act (RCRA) treatment, storage, and disposal unit regulations and corrective action provisions. The U.S. Department of Energy, the U.S. Environmental Protection Agency, and the Washington State Department of Ecology signed this comprehensive cleanup and compliance agreement on May 15, 1989.
} 


\subsection{Cast Stone Description}

The Cast Stone waste form includes the cementitious solidification material itself and a container for curing, handling, and disposing of the Cast Stone material. The following sections describe the Cast Stone waste form, its container and the production process for preparing the waste form. The Cast Stone data package prepared by Serne and Westsik (2011) provides a detailed compilation of work on the Cast Stone waste form.

\subsection{Cast Stone Product Description}

Cast Stone (also called "Containerized Cast Stone") is a cementitious waste form that is a mixture of Class F fly ash, Grade 100 or 120 ground blast furnace slag (BFS) ${ }^{1}$, and Type I/II Portland cement. CH2M HILL Hanford Group Inc. developed this waste form to solidify numerous waste streams, including secondary waste generated at the Hanford Site. The Cast Stone cementitious waste form is the current baseline for solidifying the liquid secondary wastes from WTP and other Hanford Site aqueous wastes in the Effluent Treatment Facility (ETF). A very similar waste form was developed earlier at Savannah River National Laboratory (SRNL) and is still actively used to solidify low-activity defense waste liquids at the Savannah River Site. The term Saltstone is used at SRNL for this cementitious waste form.

Both of these waste forms rely on the same three major ingredients to form a final hardened product when mixed with liquid wastes currently stored in underground storage tanks at these two DOE defense waste sites. Other minor ingredients, such as lime (calcium hydroxide), clays, zeolites, and "getter" materials have been evaluated for addition to the Cast Stone or Saltstone dry blend mix to improve either physical stability or chemical properties (e.g., improve retention of contaminants). For some formulations, either the fly ash or BFS is omitted from the dry blend or replaced by another material.

The key properties desired and accomplished by using Cast Stone or Saltstone are 1) a solid waste form that has adequate physical strength to withstand handling and transportation to a final disposal facility and to prevent subsidence in the disposal facility once it is closed, 2) constituents of concern (COCs) present in the liquid waste are retained by a combination of physical and chemical processes within the solidified waste form, and 3) resistance to dissolution/disintegration by recharge water or atmospheric gases percolating through the disposal facility. The basic process that occurs when the Cast Stone dry ingredients are mixed with liquid wastes is called hydration. This refers to chemical reactions between the compounds in the dry blend with water from the liquid waste that form new minerals and solids that bind together to form a cohesive but porous mass that both physically and chemically entraps waste species. By tailoring the dry-blend proportions, the hardened cohesive solid contains mostly very small pores (nano- and micro-meter-sized) that are tortuously connected, which results in a solid with very low permeability or hydraulic conductivity. Thus, the flow of water through the Cast Stone solid is very slow or nonexistent and forces diffusion to be the main mechanism for dissolved species to migrate through the solid. In a similar fashion, atmospheric gases, such as oxygen and carbon dioxide, also migrate through the Cast Stone, predominantly controlled by diffusion.

\footnotetext{
${ }^{1}$ Ground blast furnace slag is now commonly referred to as slag cement rather than ground BFS.
} 
The key attributes of the Portland and slag cements that make Cast Stone a good waste form candidate are 1) the high-pH environment of the cement matrix, which lowers the solubility of most metallic constituents, 2) good chemical and physical stabilization properties for most COCs present in the liquid waste 3 ) the relatively low hydraulic conductivity (permeability) of the hardened paste to both water and gas transport and 4) relatively long-term physical and chemical durability under near-surface environmental conditions. Although some contaminants can be incorporated into the structure of the hydrated calcium silicate phases, the precipitation of low-solubility metal hydroxides in the high-pH internal pore-water environment is the primary stabilization mechanism.

\subsection{Cast Stone Container Description}

The Cast Stone container/package provides both protection and containment for the waste form during production, transportation, and storage before final disposal in the IDF. A waste form container or package has not been selected for the LAW Cast Stone waste form. Conceptually, the container can be as small as a 55-gallon (208-L) drum to as large as large multimillion gallon disposal vaults filled and cured within the disposal facility similar to the rectangular and circular vaults used for Saltstone at the Savannah River Site.

The waste form container that is not a freestanding disposal vault will need to meet requirements for transporting radioactive and hazardous materials as specified in 49 CFR 173. The materials of construction for the package must be compatible with the wastes and with the protective liners included in the IDF design. Generally, the package will be fabricated using one or a combination of the following materials, which are acceptable to the IDF:

- metal, concrete, masonry

- fire-retardant-treated or painted wood

- rigid plastic with a maximum flame-spread rating or coating of 25

- flexible plastic packaging materials with similar flame-spread characteristics.

The size of the container will be dictated, in part, by criticality safety considerations. A criticality safety evaluation for the IDF qualified the following container sizes ${ }^{1}$ :

- 55-gallon (208 L, $\left.0.21 \mathrm{~m}^{3}\right)$ drums, $57.15 \mathrm{~cm}$ diameter $\times 88.14 \mathrm{~cm}$ high $(22.5$ inches in diameter $\times$ 34.7 inches high)

- 85-gallon (322 L, $\left.0.32 \mathrm{~m}^{3}\right)$ drums, $66 \mathrm{~cm}$ diameter $\times 100.3 \mathrm{~cm}$ high $(26$ inches in diameter $\times$ 39.5 inches high)

- MB-V boxes, $1.2 \mathrm{~m}$ wide $\times 1.2 \mathrm{~m}$ high $\times 2.4 \mathrm{~m}$ long $(4 \mathrm{ft}$ wide $\times 4 \mathrm{ft}$ high $\times 8 \mathrm{ft}$ long $)$

- Medium boxes with a volume between $3.95 \mathrm{~m}^{3}\left(5.17 \mathrm{yd}^{3}\right)$ and $15 \mathrm{~m}^{3}\left(19.62 \mathrm{yd}^{3}\right)$. The dimensions are not fixed.

- Small boxes with a volume less than $3.95 \mathrm{~m}^{3}\left(5.17 \mathrm{yd}^{3}\right)$. The dimensions are not fixed.

\footnotetext{
${ }^{1}$ River Protection Project. 2005. Integrated Disposal Facility Waste Acceptance Criteria, RPP-8402, Rev. 1, U.S. Department of Energy, Richland Operations Office, Richland, Washington.
} 
Other container configurations may be acceptable, but would require a criticality safety evaluation.

The size of the container will also be constrained by waste form processing and curing considerations. Any elevated temperatures of the waste form slurry as it is poured into the container will need to be dissipated as will any heat generated by the curing processes for the Cast Stone waste form. The container will need to be sized and filled such that the heat dissipates without impacting the quality of the waste form.

The container will also be configured for ease of filling to maximize the volume of waste form to meet minimum fill requirements and to minimize void spaces so that landfill subsidence issues are minimized. The flow and curing characteristics of the waste form are important considerations in maximizing the fill volume.

From a testing plan perspective, the most important information needed to aid in selecting the Cast Stone waste form container is to understand the heat generation and dissipation rate as the Cast Stone cures and to demonstrate that the Cast Stone has the appropriate flow characteristics and gel/cure times to fill the container without mounding or voids and to gel before significant phase separation occurs between the three constituents.

\subsection{Cast Stone Process Description}

The Cast Stone preparation process is very simple, not unlike that used in the commercial concrete industry. The dry ingredients are transferred quantitatively from the individual storage silos and are blended in a separate dry-blend silo. The dry blend is then metered into a mixer where it is combined with the aqueous waste stream. After mixing, the resulting slurry/paste is poured/pumped into the disposal container.

Within several hours, the Cast Stone slurry/paste gels so it does not flow under its own weight. The Cast Stone sets within several days. During these initial curing steps, the dry materials undergo hydration reactions with the water in the waste leading to the formation of the solid waste form matrix. Heat is generated from these hydration reactions that must be dissipated during the initial cure. The Cast Stone continues to cure over time frames that can span years.

The key process systems include:

- dry materials handling, storage, and blending

- waste solution storage, transfer, and metering

- process additives storage, transfer, and metering

- Cast Stone dry blend/waste mixing

- Cast Stone slurry/paste transfer/pumping

- system flush/cleaning

- process vent and air filtration

- process control system 
Figure 2.1 shows a simplified schematic of a Cast Stone process envisioned for secondary liquid wastes (Ramsey and Robbins 2012). Similar processes are envisioned for LAW solidification.

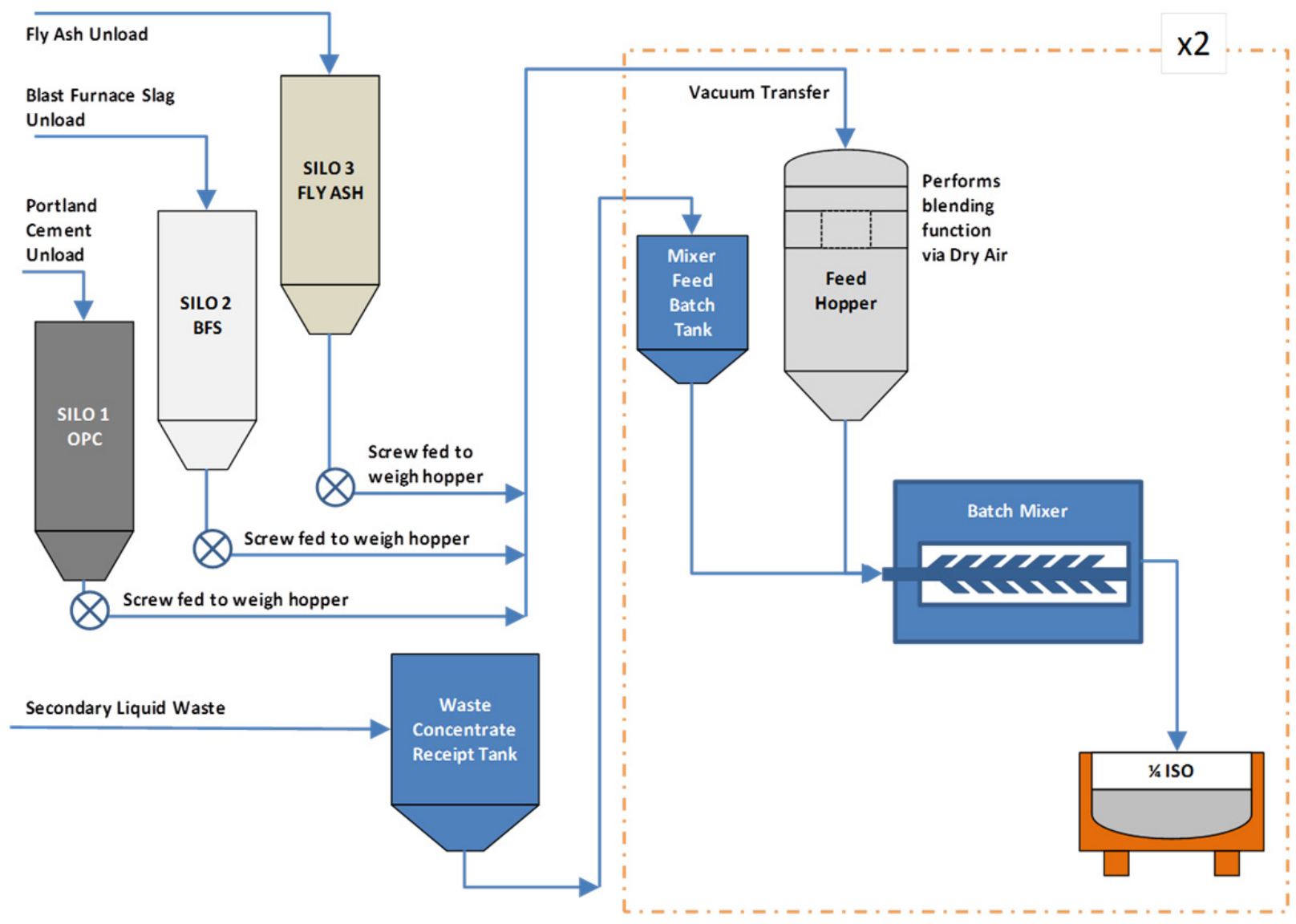

Figure 2.1. Schematic of a Cast Stone Process Flowsheet (from Ramsey and Robbins 2012)

The dry materials handling, storage, and blending system is composed of storage silos for each of the individual dry materials including Portland cement, fly ash, and BFS. The dry materials are transferred pneumatically from the transport train/truck to the silos. From the individual silos, the dry materials are transferred mechanically or pneumatically to the feed hopper where the dry materials are blended. Quantities of the transfers are typically determined by weight.

The waste storage, transfer and metering system receives waste from the upstream treatment/tank storage systems, maintains the wastes at the appropriate temperature and agitation, and provides for measured, quantitative transfers of the wastes to the Cast Stone mixer.

Under some conditions, it may be necessary to add some small quantities of chemicals to facilitate the mixing and pouring/pumping of the Cast Stone slurry/paste. These would be in the form of a fluidizer to reduce the viscosity of the slurry/paste, an air deentrainer to prevent excessive air entrainment that could lead to foaming or voids in the curing grout, and/or a set retarder to slow the curing process to allow the Cast Stone to be poured/pumped to the storage container and to flow to fill the space before setting. The process additives system provides for the storage, transfer, and metering of these potential process additives. 
The Cast Stone dry blend/waste mixing system provides for the actual mixing of the dry materials with the wastes to form the Cast Stone slurry/paste. The mixing can be conducted in either batch or continuous mode. Different types of mixers are used for the two modes. Batch mixers can be either a system in which the dry blend and wastes are mixed and then poured into the storage container or are mixed directly in the storage container. Batch sizes are dictated by the size of the container but may be reduced in size in order to limit temperature rise during the curing process. Mixing times are on the order of tens of minutes depending on the amount of shear imparted by the mixer.

Continuous mixers have shorter residence times within the mixer and serve more to provide the initial contacting between the waste and dry blend. Additional mixing is achieved in the Cast Stone slurry/paste transfer/pumping system.

The Cast Stone slurry/paste transfer/pumping system provides for the transfer of the slurry/paste from the mixer to the storage container for curing. This can be as simple as opening a gate valve to allow the slurry to drain by gravity from the batch mixer into the container. For a continuous mixing process, the transfer/pumping system, an intermediate surge tank is placed between the mixer and the pump. The pump then moves the slurry from the surge tank to the disposal container or disposal vault as is done with the Saltstone process at the Savannah River Site. These pumping and transfers through piping provide additional mixing beyond that achieved in the continuous mixer.

The flush/cleaning system provides the method(s) for cleaning the mixing, pumping, and piping of the Cast Stone slurry/paste after a production run. The process venting and filtration system provides for handling the air used in pneumatic transfers and for venting the various tanks and process equipment used in the Cast Stone production. The process control system provides for monitoring and controlling the Cast Stone production process. 


\subsection{Waste Form Qualification Testing Objectives}

This section outlines the overall test objectives for a WFQ program for a Cast Stone LAW waste form:

- Provide for acceptance of the waste form at the IDF.

- Optimize waste loading.

- Define the range of acceptable waste compositions.

- Define and demonstrate the product control strategy.

- Provide data to support risk and performance assessments.

The objectives are specific to qualification of the Cast Stone waste form for disposal in IDF. Although many test objectives for IDF disposal qualification and technology maturation coincide, this section does not include all of the testing required for technology maturation. In the discussions that follow, the "waste form" refers to the Cast Stone immobilization material itself. The "Cast Stone waste form package" refers to the Cast Stone waste form in a metal container and any fill material. A Cast Stone disposal system would include the Cast Stone waste form placed directly in a disposal vault that provides containment for the Cast Stone as it cures.

\subsection{Provide for Acceptance of Waste Form at Integrated Disposal Facility}

An important objective of waste form testing is to demonstrate that the waste form is acceptable for disposal in the IDF. Typically, a WFQ testing program includes activities before waste form production operations that demonstrate that the waste form will meet specifications and acceptance criteria. Then, during production operations, additional testing may be conducted to confirm that the actual waste form meets the requirements.

To begin the WFQ process, it is necessary to identify relevant waste acceptance criteria and waste form specifications to outline the WFQ testing program. Draft waste acceptance criteria have been developed for the IDF for wastes to be accepted for disposal at the facility (RPP-8402 2005). Also, the Washington State Department of Ecology (Ecology), in Permit WA7890008967 (Ecology 2008), defines waste acceptance criteria for the IDF. Finally, because Cast Stone performance may also be compared to that of glass, the immobilized low-activity waste (ILAW) glass specifications in the WTP contract provide a source of waste form requirements. Appendix A provides the text of each requirement from the three sources and describes the strategy for demonstrating compliance with the requirements. Ultimately, a Cast Stone LAW Waste Form Compliance Plan will be prepared that provides detailed waste form and process qualification activities that will be conducted before and during production operations.

It is important to note that the current sources of relevant specifications for the ILAW all assume that the waste form is glass. In some cases, particularly those related to waste form leach testing, equivalent performance and product consistency specifications need to be developed for the Cast Stone waste form. The WFQ testing program will need to include testing within its scope to identify relevant test methods, 
precision and bias, and performance standards that can be used in establishing waste form requirements applicable to the Cast Stone waste form.

\subsection{Optimize Waste Loading}

To minimize total mission costs, one goal is to minimize the volume of ILAW waste form to be disposed of in IDF and to maximize the throughput of waste through the pretreatment and immobilization processes such that the mission is completed in a shorter time. An objective of the waste form testing program is to then optimize the waste loading within the waste form while maintaining waste form properties to comply with specifications and acceptance criteria and to provide for efficient and controlled production of the waste form.

For the Cast Stone WFQ testing program, the waste loading will be optimized with respect to the amount of waste salts in the waste solution and the amount of waste water blended with the dry materials. The final disposal form (container versus vault) will impact this optimization. The ultimate objective is to reduce the number of waste units and total mass of the Cast Stone waste form while meeting waste form acceptance criteria and maintaining efficient operations.

\subsection{Demonstrate Waste Form Over Expected Range of Wastes}

The Hanford wastes vary in composition from tank to tank. It is important to 1) understand how the range in waste compositions affects the Cast Stone process, 2) demonstrate that the process is sufficiently robust to handle the variability in the waste, and 3) identify any compositions or waste components that may have an adverse impact on the final waste form quality. This includes evaluating the products from treating a range of waste compositions and from processing over a range of operating conditions. An objective of the WFQ and technology maturation testing is to demonstrate that the Cast Stone process can accommodate the variations in waste composition.

\subsection{Define and Demonstrate Product Control Strategy}

Compliance with waste form specifications and land disposal restrictions can be demonstrated through direct waste form product sampling and characterization and/or through implementing a process/product control strategy that relies on controlling the Cast Stone process to produce an acceptable waste form product for disposal. Extensive, routine sampling of the Cast Stone product will be expensive and will increase risks to worker safety. Through a process control strategy, it may be feasible to achieve and demonstrate adequate waste form qualities without the risks associated with frequent direct sampling and testing of the final waste form. An important WFQ testing objective is then to define, develop, and demonstrate the product control strategies for the Cast Stone immobilization process.

\subsection{Provide Data to Support Risk and Performance Assessments}

Risk assessments and PAs are conducted to evaluate the potential impacts to the health and safety of the public, DOE and contractors' employees, and the environment caused by the disposal of radioactive wastes. The LAW Cast Stone waste form will be disposed of in the IDF on the Hanford Site. Data and updated source-term models are needed to support an IDF risk/PA that includes LAW Cast Stone waste 
form disposal. Note that there will need to be iteration between the testing and predictive PA modeling as the program advances to the final licensing activities. Preliminary system PA sensitivity or probabilistic calculations will alert staff as to which parameters are most sensitive in controlling the risk or impact. This knowledge could require additional testing to improve the accuracy, reduce the range of variation in the numerical values for the key parameters, and acquire more technically defensible "backup" or supporting information before the final PA is submitted to the regulators and stakeholders.

In conducting PAs, conceptual and computer models of the disposal system and surrounding environment are used to predict the movement of infiltration water, the evolution of the waste packages and repository components over time, and the fate of any leached contaminants through the vadose zone to the aquifer and ultimately back to the accessible environment. Once contaminants, driven by chosen scenarios, reach the accessible environment through various pathways doses or impacts are calculated and compared to various criteria. Sensitivity or probabilistic analyses are used to determine 1) a range of doses or impacts to account for variability in the myriad of input parameters, 2) limitations in the numerical algorithms (usually simplifications of controlling mechanisms) used to process the complex interactions that control the degradation or weathering of system components, and 3) scenario uncertainties that describe future conditions. Section 4.14 provides further descriptions of the IDF system PA conceptual models and codes that will be considered for performing the needed fate and transport predictions.

The various tests and solid-phase characterization activities used to support a PA identify the types and amounts of minerals and other solid phases that are present at the time of disposal and the changes in both as the waste packages weather in the long term. Therefore, more data and updated waste form release models are required to demonstrate the long-term performance of the LAW Cast Stone waste form and the IDF repository.

The framework for modeling the long-term performance of cementitious waste forms has been treated in a fundamentally different manner than that for silicate-based glass and mineral forms (McGrail et al. 2003; Pierce et al. 2004). For glasses and mineral waste forms, the rate-controlling mechanism is matrix hydrolysis in which chemical bonds are broken and contaminants released. With cementitious waste forms, a physical model of contaminant diffusion has been almost universally adopted. Empirical effective diffusion coefficients measured in short-term laboratory experiments are widely used to model the long-term performance of cementitious waste forms (Albenesius 2001). The effective diffusion coefficients measured for each contaminant are used for a diffusion-controlled transport analysis in the continuous pore network of the Cast Stone coupled with diffusive-advective transport in idealized fractures. This approach is essentially equivalent to what has been performed for analysis of Saltstone at the Savannah River Site (Cook 2000).

The waste form tests required to support long-term risk assessment and PA start with wellconstrained tests conducted on the LAW Cast Stone waste form itself. These tests would include water leach tests and accelerated weathering tests that evaluate physical and mineralogical properties of the Cast Stone. Tests then progress to multicomponent tests that include the impacts of the waste container, other co-disposed waste forms, and the surrounding vadose zone sediments. Each test is used to a) identify the final solid phases and minerals formed by interaction of the starting solids with water and gases present in the surrounding sediment pores (i.e., the weathering process), b) identify a reaction network (the key minerals that form and the sequence of formation) for the LAW Cast Stone waste form and waste package, or c) obtain the values for parameters required in the diffusive release or kinetic rate-law 
equations and thermodynamic solubility and precipitation equations used by the waste form release algorithm to quantify the release of major and minor constituents in the Cast Stone waste form. Once the final solid phases and minerals that are formed by the weathering process are established and the kinetic rate-law and thermodynamic equilibrium equation parameters are established, a defensible conceptual model for long-term waste form release can be constructed for the LAW Cast Stone waste form. Predictions from the waste form release model will then be compared to the results of the multicomponent tests that include the waste container and IDF components and co-disposed wastes to verify that predictions are technically defensible. If the combined tests with waste form, container, co-disposed wastes, and sediments show that additional minerals form and control the release of contaminants from the LAW Cast Stone waste form, these minerals will be included as end products in the overall IDF geochemical conceptual model.

The following subsections focus on describing the types of waste form characterization and tests needed to support predictive modeling of risk and long-term performance. In the early stages, the test specimens will be laboratory-scale specimens (mass ranging from tens to a few hundred grams, depending on the test) produced with simulated waste containing elevated concentrations of contaminants that facilitate their detection in both the solid-phase characterization and in the leachates obtained from the various leach tests. During the early stages of testing, a range of waste and "dry blend" masses and a range of waste loadings will be used to prepare test specimens. The resultant test specimens will be subjected to physical stability and contaminant leach testing to complement the efforts to optimize the Cast Stone waste form product. As the program progresses, the test samples will include products made from actual waste streams at the loadings expected to be used in final production of the optimized Cast Stone waste form. If required to make sure that leaching data can be obtained for all important contaminants, additional mass or radioactivity will be added to the actual LAW wastes before solidification with optimized Cast Stone dry blend so that leachates contain concentrations above detection limits. Should field-scale, long-term testing of LAW Cast Stone waste form monoliths be performed, it is recommended that intermediate-scale monoliths be placed in lysimeters that are backfilled with Hanford sediments. These intermediate-scale monoliths would be made from actual wastes at the optimum loading, if regulators allow, or otherwise with simulated wastes that are mixed with the optimized Cast Stone dry blend. Different field lysimeters should be subjected to various water infiltration rates, and all drainage should be collected as a function of time and analyzed for chemical and contaminant composition. At the end of all leach tests, the "weathered" LAW Cast Stone waste form and surrounding sediment should be characterized and compared to unleached starting solids.

\subsubsection{Solid-Phase Characterization}

Detailed characterization of both unleached and leached Cast Stone waste form will be required to understand the starting mineralogy of the solids and the mineralogy present after exposure to leachants. Changes in physical properties such as total porosity, pore throat dimensions, tortuosity, compressive strength, hydraulic conductivity, and crack characteristics of the weathered Cast Stone will need to be measured and compared to the unweathered LAW Cast Stone waste forms. Particular emphasis will be placed on determining the speciation of ${ }^{99} \mathrm{Tc}$ and iodide $\left(\mathrm{I}^{-}\right)$in the Cast Stone product and the distribution of ${ }^{99} \mathrm{Tc}$ and $\mathrm{I}^{-}$in the different Cast Stone solid and mineral phases and pore water. In particular, it will be determined whether the majority of the ${ }^{99} \mathrm{Tc}$ is present in the weathered LAW Cast Stone waste form in the reduced Tc(IV) state using synchrotron-based X-ray absorption spectroscopy (XAS) and whether the ${ }^{99} \mathrm{Tc}$ is present in localized "hot" spots or homogeneously distributed using scanning electron 
microscopy-transmission electron microscopy-energy dispersive spectroscopy (SEM-TEM-EDS) microprobes.

By assimilating all the solid-phase characterization information and total chemical composition of unleached and leached LAW Cast Stone waste forms, one can better identify controlling mechanisms for species release and the solid-phase weathering sequence of the Cast Stone needed to support long-term performance of the waste form. Should natural analogs for the Cast Stone waste form be found in the literature that are relevant to the expected weathering process in IDF, they will be compared and contrasted with the findings of this program to help support the discussion on long-term performance.

\subsubsection{Waste Form Leach Testing}

Leach tests are performed to evaluate the release of contaminants from the LAW Cast Stone waste form. The tests provide data to aid in identifying the release mechanism and parameter values required in either diffusion-controlled rate-law equations or thermodynamic solubility-precipitation equations. The most appropriate leachants that will be encountered by IDF-disposed LAW Cast Stone monoliths (and waste packages within metal containers) are vadose zone sediment pore water and co-disposed IDF-glass leachate. This assumes that the LAW Cast Stone waste form will be co-disposed with IDF LAW glass, an assumption used in previous supplemental waste form risk assessments (Mann et al. 2003).

The main thrust needs to be leach testing of the multi-solid/mineral-phased optimized LAW Cast Stone waste forms produced from pilot-scale tests that more truly reflect the thermal and curing environments under which the Cast Stone waste forms are generated. The multiphase leach testing will emphasize the study of the major constituents and the key contaminants of interest (Tc, I, nitrates, and Resource Conservation and Recovery Act [RCRA] metals).

\subsubsection{Waste Package Release Testing}

The chemical impacts of the presumed metal containers in which the LAW Cast Stone waste form will be poured will be determined in tests similar to those described in Section 3.5.2. In particular, the metal container will constrain water interactions with the Cast Stone waste form for some period of time and the reducing conditions initially present before the metal is totally weathered will slow transport of redox-sensitive contaminants such as Tc. In support of risk assessment and PA needs, the transport properties of contaminants within the entire LAW Cast Stone waste package need to be understood to estimate release from the waste package to the disposal system.

\subsubsection{Physical Stability}

The long-term physical stability of the LAW Cast Stone monolith once the outer metal container has deteriorated needs to be determined. The long-term physical stability of the monolith needs to be determined to evaluate landfill subsidence and the intruder scenarios as well as the possibility of cracks becoming frequent enough to change the system from diffusive-flux to advective-flux dominated. Traditionally, the long-term physical stability of Cast Stone monoliths has been evaluated with assumed crack degradation scenarios as opposed to direct long-term testing. As this program matures, the crack propagation issue will be evaluated to see whether a better long-term disposal test method can be developed. 


\subsubsection{Update Waste Form Release Conceptual Model and Code}

A modified model for waste form release/radionuclide source terms must be developed and validated for inclusion in the future IDF PA codes. Cast Stone contaminant release conceptual models used at Hanford have been solely based on empirical diffusion-controlled release. Moving forward, these will be updated based on the combined chemical and physical conceptual models promoted by the Cementitious Barriers Partnership (CBP) that incorporate physical cracking as well as solubility-precipitation chemical conceptual models along with diffusion dominated mass transport. At this time it is not clear whether the CBP suite of computer codes (LeachXS ${ }^{\mathrm{TM}}$-ORCHESTRA-STADIUM-GoldSim) will be used or whether improvements will be made to the Subsurface Transport Over Multi-Phases (STOMP) code. Should the STOMP/eSTOMP code continue to be used, certain improvements will be added such as 1) add thermodynamic data for key cementitious solid-solution phases available in the ORCHESTRA thermodynamic database, and 2) add the impacts of cracking, re-oxidation of redox-sensitive COCs and oxidation of residual BFS, and carbonate weathering available in the Software for Transport and Degradation in Unsaturated Materials $\left(\right.$ STADIUM $\left.^{\circledR}\right)$ code.

\subsubsection{Adsorption Tests with Waste Form Leachates and Hanford Formation Sediments}

The LAW Cast Stone waste packages will be surrounded by other IDF waste packages (e.g., LAW glass) and Hanford formation sediments or other stand-alone vault components. The first tests will be classical batch adsorption tests and will be performed to investigate adsorption reactions among leachates from the LAW Cast Stone waste form with the Hanford sediments. If warranted, (based on system IDF PA predictions showing that the adsorption of key contaminants from LAW Cast Stone waste packages is a sensitive process controlling the risk to groundwater and the accessible environment), flow-through column tests (both saturated and unsaturated water conditions) will be performed. If necessary and possible, surface complexation modeling and a sorption database, which accommodates the anticipated varying background geochemical conditions, will be constructed from the adsorption experiments and literature.

\subsubsection{Performance Assessment Model Validation}

Model validation provides confidence that the computer code simulations are indicative of what is expected in the actual disposal environment. PA model validation work provides confidence that the predicted impacts of the disposal action are reasonable. To provide a basis for the validation effort, tests at laboratory and field scale are conducted to mimic the disposal system. Natural analog studies provide information on the weathering behavior of the waste form mineral phases in the environment over longer times than can be achieved in controlled experiments and testing. 


\title{
4.0 Cast Stone Waste Form Qualification Testing Elements
}

To address the Cast Stone WFQ objectives outlined in Section 3, a testing program will be undertaken to provide the necessary data and process knowledge. A test matrix was developed identifying the WFQ objectives, the specific test objectives, and the testing and data to be obtained to meet those objectives. That matrix is provided in Appendix B. The test matrix identifies the specific scale of testing (laboratory, bench/engineering, pilot, or full scale); the types of simulants and the radionuclide and hazardous component spikes or actual wastes to use; and the specific product characterization tests to be conducted. There is some overlap in the test objectives, the scale, and the characterization tests outlined in the matrix. To facilitate test planning and scheduling, the various WFQ activities have been grouped into the following broad elements:

\author{
4.1 Cast Stone Waste Loading Tests \\ 4.2 Cast Stone Process Control \\ 4.3 Large-Scale Waste Form Package Tests \\ 4.4 Land Disposal Restriction (LDR) Compliance Testing \\ 4.5 Cast Stone Physical and Chemical Properties (Laboratory Scale) \\ 4.6 Physical Stability \\ 4.7 Waste Form Leaching Methods \\ 4.8 Radionuclide Inventory Calculations \\ 4.9 Cast Stone Solid-Phase Characterization \\ 4.10 Waste Form Leach Testing - PA Support \\ 4.11 Waste Package Release Testing \\ 4.12 Waste Form Release Model \\ 4.13 Batch Adsorption Tests \\ 4.14 Validation of PA Predictions
}

Each testing element is described in the sections that follow.

Figure 4.1 shows a general sequence for conducting the groups of tests. This is a higher level test logic. In conducting the testing, there will be iterations and feedback from larger-scale tests back to laboratory-scale tests where it may be more efficient to conduct specific tests to address specific questions as a result of the larger-scale testing. The focus of the diagram is the WFQ. The WFQ testing will be conducted within the larger technology maturation testing program. With the appropriate QA pedigree, testing conducted as part of the evaluation of supplemental treatment technologies and early technology maturation testing can be used to fulfill some of the WFQ testing objectives.

In the discussions that follow, the "Cast Stone product" refers to the product from the blending the aqueous LAW with the dry materials and curing the resulting slurry/paste. The "waste form package" refers to the Cast Stone waste form in a metal container and any additional fill material in the container or the Cast Stone poured and cured directly in a disposal vault. 


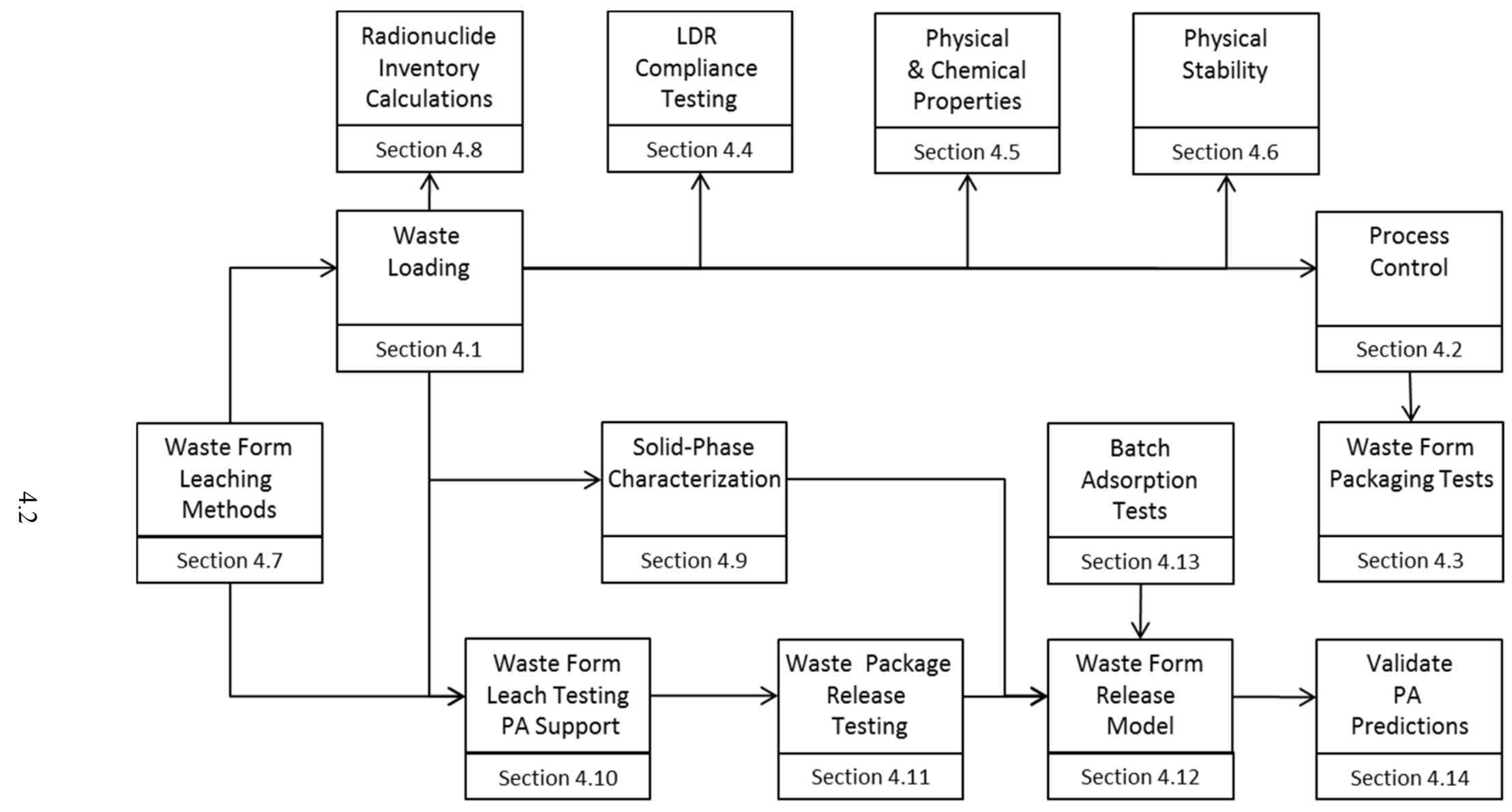

Figure 4.1. Cast Stone WFQ Test Logic 
The waste form testing objectives will be defined and characterized below as they relate to six primary testing scales. These are, in order of complexity, calculation or analysis, laboratory-scale testing, bench-scale testing, engineering- or pilot-scale testing, full-scale component testing, and production hot operations.

The calculation or analysis approach is intended to capture the research activities that are performed before testing on the laboratory or demonstration scale. These may include engineering calculations, literature reviews, dose calculations, and modeling and other paper studies with the emphasis on understanding the science and mechanisms of the objectives to be tested or demonstrated in the laboratory.

The laboratory-scale testing approach is intended to capture initial technology development and chemical analysis. This testing approach may include chemical analysis, measurement of heat of reaction, Cast Stone dry blend mix and waste/dry blend mix formulation, leach testing, and WFQ testing.

Bench-scale testing is intended to demonstrate that the basic components or operations will work together as a system to validate or achieve desired testing objectives. At this scale, the test platform could fit on a modified bench and provide Cast Stone specimens in the one- to five-gallon (four- to twenty-liter) size.

Pilot-scale testing is intended to validate the system in the relevant operating environment. This represents a major step in the technology's demonstrated readiness. The pilot scale represents the step-up from laboratory scale to engineering scale. This prototype should be capable of performing all the functions that will be required of the system, as this prototype should be used to determine scaling factors that will be used in designing the final waste processing system. The operating environment of this testing platform should closely represent the actual operating environment. At this scale, the facility may be capable of generating 200 liters or more of Cast Stone product over a single day.

Full-scale testing demonstrates an actual system prototype. This test platform is virtually complete and will be used to validate the waste form immobilization processes under all operating conditions and environments. Such testing could be performed as shakedown runs with simulants using the actual production system prior to the start of hot operations.

Production hot operations demonstrate the actual system operating over the full range of expected conditions with real waste. The production system is in its final form and will be operated with a full range of wastes in hot operations.

\subsection{Waste Loading Tests}

The Cast Stone waste loading test group is composed of the tests required to determine and demonstrate waste immobilization in the Cast Stone waste form. These tests may include laboratory-scale formulation of waste/dry blends for optimal waste loading and technology and process demonstration on a pilot-scale platform to validate waste loading. These tests will 1) emphasize the optimization of the concentration of waste in the Cast Stone product, 2) determine the impacts of waste components and waste variability on the Cast Stone product, and 3) demonstrate successful waste 
solidification over the expected range of waste compositions. Testing at this scale will also support PA analyses and will provide data to address LDRs.

The first test objective is to optimize the waste loading within the Cast Stone product. Initial formulation activities will be performed at the laboratory scale using a full range of simulants representing the expected variability in the LAW feed. Bench and/or pilot-scale test activities may be performed on simulated and spiked LAW feeds to fully characterize the waste loading in the Cast Stone. All processing parameters affecting the Cast Stone product will be measured, and the Cast Stone waste form will be fully characterized and leach tested to verify immobilization of COCs at optimized loading formulations.

An important aspect of this first objective is to identify sources of Cast Stone dry materials (fly ash, BFS, and cement) and evaluate their availability, quality and variability. Testing will be conducted to determine the impacts of the variability on the properties of the resulting Cast Stone processing characteristics and final product quality.

The second objective is to determine acceptable curing conditions for the Cast Stone waste form. The effects of temperature, humidity conditions, and cure time will be evaluated. The heat of hydration/formation will be determined.

The third objective is to determine process control parameters for Cast Stone process testing at larger scales. Testing at a laboratory scale will evaluate the impacts of variability in controlling the mix ratios for the waste and dry material components. The goals in optimizing the Cast Stone formulation are to maximize the waste loading, achieve a minimum 500 psi compressive strength, and maintain slurry properties to allow for mixing, pumping, and flow into the waste form container or vault.

The Cast Stone waste form will have to meet LDR requirements. An important test objective will be to demonstrate that the Cast Stone waste form will pass Toxicity Characteristic Leaching Procedure (TCLP) tests for RCRA metals and underlying hazardous constituents. Initial WFQ activities will be performed at the bench scale using a range of simulants, spiked with RCRA metals and other hazardous constituents, representing variability in the LAW feed. Selected representative actual LAW samples will also be used in the laboratory-scale testing. The Cast Stone waste form will be fully characterized and leach tested to verify that the product will meet requirements for LDRs as a stabilized and solidified waste form. This will include TCLP testing and may include additional characterization using new U.S. Environmental Protection Agency (EPA) methods including 1313 (EPA 2009a), 1314 (EPA 2009b), 1315 (EPA 2009c), and 1316 (EPA 2009d). Further details of testing to address LDR requirements are discussed in Section 4.4 .

Pilot- and full-scale testing of the Cast Stone process and container filling may indicate the need for adjustments to the Cast Stone formulation to improve the rheology and flowability of the Cast Stone paste/slurry and/or to adjust the set and cure times. Should it be indicated by the testing, additives such as set retarders and superplasticizers may be evaluated to improve the processing characteristics of the Cast Stone.

Similarly, leach testing and radionuclide retention studies may indicate the need for additives to reduce the release rate of COCs. Should it be indicated by the testing, additives that control redox or pore 
size or otherwise act as getters may be evaluated to improve the retention of contaminants in the Cast Stone waste form.

Table 4.1 summarizes the tests to be conducted to address the Cast Stone waste loading test objectives. This group of tests includes activities 1.1, 2.1, 3.1, 3.2, 3.3, and 14.1 in Table B.1 of Appendix B.

Table 4.1. Waste Loading Tests

\begin{tabular}{|c|c|c|c|c|}
\hline Objectives & $\begin{array}{c}\text { Approach/Testing } \\
\text { Scale }\end{array}$ & Simulant/Waste & Test/Analysis & $\begin{array}{c}\text { Parameters to be } \\
\text { Measured }\end{array}$ \\
\hline $\begin{array}{l}\text { Optimize waste } \\
\text { loading in Cast } \\
\text { Stone matrix }\end{array}$ & $\begin{array}{l}\text { Range of waste feed } \\
\text { concentrations } \\
\text { Range of dry } \\
\text { material mix ratios. } \\
\text { Range of mix ratios } \\
\text { of waste to dry } \\
\text { materials }\end{array}$ & $\begin{array}{l}\text { Selected } \\
\text { representative } \\
\text { simulants, Tc spike }\end{array}$ & $\begin{array}{l}\text { Compressive strength } \\
\text { (ASTM C39/C39M } \\
\text { [2009a]), Tc diffusivity } \\
\text { using ANSI/ANS 16.1 } \\
\text { [2003], EPA } 1315 \text { (EPA } \\
\text { 2009c), or ASTM C1308 } \\
\text { [2008b], TCLP }\end{array}$ & $\begin{array}{l}\text { Compressive } \\
\text { strength, leachate } \\
\text { chemical analysis, } \\
\text { free liquids, slurry } \\
\text { flow characteristics, } \\
\text { Tc effective diffusion } \\
\text { coefficient }\end{array}$ \\
\hline $\begin{array}{l}\text { Identify } \\
\text { impactful waste } \\
\text { components }\end{array}$ & $\begin{array}{l}\text { Optimized Cast } \\
\text { Stone formulation }\end{array}$ & $\begin{array}{l}\text { Selected } \\
\text { representative } \\
\text { simulants }\end{array}$ & $\begin{array}{l}\text { Compressive strength } \\
\text { (ASTM C39/C39M } \\
\text { [2009a]), Tc diffusivity } \\
\text { using ANSI/ANS 16.1, } \\
\text { EPA 1315, or ASTM } \\
\text { C1308, TCLP }\end{array}$ & $\begin{array}{l}\text { Compressive } \\
\text { strength, leachate } \\
\text { chemical analysis, } \\
\text { free liquids, slurry } \\
\text { flow characteristics, } \\
\text { Tc effective diffusion } \\
\text { coefficient }\end{array}$ \\
\hline $\begin{array}{l}\text { Demonstrate } \\
\text { Cast Stone on } \\
\text { range of } \\
\text { expected waste } \\
\text { compositions }\end{array}$ & $\begin{array}{l}\text { Optimized Cast } \\
\text { Stone formulation }\end{array}$ & $\begin{array}{l}\text { Range of simulants } \\
\text { representing } \\
\text { variability in LAW }\end{array}$ & $\begin{array}{l}\text { Compressive strength } \\
\text { (ASTM C39/C39M), Tc } \\
\text { diffusivity using } \\
\text { ANSI/ANS } 16.1 \text {, EPA } \\
\text { 1315, or ASTM C1308, } \\
\text { TCLP }\end{array}$ & $\begin{array}{l}\text { Compressive } \\
\text { strength, leachate } \\
\text { chemical analysis, } \\
\text { free liquids, slurry } \\
\text { flow characteristics, } \\
\text { Tc effective diffusion } \\
\text { coefficient }\end{array}$ \\
\hline $\begin{array}{l}\text { Determine } \\
\text { acceptable } \\
\text { curing } \\
\text { conditions for } \\
\text { Cast Stone } \\
\text { material }\end{array}$ & $\begin{array}{l}\text { Range of curing } \\
\text { temperatures and } \\
\text { humidity for select } \\
\text { Cast Stone } \\
\text { waste/dry-materials } \\
\text { mix ratios }\end{array}$ & $\begin{array}{l}\text { Select representative } \\
\text { simulants, some } \\
\text { spiked with COCs } \\
\text { such as Tc, stable I } \\
\text { and RCRA metals }\end{array}$ & $\begin{array}{l}\text { Compressive strength } \\
\text { (ASTM C39/C39M), Tc } \\
\text { diffusivity using } \\
\text { ANSI/ANS 16.1, EPA } \\
\text { 1315, or ASTM C1308. } \\
\text { SEM, microtomography, } \\
\text { Hg intrusion, TCLP }\end{array}$ & $\begin{array}{l}\text { Compressive } \\
\text { strength, leachate } \\
\text { chemical analysis, } \\
\text { free liquids, Tc and } \\
\text { COC effective } \\
\text { diffusion coefficient, } \\
\text { porosity and pore } \\
\text { size. Heat of } \\
\text { hydration }\end{array}$ \\
\hline $\begin{array}{l}\text { Determine } \\
\text { process control } \\
\text { parameters for } \\
\text { Cast Stone } \\
\text { waste form } \\
\text { preparation }\end{array}$ & $\begin{array}{l}\text { Range of waste feed } \\
\text { concentrations } \\
\text { Range of dry } \\
\text { material mix ratios. } \\
\text { Range of mix ratios } \\
\text { of waste to dry } \\
\text { materials }\end{array}$ & $\begin{array}{l}\text { Select representative } \\
\text { simulants, some } \\
\text { spiked with COCs } \\
\text { such as Tc, stable I } \\
\text { and RCRA metals }\end{array}$ & $\begin{array}{l}\text { Compressive strength } \\
\text { (ASTM C39/C39M), Tc } \\
\text { diffusivity using } \\
\text { ANSI/ANS 16.1, EPA } \\
\text { 1315, or ASTM C1308. } \\
\text { SEM, microtomography, } \\
\text { Hg intrusion, TCLP }\end{array}$ & $\begin{array}{l}\text { Compressive } \\
\text { strength, leachate } \\
\text { chemical analysis, } \\
\text { free liquids, Tc and } \\
\text { COC effective } \\
\text { diffusion coefficient, } \\
\text { porosity and pore } \\
\text { size }\end{array}$ \\
\hline
\end{tabular}

ANSI = American National Standards Institute ANS $=$ American Nuclear Society 


\subsection{Process Control Tests}

The Cast Stone process includes all the technologies and processes required for 1) handling and delivering dry materials components and the waste solution, 2) mixing dry components and aqueous waste solution, 3) pouring slurry into storage containers, and 4) curing final waste forms. The test objectives described below represent a group of tests required to demonstrate the control of waste/dry-materials mixing, transfer, and slurry discharge into the final container and the control of the dry-materials mix ratios and composition for the generation of waste forms that satisfy IDFWAC.

These tests will be performed on a pilot-scale testing platform. The pilot-scale testing will validate the system in the relevant operating environments. This represents a major step in the technology's demonstrated readiness. This prototype should be capable of performing all the functions that will be required of the system, as this prototype should be used to validate scaling factors that will be used to design the full-scale system. The operating environment of this testing platform should closely represent the actual operating environment.

A pilot-scale testing platform of the Cast Stone process will be used to demonstrate the control of container filling to prevent or minimize overfill and spillage while simultaneously minimizing gross void spaces within the finalized waste form.

This pilot-scale testing platform will be used to demonstrate the control of dry-materials mix ratios and composition. Initial testing performed in the laboratory (see Section 4.1) will be used to optimize the Cast Stone formulation with respect to waste loading and to minimize free liquid formation during curing. Waste/dry-materials mix control testing on the pilot-scale platform will include examining filled containers during curing for the formation of free liquids.

An objective of the Cast Stone process control strategy is to demonstrate the operating envelope for the Cast Stone immobilization process. The Cast Stone process operating envelope will be demonstrated on a range of waste compositions and waste/dry-materials mix ratios. The cured Cast Stone waste form will be characterized and those waste forms containing the key COCs will be leach tested to demonstrate predicted immobilization.

Related to the demonstration of the Cast Stone process operating envelope is the demonstration of Cast Stone slurry/paste flow characteristics. This test objective is concerned with demonstrating transfer, pumpability, and flow into the waste form package of the Cast Stone slurry (composed of aqueous waste solution and dry material mix). The slurry transfer will be demonstrated on a range of Cast Stone slurries consisting of various blend ratios of differing wastes and dry-materials mixes.

Another test objective, associated with the demonstration of the flow of the Cast Stone slurry/paste, is to demonstrate the mixing of the aqueous waste and dry-materials mix. The slurry mixing will be demonstrated on a range of Cast Stone slurries consisting of various blend ratios of differing wastes and dry-materials mixes.

Table 4.2 summarizes the testing to address the test objectives of the Cast Stone process controls. These objectives include activities 1.10, 1.14, 5.1, and 5.4 in Table B.1 in Appendix B. 
Table 4.2. Cast Stone Process-Control Tests on Pilot-Scale Tests

\begin{tabular}{|c|c|c|c|c|}
\hline Objectives & $\begin{array}{l}\text { Approach/ } \\
\text { Testing } \\
\text { Scale }\end{array}$ & Simulant/Waste & Test/Analysis & $\begin{array}{l}\text { Parameters to be } \\
\text { Measured }^{(a)}\end{array}$ \\
\hline $\begin{array}{l}\text { Demonstrate container } \\
\text { fill volume control }\end{array}$ & Pilot & $\begin{array}{l}\text { Selected Cast } \\
\text { Stone waste and } \\
\text { dry-materials } \\
\text { mix }\end{array}$ & Examine filled containers & $\begin{array}{l}\text { Level, weight, flow } \\
\text { rate }\end{array}$ \\
\hline $\begin{array}{l}\text { Demonstrate control of } \\
\text { waste/dry-materials mix } \\
\text { ratios and composition }\end{array}$ & Pilot & $\begin{array}{l}\text { Selected Cast } \\
\text { Stone waste and } \\
\text { dry-materials } \\
\text { mixes }\end{array}$ & $\begin{array}{l}\text { Examine filled containers } \\
\text { for free liquids }\end{array}$ & $\begin{array}{l}\text { Estimate quantity of } \\
\text { free liquids }\end{array}$ \\
\hline $\begin{array}{l}\text { Demonstrate Cast Stone } \\
\text { operating envelope }\end{array}$ & Pilot & $\begin{array}{l}\text { Selected } \\
\text { COC-spiked Cast } \\
\text { Stone } \\
\text { formulations }\end{array}$ & $\begin{array}{l}\text { ANSI/ANS 16.1, EPA } \\
\text { 1315, ASTM C1308, } \\
\text { ASTM C39/C39M, } \\
\text { Rheology }\end{array}$ & $\begin{array}{l}\text { Mixing, pumpability, } \\
\text { porosity, pore size, } \\
\text { voids, tortuosity }\end{array}$ \\
\hline $\begin{array}{l}\text { Demonstrate } \\
\text { pumpability, flowability }\end{array}$ & Pilot & $\begin{array}{l}\text { Selected Cast } \\
\text { Stone waste and } \\
\text { dry-materials } \\
\text { mixes }\end{array}$ & Rheology & $\begin{array}{l}\text { Mixing, pumpability, } \\
\text { porosity, pore size, } \\
\text { voids, tortuosity }\end{array}$ \\
\hline $\begin{array}{l}\text { Demonstrate mixing } \\
\text { waste and dry materials }\end{array}$ & Pilot & $\begin{array}{l}\text { Selected Cast } \\
\text { Stone waste and } \\
\text { dry-materials } \\
\text { mixes }\end{array}$ & Rheology & $\begin{array}{l}\text { Pumpability, flow, } \\
\text { moisture content, } \\
\text { particle distribution }\end{array}$ \\
\hline
\end{tabular}

(a) Listed measured parameters for the investigation of test objectives are not expected to be comprehensive.

\subsection{Full-Scale Waste Form Package Tests}

The final disposal form for Hanford LAW immobilized in a Cast Stone waste form is to be determined. Options include Cast Stone slurry/paste poured into a metal container for curing and handling and transport to the IDF for disposal or Cast Stone slurry/paste pumped directly to a large disposal vault for curing and disposal in place. The discussion that follows assumes Cast Stone in a container for curing, transportation and storage. A scaled test system would be needed if a large disposal vault is the final storage container.

As part of the WFQ work, full-scale Cast Stone waste form packages will be prepared and characterized to demonstrate compliance with IDFWAC for the waste form container and the filled waste package. The Cast Stone waste form will also be characterized to demonstrate process control and confirm the waste form quality at full scale.

The first objective is to demonstrate that the waste form container complies with IDFWAC. The container must meet requirements with respect to materials of construction, labeling, closure and sealing, and package lifting and handling. Prototypic waste form packages will be fabricated and filled as part of full-scale testing of the preparation process for the Cast Stone waste form. The functionality of the waste form container features will be demonstrated.

The second objective is to determine the gross characteristics of the filled waste package, including mass, fill height, and void space as well as the presence of any free liquids. 
The third objective is to characterize the temperature profile in the waste package as the container is filled and as the Cast Stone cures. Temperatures will be measured at the container wall and various locations within the waste form to determine the wall temperature and cooling curves for the Cast Stone. The results will be compared with laboratory evaluations of curing conditions to confirm that the temperature profile does not affect waste form quality.

The fourth objective is to identify any macroscopic inhomogeneities in the Cast Stone waste form. The filled container will be destructively examined for large voids, bubbles, and cracking as well as for evidence of layering. Waste form samples from various locations will be examined for evidence of settling and segregation and for variation in porosity and pore size.

The fifth objective is to demonstrate consistency in the waste form characteristics throughout the fullscale waste form package. Samples of the Cast Stone waste form from various locations within the package will be characterized with respect to chemical and mineral composition and leachability.

Table 4.3 shows the WFQ testing to be conducted on full-scale prototypic Cast Stone waste form packages. This group of tests includes activities $1.4,1.5,1.10,1.11,1.12,1.13,1.14,1.27,7.6,14.3$, and 14.4 in Table B.1 in Appendix B.

\subsection{Land Disposal Restrictions Compliance Testing}

The Cast Stone waste form land disposal restriction (LDR) compliance testing will provide the process demonstration and waste form product data to demonstrate that the LAW Cast Stone waste form meets the land disposal restrictions in 40 CFR 268 and WAC 173-303-140.

Hanford tank wastes contain characteristic and listed wastes and underlying hazardous constituents that require treatment using specified treatment technologies or concentration-based treatment standards. The wastes have the corrosivity characteristic (D002) because of their $\mathrm{pH}$ and the toxicity characteristic because of the presence of arsenic, barium, cadmium, chromium, lead, mercury, selenium, and silver (D004-D011). The treatment standard for these corrosivity and toxicity characteristics in HLW is HLVIT or vitrification (40 CFR 268.40).

Hanford tank wastes also contain organic species that have the toxicity characteristic (D018, D019, D022, D028, D029, D030, D033, D034, D035, D036, D038, D039, D040, D041, D043) or are listed constituents in 40 CFR 261.31 (F001 through F005). To be acceptable for land disposal, these characteristic and listed wastes, as well as any underlying hazardous constituents (antimony, beryllium, nickel, and thallium), must be treated to federal and state concentration-based treatment standards.

The approach to addressing these regulatory requirements needs to be developed for the LAW Cast Stone waste form. At a minimum, testing will be required to demonstrate that the LAW Cast Stone passes the TCLP (EPA Method 1311 [EPA 2008]) with respect to the Universal Treatment Standards in 40 CFR 268. By the end of calendar year 2012, the EPA is expected to add four new test methods for evaluating the release of contaminants from waste forms. These four methods $(1313,1314,1315$, and 1316) are described in detail in Section 4.9 below. The regulatory framework for using these methods to address LDRs has not been established. They will be conducted, as necessary, to address any changes in LDR requirements. 
Table 4.3. Full-Scale Waste Form Package Testing

\begin{tabular}{|c|c|c|c|c|}
\hline Objectives & $\begin{array}{c}\text { Approach/Testing } \\
\text { Scale }\end{array}$ & $\begin{array}{l}\text { Simulant/ } \\
\text { Waste }\end{array}$ & Test/Analysis & $\begin{array}{c}\text { Parameters to be } \\
\text { Measured }\end{array}$ \\
\hline $\begin{array}{l}\text { Demonstrate waste } \\
\text { form container } \\
\text { meets criteria }\end{array}$ & $\begin{array}{l}\text { Full-scale prototypic } \\
\text { waste form container }\end{array}$ & None & $\begin{array}{l}\text { Demonstrate functionality } \\
\text { of labeling, closure and } \\
\text { sealing, and lifting and } \\
\text { handling features }\end{array}$ & $\begin{array}{l}\text { Visual } \\
\text { observation before } \\
\text { and after filling }\end{array}$ \\
\hline $\begin{array}{l}\text { Determine physical } \\
\text { characteristics of } \\
\text { filled Cast Stone } \\
\text { waste form } \\
\text { container }\end{array}$ & $\begin{array}{l}\text { Full-scale prototypic } \\
\text { waste form container } \\
\text { filled with } \\
\text { representative Cast } \\
\text { Stone product }\end{array}$ & $\begin{array}{l}\text { Selected } \\
\text { representative } \\
\text { simulant }\end{array}$ & $\begin{array}{l}\text { Mass, fill height, void } \\
\text { space, free liquids }\end{array}$ & $\begin{array}{l}\text { Weight of filled } \\
\text { container, } \\
\text { measure } \\
\text { dimensions of } \\
\text { void space above } \\
\text { fill, visual } \\
\text { examination for } \\
\text { free liquids }\end{array}$ \\
\hline $\begin{array}{l}\text { Determine } \\
\text { temperature profile } \\
\text { in Cast Stone waste } \\
\text { form package }\end{array}$ & $\begin{array}{l}\text { Full-scale prototypic } \\
\text { waste form container } \\
\text { filled with } \\
\text { representative Cast } \\
\text { Stone product }\end{array}$ & $\begin{array}{l}\text { Selected } \\
\text { representative } \\
\text { simulant }\end{array}$ & $\begin{array}{l}\text { Temperature profile } \\
\text { during filling and curing }\end{array}$ & $\begin{array}{l}\text { Temperatures at } \\
\text { container walls, } \\
\text { centerline and in } \\
\text { the bulk waste } \\
\text { form as a function } \\
\text { of time }\end{array}$ \\
\hline $\begin{array}{l}\text { Identify } \\
\text { macroscopic } \\
\text { inhomogeneities in } \\
\text { waste form package }\end{array}$ & $\begin{array}{l}\text { Destructive } \\
\text { examination of full- } \\
\text { scale prototypic waste } \\
\text { form container filled } \\
\text { with representative Cast } \\
\text { Stone product }\end{array}$ & $\begin{array}{l}\text { Selected } \\
\text { representative } \\
\text { simulant }\end{array}$ & $\begin{array}{l}\text { Visual observation of } \\
\text { internal void space, } \\
\text { bubbles, layering, } \\
\text { cracking, segregation of } \\
\text { Cast Stone product }\end{array}$ & $\begin{array}{l}\text { Visual } \\
\text { observation, } \\
\text { SEM/EDS, } \\
\text { Porosity and pore } \\
\text { size }\end{array}$ \\
\hline $\begin{array}{l}\text { Demonstrate } \\
\text { consistency in } \\
\text { waste form } \\
\text { properties within } \\
\text { Cast Stone waste } \\
\text { form package }\end{array}$ & $\begin{array}{l}\text { Destructive } \\
\text { examination of full- } \\
\text { scale prototypic waste } \\
\text { form container filled } \\
\text { with representative Cast } \\
\text { Stone product }\end{array}$ & $\begin{array}{l}\text { Selected } \\
\text { representative } \\
\text { simulant spiked } \\
\text { with key COCs }\end{array}$ & $\begin{array}{l}\text { Waste form samples from } \\
\text { corners, walls, centerline, } \\
\text { and selected locations in } \\
\text { the Cast Stone waste form } \\
\text { package. Chemical } \\
\text { composition, mineralogy, } \\
\text { TCLP (EPA Method } \\
\text { 1311, EPA 2008), } \\
\text { diagnostic leach test } \\
\text { method to be determined }\end{array}$ & $\begin{array}{l}\text { Chemical } \\
\text { analysis, XRD, } \\
\text { Leachate chemical } \\
\text { analysis }\end{array}$ \\
\hline
\end{tabular}

$\mathrm{XRD}=\mathrm{X}$-ray diffraction

Based on previous work with bulk vitrification as a supplemental LAW treatment technology, the regulatory compliance approach for LAW Cast Stone may need to support 1) testing to show that the Cast Stone can meet applicable LDR treatment standards and 2) a treatability variance to allow for Cast Stone operations without extensive waste form sampling and testing to demonstrate compliance with concentration-based treatment standards. A treatability variance will be pursued because of the health risk associated with an extensive sampling and analysis program required to demonstrate compliance with the concentration-based standards during production.

The scope of the testing for compliance with the LDR treatment standards and the treatability variance will be developed in conjunction with Ecology and the U.S. EPA. Based on a testing plan developed for bulk vitrification, the testing will include work at the laboratory, engineering, and full scale (CH2M HILL 2005). The Data Quality Objectives (DQO) process (EPA 2006) will be followed to 
establish performance and acceptance criteria, which will serve as the basis for designing a plan for collecting data of sufficient quality and quantity to support the goals of the study.

Table 4.4 shows the testing conditions to address the test objectives for the Cast Stone LDR compliance testing. This group of tests addresses activities 14.1, 14.2, 14.3, and 14.4 in Table B.1 in Appendix B.

Table 4.4. Test Conditions for Cast Stone LDR Compliance Testing

\begin{tabular}{|c|c|c|c|c|}
\hline Objectives & $\begin{array}{c}\text { Approach/ Testing } \\
\text { Scale }\end{array}$ & Simulant/Waste & $\begin{array}{c}\text { Test/ } \\
\text { Analysis }\end{array}$ & $\begin{array}{c}\text { Parameters to be } \\
\text { Measured }\end{array}$ \\
\hline $\begin{array}{l}\text { Demonstrate Cast } \\
\text { Stone reduces } \\
\text { toxicity of } \\
\text { underlying } \\
\text { hazardous } \\
\text { constituents }\end{array}$ & $\begin{array}{l}\text { Optimized Cast } \\
\text { Stone formulation }\end{array}$ & $\begin{array}{l}\text { Selected representative } \\
\text { simulants spiked with } \mathrm{Sb} \text {, } \\
\mathrm{Be}, \mathrm{Ni}, \mathrm{Tl}\end{array}$ & $\begin{array}{l}\text { TCLP } \\
\text { (EPA } \\
\text { Method } \\
1311 \text { ) }\end{array}$ & $\begin{array}{l}\text { Chemical analysis of } \\
\text { TCLP leachate }\end{array}$ \\
\hline $\begin{array}{l}\text { Demonstrate Cast } \\
\text { Stone removes } \\
\text { corrosivity } \\
\text { characteristic }\end{array}$ & $\begin{array}{l}\text { Optimized Cast } \\
\text { Stone formulation }\end{array}$ & $\begin{array}{l}\text { Selected representative } \\
\text { simulants }\end{array}$ & $\begin{array}{l}\text { Material } \\
\text { pH (EPA } \\
\text { Method } \\
9045)\end{array}$ & Solution $\mathrm{pH}$ \\
\hline $\begin{array}{l}\text { Demonstrate Cast } \\
\text { Stone consistently } \\
\text { produces compliant } \\
\text { waste form }\end{array}$ & $\begin{array}{l}\text { Optimized Cast } \\
\text { Stone formulation. } \\
\text { Lab-, pilot-, and } \\
\text { full-scale Cast Stone } \\
\text { product }\end{array}$ & $\begin{array}{l}\text { Selected representative } \\
\text { simulants spiked with } \mathrm{Sb} \text {, } \\
\mathrm{Be}, \mathrm{Ni}, \mathrm{Tl}, \mathrm{Ag}, \mathrm{As}, \mathrm{Ba} \text {, } \\
\mathrm{Cd}, \mathrm{Cr}, \mathrm{Hg}, \mathrm{Pb}, \mathrm{Se}\end{array}$ & $\begin{array}{l}\text { TCLP } \\
\text { (EPA } \\
\text { Method } \\
1311)\end{array}$ & $\begin{array}{l}\text { Chemical analysis of } \\
\text { TCLP leachates. } \\
\text { Chemical analysis of } \\
\text { Cast Stone waste form }\end{array}$ \\
\hline $\begin{array}{l}\text { Demonstrate Cast } \\
\text { Stone immobilizes } \\
\text { inorganic hazardous } \\
\text { constituents }\end{array}$ & $\begin{array}{l}\text { Optimized Cast } \\
\text { Stone formulation }\end{array}$ & $\begin{array}{l}\text { Selected representative } \\
\text { simulants spiked with } \mathrm{Sb} \text {, } \\
\mathrm{Be}, \mathrm{Ni}, \mathrm{Tl}, \mathrm{Ag}, \mathrm{As}, \mathrm{Ba} \text {, } \\
\mathrm{Cd}, \mathrm{Cr}, \mathrm{Hg}, \mathrm{Pb}, \mathrm{Se}\end{array}$ & $\begin{array}{l}\text { TCLP } \\
\text { (EPA } \\
\text { Method } \\
1311)\end{array}$ & $\begin{array}{l}\text { Chemical analysis of } \\
\text { Cast Stone waste form, } \\
\text { secondary waste streams, } \\
\text { process equipment } \\
\text { accumulations }\end{array}$ \\
\hline $\begin{array}{l}\text { Demonstrate Cast } \\
\text { Stone immobilizes } \\
\text { hazardous organic } \\
\text { constituents }\end{array}$ & $\begin{array}{l}\text { Optimized Cast } \\
\text { Stone formulation }\end{array}$ & $\begin{array}{l}\text { Selected real waste } \\
\text { samples containing } \\
\text { hazardous organics }\end{array}$ & $\begin{array}{l}\text { Total } \\
\text { analysis }\end{array}$ & $\begin{array}{l}\text { Compare to } 40 \text { CFR } 268 \\
\text { limits for hazardous } \\
\text { organics by total analysis }\end{array}$ \\
\hline
\end{tabular}

\subsection{Cast Stone Physical and Chemical Properties (Laboratory Scale)}

The physical and chemical properties of Cast Stone must be characterized to support the development and optimization of the formulation. This includes processing properties that impact the production of the Cast Stone waste form and the resulting waste form properties that are important to address IDFWAC and to support PA analyses.

\subsubsection{Cast Stone Processing Properties}

Cast Stone processing properties are important to the design and control of the Cast Stone preparation process including mixing, pumping, and flow distribution of the Cast Stone slurry/paste and then the curing to form the final solid Cast Stone waste form product. Relevant properties include rheology, gel and hardening time, temperature rise, and free/bleed water. 
The rheology of the Cast Stone slurry/paste is important for sizing the mixers and pumps used in preparing the Cast Stone. In the laboratory, the viscosity of the slurry/paste is measured with a rheometer. The viscosity and yield stress are measured over a period of time to determine how the rheological properties change as the Cast Stone hydration reactions proceed and the slurry/paste begins to stiffen. Larger-scale flow tests (see Section 4.2) demonstrate that the slurry/paste is sufficiently fluid to flow to the corners in the final disposal container.

Curing times for cementitious material are typically described in terms of an initial and final set time. The initial set time is the time when the paste begins to stiffen and retain its shape. The final set time is the time at which the paste has hardened sufficiently to resist a known pressure without deforming. Various simple slump and pour tests can be used to determine this gel time. ASTM C191 (ASTM 2008c) uses the Vicat needle test to determine both the initial and final set time. The slump and pour tests and the Vicat needle test provide indications of the stiffening process at discrete time intervals. A technique based on ultrasonic wave reflection has been used to provide continuous monitoring of the Cast Stone early hydration and stiffening (Sundaram et al. 2011).

The hydration reactions as the cement and fly ash interact with the aqueous wastes generate heat during the Cast Stone curing process. This heat must be dissipated during the curing process so that the Cast Stone does not reach temperatures that can be deleterious to the final waste form. Adiabatic and isothermal calorimetry are used to determine the amount of heat generated by the hydration reactions. Thermal conductivity and heat capacity are then needed to estimate the expected temperature rise. Alternatively, the temperature rise can be measured directly with thermocouples with corrections for heat loss from the specimens during the measurements.

Some bleed water or free water may form during the initial curing of the Cast Stone. Normally, this water is needed for the hydration/curing process and will disappear over a few days. Beyond that time, free liquids suggest that there is too much water in the formulation and adjustments must be made. Free water is typically observed visually.

\subsubsection{Cast Stone Waste Form Properties}

Characterization of the Cast Stone waste form properties and their changes due to weathering and other environmental conditions are addressed in several sections of the testing plan. This section addresses waste form properties that may be needed for various engineering calculations and other analyses. They include:

- density

- porosity/pore size

- hydraulic conductivity

- thermal conductivity

- heat capacity

The physical and chemical properties of the Cast Stone must be characterized to address slurry/paste properties important to processing and final waste form properties to address waste acceptance criteria for the IDF and to support PA analyses. Many of these properties can be determined on Cast Stone samples 
prepared in the laboratory and from Cast Stone specimens cut from engineering- and pilot-scale tests. Table 4.5 summarizes the laboratory-scale testing to characterize the Cast Stone physical and chemical properties. This group of tests includes activities 1.4, 1.6, 1.13, 1.21, 1.22, 1.25, 7.4, 7.5, 7.6, and 10.1 in Table B.1 in Appendix B.

Table 4.5. Cast Stone Chemical and Physical Properties Testing

\begin{tabular}{|c|c|c|c|c|}
\hline Objectives & $\begin{array}{c}\text { Approach/Testing } \\
\text { Scale }\end{array}$ & $\begin{array}{l}\text { Simulant/ } \\
\text { Waste }\end{array}$ & Test/Analysis & $\begin{array}{c}\text { Parameters to be } \\
\text { Measured }\end{array}$ \\
\hline $\begin{array}{l}\text { Determine density } \\
\text { of Cast Stone waste } \\
\text { form }\end{array}$ & $\begin{array}{l}\text { Laboratory scale with } \\
\text { representative Cast } \\
\text { Stone formulations }\end{array}$ & $\begin{array}{l}\text { Selected } \\
\text { representative } \\
\text { simulant }\end{array}$ & Density & Density \\
\hline $\begin{array}{l}\text { Determine } \\
\text { chemical } \\
\text { composition and } \\
\text { mineralogy of Cast } \\
\text { Stone waste form }\end{array}$ & $\begin{array}{l}\text { Laboratory scale with } \\
\text { representative Cast } \\
\text { Stone formulations }\end{array}$ & None & $\begin{array}{l}\text { Chemical composition and } \\
\text { mineralogy }\end{array}$ & $\begin{array}{l}\text { Chemical analysis, } \\
\text { XRD, SEM/EDS, } \\
\text { transmission } \\
\text { electron } \\
\text { microscopy (TEM) }\end{array}$ \\
\hline $\begin{array}{l}\text { Determine Cast } \\
\text { Stone slurry/paste } \\
\text { rheology }\end{array}$ & $\begin{array}{l}\text { Laboratory scale with } \\
\text { representative Cast } \\
\text { Stone formulations }\end{array}$ & $\begin{array}{l}\text { Selected } \\
\text { representative } \\
\text { simulant }\end{array}$ & Rheology & $\begin{array}{l}\text { Viscosity, yield } \\
\text { stress }\end{array}$ \\
\hline $\begin{array}{l}\text { Determine Cast } \\
\text { Stone set time }\end{array}$ & $\begin{array}{l}\text { Laboratory scale with } \\
\text { representative Cast } \\
\text { Stone formulations }\end{array}$ & $\begin{array}{l}\text { Selected } \\
\text { representative } \\
\text { simulant }\end{array}$ & $\begin{array}{l}\text { Pour and slump tests, } \\
\text { ASTM C191 }\end{array}$ & $\begin{array}{l}\text { Initial and final set } \\
\text { time }\end{array}$ \\
\hline $\begin{array}{l}\text { Measure heat } \\
\text { generation for Cast } \\
\text { Stone }\end{array}$ & $\begin{array}{l}\text { Laboratory scale with } \\
\text { representative Cast } \\
\text { Stone formulations } \\
\text { Lab- and pilot-scale } \\
\text { temperature } \\
\text { measurement }\end{array}$ & None & $\begin{array}{l}\text { Heat of hydration, thermal } \\
\text { conductivity, temperature } \\
\text { rise }\end{array}$ & $\begin{array}{l}\text { Adiabatic and/or } \\
\text { isothermal } \\
\text { calorimetry, } \\
\text { thermal } \\
\text { conductivity, } \\
\text { temperature }\end{array}$ \\
\hline $\begin{array}{l}\text { Evaluate Cast } \\
\text { Stone/container } \\
\text { interactions }\end{array}$ & $\begin{array}{l}\text { Laboratory scale with } \\
\text { representative Cast } \\
\text { Stone formulations and } \\
\text { container material }\end{array}$ & $\begin{array}{l}\text { Selected } \\
\text { representative } \\
\text { simulant }\end{array}$ & $\begin{array}{l}\text { Examine waste } \\
\text { form/container interface } \\
\text { for evidence of } \\
\text { interactions/corrosion }\end{array}$ & $\begin{array}{l}\text { SEM/EDS, } \\
\text { Metallography }\end{array}$ \\
\hline $\begin{array}{l}\text { Determine redox } \\
\text { capacity of Cast } \\
\text { Stone }\end{array}$ & $\begin{array}{l}\text { Laboratory scale with } \\
\text { representative Cast } \\
\text { Stone formulations }\end{array}$ & None & $\begin{array}{l}\text { Cerium(IV) oxidant } \\
\text { (Angus and Glasser 1985) } \\
\text { and chromium (VI) } \\
\text { oxidant (Lee and Batchelor } \\
\text { 2003) }\end{array}$ & $\begin{array}{l}\text { See referenced } \\
\text { procedures }\end{array}$ \\
\hline $\begin{array}{l}\text { Determine porosity } \\
\text { and pore size of } \\
\text { Cast Stone waste } \\
\text { form }\end{array}$ & $\begin{array}{l}\text { Laboratory scale with } \\
\text { representative Cast } \\
\text { Stone formulations }\end{array}$ & $\begin{array}{l}\text { Selected } \\
\text { representative } \\
\text { simulant }\end{array}$ & $\begin{array}{l}\text { SEM, microtomography, } \\
\text { Hg intrusion, gas } \\
\text { adsorption Brunauer- } \\
\text { Emmett-Teller (BET) } \\
\text { measurement }\end{array}$ & Porosity, pore size \\
\hline $\begin{array}{l}\text { Determine } \\
\text { hydraulic } \\
\text { conductivity }\end{array}$ & $\begin{array}{l}\text { Laboratory scale with } \\
\text { representative Cast } \\
\text { Stone formulations }\end{array}$ & $\begin{array}{l}\text { Selected } \\
\text { representative } \\
\text { simulant }\end{array}$ & $\begin{array}{l}\text { Static column or } \\
\text { ultracentrifuge flow } \\
\text { apparatus (UFA) }\end{array}$ & Permeability \\
\hline
\end{tabular}

\subsection{Physical Stability}

There is an IDF acceptance requirement for compressive strength of the waste forms destined for final disposal in IDF. The requirement is: "The mean compressive strength of the waste form shall be 
determined by testing representative non-radioactive samples. The compressive strength shall be at least 3.45 MPa when tested in accordance with ASTM C39/C39M-99 or an equivalent method." Waste or waste packages destined for burial in IDF must have structural stability. Structural stability can be provided by the waste form itself, by processing the waste to a stable form, or by placing the waste in a disposal container or structure that provides stability after disposal.

In support of both the IDF waste package acceptance criteria and long-term stability assessments, Cast Stone waste form monoliths made with un-spiked simulant LAW and monoliths that have been subjected to accelerated weathering cycles (see discussions in NRC 1991 and Um et al. 2011) will be compression strength tested using ASTM C39/C39M methodology ASTM (2009a). The U.S. Nuclear Regulatory Commission (NRC) regulations for low-level nuclear waste [10 CFR 61.56(b)(1)] state that " $a$ structurally stable waste package will generally maintain its physical dimensions and form, under the expected disposal conditions such as weight of overburden and compaction equipment, the presence of moisture and microbial activity, and internal factors such as radiation effects and chemical changes" for at least 300 years. The NRC branch technical position guidance (NRC 1991) recommends that waste packages have at least $3.45 \mathrm{MPa}(500 \mathrm{psi})$ compressive strength and that after various stresses, such as freeze-thaw cycling, water immersion, biodegradation, and radiation exposure, the compressive strength does not diminish below $75 \%$ of its prestressed state. Of particular interest to this project will be impacts of carbonation (absorption and reaction of atmospheric $\mathrm{CO}_{2}$ ) and sulfates on the Cast Stone waste form. Several laboratory-scale Cast Stone waste form specimens will be alternately reacted in elevated $\mathrm{CO}_{2}$ atmospheres under relative humidity conditions conducive to accelerating carbon dioxide reactions and then drying for several cycles. The resultant monoliths will be tested for compressive strength and after specimens have been forced to fail, they will be profiled and detailed characterization of the mineralogy (using XRD), porosity, and pore throat size distributions (using microtomography, SEM, and Hg intrusion techniques) and depth profiles of the carbonation and $\mathrm{pH}$ fronts will be measured.

The compressive strength test protocol uses cylindrical monoliths, most commonly with dimensions 2-in. diameter by 4-in. length. The right-circular-cylinder monoliths are placed in the test apparatus, and a compressive axial load is applied at a rate that is within a prescribed range until failure occurs. Compression tests of moist Cast Stone waste form specimens should be made as soon as practicable after removal from the curing molds, or alternatively, test specimens shall be kept moist by any convenient method during the period between removal from the curing molds or accelerated weathering cycling processes and the compressive strength testing.

Care must be exercised in interpreting the significance of compressive strength determinations because strength is not a fundamental or intrinsic property of encapsulated waste forms. Values obtained will depend on the size and shape of the encapsulated specimen, the batching and mixing procedures used to prepare the Cast Stone product, the waste loading in the Cast Stone, the age, temperature, and moisture conditions during curing, and perhaps the type of leachant used in the leach testing and length of leach testing. The key question to be addressed by the compressive strength testing of the leached monoliths is whether there is any significant decrease in the compressive strength values in comparison to measurements made after curing but no water immersion testing.

Table 4.6 summarizes the testing to address the physical stability data needs. The compressive strength testing of the long-term leached Cast Stone waste form specimens planned in this effort will supply empirical data to compare with the compressive strength values required by the IDF acceptance requirements and the NRC guidance and provide the data to resolve issue 10.1 shown in Table B.1. 
Table 4.6. Physical Stability Testing

\begin{tabular}{|c|c|c|c|c|}
\hline Objectives & $\begin{array}{l}\text { Approach/ } \\
\text { Testing Scale }\end{array}$ & Simulant/Waste & Test/ Analysis & $\begin{array}{l}\text { Parameters to be } \\
\text { Measured }\end{array}$ \\
\hline $\begin{array}{l}\text { Determine } \\
\text { compressive } \\
\text { strength of Cast } \\
\text { Stone waste form }\end{array}$ & $\begin{array}{l}\text { Laboratory scale } \\
\text { with } \\
\text { representative } \\
\text { Cast Stone } \\
\text { formulations }\end{array}$ & $\begin{array}{l}\text { Selected } \\
\text { representative } \\
\text { simulant }\end{array}$ & $\begin{array}{l}\text { Compressive strength } \\
\text { (ASTM C39/C39M [2009a]) }\end{array}$ & $\begin{array}{l}\text { Compressive } \\
\text { strength }\end{array}$ \\
\hline $\begin{array}{l}\text { Demonstrate } \\
\text { biodegradation, } \\
\text { immersion, } \\
\text { radiation, and } \\
\text { thermal stability }\end{array}$ & $\begin{array}{l}\text { Laboratory scale } \\
\text { with } \\
\text { representative } \\
\text { Cast Stone } \\
\text { formulations }\end{array}$ & $\begin{array}{l}\text { Selected } \\
\text { representative } \\
\text { simulant }\end{array}$ & $\begin{array}{l}\text { Thermal cycling (ASTM } \\
\text { B553 [1985]), biodegradation } \\
\text { (ASTM G21 [2009d], ASTM } \\
\text { G22 [1996]), irradiation to } \\
10^{8} \text { Rad, and water } \\
\text { immersion tests (ANSI/ANS } \\
16.1 \text { to } 90 \text { days) }\end{array}$ & $\begin{array}{l}\text { Visual examination } \\
\text { of cracking, spalling } \\
\text { or bulk } \\
\text { disintegration. } \\
\text { Compressive } \\
\text { strength (ASTM } \\
\text { C39/C39M) }\end{array}$ \\
\hline $\begin{array}{l}\text { Evaluate } \\
\text { carbonation effects }\end{array}$ & $\begin{array}{l}\text { Laboratory scale } \\
\text { with } \\
\text { representative } \\
\text { Cast Stone } \\
\text { formulations }\end{array}$ & $\begin{array}{l}\text { Selected } \\
\text { representative } \\
\text { simulant }\end{array}$ & $\begin{array}{l}\text { Compressive strength } \\
\text { (ASTM C39/C39M [2009a]) } \\
\text { XRD, SEM, } \\
\text { microtomography, Hg } \\
\text { intrusion, gas adsorption } \\
\text { Brunauer-Emmett-Teller } \\
\text { (BET) measurement }\end{array}$ & $\begin{array}{l}\text { Compressive } \\
\text { strength, } \\
\text { Porosity, pore size }\end{array}$ \\
\hline
\end{tabular}

\subsection{Waste Form Leaching Methods}

Immobilized waste forms to be disposed of in the IDF must meet leaching test requirements. The IDFWAC requires leach testing for waste form packages having significant amounts of radioactivity, which could include the Cast Stone waste packages ${ }^{1}$. The tests include the American National Standards Institute (ANSI)/American Nuclear Society (ANS) ANSI/ANS 16.1 (ANSI/ANS 2003) Leachability Index test method for solidified waste forms including grouts. The ILAW glass waste form must meet Vapor Hydration Test (VHT) (ASTM C1663 [2009b]), Product Consistency Test (PCT) (ASTM C1285 [2008a]), and TCLP (EPA Method 1311, EPA 2008) requirements (Ecology 2008). The WTP specifications for ILAW glass include specific performance requirements for the glass in the PCT and VHT (DOE 2000).

The PCT was developed to characterize HLW glasses with respect to the effects of processing variables and the performance of the glass as a waste form (Jantzen and Bibler 2008). Through extensive testing, including intra- and inter-laboratory testing, the PCT has been shown to distinguish between glasses of different quality and durability and to yield reproducible results. The test is a seven-day test that can be conducted in glove boxes and hot cells with radioactive samples. It has been developed into an ASTM standard (ASTM C1285 [2008a]) to evaluate the chemical durability of glasses including homogeneous, devitrified, and phase-separated glasses; glass ceramics; and multiphase glass ceramics.

1 River Protection Project. 2005. Integrated Disposal Facility Waste Acceptance Criteria, RPP-8402, Rev. 1, U.S. Department of Energy, Richland Operations Office, Richland, Washington. 
Similar diagnostic leaching tests may be needed for the LAW Cast Stone waste form. As with the PCT, the Cast Stone diagnostic leaching tests need to have the following characteristics (Jantzen and Bibler 2008):

- sensitive to waste form composition and homogeneity

- indicative of waste form performance

- reproducible results with precision

- minimum time required to demonstrate waste form quality

- ease of leach test specimen preparation for use in radioactive environments

There are a number of standard test methods that have been developed to characterize the leaching of radioactive, hazardous, and mixed waste forms including the PCT (ASTM C1285 [2008a]), VHT (ASTM C1663 [2009b]), single-pass, flow-through (SPFT) test (ASTM C1662 [2007]), diffusivity/leachability index tests (ANSI/ANS 16.1 [2003], ASTM C1308 [2008b], EPA Draft Method 1315 [2009c]), Materials Characterization Center (MCC) MCC-1 and MCC-3 tests (Mendel 1983), pressurized unsaturated flow (PUF test), TCLP (EPA 2008), and EPA draft methods (1313, 1314, and 1316 [2009a, b, d]).

The objective of this work is to select one or two leaching tests that can reproducibly indicate the quality of the Cast Stone waste form and to develop the data on the waste form performance in the leaching tests to provide the foundation for product specifications for the LAW Cast Stone waste form. Table 4.7 summarizes the testing to address this objective. This group of tests includes activities 1.17, $1.18,1.19$, and 1.20 in Table B.1 in Appendix B.

Table 4.7. Testing for Waste Form Leaching Methods

\begin{tabular}{lllll}
\hline \multicolumn{1}{c}{ Objectives } & \multicolumn{1}{c}{ Approach/Testing Scale } & \multicolumn{1}{c}{ Simulant/Waste } & \multicolumn{1}{c}{$\begin{array}{c}\text { Test/ } \\
\text { Analysis }\end{array}$} & $\begin{array}{c}\text { Parameters to be } \\
\text { Measured }\end{array}$ \\
\hline $\begin{array}{l}\text { Develop leaching test } \\
\text { and supporting data }\end{array}$ & Laboratory and pilot-scale & Selected & Selected & Chemical analysis \\
indicative of the & Range of waste loadings and & representative & leach test & of Cast Stone \\
quality of the LAW & quality of Cast Stone waste & COC spike, actual & procedures & waste form. \\
$\begin{array}{l}\text { Cast Stone waste } \\
\text { form }\end{array}$ & form & waste & & Leachate analysis \\
\hline
\end{tabular}

\subsection{Radionuclide Inventory Calculations}

The objective of the radionuclide inventory calculations is to demonstrate that the Cast Stone waste form will meet the IDFWAC for dose-equivalent curies, fissile gram equivalents, maximum surface dose, and radiogenic heat. Compliance with these requirements requires estimates based on the radionuclide inventory in the waste package. Prior to Cast Stone production operations, compliance will be demonstrated based on the projected radionuclide concentration in the Cast Stone waste form product. The radionuclide concentration will be estimated based on tank waste inventory projections, flowsheet models of the pretreatment, immobilization, and recycle stream processes and the target waste loading in the Cast Stone waste form. 
During Cast Stone production operations, compliance with requirements for dose-equivalent curies, fissile gram equivalents, and radiogenic heat will be demonstrated based on the reported radionuclide inventory in the Cast Stone waste packages. The radionuclide inventory will be based on waste sampling and analyses and process knowledge. The specific method for documenting the radionuclide inventory will be documented in the LAW Cast Stone waste form compliance plan. Cast Stone testing requirements to demonstrate compliance with requirements based on the radionuclide inventory are shown in Table 4.8. Surface dose will be measured directly on the production waste form packages. This group of tests includes activities 1.8, 1.9, and 1.13 in Table B.1 in Appendix B.

Table 4.8. Testing for Waste Acceptance Criteria Based on Radionuclide Inventory

\begin{tabular}{|c|c|c|c|c|}
\hline Objectives & $\begin{array}{c}\text { Approach/ } \\
\text { Testing Scale }\end{array}$ & $\begin{array}{l}\text { Simulant/ } \\
\text { Waste }\end{array}$ & Test/Analysis & $\begin{array}{c}\text { Parameters to be } \\
\text { Measured }\end{array}$ \\
\hline $\begin{array}{l}\text { Demonstrate compliance with } \\
\text { IDF waste acceptance } \\
\text { requirements for dose-equivalent } \\
\text { curies, fissile gram equivalents, } \\
\text { and radiogenic heat }\end{array}$ & $\begin{array}{l}\text { Operations of } \\
\text { full-scale Cast } \\
\text { Stone }\end{array}$ & $\begin{array}{l}\text { Actual } \\
\text { waste }\end{array}$ & $\begin{array}{l}\text { Radionuclide } \\
\text { inventory }\end{array}$ & $\begin{array}{l}\text { Radiochemical analysis. } \\
\text { Sample locations to be } \\
\text { documented in Cast Stone } \\
\text { WFQ plan }\end{array}$ \\
\hline $\begin{array}{l}\text { Demonstrate compliance with } \\
\text { IDF surface dose requirements }\end{array}$ & $\begin{array}{l}\text { Full-scale Cast } \\
\text { Stone production } \\
\text { waste form } \\
\text { packages }\end{array}$ & $\begin{array}{l}\text { Actual } \\
\text { waste }\end{array}$ & Surface Dose & Surface dose \\
\hline
\end{tabular}

\subsection{Cast Stone Solid-Phase Characterization}

Detailed characterization of both unleached and leached Cast Stone waste forms are needed to understand the starting mineralogy of the various solids and the mineralogy present after exposure-the weathering process-to leachants including oxygen and carbon dioxide gases present in the vadose zone air-filled pores. Without an understanding of the starting mineralogy of the Cast Stone waste form and the subsequent changes (mineralogical, chemical and physical) in the waste form as it weathers in the IDF subsurface, it is difficult to predict the long-term release of contaminants of concern and the long-term performance of the Cast Stone waste form. Further, the relatively short-term regulatory testing (e.g. monolith leach tests, compressive strength tests, TCLP) do not purport to project/extrapolate to long-term performance. Cast Stone waste form materials that have been leached in IDF-relevant fluids and deionized water in leaching tests described in Sections 4.7, 4.10 and 4.11 will be characterized in detail along with the unleached Cast Stone solids. In addition, LAW Cast Stone waste forms that have been exposed, using controlled atmosphere chambers, to higher than normal concentrations of carbon dioxide and oxygen for varying time periods and relative percent relative humidity will be characterized in detail using methods discussed in Um et al. (2011). The evolution of the mineralogy and physical properties of the Cast Stone waste form is needed to predict the long-term evolution of the disposed waste form as it weathers (see Table B.1 activity 7.3). Through knowledge of the starting Cast Stone mineralogy and physical properties and the weathered Cast Stone waste form mineralogy and changed physical properties, one can develop a combined physical and chemical conceptual model of the weathering process. Of particular interest in supporting the long-term projections of the fate of key contaminants is identification of the solid-phase speciation of ${ }^{99} \mathrm{Tc}$ and ${ }^{129} \mathrm{I}$ (stable iodide will be used) in the Cast Stone waste form (see Table B.1 activities 7.1 and 7.2). 
The solids characterization of selected samples will include determining

- mineralogy using bulk powder X-ray diffraction (XRD) and micro-XRD of selected samples

- mineralogy and particle size/shape using SEM and TEM equipped with chemical microprobe energy-dispersive X-ray fluorescence

- porosity and pore structure (size distribution and pore throat shapes and sizes) and crack numbers and sizes using X-ray and neutron microtomography, $\mathrm{Hg}$ intrusion porosimetry, BET, BJH, and SEM

- valence state and nearest neighbor atoms determination using synchrotron XAS (X-ray absorption near-edge structure [XANES] and extended X-ray absorption fine structure [EXAFS])

- redox capacity of individual dry materials and Cast Stone waste form product

- specific surface area using $\mathrm{N}_{2}$ and/or Ar gas adsorption (BET)

- bulk chemical composition

Brief descriptions of most of these characterization techniques are found in Appendix C.

Classical bulk XRD characterization often is hindered by microcrystalline-sized minerals yielding broad and nondistinct X-ray patterns. Further, bulk XRD generally requires that 2 or more wt\% of a mineral be present to be detected. Therefore, SEM and TEM aid in determining mineralogy via chemical composition and particle shape identification, especially for minerals at low abundance and small particle size. The synchrotron-based XANES techniques can identify the valence state of key redox-sensitive constituents such as ${ }^{99} \mathrm{Tc}$ and ${ }^{129} \mathrm{I}$ present in the solid, and EXAFS can identify molecular scale information such as coordination number and interatomic distance between atoms. Knowledge of the molecular structure and bonding lengths can aid in determining how strongly the key contaminants are retained in the Cast Stone waste form. Micro-XRD and micro-X-ray fluorescence (XRF) techniques can be used to isolate very small regions or individual particles in mounted samples such that key areas can be located to optimize the XAS characterization efforts on locations with the highest concentrations of the key COCs. Also, using XRF and SEM mapping technique, we can determine the location and atomic distributions of each contaminant in Cast Stone.

One key effort needed to allow quantitative mineralogy estimates for the Cast Stone product is to generate XRD calibrated spectra from mixtures of known masses of standards of the known minerals present. Pure-phase solids of the minerals will either be procured from commercial sources or created using ceramic or hydrothermal synthesis from reagent-grade chemicals. The XRD spectra for the purephase minerals and known mixtures of the three will be systematically prepared to allow empirical algorithms (XRD calibration curves) to be developed. The calibration curves will be used to devolve the spectra for the Cast Stone product used in the leach testing and the final weathered solid phases to allow quantitative estimates of the mineralogy of unreacted and weathered Cast Stone solids.

The redox capacity of the unleached Cast Stone product will be measured to understand the capacity for the Cast Stone waste form to maintain redox-sensitive elements such as Tc in their less mobile (reduced) states (see Table B.1 activity 7.5). Redox capacity will be measured using two techniques (Lee and Batchelor 2003, Angus and Glasser 1985). 
The BET surface area of the unleached crushed and sieved Cast Stone waste form material will also be measured by nitrogen gas absorption (Brunauer et al. 1938). The specific surface areas of the crushed and sieved Cast Stone waste form are required in order to calculate various leaching constants and rates in several of the leach tests described in Section 4.9.

The bulk chemical compositions of the dry materials and the final Cast Stone waste form need to be determined as input to some of the leach tests described below as well as to aid in mineral identification by the various solid-phase characterization techniques. Microwave digestion uses high temperatures and pressures to accelerate the digestion process of solid matrices with strong acids such as nitric, hydrochloric, and hydrofluoric. The use of hydrofluoric acid helps to achieve total dissolution of solid materials (EPA SW-846 Method 3052, Microwave Assisted Acid Digestion of Siliceous and Organically Based Matrices). The resulting solution is then analyzed by inductively coupled plasma optical emission spectroscopy (ICP-OES) for major elements such as $\mathrm{Al}, \mathrm{Ca}, \mathrm{Fe}, \mathrm{K}, \mathrm{Mg}, \mathrm{Mn}, \mathrm{Na}, \mathrm{Ni}, \mathrm{P}, \mathrm{Pb}, \mathrm{S}, \mathrm{Si}$, and Ti and inductively coupled plasma mass spectroscopy (ICP-MS) for RCRA trace metals, Cs, Re, ${ }^{99} \mathrm{Tc}$ and iodide. When iodide is present, a separate aliquot of the solids needs to be digested using an alkaline fusion as described in Brown et al. (2005). Anion content in the solids is determined from a sodium peroxide/sodium hydroxide fusion at $600^{\circ} \mathrm{C}$ followed by water dissolution of the fused material (ASTM $\mathrm{C} 1463$ [2000]). The resulting water solution is then analyzed by ion chromatography for $\mathrm{NO}_{3}^{-}, \mathrm{F}^{-}$, and $\mathrm{Cl}^{-}, \mathrm{SO}_{4}{ }^{2-}$ and $\mathrm{PO}_{4}{ }^{3-}$. The total carbon and inorganic carbon content of the solids is directly measured by a total carbon analyzer using a few hundred mg of crushed solid (e.g., ASTM D4319-93 [ASTM 2001]). Organic carbon is calculated from the difference between total and inorganic carbon.

Through assimilation of all the solid-phase characterization information and total chemical composition of unleached and leached Cast Stone waste form, one can better identify controlling mechanisms for species release and the mineral weathering sequence of the waste form needed to support long-term performance modeling of the waste form.

\subsection{Waste Form Leach Testing-PA Support}

The LAW Cast Stone waste form needs to be studied to gain an understanding of the mechanisms that control the release of major constituents as well as the trace contaminants that cause the greatest risk to humans and groundwater. From knowledge of the controlling release mechanisms, one can build either mechanistic (physicochemical) or empirical algorithms that are needed by PA computer codes to generate long-term predictions on the fate of potential contaminants in the waste forms. Examples of the types of mechanistic and empirical algorithms and overall PA process are found in Bacon et al. (2000), Bacon and McGrail et al. (2001), McGrail et al. (2001) and Mann et al. (2001).

The following activities are needed to study the release mechanisms of major and trace contaminant species from the Cast Stone waste form capable of meeting the IDF facility requirements. The main goals of the tests are to provide insight into the chemical and mass transport processes that control the weathering, corrosion, or leaching of species from the solid waste forms and monoliths and to provide numerical data on key parameters that feed construction of algorithms used in PA codes used to predict the long-term fate of species within the waste forms/packages. The following subsections focus on describing the types of waste form characterization and tests needed to support risk and long-term performance predictive modeling. 


\subsubsection{Cast Stone Monolith Leach Testing}

There is a proposed IDF waste package acceptance criterion that states that the waste form shall exhibit a sodium leachability index greater than 6.0 when tested in deionized water over a 90-day period using the ANSI/ANS-16.1 testing procedure (ANSI/ANS 2003). For PA support, such monolith leach testing is performed for longer time periods and often uses more relevant leachants than deionized water. Further, there are at least two other very similar monolith leach test protocols, EPA 1315 (EPA 2009) and ASTM C1308 (ASTM 2008b), that use the same equipment and basic test protocols with only slight variations in sampling times. The ASTM C1308 procedure has an accompanying computer code, Accelerated Leach Test (ALT) (Furhmann et al. 1990), that aids in data reduction and evaluation as to whether certain diffusion laws are evidenced in the raw data.

These intermittent solution-exchange monolith leach procedures generally are used to determine the apparent diffusion coefficient for specific contaminants out of monolithic waste forms. The test protocols, shown schematically in Figure 4.2, immerse monoliths (generally right circular cylinders) into a volume of leachant (measured in $\mathrm{mL}$ ) that is 10 times larger than the geometric surface area measured in $\mathrm{cm}^{2}$. At set times, the monolithic waste form is moved to a second container with fresh leachant, and the diffusion leach testing continues. At the next designated time, the waste form is placed back in the first container that now contains fresh leachant. The process of alternating the placement of the monolithic waste form between the two containers continues for the duration of the test. The ANS-16.1 protocol has ten solution exchanges occurring after 2, 7, 24, 48, 72, 96, 120, 456, 1128, and 2160 hours (total of 90 days), but there is no requirement to stop the leach tests after 90 days when collecting data to support long-term PA algorithm development. The concentration of all contaminants of interest in each leachate is measured and used to calculate individual time increment (n) effective diffusion coefficients using Equation 4.1. Often major constituents in the leachates as well as $\mathrm{pH}$ and Eh are measured to allow geochemical speciation and saturation index calculations to be performed as an aid to understanding the leach mechanisms that might be controlling the release of specific contaminants out of the monolith.

$$
\mathrm{D}_{\mathrm{e}(\mathrm{n})}=\pi\left[\left(\mathrm{a}_{\mathrm{n}} / \mathrm{A}_{0}\right) / \Delta \mathrm{t}_{\mathrm{n}}\right]^{2}[\mathrm{~V} / \mathrm{S}]^{2}[\mathrm{~T}]
$$

where $D_{e(n)}=$ effective diffusivity coefficient $\left(\mathrm{cm}^{2} / \mathrm{s}\right)$ for leaching interval, $t_{n}-t_{n-1}$

$a_{n}=$ activity or mass of contaminant leached during the leaching interval, $t_{n}-t_{n-1}$ units $\mu \mathrm{g}$ or $\mu \mathrm{Ci}$

$\mathrm{A}_{0}=$ total initial activity of contaminant in the waste form monolith-units $\mu \mathrm{g}$ or $\mu \mathrm{Ci}$

$=$ fraction of radionuclide leached during interval $t_{n}-t_{n-1}$

$\mathrm{a}_{\mathrm{n}} / \mathrm{A}_{0}$

$\Delta t_{n}=$ duration of the $n$th leaching interval $t_{n}-t_{n-1}$ in $s$

$\mathrm{V}=$ volume of specimen, $\mathrm{cm}^{3}$

$\mathrm{S}=$ geometric surface area of the specimen, $\mathrm{cm}^{2}$

$\mathrm{T}=$ mean leaching time $=\left[1 / 2\left({ }_{t_{n}}+\sqrt{ } t_{n-1}\right)\right]^{2}$ in $s$.

The leachability index (LI) for each time interval is defined in Equation 4.2 as

$$
\mathrm{LI}_{\mathrm{n}}=\log \left(\beta / \mathrm{D}_{\mathrm{e}(\mathrm{n})}\right)
$$


where $\beta=a$ constant $=1 \mathrm{~cm}^{2} / \mathrm{s}$, and $\mathrm{D}_{\mathrm{e}(\mathrm{n})}$ is the effective diffusion coefficient for the contaminant for leach interval $\mathrm{n}$.

An average of the sodium leachability indices for the ten individual ANS16.1 solution exchanges is calculated as shown in Equation 4.3.

$$
\mathrm{LI}_{90-\text { day }}=\left(\sum_{n=1,10}\left[\log \left(\frac{\beta}{D_{e(n)}}\right)\right]\right) \div 10
$$

The EPA 1315 leach protocol (EPA 2009), quite similar to the ANS-16.1 protocol, has been proposed to replace the ANS-16.1 method by slightly modifying the times at which the leachant solution replacements occur. The method also endorses carrying out the leach tests for time periods beyond 90 days and suggests that leachants other than deionized water be used that are more relevant to the waste form disposal environments. The ASTM C-1308 also recommends using more relevant leachants, various temperatures, and longer time periods to evaluate the appropriateness of relying on diffusion processes to model the raw data.

In support of risk assessment and PA needs, empirical effective diffusivities for key contaminants and major waste constituents will be measured in long-term leach tests using LAW Cast Stone waste form monoliths. The intermittent solution-exchange leach test will be extended well beyond the 90 -day contact time typically used for regulatory purposes, and the two more IDF-relevant leachants, vadose zone pore water and IDF glass leachate, will be used for most tests. The chemical compositions of the latter two leachants are shown in (Table 4.9). After approximately one year of testing, select monoliths will be sectioned and characterized by the solid-phase techniques mentioned in Section 4.9 to understand the types of minerals that occur on the surface and within the weathering monolith. A pH and redox capacity profile from the outer edge to the interior of the monolith being characterized will be measured using a phenolphthalein indicator (Powers 2005) and the redox capacity methods (Lee and Batchelor 2003, Angus and Glasser 1985). These profiles will aid in understanding the $\mathrm{pH}$ buffering caused by carbon dioxide ingress and the oxidation caused by oxygen ingress. Both processes must be considered when estimating long-term performance of the waste forms disposed of in the IDF.

Other monolith leach tests will be continued beyond the one-year contact period as long as practical to continue collecting contaminant release data for longer time periods. Once leach testing is completed, similar solid-phase characterization and $\mathrm{pH}$ and Eh depth profiles will be performed, if found to be useful, to identify the minerals formed during the weathering process and the release mechanisms, and to quantify the effective diffusion of contaminants out of and reactants (e.g., oxygen and carbonate) into the monoliths. The tests and characterization described in this subsection will generate the necessary information and data to address issues 9.1 and 9.2 in Table B.1.

In a similar fashion LAW Cast Stone waste form monoliths that have been weathered under accelerated atmospheres of carbon dioxide and oxygen will be leach tested to evaluate whether the release of key contaminants is changed after accelerated weathering. 


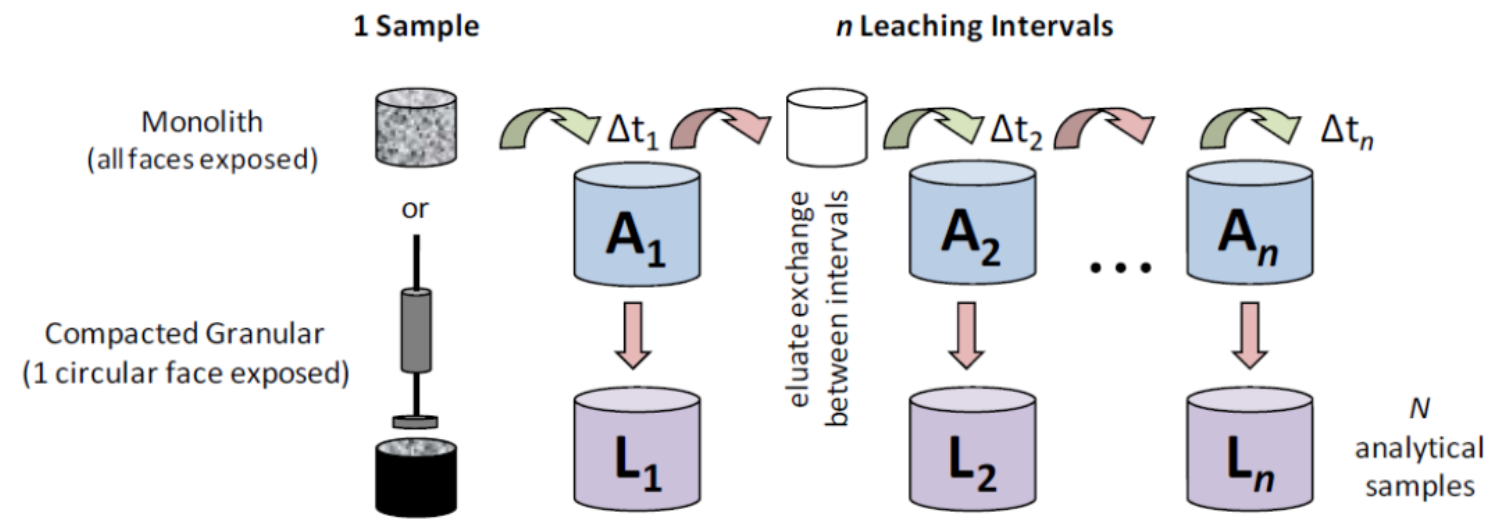

Figure 4.2. Schematic of Intermittent Solution-Exchange Leach Test Methods Such as ANSI 16.1, ASTM C1308, or EPA 1315 Test Method

Table 4.9. Composition of and Chemicals Used to Create IDF Vadose Zone Pore Water and LAW Glass Leachate

\begin{tabular}{lllllc}
\hline Constituents & $\begin{array}{c}\text { IDF pore water } \\
\text { (a) } \\
\mathbf{M}\end{array}$ & $\begin{array}{c}\text { LAW Glass } \\
\text { leachate (a) }\end{array}$ & Chemicals & $\begin{array}{c}\text { IDF pore } \\
\text { water } \\
\mathbf{M}\end{array}$ & $\begin{array}{c}\text { LAW Glass } \\
\text { leachate } \\
\text { M }\end{array}$ \\
\hline $\mathrm{Ca}$ & 0.012 & 0 & $\mathrm{CaSO}_{4}$ & $1.2 \times 10^{-2}$ & \\
$\mathrm{Mg}$ & 0.005 & 0 & $\mathrm{NaNO}_{3}$ & $3.4 \times 10^{-3}$ & \\
$\mathrm{Na}$ & 0.0058 & 1.12 & $\mathrm{NaHCO}_{3}$ & $3.0 \times 10^{-4}$ & $2.3 \times 10^{-1}$ \\
$\mathrm{~K}$ & 0.0007 & 0.0005 & $\mathrm{Na}_{2} \mathrm{CO}_{3}$ & & $4.6 \times 10^{-1}$ \\
$\mathrm{HCO}_{3}$ & 0.0003 & 0.23 & $\mathrm{NaCl}^{-1}$ & $2.1 \times 10^{-3}$ & \\
$\mathrm{CO}_{3}$ & 0 & 0.46 & $\mathrm{Na}_{2} \mathrm{SiO}_{3} \cdot 9 \mathrm{H}_{2} \mathrm{O}$ & & $1.9 \times 10^{-2}$ \\
$\mathrm{NO}_{3}$ & 0.0034 & 0 & $\mathrm{NaOH}^{-3}$ & & $2.5 \times 10^{-3}$ \\
$\mathrm{Cl}$ & 0.0076 & 0 & $\mathrm{MgSO}_{4}$ & $2.6 \times 10^{-3}$ & \\
$\mathrm{SO}_{4}$ & 0.0146 & 0 & $\mathrm{MgCl}_{2}$ & $2.4 \times 10^{-3}$ & \\
$\mathrm{BO}_{3}$ & 0 & 0.013 & $\mathrm{KCl}^{-4}$ & $7.0 \times 10^{-4}$ & \\
$\mathrm{SiO}_{3}$ & 0 & 0.019 & $\mathrm{KOH}^{-4}$ & & $5.2 \times 10^{-4}$ \\
$\mathrm{OH}_{\mathrm{pH}}$ & 0 & 0.0005 & $\mathrm{H}_{3} \mathrm{BO}_{3}$ & & $1.3 \times 10^{-2}$ \\
\hline
\end{tabular}

\subsubsection{EPA 1313 and 1316 Batch Leach Tests Using Crushed LAW Cast Stone Waste Forms}

Method 1313 is used to determine the liquid-solid partitioning between water and a solid material at equilibrium over a broad range of $\mathrm{pH}$. The procedure is comprised of nine parallel batch extractions of particle-size reduced material over a $\mathrm{pH}$ range between 2 and 13 by the addition of pre-determined amounts of acid or base to achieve specified final $\mathrm{pH}$ values (see Figure 4.3 for a schematic of the method). 


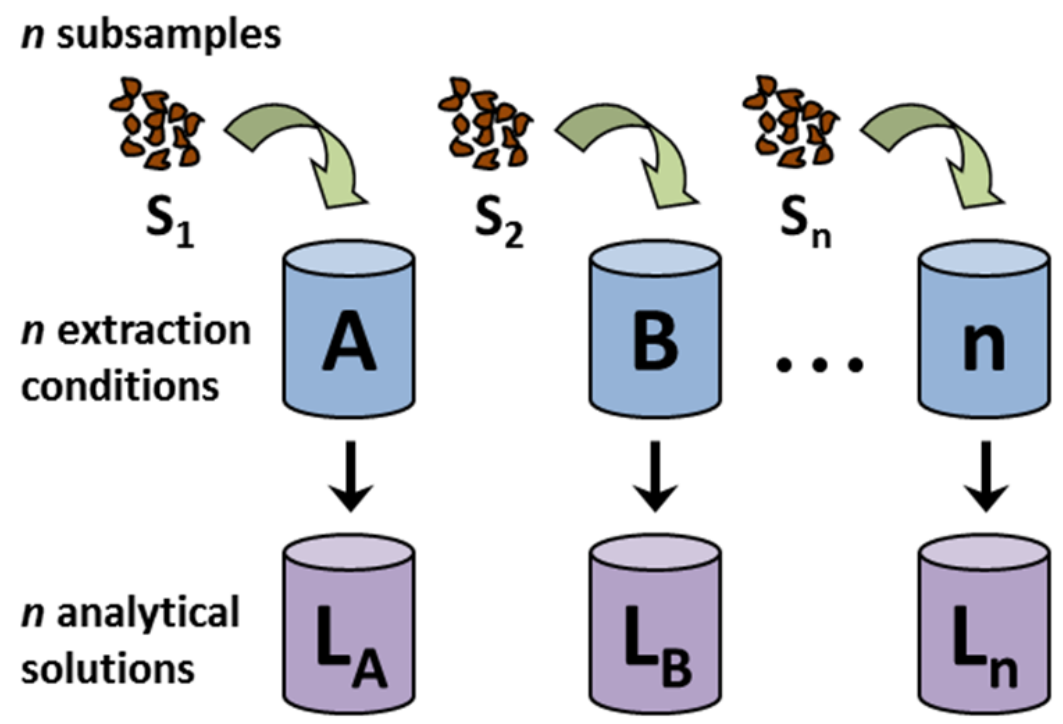

Figure 4.3. Schematic of Batch Test EPA Method 1313 and Method 1316

A known mass of disaggregated solid material is placed in each of nine extraction vessels and contacted with water at a liquid-solid ratio $(\mathrm{L} / \mathrm{S})$ of $10 \mathrm{~mL} / \mathrm{g}$-dry. Nitric acid or sodium hydroxide is added to each vessel to obtain a specified final $\mathrm{pH}$ value based on a pre-test titration curve. The nine vessels are gently stirred continuously or tumbled in an end-over-end fashion for a time commensurate with reaching steady-state effluent concentrations (often estimated based on diffusion out of the maximum particle size generated by the disaggregation process and generally 24 to 72 hours). Eluate $\mathrm{pH}$ and conductivity are recorded. Analytical samples are filtered, preserved and sent for chemical analysis of major, minor and trace contaminant concentrations. Constituent concentrations $[\mathrm{mg} / \mathrm{L}]$ or mass release $[\mathrm{mg} / \mathrm{kg}]$ are plotted as a function of eluate $\mathrm{pH}$ (see Figure 4.4 for an example). Constituent concentrations over the $\mathrm{pH}$ range typically show characteristic behavior for cationic, anionic, oxyanionic and highly soluble species. The results of this test are used to (i) obtain maximum (available) release values, and (ii) show equilibrium concentrations when the environment dominates $\mathrm{pH}$. Results form the basis for geochemical speciation modeling of release-controlling phases.

Eluate constituent concentrations may be used in conjunction with information regarding environmental disposal scenarios to estimate the anticipated leaching concentrations, release rate and extent for individual material constituents under the expected disposal conditions. Eluate constituent concentrations generated by this method may also be used along with geochemical speciation modeling to infer the mineral phases that control the leaching or release processes of the solid material. 


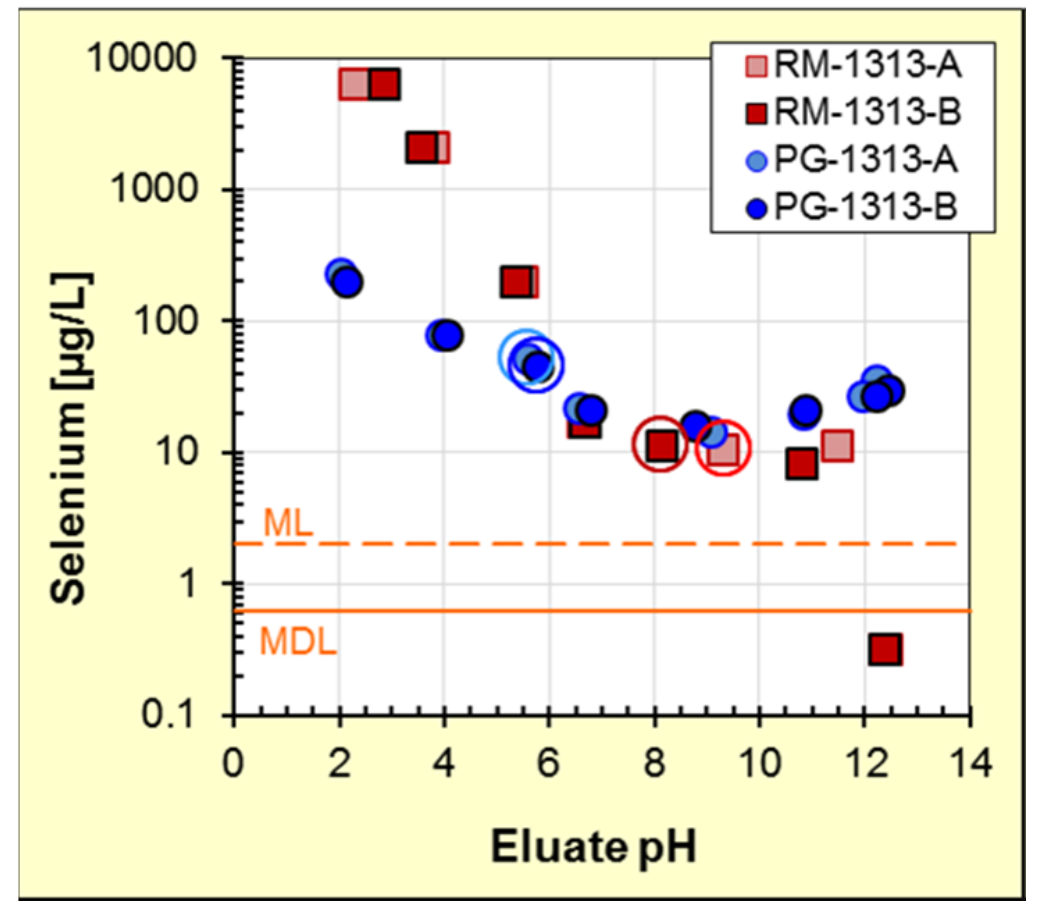

Figure 4.4. Example Plot of Data Generated from EPA 1313 Method. "ML" and "MDL" lines represent minimum level of quantitation and method detection limit, respectively.

The EPA Method 1316 batch test measures the liquid-solid partitioning attributes of a crushed waste form at the natural $\mathrm{pH}$ of the solid material as a function of liquid to solid ratio (L/S) under conditions that approach chemical equilibrium between the liquid and solid phases. This protocol consists of five parallel extractions of particle-size reduced solid material (to facilitate the approach to equilibrium) in a leachant over a range of L/S values (see Figure 4.3 for a schematic of the batch tests). The eluate concentrations at a low L/S provides insight into pore solution composition either in a granular bed or in the pore space of low-permeability material (e.g., solidified monolithic or compacted granular fill).

Method 1316 is used to determine the leaching or release attributes between water and a solid material at equilibrium. This test is a parallel batch procedure with each extraction conducted at different $\mathrm{L} / \mathrm{S}$ ratios. This equilibrium test is conducted on a granular sample of material such that particle size reduction may be required to facilitate equilibrium. A known mass of solid material is placed in each of five extraction vessels and deionized water (or other appropriate leachant) is added at L/S of 10, 5, 2, 1, and $0.5 \mathrm{~mL} / \mathrm{g}$-dry. The vessels are gently stirred or tumbled in an end-over-end fashion for a contact time sufficient to reach equilibrium (steady state depending on particle size). Eluant $\mathrm{pH}$ and conductivity are recorded and analytical samples are filtered, preserved and sent for chemical analysis.

The measured eluent parameters from the Method 1316 test (pH, conductivity, constituent concentrations, and cumulative mass release) are represented as a function of $\mathrm{L} / \mathrm{S}$ ratio. The results of this test are used to show changes in equilibrium concentrations as L/S approach that of field conditions and to estimate pore-water concentrations at low L/S. An example plot of Method 1316 data is shown in Figure 4.5. 


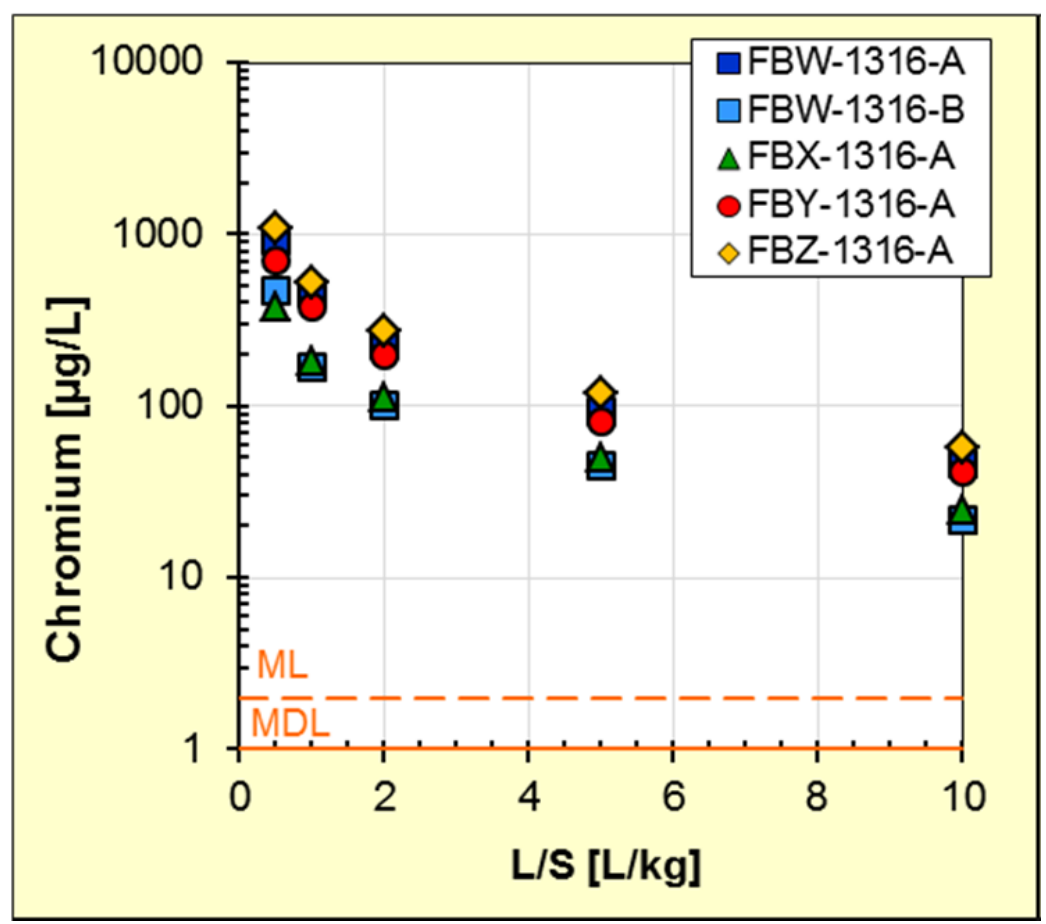

Figure 4.5. Example Plot of EPA Method 1316 Data

\subsubsection{EPA 1314 Flow-Through Leach Tests Using Crushed LAW Cast Stone Waste Forms}

The EPA 1314 test (EPA 2009b) is designed to provide the liquid-solid partitioning of constituents in a granular solid material as a function of $\mathrm{L} / \mathrm{S}$, based on elution volume, under percolation (flow-through) conditions. Granular material is packed into a cylindrical column to moderate bulk density and is contacted by leaching solution at a low flow rate. Solution is introduced in an up-flow pumping mode to minimize air entrainment, flow channeling, and to achieve $\sim 100 \%$ water saturation (see Figure 4.6 for a schematic of the test method). Effluent concentrations and cumulative mass releases of COCs are plotted as a function of cumulative L/S (or time). Effluent concentrations may be compared to regulatory assessment limits to evaluate whether release rates are acceptable. This method is intended to be used as part of environmental leaching assessment, in concert with the other EPA leach tests described or other test methodologies, for the evaluation of waste form performance after disposal.

This test method is intended as a means for obtaining a series of extracts (i.e., the effluents) of a granular solid material which may be used to show eluate concentrations and/or cumulative release as a function of $\mathrm{L} / \mathrm{S}$ ratio. These can be related to a time scale when data on mean infiltration rate, waste form density and waste form height in one-dimensional transport conceptual models are used to predict COC release. Effluent concentrations may also be used along with geochemical speciation modeling to infer the mineral phases that control the release of key constituents from the pore structure of the solid waste form. 


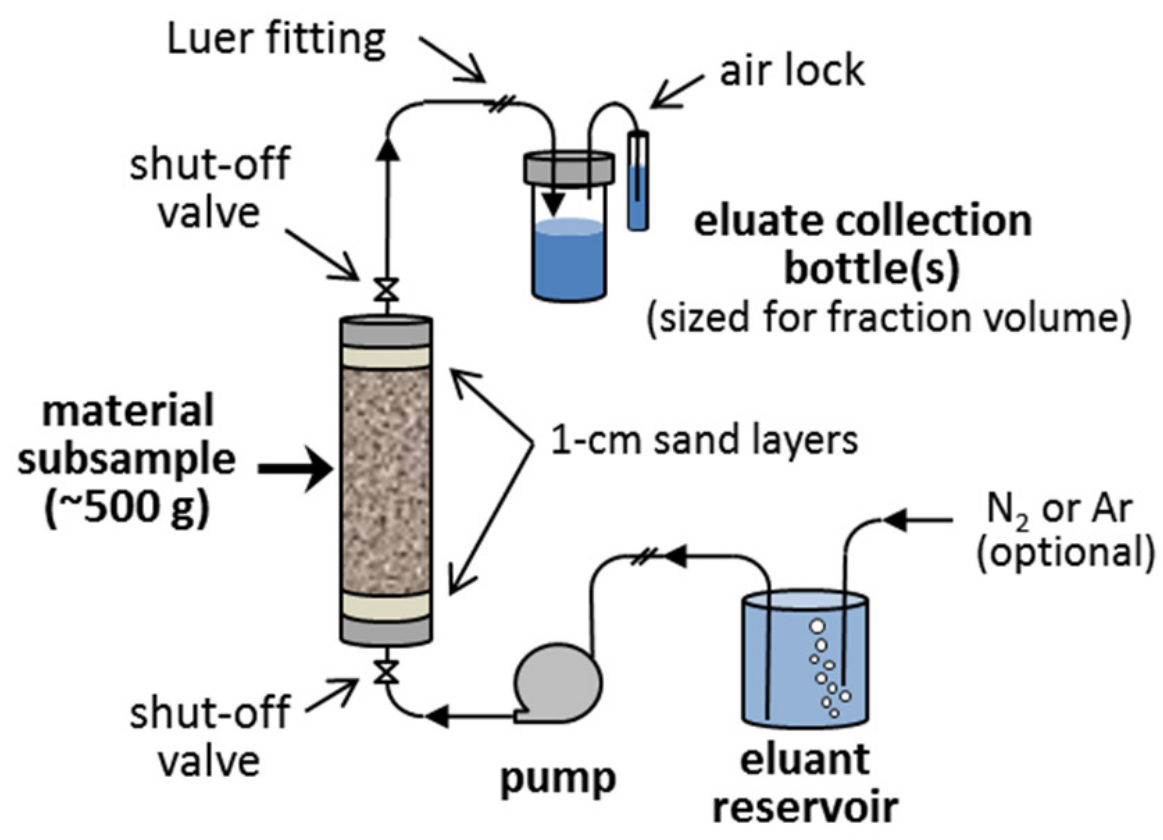

Figure 4.6. Schematic of the EPA Method 1314 Up-Flow Column Test

The flow rate is usually maintained between $0.5-1.0 \mathrm{~L} / \mathrm{S} /$ day to increase the likelihood of local equilibrium between the solid and liquid phases. L/S is represented as the cumulative volume of leaching solution passing through a column containing a known mass of material. For some materials, particle size reduction may be required to meet column dimension requirements and facilitate the approach to equilibrium. All effluents are collected in containers that are changed at specific cumulative L/S values between L/S 0.2 and $10 \mathrm{~mL} / \mathrm{g}$-dry. Effluent volumes in each effluent container are recorded and constituent concentrations in each container are measured. The cumulative mass releases for key constituents are plotted as a function of L/S (or time). The results of Method 1314 provide an estimate of pore-water concentrations at low L/S and illustrate how release changes as soluble constituents are released during successive pore volumes. Figure 4.7 is an example of how data are presented.

The first effluents $(\mathrm{L} / \mathrm{S}<0.2)$ of the column test provide insight into pore solution composition in the pore space of low-permeability material (e.g., solidified monolithic or compacted granular fill). 


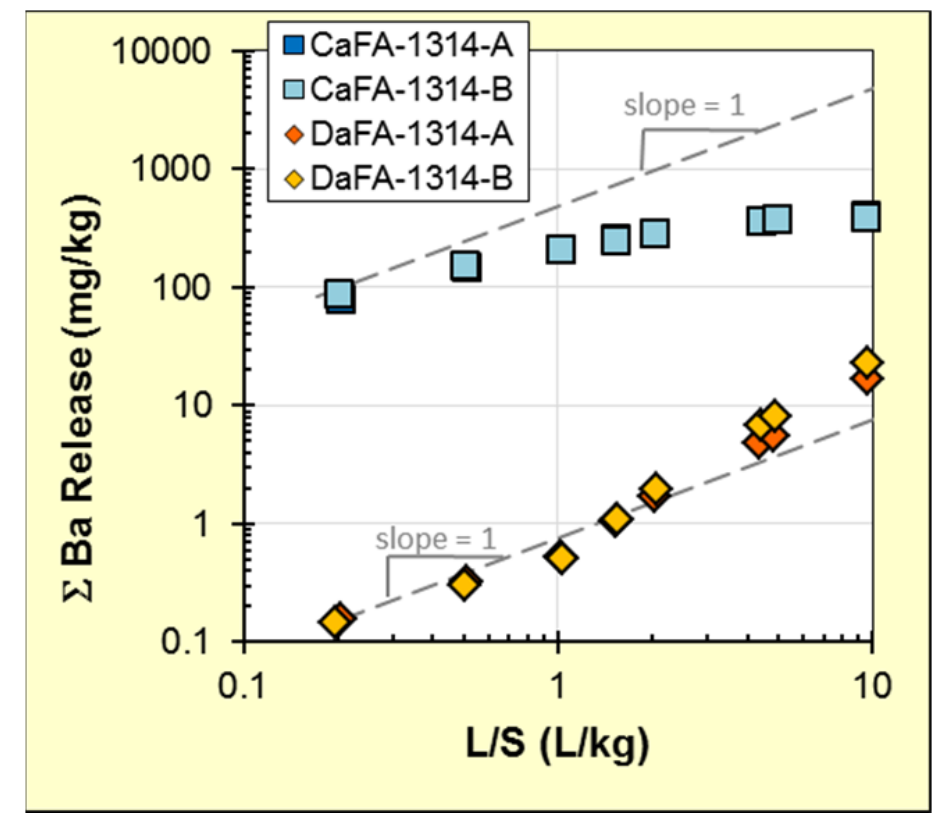

Figure 4.7. Example Plot of EPA Method 1314 Data. Note that a slope $=1$ suggests solubility control for the plotted constituent.

\subsubsection{Single-Pass Flow Through (SPFT) Testing}

The long-term release of constituents from glass has been successfully predicted from an algorithm based on a quasi-theoretical kinetic rate law (Bacon and McGrail 2001: McGrail et al. 2001). Dissolution rates and activation energies of dissolution are parameters needed for the quasi-theoretical kinetic rate law. SPFT testing has been shown to be a good test methodology to measure these key parameters. The SPFT methodology has been standardized as ASTM C1662 (ASTM 2007). Waste form experts are evaluating whether similar theoretical constructs can be generated for the Cast Stone waste form. SPFT testing will not be conducted until it is determined that the method will provide meaningful results with respect to grout waste forms.

\subsubsection{Pressurized Unsaturated Flow (PUF) Tests}

PUF experiments are conducted under hydraulically unsaturated conditions similar to the subsurface conditions found at the IDF. PUF experiments are unique because they mimic the vadose zone environment and allow the corroding waste form to achieve its final reaction state under IDF-relevant conditions. PUF tests can provide information on the 1) alteration phase or phases that form as a result of accelerated weathering (when performed at elevated temperature), 2) evolution of leachate chemistry that occurs as a result of the Cast Stone waste-form/water interactions, and 3) Cast Stone waste-form/water reaction under hydraulically unsaturated conditions similar to those expected in a disposal-system environment. The PUF systems, available at Pacific Northwest National Laboratory (PNNL), consist of 7.62-cm long and 1.91-cm diameter inner columns of inert materials (polyetheretherketone or titanium). Each column has a special bubbling pressure plate at the bottom of the column to allow water, but not air, to pass through. The bubbling pressure plate creates the unsaturated flow conditions once pressure is applied between the inner and outer columns. As long as the air or inert gas pressure within the outer chamber is kept below the bubbling pressure, the material packed within the inner column will be 
maintained at unsaturated moisture conditions, dependent on the flow rate of water added to the top of the column and the permeability of the material packed in the column. A schematic and a photograph of the PUF system are shown in Figure 4.8.
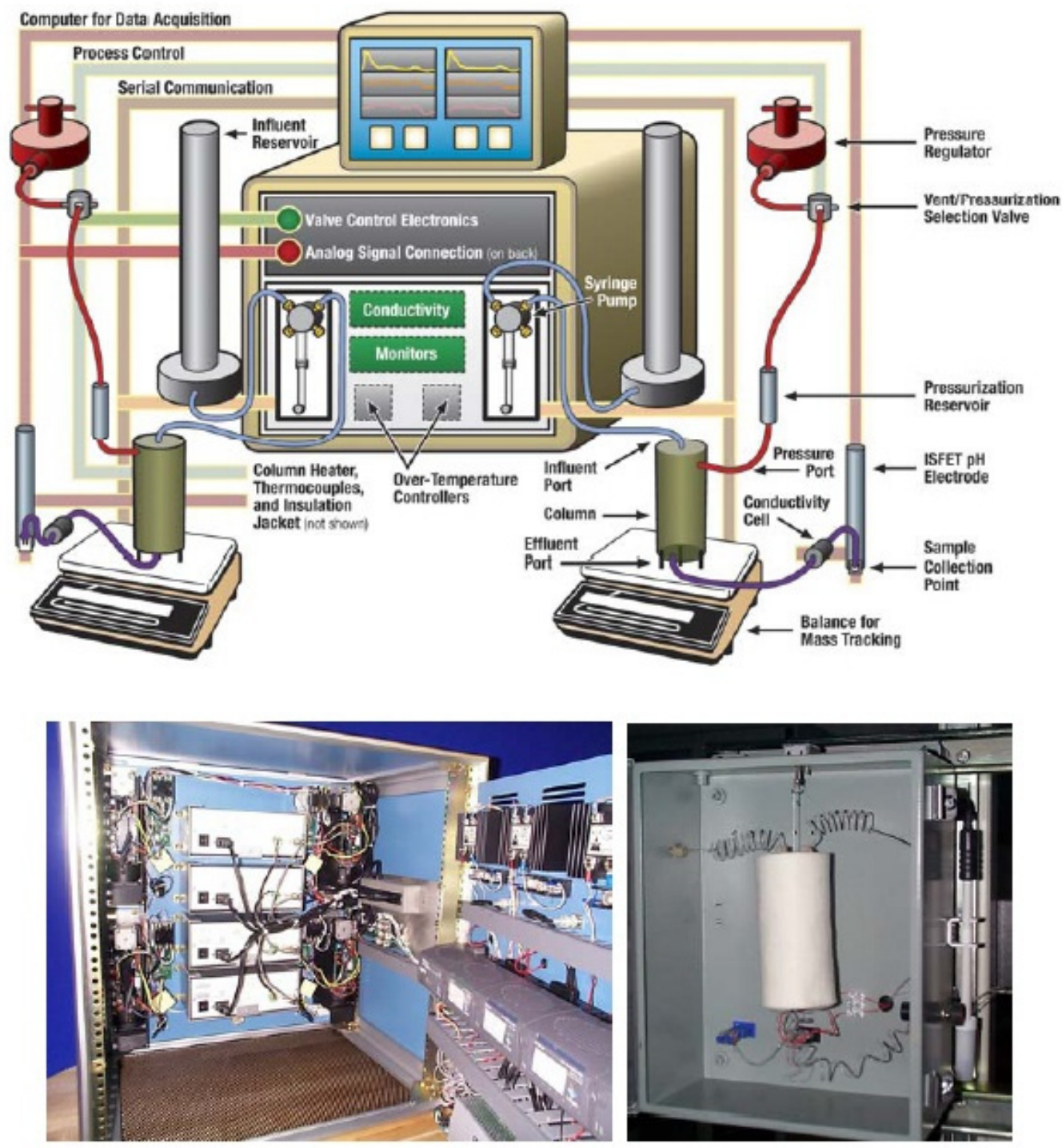

Figure 4.8. Schematic and Photographs of the PUF System. Bottom left: the third-generation PUF apparatus, which has the capability to conduct four simultaneous tests. Bottom right: the PUF box (grey box), insulation-wrapped column (center of the box), strain gauge (center of the box above the column), pressure/PUF port Teflon ${ }^{\circledR}$ line (top left of the column), influent solution Teflon line (top right of the column), effluent solution Teflon line (bottom of the column), thermocouples (type $\mathrm{J}$ [blue connector] and type $\mathrm{T}$ [black connector] shown inside the box with black/red wire), $\mathrm{pH}$ probe (outside the box shown in white), and collection vial (outside the box connected to the $\mathrm{pH}$ probe). 
To support the performance evaluations of the Cast Stone waste form, several PUF tests will be conducted using either crushed and sieved LAW Cast Stone waste forms prepared with ${ }^{99} \mathrm{Tc}$, stable I, and RCRA metals-spiked LAW simulants. The specific tests will support activities 8.1, 8.4, and 9.1 in Table B.1.

The PUF system with the LAW Cast Stone waste form can be applied at both ambient and elevated temperatures with both IDF vadose zone pore water and IDF glass leachate (see Table 4.9) to monitor the evolution of leachate under disposal system unsaturated water conditions. If the effluent reaches a steady-state composition after several months and remains fairly constant over an additional month or so, the PUF tests will be stopped, and the leached solids will be characterized by several of the techniques listed in Section 4.9 to identify the types and amounts of secondary minerals formed by weathering under unsaturated conditions. If the leachate chemical composition does not reach a steady state, PUF tests will be continued as long as feasible with a few terminated at set times to provide information on the amounts and types of secondary minerals that form during the weathering process. It may be possible to evaluate the weathering kinetics of Cast Stone from PUF tests run at various temperatures.

\subsection{Waste Package Release Testing}

No full-scale waste package release tests are planned be performed on the LAW Cast Stone waste form within its metal container. Future PAs are not expected to take credit for container properties in minimizing contaminant releases, based on the slow release from the Cast Stone matrix and based on previous PA treatments of the containers' role in long term release. However, some tests used to study the Cast Stone waste form to support the development of the release model needed in the system's PA code will include higher concentrations of ferrous iron and low redox conditions to quantify the impacts of corroding iron containers on mass transport out of the low-permeability Cast Stone monolith. This will allow effects of the metal container and its corrosion products (e.g., iron oxides) on the leach rates of constituents from the Cast Stone waste form and re-adsorption of constituents onto the corrosion products to be estimated (see activity 9.1 in Table B.1).

Depending on the container selected, it may be necessary to investigate waste form/interior container interactions that could lead to premature degradation of the container. Another scenario would be the impacts of co-disposal of LAW glass and its leachates on Cast Stone container's outer surface corrosion.

\subsection{Waste Form Release Model}

Quantifying the rate and extent of element or contaminant release from pure minerals, glasses, mixtures of minerals and amorphous solids, such as the Cast Stone waste form, has been a challenge to predictive geochemistry modeling for decades. The early geochemistry studies relevant to creating release models of solids similar to nuclear waste forms have focused on understanding the weathering of primary minerals and basaltic glasses contained in the earth's crust. Theories related to mineral and glass weathering developed within the geochemistry community, such as Transition State Theory of Chemical Kinetics (e.g., Lasaga 1998), have been used to predict the release of contaminants from nuclear waste forms and other engineered materials. The weathering of these materials is impacted by a series of 
sequential and/or simultaneous competing chemical and physical reactions/processes that control the mass transfer of contaminants from the waste form into solution. These reaction/processes include, but are not limited to, the following:

- diffusion/advection

- dissolution/precipitation

- adsorption/absorption/desorption

- complexation and ion exchange

- oxidation/reduction

- paragenetic mineral transformations.

The overall impact of individual or coupled reactions/processes on the long-term performance of the Cast Stone waste form will depend on a number of different variables, such as composition, the resistance of materials to physical and chemical degradation, the dominant mechanism controlling contaminant release, and the disposal system environment. Therefore, performance testing must focus on the use of experiments that provide model parameters that explain the key processes and in some cases accelerate the weathering process to obtain the data needed to predict performance in a realistic time frame. The results produced from the laboratory-scale testing and experiments discussed in this test plan will be used to provide the parameters needed to predict performance and contaminant release over $\sim 10,000$ years, which is the expected period of performance needed for the IDF engineered system and the Hanford subsurface natural environment.

Performance testing must address the following issues:

- Identify the key reactions and/or processes affecting waste form durability and contaminant release.

- Quantify the extent and rate of these reactions and/or processes.

- Obtain the model parameters needed to describe these reactions and/or processes and predict the behavior of the system.

- Verify the derived model parameters.

The future enhanced source-term algorithm for Cast Stone is currently being evaluated with two different software suites being considered. One software suite was developed by Bacon and McGrail (2005) and Freedman et al. (2007). This suite of codes has been chosen for glass waste forms and may be applicable for Cast Stone if the following key additions/improvements are developed:

- The release rates of the major components for each identifiable Cast Stone solid phase will be included (unless certain ones are found to be unimportant).

- Updated thermodynamic data for the pure end-member and/or idealized solid-solution mineral phases that constitute Cast Stone will be either directly measured or estimated.

- Common ion effects (Al, $\mathrm{Si}, \mathrm{Ca}$, and perhaps other species) obtained in preliminary leach experiments (perhaps using the SPFT method) will be explicitly incorporated in the Cast Stone waste form/waste package release model(s). 
- Mass transport properties/limitations (including physical changes to pore structures caused by cracks, carbonation, and other secondary mineral diagenesis) measured on Cast Stone waste form monoliths will be explicitly incorporated in the waste form/waste package release model(s).

- Partitioning of ${ }^{99} \mathrm{Tc},{ }^{129} \mathrm{I}$, and key RCRA metals among the Cast Stone freshly cured phases and the evolution as the Cast Stone continues to cure and weather will be explicitly incorporated in the waste form/waste package release model(s). Either mechanistically based or empirically based paragenetic reaction networks (i.e., element-specific release algorithms) for each of the key COCs will also be explicitly incorporated in the waste-form/waste-package release model(s).

The second software suite is tailored for cementitious waste forms such as Cast Stone and has been constructed by a consortium of organizations under the CBP (see $<$ http://cementbarriers.org/about $/>$ for information about the CBP). The CBP currently is constructing a linked suite (integrated framework) of computer codes that are state-of-the-art phenomenological tools that describe important phenomena that describe the performance of cementitious waste forms and engineered barriers. These software codes require a significant amount of physical and chemical data as input, may involve a detailed computational grid as part of the solution, and describe a specific behavior of the cementitious entity (see Section 4.14 for additional details). Current and planned CBP software will offer:

- a capability to predict physical and chemical properties of cementitious materials through time, and

- the transport/leaching of contaminant species from cementitious waste forms and through concrete barriers.

Regardless of which suite of codes is chosen to model the long-term fate of contaminants for the LAW Cast Stone waste form, the process for developing the improved waste form release model relies on the laboratory testing discussed in this testing plan to quantify the needed parameters used in the numerical predictive long-term PA models to simulate the key reactions and/or processes affecting release over long time frames. The technical defensibility of the release model is bolstered by showing allegiance to or similarity between the numerical release algorithms and basic thermodynamic and kinetic theories. A key tenet of supporting the technical defensibility of the process is reliance on determining the chemical durability of relevant pure-phase minerals. To accurately model the release of the key risk driver contaminants that may segregate into specific solid phases within the LAW Cast Stone waste form, an understanding of dissolution kinetics of each dominant solid phase (be it mineral or a solid solution) is needed. Therefore, testing will evaluate the efficacy of using the forward rate of dissolution parameters as measured with the SPFT test method using both key cementitious individual phases and the bulk Cast Stone. Preliminary tests will be conducted as a function of $\mathrm{pH}$, temperature, and solution composition on the bulk Cast Stone as well as a few key individual cementitious minerals to evaluate whether this approach is generating useful data. The predictability of the dissolution process of both the bulk Cast Stone and its key individual minerals will be compared with predictions from the selected code suite.

Basic thermodynamic properties of each pure reference phase will be found in the literature or experimentally determined if not available in the literature. For example, the solubility constant $\left(\mathrm{K}_{\mathrm{sp}}\right)$ or Gibbs free energy of reaction for the dissolution of each reference phase may not be available. Solubility tests such as described in Yang and Steefel (2008) can be conveniently performed using the SPFT apparatus with stop-flow periods. Other basic thermodynamic parameters, such as heat capacity $\left(\Delta \mathrm{c}_{\mathrm{p}}\right)$, may need to be measured on some of the reference mineral phases to allow the enthalpy to be determined. Then using the van't Hoff equation describing the temperature dependence of the equilibrium constant 
(Moore 1972), the solubility or $\log \mathrm{K}$ at various temperatures can be calculated. Heat capacity measurements are performed using calorimetry, generally with a constant-pressure calorimeter.

\subsection{Batch Adsorption Tests}

Once contaminants leach from the waste package, they migrate with the leachate through the rest of the IDF subsurface components in the disposal system and Hanford sediments disturbed by construction activities. Currently the IDF PA, similar to most other repository PAs, does not give any credit to favorable interactions (e.g., adsorption) of the dissolved contaminants with materials, such as metallic container corrosion products and degraded liners. The reason that metal container corrosion products, degraded liners, etc. are ignored is that they represent a very small mass compared to the waste packages themselves. Thus, their ability to either favorably or deleteriously affect the fate of dissolved contaminants has been deemed to be insignificant. Recent work in Europe related to the long-term performance of waste buried in deep repositories includes the interactions of dissolved contaminants from waste packages with the container corrosion products, backfill materials (often clays), and structural concrete used in the tunnels and vaults (De Windt et al. 2006; Grambow and Giffaut 2006; Van Iseghem et al. 2006; Mitsui et al. 2009). This literature on multicomponent impacts on waste form performance will be monitored to determine whether there are any significant differences in performance predictions when including such interactions in near-field release models versus the long-term predictions of contaminant fate in the current more simplistic PA conceptual models. Any significant differences in overall system performance discovered in the more detailed and inclusive near-field fate and transport modeling will need to be considered for future improvements in IDF PA models. For the IDF PA (see Bacon and McGrail 2005), some fully coupled flow and reactive transport calculations were performed for glass, grout, and bulk vitrification waste forms surrounded by backfill (assumed to have properties similar to the surrounding sediment), but other possible interactions with metal containers and their corrosion products have not been considered as yet.

Another assumption used in the supplemental waste risk assessment (Mann et al. 2003) was that the co-disposed waste forms (LAW glass, Cast Stone, Fluidized Bed Steam Reforming, and Bulk Vitrification) were separated in the IDF trenches by sufficient distances that the leachates from each did not mix with or affect each other within the near field. This simplification will be kept in mind when performing future PA predictions for the current effort where LAW glass and LAW Cast Stone waste form could be co-disposed in the first IDF trench. Some of the proposed leach testing on the Cast Stone waste form will be performed using a simulated LAW glass leachate such that information will be available early in the contaminant-release data-collection process to assess whether the presence of the two waste forms in the same trench leads to deleterious or favorable interactions.

Until new information indicates otherwise, it will be assumed that LAW Cast Stone waste package leachates that migrate beyond the IDF-influenced "near-field" and reach the "far-field" will only interact with Hanford formation vadose zone sediments and aquifer sediments. The key far-field interaction considered is contaminant adsorption-desorption processes, although leachate $\mathrm{pH}$ buffering reactions with the sediment could induce some selected precipitation of contaminants or dissolution of additional major components from the Hanford sediments. Such $\mathrm{pH}$-induced precipitation-dissolution reactions are already accommodated in simple reactions between the leachates and the model pure-phase minerals used to represent the near-field Hanford formation sediments surrounding the waste forms in the STOMP code. Therefore, the more significant need is to develop empirical adsorption parameters as well as surface 
complexation formation constants for the key contaminants in LAW Cast Stone waste form leachates with both the Hanford near-field and far-field sediments for incorporation in transport algorithms.

\subsubsection{Batch Adsorption Tests}

We assume that the simple distribution coefficient $\left(\mathrm{K}_{\mathrm{d}}\right)$ construct will continue to be used in the next generation IDF PA conceptual model for far-field transport. Thus, the first tests will be simple batch $\mathrm{K}_{\mathrm{d}}$ adsorption tests using Cast Stone waste form leachates or simulants based on the actual leachates from the various leach tests described in Sections 4.10 and 4.11 that have been spiked with additional concentrations of contaminants, if needed (because of concentrations that are low or below the detection limit), to allow contaminant-specific $\mathrm{K}_{\mathrm{d}}$ values to be determined. Care will be taken to make sure that spike concentrations are stable and do not promote contaminant precipitation, which would inflate the calculated $K_{d}$ value (see Relyea et al. 1980, ASTM D4319-93 [ASTM 2001], or EPA 1999) for details on how to properly conduct batch $\mathrm{K}_{\mathrm{d}}$ tests. The proposed batch $\mathrm{K}_{\mathrm{d}}$ tests will provide the necessary data to support activity 12.1 in Table B.1. In addition, the batch $\mathrm{K}_{\mathrm{d}}$ tests will be performed in a systematic fashion that allows surface complexation models (SCM) to be developed that explicitly accommodate the effects of varying $\mathrm{pH}$ and macroconstituent concentrations so that more sophisticated adsorption numerical models could be used.

\subsubsection{Saturated and Unsaturated Column Tests on LAW Cast Stone Waste Form Solids Embedded in Sediments}

Traditionally, risk assessment and PA codes rely solely on site-specific batch $\mathrm{K}_{\mathrm{d}}$ tests to obtain necessary sorption values and often also make "worst case" predictions that assume there is no adsorption of key COCs from the waste package leachates (e.g., Mann et al. 2001 and 2003). Should the batch $\mathrm{K}_{\mathrm{d}}$ test results for some specific contaminants show difficulties in quantitation (such as very low sorption generally found for ${ }^{99} \mathrm{Tc}$ and ${ }^{129} \mathrm{I}$ ) and if the preliminary IDF system PA predictions show that the adsorption of contaminants from the waste package leachates is a key process needed to show compliance with risk criteria, then laboratory-scale flow-through columns, under both saturated and unsaturated flow conditions, are proposed. Flow-through column tests are the most accurate method of determining $\mathrm{K}_{\mathrm{d}}$ values for contaminants that exhibit low adsorption. If the above situations prevail and flow-through tests are performed, the flow-through column tests would use both small monoliths and crushed and sieved Cast Stone waste form specimens that are sandwiched within Hanford formation sediment. The leachant that would be percolated through the packed columns would be simulated vadose zone pore water in some cases and simulated LAW glass leachate in other tests. These tests allow the combined leaching and contaminant adsorption on sediment and transport processes to be conveniently studied. The effluent from the columns is monitored as a function of time or pore volume displaced, and the retardation factor (ratio of the velocity of the water flow to contaminant flow rate) is determined. The retardation factor can be converted to a $\mathrm{K}_{\mathrm{d}}$ value with knowledge of the packed column's water content, bulk density, and porosity. The retardation factor can be used as direct input to most transport codes to represent the entire suite of chemical reactions between the Cast Stone and the leachants and sediments.

These column tests allow sensitive measurement of the sorption tendencies of poorly sorbing contaminants such as ${ }^{99} \mathrm{Tc}$ and ${ }^{129} \mathrm{I}$ when compared with batch tests that rely on finding an appreciable difference in solution concentration before and after contact with the sediment. For poorly sorbing 
species, the small difference in concentrations before and after sediment contact leads to poor reproducibility in batch $\mathrm{K}_{\mathrm{d}}$ measurements.

In addition, these types of packed-column experiments are useful alternatives to using the costly specialized PUF system described in Section 4.10.5. Because the PUF system often experiences colloid plugging problems where the effluent flow through the bubbling plate frit either slows or completely stops over time, these simpler flow-through column tests could be used to perform many of the Cast Stone waste form proposed leach tests (with or without the presence of the sediment). However, the Wierenga-style unsaturated column devices (Wierenga et al. 1993, Horton et al. 1982;

http://www.soilmeasurement.com/column.html) also use bubbling pressure plates for exactly the same reasons as the PUF system to maintain unsaturated moisture conditions. The hanging column technique is a third option for performing unsaturated soil column tests (see ASTM D6836) for the wetter end of unsaturation, but most hanging-water-column test configurations also use a ceramic plate at the bottom of the packed columns to minimize air entry that can interfere with maintaining a constant suction on the packed column controlled by the hanging water column (see Figure 4.9). The hanging water column technique has been successfully used to study colloid transport through Hanford formation sediments under unsaturated conditions (Cherrey et al. 2003). The Wierenga-style and hanging water unsaturated column devices are also less suited for higher temperature experiments that are often used in the PUF system to accelerate chemical reactions (weathering). Thus some decisions will be made as to which methodologies - PUF versus more traditional flow-through packed columns - are most cost effective after preliminary data becomes available on Cast Stone waste form performance and preliminary risk assessment and PA predictions indicate which parameters require more data collection.

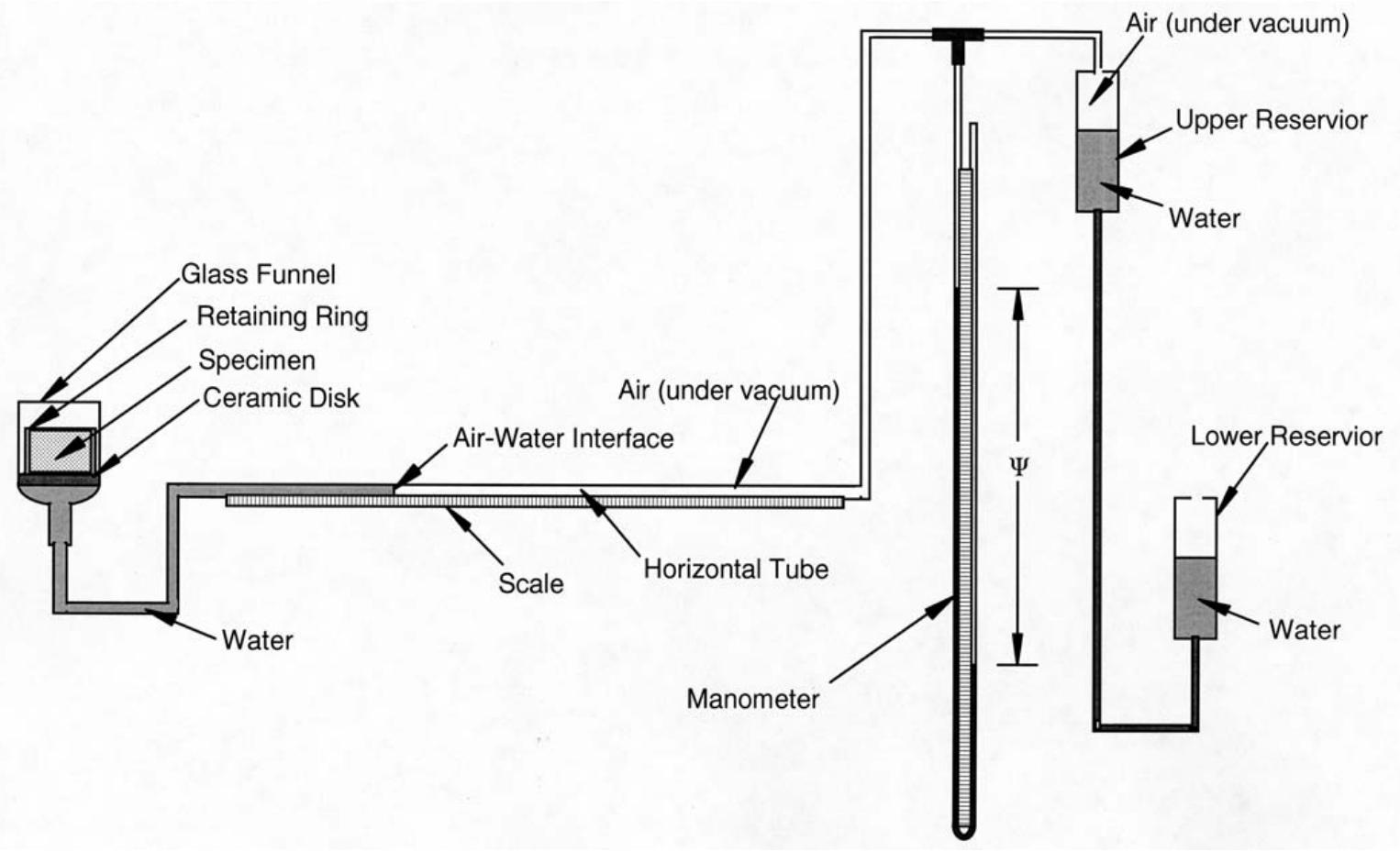

Figure 4.9. Schematic of a Hanging Water Column System. The suction (denoted by $\Psi$ ) produced by the difference in elevation of water in the two reservoirs creates the unsaturated conditions in the sediment column (denoted as the specimen within the retaining ring in the left-hand portion of the schematic. 
Figure 4.10 shows three possible configurations where monoliths or crushed and sieved Cast Stone waste form are packed in Hanford formation sediments within the columns. Such flow-through testing was quite successful in obtaining useful data on Hanford grout waste forms interacting with Hanford sediments that supported the past Grout PA (Serne et al. 1987). The two leachants shown in Table 4.9 would be pumped through the columns at a constant flow rate. The effluents' $\mathrm{pH}$ and major and trace constituents would be measured, and at the end of the tests, the columns would be dismantled. The Cast Stone waste form material and surrounding Hanford sediments would be characterized for mineralogy (looking particularly for alteration products) and the quantity of key contaminants bound to the surfaces of the waste form solids and Hanford sediment. The packed-column test data would aid in determining whether the surrounding sediments have synergistic or antagonistic impacts on the release of contaminants from the LAW Cast Stone waste form.

These flow-through column tests that contain the waste form and surrounding backfill/near-field sediments can be used as one facet of the "validation" activity of the overall IDF PA long-term predictions. Other "validation" activities could be laboratory- or intermediate-scale sand box tests that simulate LAW Cast Stone waste packages placed in sediments and leached with vadose zone pore waters or other solutions (LAW glass leachates, Cast Stone simulated leachates, rain water, etc.), field lysimeter, and natural analog studies (should suitable analogs be found in nature). For instance, archaeological glasses have been used as natural analogs for radioactive glass waste forms (see for example McLoughlin et al. 2006 and Gin et al. 2009).

\subsection{Validate PA Predictions}

Risk assessments and PAs are conducted to evaluate the potential long-term impacts to the health and safety of the public, DOE employees and contractors, and the environment caused by disposal of radioactive and hazardous chemical wastes. The LAW Cast Stone waste package is slated for disposal in the IDF on the Hanford Site. Logic diagrams that show the relationship between the proposed test methodologies, the specific parameters obtained from each test, and the proposed PA conceptual model are shown in Figure 4.11 and Figure 4.12. Note that there is a need to iterate between the testing and predictive PA modeling as the program advances to the final licensing activities. Preliminary system PA sensitivity or probabilistic calculations will alert staff as to which parameters are most sensitive in controlling the risk or impacts. This knowledge could require additional laboratory testing to improve the accuracy, reduce the range of variation in the numerical values for the key parameters, and acquire more technically defensible "backup" or supporting information before the final PA is submitted to the regulators and other stakeholders. This iterative process of identifying and testing controlling mechanisms for use in predictive modeling are discussed further in Peters and Ewing (2007). This paper was one of the key documents reviewed to make sure that the logic diagram captured all the relevant processes and variables needed for a technically defensible risk assessment and PA effort.

The right hand side of Figure 4.11 shows a schematic of the overall subsurface layers from the ground surface to the unconfined aquifer below the IDF. Just to the left of the subsurface schematic are descriptive boxes that list the types of data or numerical subroutines that are required to perform a system PA. The boxes represent the activities that are performed to predict the fates of water and gases; the evolution of the waste packages and repository components over time; and the fate of any leached contaminants, the macro solutes, and reactive gases through the vadose zone to the aquifer and ultimately 
back to the accessible environment. Once contaminants, driven by chosen scenarios, reach the accessible environment through various pathways, doses or impacts are calculated and compared to various criteria.

\section{Configuration A}

Intact

Cast Stone Monolith

Sediment (H2 unit)

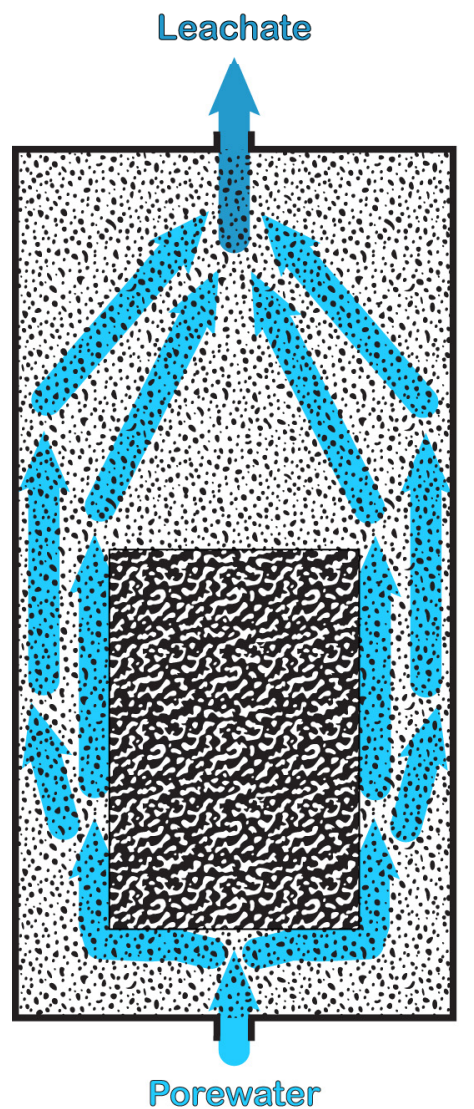

Configuration B Crushed

Crushed Cast Stone

6 Sediment ( $\mathrm{H} 2$ unit)

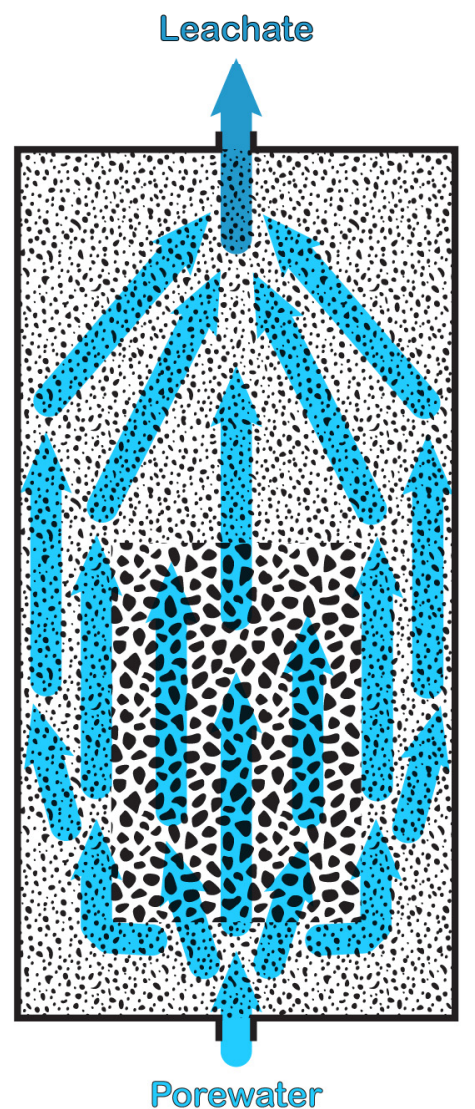

Configuration C Layered

$8:-8$ Crushed Cast Stone

Sediment ( $\mathrm{H} 2$ unit)

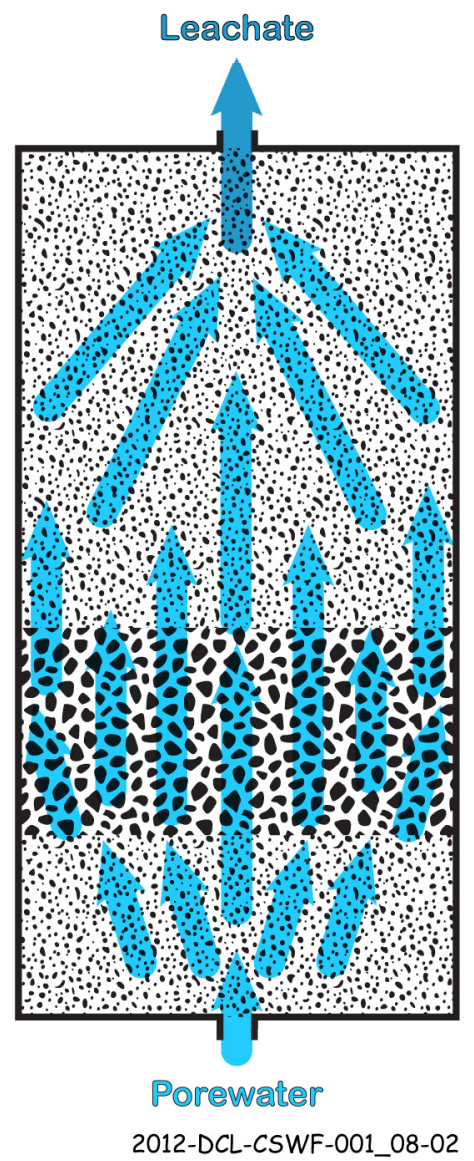

Figure 4.10. Flow-Through Column Configurations: (A) monolith of Cast Stone waste form, (B) crushed and sieved Cast Stone waste form in geometry of a right cylinder, (C) crushed and sieved Cast Stone waste form in geometry of a continuous layer sandwiched between Hanford sediments. Note that flow-through columns are generally run with fluid travelling from bottom to top to minimize preferred channeling and trapped air.

Sensitivity or probabilistic analyses are used to determine a range of doses or impacts to account for variability in the myriad of input parameters, limitations in the numerical algorithms (usually simplifications of controlling mechanisms) used to process the complex interactions that control the degradation or weathering of system components, and scenario uncertainties associated with future conditions. 


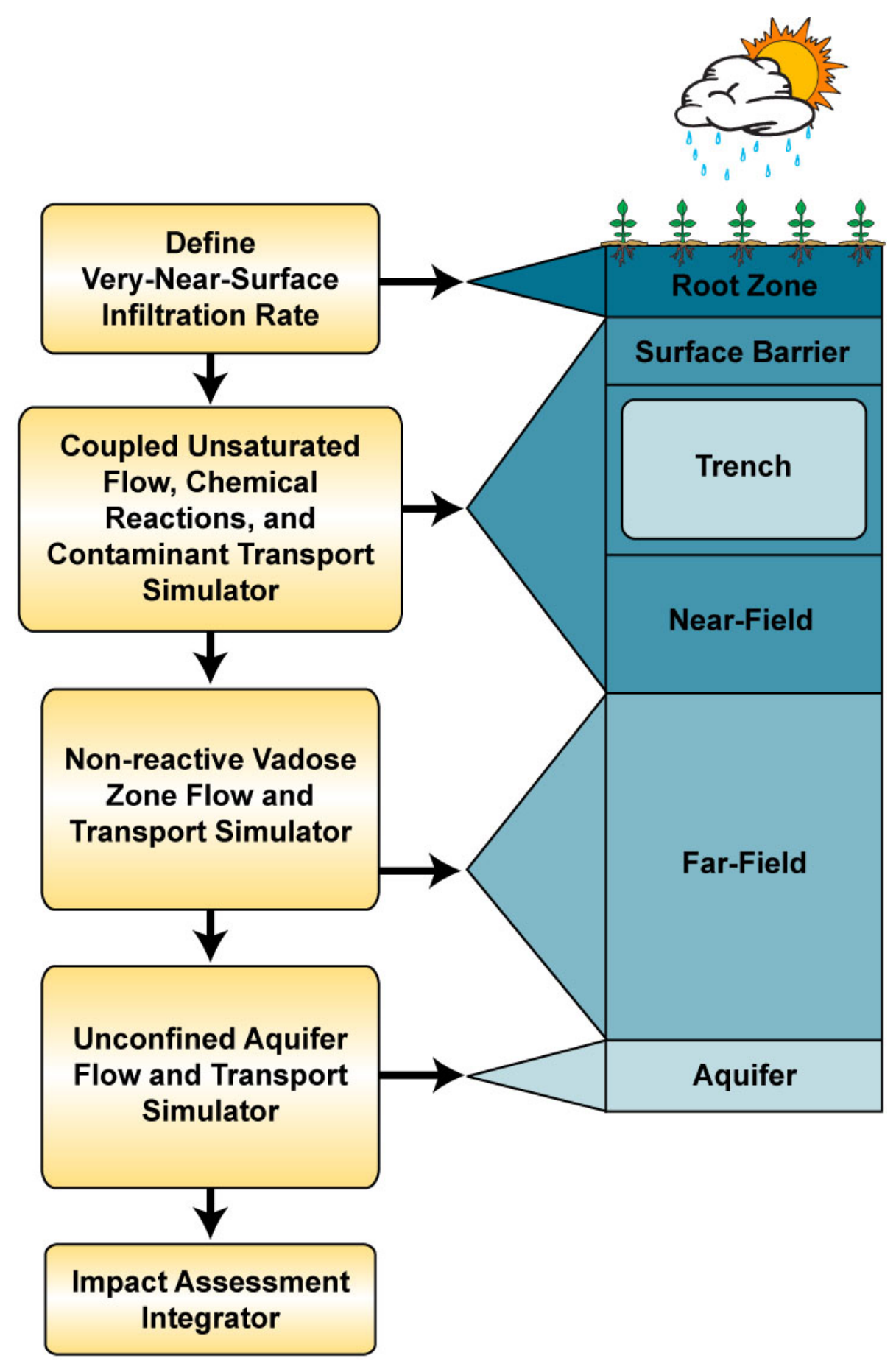

Figure 4.11. Schematic of the IDF System PA Activities Logic Flow 


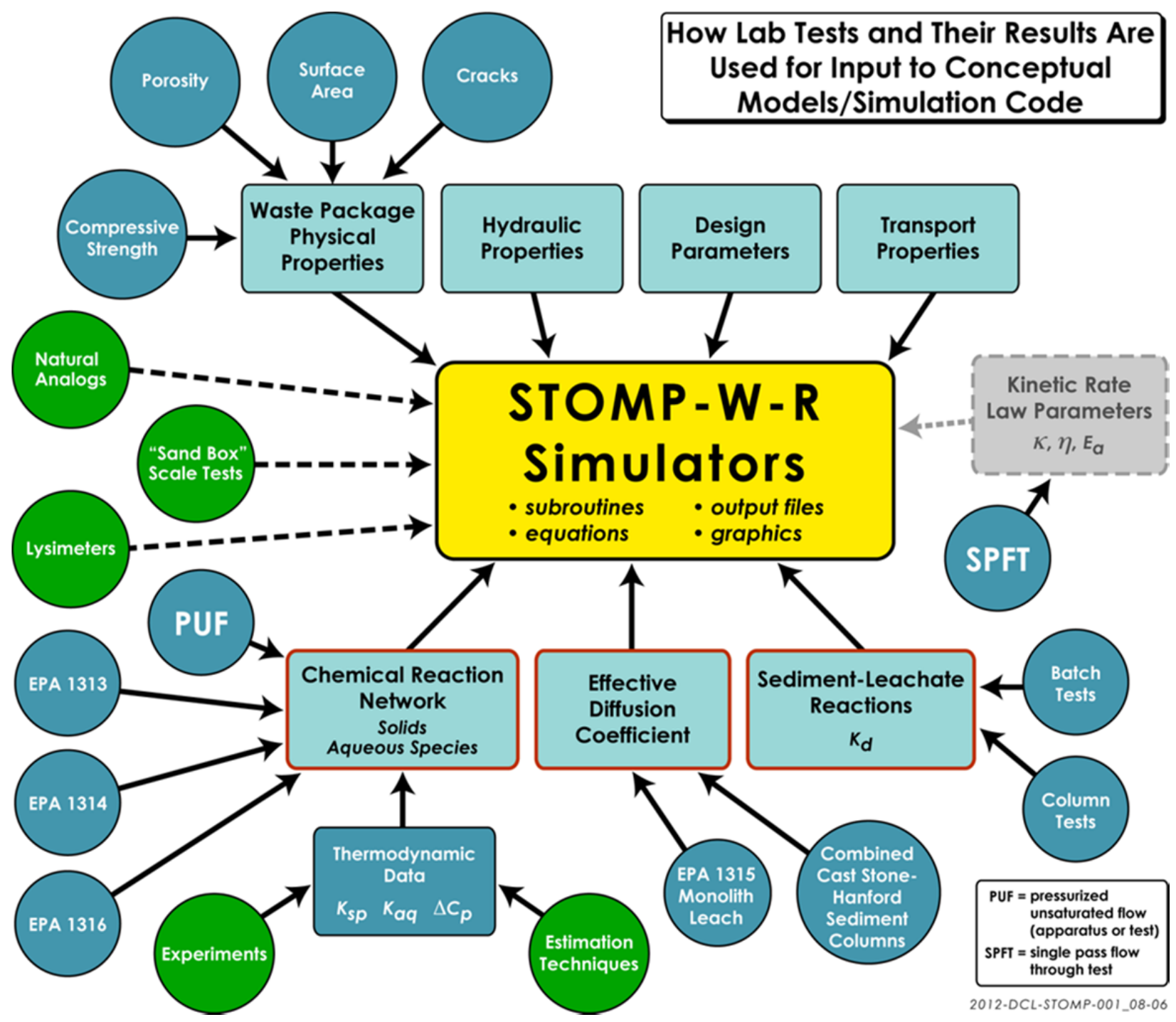

Figure 4.12. Schematic Showing Relationship Between Characterization and Testing Methods and the STORM/STOMP-W-R Simulators

\subsubsection{Reactive Transport Simulators for the Waste Form Calculations}

The main focus of the testing described in this test plan fits into the second descriptive box in Figure 4.11 labeled Coupled, Unsaturated Flow, Chemical Reactions, and Contaminant Transport Simulator. The following subsections on PA codes are one example of how a detailed technically robust PA could be generated. Other codes and approaches exist and should be vetted by the project team early in the project's life so that close co-ordination between the data collectors and the PA modelers can be established. Historically, the IDF system PA has used the Subsurface Transport Over Reactive Multi Phases (STORM) code (Bacon et al. 2000, 2004), to perform the calculations of radionuclide releases from the glass. STORM was developed by coupling STOMP, a nonisothermal multiphase flow simulator (White and Oostrom 2006), with AREST-CT Version 1.1, a reactive transport and porous medium alteration simulator (Chen et al. 1995, 1997). STORM represented subsurface flow and transport as a set of coupled, nonlinear, partial differential equations. The equations describe the rate of change of 
pore-water solute concentrations in variably water-unsaturated, nonisothermal porous media. STORM capabilities include kinetic dissolution of glass (or other waste forms), kinetically controlled precipitation and dissolution of secondary phases, equilibrium aqueous solutes speciation, gas-aqueous equilibria, two-phase flow (water and air), and dynamic updates to porosity and permeability as changes in mineral volumes occur. Most importantly, STORM simulates the waste form dissolution kinetic reaction in which equilibrium depends on only silica and aluminum. Reactive transport in STORM is coupled with unsaturated flow; the unsaturated flow field may be altered by mineral dissolution and precipitation reactions. STORM can also run efficiently in parallel on multi-core workstations and supercomputers, shortening execution times.

However, the STORM simulator limits reactive transport to two dimensions and cannot simulate three-dimensional flow and transport resulting from heterogeneities in the subsurface. Moreover, STORM is no longer under active development and has not received a Class C Safety and Hazard Analysis and Design Software classification. Therefore, under DOE Order 414.1D (DOE 2011), STORM cannot be used for future risk and PA analyses. More details on STORM can be found in Bacon et al. (2000, 2004), Bacon and McGrail (2001), McGrail et al. (2001), and Mann et al. (2001, 2003).

For reasons of continuity with past IDF PA activities, the new version of STORM, STOMP-W-R as described below, is one logical choice for performing future long-term IDF performance predictions. STOMP (White and Oostrom, 2000, 2006) can simulate flow and reactive transport in three dimensions, and adheres to rigorous QA procedures that are compliant with DOE Order 414.1C, STOMP was updated with the waste form release calculations in fiscal year (FY) 2011 (report citation 2011). STOMP is a general purpose simulator that was developed at PNNL for modeling subsurface flow and transport under variably saturated conditions. The simulator uses a variable source code configuration that allows the execution memory and speed to be tailored to the problem specifics. Quantitative predictions from the STOMP simulator are generated from the numerical solution of partial differential equations that describe subsurface environment transport phenomena. Governing equations for solute mass conservation are solved sequentially, following the solution of the coupled flow equations. The ECKEChem (EquilibriumConservation-Kinetic Equation Chemistry) module (White and McGrail 2005) is used to simulate reactive geochemistry. Using the variable source code configuration of STOMP, simulations for the IDF PA use an executable designated as STOMP-W-R, which simulates the governing equations for flow, solute transport and reactive geochemistry.

STOMP development is managed under a Configuration Management Plan (CMP) in conjunction with a Software Test Plan (STP), that detail the procedures used to test, document and archive modifications to the source code. Formal procedures for software problem reporting and corrective actions for software errors and updates are maintained and rigorously implemented. Documentation of all verification and validation testing is publicly available.

Work is currently underway to update eSTOMP, the highly scalable (parallel) version of STOMP, with the same waste form calculations that have already been incorporated into STOMP. The eSTOMP simulator was developed from STOMP using a component-based approach. The key features of this conversion were 1) the definition of a data model to describe a grid that is distributed over multiple processors, 2) the definition of a grid component interface based on this model, and 3) the implementation of the grid component and the conversion of the remaining portions of the code using the Global Arrays toolkit (GA) (Nieplocha et al., 2006). The GA toolkit supports a one-sided communication, shared-memory style programming model on both shared and distributed memory platforms. Because the 
eSTOMP simulator is highly scalable, it is ideally suited for running waste form calculations since long run times can result when they are executed with a serial code. However, the eSTOMP simulator still requires additional documentation and testing to bring it into NQA-1 compliance for Safety Software.

\subsubsection{Model Inputs}

Figure 4.12 is a schematic showing the relationship between various types of parameter property inputs and specific waste-form and waste-package leach tests needed for subsurface simulation. The solid-phase characterization activities and waste form and waste package tests described in Sections 4.10 through 4.13 provide the parameters that describe temporal weathering as well as the means to validate various portions of the system PA algorithms. The various tests and solid-phase characterization activities identify the types and amounts of minerals that are present at the time of disposal and the changes in both as the waste packages weather in the long term. Both STOMP and eSTOMP accommodate the interactions of the waste package leachates with the surrounding sediments. Both $\mathrm{K}_{\mathrm{d}}$ and solubility-precipitation constructs are used to predict the proportions of leached contaminants between the sediments and vadose zone pore waters. Tests described in Section 4.13 will generate the necessary Cast Stone waste form leachate-sediment-specific $\mathrm{K}_{\mathrm{d}}$ values for each contaminant. Data sets will also be provided for validating predictions based on processes described in the light blue rectangular boxes in Figure 4.12.

Similar leachate-sediment interactions and subroutines are used for far-field predictions as well as fluxes to the water table (e.g., the third and fourth descriptive boxes in Figure 4.10). In zones where the pore water is still dominated by waste package leachates, the $\mathrm{K}_{\mathrm{d}}$ parameter values are fed from the outputs from the STORM/STOMP-W-R simulator shown in Figure 4.11. Once the vadose zone and aquifer sediments and pore water properties are more similar to background conditions, the simulators used in the third and fourth descriptive boxes of Figure 4.10 will rely on data already tabulated for past IDF PAs (see Krupka et al. 2004).

\subsubsection{Cementitious Barriers Partnership Modeling Suite}

As noted in Section 4.12, a second software suite that is being considered to improve the Cast Stone release model is tailored for cementitious waste forms and has been constructed by a consortium of organizations under a partnership named Cementitious Barriers Partnership (CBP) (see $<$ http://cementbarriers.org/about/> for details). The CBP currently is constructing a linked suite (integrated framework) of computer codes that are state-of-the-art phenomenological tools that describe important phenomena that describe the performance of cementitious waste forms and engineered barriers. These software codes require a significant amount of physical and chemical data as input, may involve a detailed computational grid as part of the solution, and describe a specific behavior of the cementitious entity. Current and planned CBP software will offer:

- a capability to predict physical and chemical properties of cementitious materials through time, and

- the transport/leaching of contaminant species from cementitious waste forms and through concrete barriers.

The software suite includes LeachXS, Objects Representing CHEmical Speciation and TRAnsport models (ORCHESTRA), STADIUM ${ }^{\circledR}$, and in the future Thermodynamic Hydration And Microstructure 
Evolution Simulator (THAMES). LeachXS is a database/expert decision-support system for characterization and environmental impact assessment based on estimated contaminant release as derived from leaching tests. Databases used by LeachXS include leaching for $600+$ materials, scenarios, and regulations to allow comparisons of test data versus specific utilization or disposal conditions. A logic diagram, similar to the STOMP diagram, that shows the relationship between each activity (test, measured parameter, or literature input) proposed in this test plan feeds the CBP suite of codes is shown in Figure 4.13.

ORCHESTRA is a modeling framework for defining state-of-the-art geochemical equilibrium models and combining these models with mass transport for user-defined processes. The ORCHESTRA chemical module can calculate chemical thermodynamic equilibrium in a way similar to well-known speciation codes, but is internally organized very differently. Instead of defining all model equations within the source code, equations are defined in a separate user-accessible text file in ORCHESTRA. ORCHESTRA has been used in practice for a wide range of applications that include aqueous speciation, precipitation, different forms of surface complexation, ion exchange, diffusion (including radial and electroneutral), convection, solid solutions, colloid adsorption, and biota uptake.

SIMCO Technologies, Inc. developed the STADIUM (Software for Transport and Degradation in Unsaturated Materials) numerical model that can be used to predict the transport of ions and liquids in reactive porous media. The model has been used to predict the degradation of unsaturated concrete structures exposed to chemically aggressive environments. The results provided by STADIUM have been validated on the basis of laboratory test results and field exposure observations. The model has been used to predict the behavior of numerous existing structures exposed to various forms of chemical degradation phenomena. The first STADIUM module accounts for coupled transport of ions and water without considering chemical reactions (e.g., dissolution, precipitation, etc.). Transport is modeled with a volume-averaged version of the extended Nernst-Planck equation, which accounts for the electrical coupling between the ions as well as for the chemical activity of the species in solution. Terms are added to consider the impact of fluid flow and temperature gradients on ionic fluxes. The transport equations are coupled to Poisson's equation, which gives the electrical potential in the material as a function of the distribution of ionic profiles. Coupling with moisture conservation and heat conduction equations is also taken into account. The second STADIUM module is a chemical equilibrium code. After each transport step, this module equilibrates the concentrations at each node of the finite-element mesh with the phases of the hydrated cement paste. Solid phases can also be formed as a result of the penetration of aggressive species into the porous network of the material. The variation of solid phases will lead to local variations in porosity. These variations are likely to affect the transport properties of the material locally.

STADIUM takes this locally varying phenomenon into account in the transport module described above. 


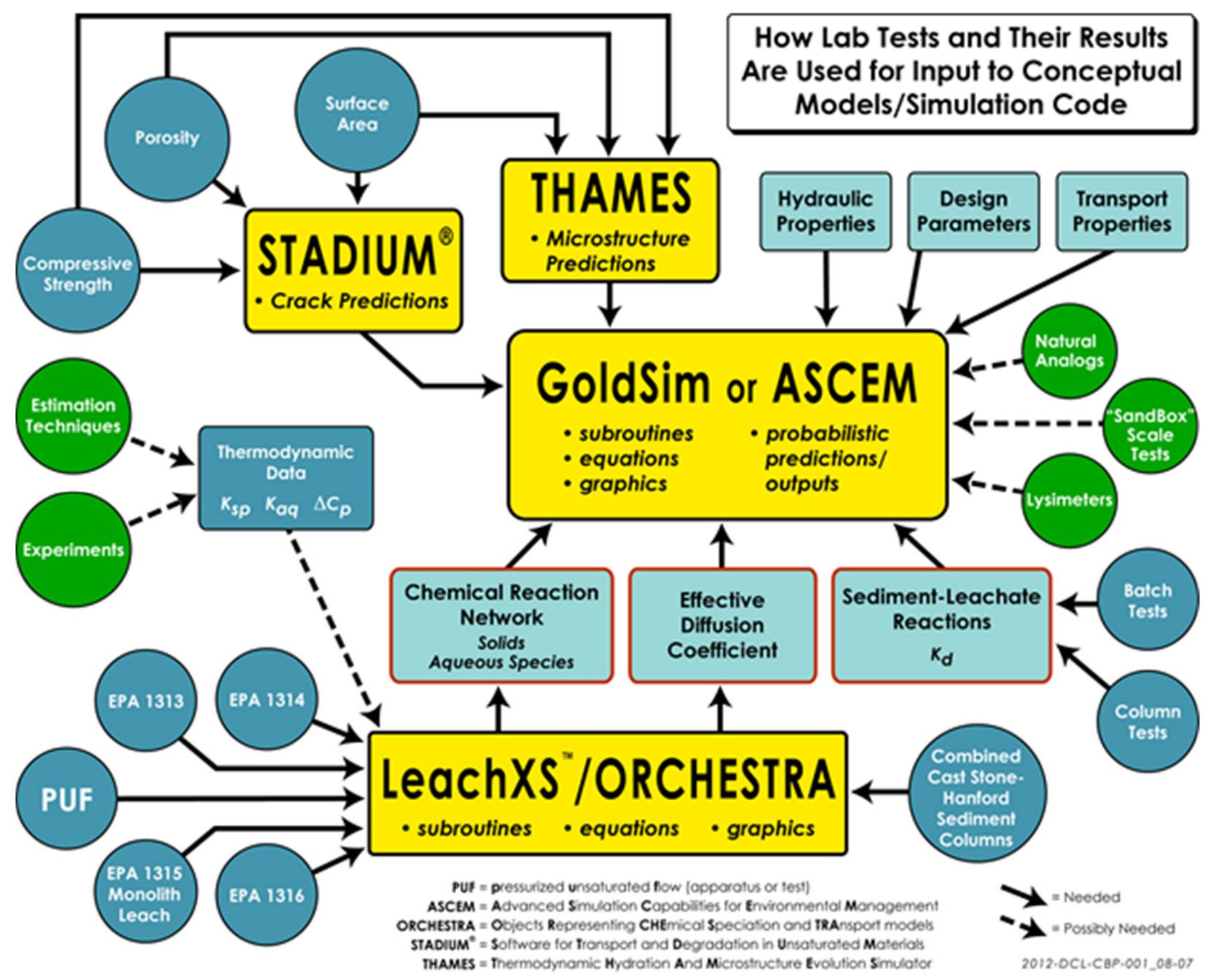

Figure 4.13. Schematic Showing Relationship Between Characterization and Testing Methods and the CBP Suite of Codes

THAMES (Thermodynamic Hydration And Microstructure Evolution Simulator) is a model/code that describes cementitious binder microstructures and calculates important engineering properties during hydration and degradation. THAMES serves as a "microprobe" that will be called by other programs in the integrated CBP model to update microstructure (e.g. pore space volume and connectedness) and properties (e.g. diffusivity, elastic moduli) as hydration and degradation proceed through the projected lifetime of the barrier material. THAMES is built around a thermodynamic engine, which rapidly predicts bulk mineral phase volumes as a function of time in cement paste microstructures evolving by hydration or degradation phenomena. However, the bulk information alone is insufficient to make accurate predictions of transport properties and mechanical properties; microstructure information is also required. A model must predict not only the overall phase quantities, but also how these phases are distributed in space. THAMES ultimately will include 1) a module for generating a representative threedimensional (3-D) initial microstructure of cementitious particles in water (GENMIC), 2) a module for simulating microstructure changes (THAMES) guided by the thermodynamic calculations (e.g., GEMS), and 3) a module for calculating the elastic moduli, DC conductivity/diffusivity, and permeability on the predicted cement paste and mortar/concrete microstructure 
The CBP is generally focused on phenomena occurring in the near field, within and adjoining engineered structures and contaminant source zones, at the centimeter to meter scale. Software modules are expected to be developed by the CBP and used by the Advanced Simulation Capability for Environmental Management (ASCEM)(http://esd.lbl.gov/research/projects/ascem/) system model for source zone material properties and/or contaminant flux.

Regardless of which of the two suites of codes is chosen to model the long-term fate of contaminants for the LAW Cast Stone waste form, the process for developing the improved waste form release model relies on the laboratory testing activities discussed in this test plan to quantify the needed parameters used in the numerical predictive long-term PA models to simulate the key reactions and/or processes affecting release over long time frames. The technical defensibility of the release model is bolstered by showing allegiance to or similarity between the numerical release algorithms to basic thermodynamic and kinetic theories.

\subsubsection{Validation Support}

The waste form leach tests required to support long-term risk assessment and PA start with wellconstrained tests using leachants germane to the IDF (see Table 4.8) contacting LAW Cast Stone. Leach tests then progress to multicomponent tests where samples of LAW Cast Stone are surrounded by the backfill Hanford formation sediments and perhaps canister metal and/or canister corrosion products. Each of the leach tests is used either to identify the final minerals formed by interaction of the starting solids with water (i.e., the weathering process) or to obtain the values for parameters required in the diffusion-based release rate law used to quantify the release of major and minor constituents in the waste form/package. Once the final minerals that are formed by the weathering process are established, and the kinetic rate-law equation parameters or effective diffusion-controlled release for individual LAW Cast Stone minerals/solid phases are established, a defensible conceptual model for long-term waste form release can be constructed. Once there are acceptable predictions for the waste package release, other chemical processes germane to the entire IDF disposal system, such as the subsequent interactions of leachates with Hanford formation sediments, will be modeled. These predictions can be compared with actual packed-column, flow-through tests or two- and three-dimensional sand box tests or even decades or longer field-scale lysimeter tests if there is a need for longer-term validation. If relevant natural analogs can be found, findings from detailed characterization of their properties and surroundings can be used to further validate long-term predictions produced from the IDF system computer code.

The validation efforts will compare such natural analog results with predictions from the IDF system PA computer models. The PA code predictions use numerical representations of controlling mechanisms based as much as possible on known physicochemical theories or laws. The individual component (rectangular boxes in Figure 4.11) will be used with LAW Cast Stone laboratory-test-derived input values tempered with results from flow-through "system tests" that include the Cast Stone waste form and surrounding sediments. The scale of the "system tests" may include laboratory columns, meter-sized sand boxes, and several meter-scaled field lysimeters. When practical, the "system tests" will be conducted so that reactions can be accelerated using appropriate higher temperatures, leachant flow rates, or other stressors. If found, relevant natural analogs will be the final method used to validate the IDF system PA predictions. These activities will support the resolution of issue 13.1 in Table B.1. 


\subsection{Hanford Tank Waste Simulants for Cast Stone Tests}

The Cast Stone process will be used to treat and immobilize LAWs separated from the radioactive wastes currently stored in the underground storage tanks at Hanford. The LAW fraction of the wastes is characterized as a large-volume, low-radioactivity liquid process stream stripped of most of the solids, transuranic elements and long-lived radionuclides. The LAW is derived from the aqueous solutions in the tanks and dissolved saltcake. The composition of the LAW will vary from tank to tank because of the variability in types and sources of wastes stored in the individual tanks and the processes used to separate the wastes into HLW and LAW fractions.

The baseline source of the LAW wastes to be treated and immobilized through the Cast Stone process is the separations processes within the WTP pretreatment facility. The liquid wastes from the tanks pass through ultrafilters in the pretreatment facility to remove solids and insoluble radioisotopes, primarily strontium and transuranics (TRU). For some tank wastes, additional processing as part of the ultrafiltration process will remove aluminum and/or chromium from the solids destined for HLW, and the $\mathrm{Al}$ and $\mathrm{Cr}$ will be added to the LAW stream. Some tanks contain organic complexants that keep strontium and transuranic elements in the aqueous phase. The treatment of these wastes will include a precipitation step to remove the Sr and TRU from solution before the ultrafiltration step. For LAW wastes with higher concentrations of organic complexants, it may be decided to send these wastes to LAW vitrification because of the organic content.

The liquid filtrate from the ultrafilters will then pass through ion exchange columns to remove cesium. The effluent from the ion exchange columns is then concentrated in an evaporator to a specified sodium concentration, depending on the waste chemistry. A recycle stream from the LAW melter off-gas treatment submerged bed scrubbers (SBSs) and wet electrostatic precipitators is blended with the ion exchange effluent as it enters the evaporator. The concentrated solution from the evaporator is the LAW feed for the immobilization process. The waste feed will be principally alkaline solutions of sodium with nitrates, nitrites, and carbonates and a spectrum of radioactive fission products.

To supplement WTP capacity, in-tank and at-tank separations are being considered to provide LAW feed directly to the Cast Stone process without processing through the WTP pretreatment facility. These near-tank processes would include a filtration step via a cross-flow filter or a rotary microfilter to remove the solids and insoluble radionuclides. Cesium would be removed through ion exchange. The separated solids and cesium would be returned to the double-shell tank system for eventual treatment and immobilization as HLW. A process for removing technetium from the LAW waste to be immobilized in Cast Stone is also planned. The liquid effluent from these separation processes becomes the feed to the LAW Cast Stone immobilization process.

Some tank wastes may be acceptable for direct Cast Stone processing without additional separations. An example of this is low-curie salt solutions generated during the later stages of washing/dissolving saltcake from the tanks. Experience has shown that the cesium is removed in the earlier stages of washing the saltcake such that the saltcake dissolved later is relatively free of the ${ }^{137} \mathrm{Cs}$ and could be immobilized without further processing. Other tank wastes have already had soluble liquids removed or had low curie content to begin with and could be processed with minimal or no pretreatment. 
A number of LAW simulants have been used for LAW glass waste-form product and process testing and for evaluation of supplemental treatment options. Most have been selected and developed based on the knowledge of which waste components are most impactful to glass formulations and vitrification processes. The simulants are selected to maximize the variability in these components to optimize glass formulations and vitrification process control to mitigate their impacts. These same constituents may or may not affect the Cast Stone process. The simulants described below provide a starting point for the Cast Stone technology maturation and for the WFQ process. It is expected that, through the technology maturation process, the waste constituents most impactful to the Cast Stone immobilization process will be identified, and the simulants used for WFQ testing may be modified to demonstrate the robustness of the process and waste form for the expected range of those impactful components.

Most of the WFQ testing for Cast Stone can be conducted with nonradioactive simulants of the projected LAW feeds for the Cast Stone immobilization process. The chemistry of the nonradioactive isotopes is the same as that of the radioisotopes. Technetium does not have a stable isotope; though its concentration is relatively low in the LAW. Because of its long half-life $\left(2.1 \times 10^{5}\right.$ years $)$ and relatively high mobility in the environment, ${ }^{99} \mathrm{Tc}$ is a significant contributor to the environmental impacts of waste disposal in the IDF.

The following sections describe LAW simulants that have been developed and used for evaluation of supplemental treatment technologies and for glass formulation development and melter testing. Spikes of

${ }^{99} \mathrm{Tc}, \mathrm{RCRA}$ metals, and underlying hazardous waste constituent metals and organics can be added as needed to address specific WFQ requirements. Also, as tests are conducted with actual wastes, simulants may need to be developed for those specific compositions so that testing can be done to demonstrate the correlation between the simulants and actual wastes to validate the simulant work.

\subsection{Saltcake Simulant}

Saltcake waste is a predominant form of wastes in a large fraction of the single-shell tanks at Hanford. These wastes can be readily dissolved, stripped of cesium, and converted to glass or Cast Stone waste forms for disposal. To support an evaluation of supplemental treatment alternatives for immobilizing these LAW wastes, a saltcake simulant waste was developed based on a blend of samples from single-shell tanks S-101, S-109, S-110, S-111, U-106, and U-109 (Rassat et al. 2003). Table 5.1 shows the nominal simulant composition. A recipe for preparing the simulant is provided by Rassat et al (2003). This SST blend saltcake simulant has been used in previous Cast Stone testing with Hanford LAW simulants. The composition matches the average composition of saltcake from 68 Hanford SSTs representing 85 percent of the total saltcake inventory in all Hanford SSTs and DSTs at that time (Gasper et. al., 2002).

\subsection{LAW Envelope A, B, and C Simulants}

The LAWs to be retrieved from the Hanford tanks and delivered to the WTP have been grouped into three "envelopes," A, B, and C. A number of simulants have been developed to represent individual tanks as subsets to each envelope. These have been used in various LAW glass formulation studies and melter tests (Matlack et al. 2007, 2009). Table 5.2 lists the simulant compositions, and recipes are provided by Matlack et al. $(2007,2009)$. 
Table 5.1. Nonradioactive Dissolved Saltcake Solution Simulant Composition (Rassat et al. 2003)

\begin{tabular}{cc}
\hline $\begin{array}{c}\text { Waste } \\
\text { Constituent }\end{array}$ & $\begin{array}{c}\text { Concentration } \\
(\mathbf{M})\end{array}$ \\
\hline $\mathrm{Al}$ & 0.0637 \\
$\mathrm{Cs}$ & $5.1 \times 10^{-8}$ \\
$\mathrm{Cr}$ & 0.0104 \\
$\mathrm{~K}$ & 0.0124 \\
$\mathrm{Na}$ & 5.00 \\
$\mathrm{Cl}$ & 0.0438 \\
$\mathrm{CO}_{3}$ & 0.475 \\
$\mathrm{~F}$ & 0.0316 \\
$\mathrm{NO}_{2}$ & 0.424 \\
$\mathrm{NO}_{3}$ & 2.51 \\
$\mathrm{PO}_{4}$ & 0.0492 \\
$\mathrm{SO}_{4}$ & 0.0900 \\
$\mathrm{C}_{2} \mathrm{O}_{4}$ (oxalate) & 0.0118 \\
$(\mathrm{TOC}$ Total & 0.263 \\
\hline OH Total & 0.287 \\
Free OH & 0.740 \\
\hline Other $\mathrm{TOC}^{(\mathrm{a})}($ arbon, from acetate $)$ & 0.485 \\
\hline
\end{tabular}

(a) $\mathrm{TOC}=$ total organic carbon

\subsection{Waste Variability Simulants}

To support the LAW supplemental treatment technology assessment, Mahoney and Vienna (2005) assessed the variability in waste compositions that would be processed through the LAW supplemental treatment immobilization process. The sources of wastes included LAW waste from the WTP pretreatment process, the SBS condensate and wet electrostatic precipitator streams, demineralized water to adjust WTP LAW off-gas condensate chemistry, and LAW from low-curie saltcake tanks that would be sent to supplemental treatment without passing through the WTP pretreatment plant. Using WTP flowsheet models and Best Basis Inventories and separations factors, feed compositions to supplemental treatment were estimated. Then, using statistical cluster analyses, 25 cluster compositions were identified representing the variability in the composition of the wastes. These clusters include one SBS/wet-electrostatic-precipitator-dominated stream, one high-fluorine LAW stream from WTP, 15 lowfluorine LAW streams from WTP, and 8 LAW clusters from the low-curie saltcake tanks. Mahoney and Vienna (2005) include tables of oxide compositions of major and minor components and radionuclides for each cluster. These will need to be converted into simulant recipes if they are used for Cast Stone testing. 
Table 5.2. LAW Envelope A, B, and C Simulants Used in Glass Formulation and Melter Tests

\begin{tabular}{|c|c|c|c|c|c|c|c|}
\hline $\begin{array}{l}\text { Tank } \\
\text { Component }\end{array}$ & $\begin{array}{c}\text { A1 } \\
\text { AN-105 } \\
\text { M }\end{array}$ & $\begin{array}{c}\text { A2 } \\
\text { AP-101 } \\
\text { M }\end{array}$ & $\begin{array}{c}\text { A3 } \\
\text { AN-104 } \\
\text { M }\end{array}$ & $\begin{array}{c}\text { B1 } \\
\text { AZ-101 } \\
\text { M }\end{array}$ & $\begin{array}{c}\text { B2 } \\
\text { AZ-102 } \\
\text { M }\end{array}$ & $\begin{array}{c}\text { C1 } \\
\text { AN-107 } \\
\text { M }\end{array}$ & $\begin{array}{c}\mathrm{C2} \\
\mathrm{AN}-102 \\
\mathrm{M}\end{array}$ \\
\hline$\overline{\mathrm{Al}}$ & 1.132 & 0.357 & 1.062 & 0.309 & 0.013 & 0.006 & 0.368 \\
\hline B & 0.007 & 0.001 & - & - & - & - & 0.003 \\
\hline $\mathrm{Ca}$ & - & - & - & - & - & 0.009 & 0.010 \\
\hline $\mathrm{Cr}$ & 0.003 & 0.014 & 0.005 & 0.018 & 0.025 & 0.002 & 0.003 \\
\hline Cs (spike) & - & - & 0.011 & 0.014 & - & 0.011 & 0.011 \\
\hline $\mathrm{Fe}$ & - & - & - & - & - & 0.019 & - \\
\hline K & 0.118 & 1.440 & 0.121 & 0.157 & 0.149 & 0.025 & 0.041 \\
\hline $\mathrm{Mn}$ & - & - & - & - & - & 0.007 & - \\
\hline $\mathrm{Na}$ & 8.000 & 8.000 & 8.000 & 7.000 & 5.500 & 8.000 & 8.000 \\
\hline $\mathrm{Ni}$ & - & 0.001 & - & - & - & 0.006 & 0.006 \\
\hline $\mathrm{Pb}$ & - & 0.0005 & - & - & - & - & 0.001 \\
\hline $\mathrm{Si}$ & 0.006 & 0.006 & 0.009 & 0.003 & 0.017 & - & 0.003 \\
\hline $\mathrm{Cl}$ & 0.065 & 0.077 & 0.183 & 0.009 & 0.004 & 0.031 & 0.110 \\
\hline $\mathrm{F}$ & 0.048 & 0.057 & 0.004 & 0.145 & 0.062 & 0.256 & 0.107 \\
\hline $\mathrm{PO}_{4}$ & - & 0.024 & 0.027 & 0.024 & 0.007 & 0.032 & 0.047 \\
\hline $\mathrm{SO}_{4}$ & 0.024 & 0.060 & 0.068 & 0.212 & 0.343 & 0.065 & 0.142 \\
\hline $\mathrm{NO}_{2}$ & 1.857 & 1.263 & 1.954 & 1.834 & - & 0.895 & 1.503 \\
\hline $\mathrm{NO}_{3}$ & 2.048 & 2.953 & 2.289 & 1.167 & 0.348 & 2.138 & 2.887 \\
\hline $\mathrm{CO}_{3}$ & - & 0.746 & 0.603 & - & - & - & 0.739 \\
\hline $\mathrm{NH}_{3}$ & - & - & - & - & - & - & 0.007 \\
\hline $\mathrm{TOC}^{(\mathrm{a})}$ & 0.174 & 0.227 & 1.195 & 0.0258 & 0.139 & 2.057 & 1.964 \\
\hline Acetate & 0.038 & 0.051 & 0.044 & - & - & (e) & - \\
\hline Formate & 0.047 & 0.049 & 0.106 & 0.015 & - & (e) & 0.580 \\
\hline Oxalate & - & 0.038 & - & 0.022 & 0.070 & (e) & 0.017 \\
\hline Glycolate & 0.025 & - & - & - & - & (e) & 0.451 \\
\hline Citric Acid & - & - & - & - & - & (e) & 0.075 \\
\hline EDTA $^{(b)}$ & - & - & - & - & - & (e) & - \\
\hline HEDTA $^{(\mathrm{c})}$ & - & - & - & - & - & (e) & - \\
\hline Gluconate & - & - & - & - & - & (e) & - \\
\hline Glycolic Acid & - & - & - & - & - & (e) & - \\
\hline $\mathrm{NTA}^{(\mathrm{d})}$ & - & - & - & - & - & (e) & - \\
\hline Iminodiacetic Acid & - & - & - & - & - & (e) & - \\
\hline \multicolumn{8}{|c|}{$\begin{array}{l}\text { (a) total organic carbon } \\
\text { (b) ethylenediaminetetraacetic acid } \\
\text { (c) N-(2-hydroxyethyl) ethylenediaminetetraacetic acid } \\
\text { (d) nitrilotriacetic acid } \\
\text { (e) Simulant includes these organic species. See Matlac }\end{array}$} \\
\hline
\end{tabular}




\subsection{Simulants Based on System Plan 6 HTWOS Modeling}

Three simulants were developed to represent the range of LAW tank wastes that could be immobilized in a Cast Stone waste form. The simulants were developed based on runs of the Hanford Tank Waste Operations Simulator (HTWOS) model to support the River Protection Project System Plan revision 6 (Certa, Empey, and Wells, 2011). As one of the outputs, the HTWOS model provides the feed vector to a supplemental immobilization facility over the course of the tank cleanup mission.

The first simulant is an overall average of the 1046 weeks of modeled waste feed over a twenty-year mission (Russell et al. 2013). The second simulant is characterized by aluminum and chloride concentrations near their maximums. The third simulant is characterized by phosphate near its maximum and sulfate and fluoride at relatively high concentrations.

Table 5.3 shows the three simulants as well as the "Rassat" SST blend saltcake simulant described in Section 5.1 above. For comparison purposes, the simulants have been normalized to one-molar sodium and are expressed as moles per mole sodium. The three simulants identified from the HTWOS modeling were charged balanced by adjusting the anion concentrations relative to the other components (Russell et al. 2013). The concentrations of the fluoride and phosphate for the overall average and high sulfate simulants were reduced from the HTWOS values because of excess solids formation observed in preliminary simulant batches.

Table 5.3. LAW Simulants Based on HTWOS Modeling

\begin{tabular}{|c|c|c|c|c|}
\hline Waste Constituent & $\begin{array}{c}\text { Rassat } \\
\text { Saltcake } \\
\text { SST Blend } \\
\end{array}$ & $\begin{array}{c}\text { HTWOS } \\
\text { Overall } \\
\text { Average }\end{array}$ & $\begin{array}{c}\text { HTWOS } \\
\text { High } \\
\text { Al, Cl } \\
\end{array}$ & $\begin{array}{c}\text { HTWOS } \\
\text { High } \\
\mathrm{SO}_{4} \\
\end{array}$ \\
\hline & \multicolumn{4}{|c|}{ Concentration (moles / mole Na) } \\
\hline $\mathrm{Al}$ & 0.013 & 0.061 & 0.112 & 0.047 \\
\hline Cs & $1.02 \times 10^{-8}$ & - & - & - \\
\hline $\mathrm{Cr}$ & 0.002 & - & - & - \\
\hline $\mathrm{K}$ & 0.002 & 0.007 & 0.028 & - \\
\hline $\mathrm{Na}$ & 1.000 & 1.000 & 1.000 & 1.000 \\
\hline $\mathrm{Cl}$ & 0.009 & 0.008 & 0.018 & 0.007 \\
\hline $\mathrm{CO}_{3}$ & 0.095 & 0.055 & 0.040 & 0.035 \\
\hline $\mathrm{F}$ & 0.006 & $0.006^{\mathrm{a}}$ & 0.010 & $0.012^{\mathrm{a}}$ \\
\hline $\mathrm{NO}_{2}$ & 0.085 & 0.113 & 0.194 & 0.098 \\
\hline $\mathrm{NO}_{3}$ & 0.502 & 0.324 & 0.287 & 0.367 \\
\hline $\mathrm{PO}_{4}$ & 0.010 & $0.010^{\mathrm{a}}$ & 0.005 & $0.010^{\mathrm{a}}$ \\
\hline $\mathrm{SO}_{4}$ & 0.018 & 0.017 & 0.004 & 0.030 \\
\hline TOC Total & 0.057 & 0.015 & 0.021 & 0.007 \\
\hline Free $\mathrm{OH}$ & 0.097 & 0.312 & 0.293 & 0.306 \\
\hline
\end{tabular}

${ }^{a}$ Concentration of $\mathrm{F}$ and $\mathrm{PO}_{4}{ }^{3-}$ reduced from HTWOS values because of solids formation observed in preliminary simulants.

Some testing will require the use of spikes of COCs to address their retention and release within the Cast Stone waste form. To address LDRs including performance in the TCLP, spikes will include RCRA metals and underlying hazardous constituents. To understand the retention and release of radionuclides of concern, spikes of Tc-99, I-129, and/or uranium may be added to Cast Stone batches prepared for leach 
testing studies. Table 5.4 shows the range of spike levels. As a general strategy, the spikes will be at the maximum concentrations unless there are specific radiological or health considerations in the facilities where the work will be conducted. Spike concentrations may be increased to address analytical detection limits. If test results show that the spike levels are too high, more-representative spike levels will be used.

Table 5.4. Spike Levels for Hazardous Constituents and Radionuclides for HTWOS Simulants

\begin{tabular}{cccc}
\hline Waste Constituent & $\begin{array}{c}\text { HTWOS } \\
\text { Overall } \\
\text { Average }\end{array}$ & $\begin{array}{c}\text { HTWOS } \\
\text { Maximum }\end{array}$ & $\begin{array}{c}\text { Other } \\
\text { Considerations }\end{array}$ \\
\hline RCRA Metals & moles/mole Na & moles/mole Na & moles/mole Na \\
\hline $\mathrm{As}$ & $4.24 \mathrm{E}-06$ & $4.78 \mathrm{E}-05$ & - \\
$\mathrm{Ba}$ & $5.65 \mathrm{E}-07$ & $5.21 \mathrm{E}-06$ & - \\
$\mathrm{Cd}$ & $2.78 \mathrm{E}-06$ & $3.19 \mathrm{E}-05$ & - \\
$\mathrm{Cr}$ & $2.42 \mathrm{E}-03$ & $9.99 \mathrm{E}-03$ & - \\
$\mathrm{Pb}$ & $1.16 \mathrm{E}-05$ & $5.13 \mathrm{E}-05$ & - \\
$\mathrm{Hg}$ & $1 / 37 \mathrm{E}-06$ & $6.97 \mathrm{E}-06$ & - \\
$\mathrm{Se}$ & $1 / 95 \mathrm{E}-05$ & $4.63 \mathrm{E}-05$ & - \\
$\mathrm{Ag}$ & $7.49 \mathrm{E}-07$ & $5.40 \mathrm{E}-06$ & - \\
\hline $\mathrm{Sb}$ & $\mathrm{Underlying} \mathrm{Hazardous} \mathrm{Constituents}$ & & - \\
$\mathrm{Be}$ & $2.82 \mathrm{E}-06$ & $1.97 \mathrm{E}-05$ & - \\
$\mathrm{Ni}$ & $1.58 \mathrm{E}-06$ & $2.06 \mathrm{E}-05$ & - \\
\hline $\mathrm{Tl}$ & $6.41 \mathrm{E}-05$ & $6.61 \mathrm{E}-04$ & $\mathrm{Ci} / \mathrm{mole} \mathrm{Na}$ \\
\hline $\mathrm{Radionuclides}$ & $1.42 \mathrm{E}-05$ & $1.37 \mathrm{E}-05$ & - \\
\hline $99 \mathrm{Tc}$ & $\mathrm{Ci} / \mathrm{mole} \mathrm{Na}$ & $\mathrm{Ci} / \mathrm{mole} \mathrm{Na}$ & $3.54 \mathrm{E}-06^{\mathrm{b}}$ \\
\hline $129 \mathrm{I}$ & $1.13 \mathrm{E}-05$ & $4.13 \mathrm{E}-05$ & - \\
\hline $\mathrm{U}$ & $1.44 \mathrm{E}-08$ & $8.01 \mathrm{E}-08$ & $5.63 \mathrm{E}-08$ \\
\hline
\end{tabular}

${ }^{\mathrm{a}} \mathrm{Cr}$ concentration adjusted based on review of best basis inventory and previous simulant work.

${ }^{\mathrm{b}} \mathrm{I}$ concentration increased to address possible detection limits in waste form leach tests. 


\subsection{Near-Term Testing to Support TPA Milestone M-062-40ZZ}

As part of the Hanford Federal Facility Agreement and Consent Order, or Tri-Party Agreement (TPA)(Ecology, EPA and DOE 1989), DOE will submit a one-time Hanford Tank Waste Supplemental Treatment Technologies Report to meet the requirements of milestone M-062-40ZZ, currently due by October 31, 2014. TPA Milestone M-062-45 then describes the process for Ecology and DOE to complete a negotiated LAW immobilization technology selection process by April 2015. In support of these TPA milestones, a testing program is planned for FY2013 and 2014 to obtain additional information on the Cast Stone option for immobilizing the LAW. The objectives of the testing program are to

- Determine an acceptable formulation for the LAW Cast Stone waste form.

- Evaluate sources of dry materials for preparing the LAW Cast Stone.

- Demonstrate the robustness of the waste form for the range of LAW compositions.

- Demonstrate the robustness of the formulation for variability in the Cast Stone process.

- Provide Cast Stone contaminant release data for PA and risk assessment evaluations.

\subsection{Cast Stone Formulation Screening Tests}

The first step in determining an acceptable formulation for the LAW Cast Stone waste form is to conduct screening tests to examine expected ranges in waste composition, waste stream concentrations, dry-materials sources, and mix ratios of waste (free water) to dry blend. A statistically designed test matrix will be used to evaluate the effects of these key parameters on the properties of the Cast Stone as it is initially prepared and after curing. The screening tests will look at the effects of individual test parameters, including waste compositions using the simulants described in Section 5.0, waste stream concentration (e.g. $5 \mathrm{M} \mathrm{Na}$ - and 7.8 M Na-normalized), fly ash source, BFS source, and the mix ratio of free water to dry solids (e.g. 0.40 gram water per gram dry solids, which is similar to the 0.35 ratio used for the secondary-waste Cast Stone formulation work [Mattigod et al. 2011], and 0.60 gram free water per gram of dry solids as is used at the Saltstone facility at the Savannah River Site). The dry-blend mix ratio will be held constant at $8 \mathrm{wt} \%$ cement, $45 \mathrm{wt} \%$ fly ash, and $47 \mathrm{wt} \%$ BFS for these screening tests. A single source of cement will be used for all of the testing because the variability in the cement composition is not expected to be significant among the various sources. The ranges of parameters will be finalized in the detailed test plan to be developed to guide the screening testing.

Cast Stone specimens for the screening tests will be prepared in the laboratory and will be characterized for processing properties and 28-day cured waste form properties. Processing properties include gel time (a semi-quantitative indication of when the Cast Stone slurry/paste no longer flows freely), slurry/paste rheology, Cast Stone hardening time, heat generation during curing, and residual free liquids.

Cast Stone waste form properties are measured after the test specimens have cured for at least 28 days. Compressive strength, density, and porosity will be measured on the test specimens. The TCLP will be conducted to examine the retention of RCRA metals (As, $\mathrm{Ba}, \mathrm{Cd}, \mathrm{Cr}, \mathrm{Pb}, \mathrm{Hg}, \mathrm{Se}$, and $\mathrm{Ag}$ ) and underlying hazardous constituents ( $\mathrm{Sb}, \mathrm{Be}, \mathrm{Ni}$, and $\mathrm{Tl}$ ) to address LDRs. Cast Stone monolith leach tests will be conducted for up to 63 days using EPA Method 1315 to measure the effective diffusivity of key 
constituents including Tc, sodium, and nitrate. Chemical compositions and mineralogy will be determined for the Cast Stone specimens tested in this screening exercise. Details of the processing and waste form characterization tests will be described in the test plan to be developed to guide the screening testing.

Statistical analysis of the results of the screening testing and characterization will be used to assess the effects of the individual test parameters and evaluate selected two-parameter interactions. It is expected that the results of the testing and statistical analyses will lead to the selection of a single source each for the fly ash and BFS and may reduce the number of simulants needed in the next phases of testing to represent the variability in the wastes. The testing will provide an initial indication of the robustness of the Cast Stone waste form to waste composition and process variability.

These screening tests will address some of the testing needs identified above in Sections 4.1, Waste Loading Tests; 4.4, Land Disposal Restrictions Compliance Testing; 4.5, Cast Stone Physical and Chemical Properties; 4.8, Cast Stone Solid-Phase Characterization; 4.9, Waste Form Leach Testing-PA Support; and 4.11 Physical Stability.

\subsection{Cast Stone Waste Loading and Waste Form Qualification Testing}

The next phase of testing is focused on final selection of the nominal Cast Stone formulation and demonstrating that Cast Stone can meet possible waste form requirements for disposal in the IDF. It is expected that this testing will use the results of the screening tests to define a smaller suite of tests to refine the waste loading in the Cast Stone formulation. The key parameters are expected to be the waste concentration (e.g. $4 \mathrm{M}, 6 \mathrm{M}$, and $8 \mathrm{M} \mathrm{Na}$ ) and waste-to-dry-blend ratio (e.g. 0.4, 0.5, and 0.6 grams of free water per gram of dry materials). It is expected that the previous screening tests will have selected single sources of cement, fly ash, and BFS. Variations in the dry-blend mix ratio will be considered in addition to formulation enhancements to reduce permeability and retain key COCs. The ranges of parameters will be finalized in the detailed test plan to be developed to guide the waste loading and WFQ testing.

Cast Stone specimens for the waste loading and WFQ tests will be prepared in the laboratory and will be characterized for processing properties and final waste form properties. Processing properties include gel time, slurry/paste rheology, Cast Stone hardening time, heat generation during curing, and residual free liquids.

Cast Stone waste form properties are measured after the test specimens have cured for at least 28 days. Compressive strength, density, and porosity will be measured on the test specimens. The TCLP will be conducted to examine the retention of RCRA metals and underlying hazardous constituents to address LDRs. Cast Stone monolith leach tests will be conducted using the EPA 1315 method for up to 63 days to measure the effective diffusivity of key constituents including Tc, Na, and nitrates. Leach testing beyond the 63 days will be continued on selected samples as described below in Section 6.5.1. Chemical compositions and mineralogy will be determined for the Cast Stone specimens both before and after leaching.

The WFQ testing to demonstrate that the LAW Cast Stone can meet possible waste form requirements for disposal in IDF are expected to include the free liquids, compressive strength, TCLP, and leach testing identified above. Simple tests will also be conducted to demonstrate that the Cast Stone 
is neither flammable nor ignitable. Per guidance in DOE G435.1 (DOE 1999) to consider tests discussed in the NRC's Technical Position on Waste Form (NRC 1991), additional compressive strength tests will be conducted on selected Cast Stone specimens after exposure to radiation, thermal cycling, biodegradation, and water immersion to demonstrate structural stability of the LAW Cast Stone. Also, the EPA is expected in late 2012 to issue a suite of four test methods to be used as part of environmental leaching assessment for evaluation of treatment effectiveness of solid materials. These new EPA methods will be published in SW-846 (http://www.epa.gov/osw/hazard/testmethods/sw846/) and will examine pH effects (EPA 1313), saturated column leaching (EPA 1314), effective diffusivity (EPA 1315), and solidto-liquid ratio (EPA 1316) (see Section 4.10 above). The regulatory framework under which these test methods are to be conducted is not known at this time. It may be necessary to include them as part of the WFQ testing to address LDR. Details of the processing and waste form characterization tests will be described in the test plan to be developed to guide the waste loading and WFQ testing.

The final outcome of these waste loading and WFQ tests will be identification of an optimal nominal formulation for the LAW Cast Stone and further demonstration of the robustness of the Cast Stone to waste and process variability. The testing will address some of the testing needs identified above in Sections 4.1, Waste Loading Tests; 4.4, Land Disposal Restrictions Compliance Testing; 4.5, Cast Stone Physical and Chemical Properties; 4.8, Cast Stone Solid-Phase Characterization; 4.9, Waste Form Leach Testing-PA Support; and 4.11, Physical Stability.

\subsection{Cast Stone Actual Waste Tests}

Preparation and testing of LAW Cast Stone containing actual radioactive wastes will be conducted to provide confirmation that the results observed with simulants in the screening and waste loading and WFQ testing are representative of what is expected with actual wastes.

Cast Stone specimens will be prepared with the nominal Cast Stone formulation defined in the waste loading and WFQ testing described above and will include at least two actual wastes. The final nominal Cast Stone formulation identified through the screening and waste loading and WFQ testing will be used to solidify one to three actual waste samples from the Hanford tanks. Cesium will be stripped from the actual wastes before preparing the Cast Stone specimens. Blending or shimming of the tank waste samples may be considered to provide waste compositions similar to the nonradioactive simulants used in the screening, waste loading, and WFQ studies.

One actual waste sample will be prepared at SRNL using wastes from Tank 50 that are shimmed to match the Rassat saltcake simulant shown in Table 5.3. This tank is the feed tank for the Saltstone facility at the Savannah River Site. Shimming this waste stream to match the Hanford saltcake simulant was done previously for the fluidized bed steam reformed waste form that was also tested as a LAW waste form candidate. Final selection and adjustment of the other tank wastes to be used for preparing the Cast Stone actual waste specimens will be described in the test plan to be developed to guide the actualwaste testing.

Cast Stone specimens for the actual-waste testing will be characterized for processing properties and final waste form properties. Processing properties include Cast Stone slurry/paste rheology, temperature rise during curing, and residual free liquids. 
Actual-waste Cast Stone waste form properties are measured after the test specimens have cured for at least 28 days. Compressive strength, density, and porosity will be measured on the test specimens. The TCLP will be conducted to examine the retention of RCRA metals and underlying hazardous constituents to address LDRs. The new EPA waste form release test methods for evaluating the treatment effectiveness of the Cast Stone will also be considered for testing the actual waste specimens. Monolith leach tests will be conducted for up to 63 days using EPA Method 1315 to measure the effective diffusivity of key constituents. Leach testing beyond the 63 days will be continued on selected samples to obtain long term waste form performance data to support risk assessment and PA activities described in Section 6.5 below. Those activities would be conducted under a separate, but coordinated DOE/HQ initiative. Chemical compositions will be determined for the Cast Stone specimens both before and after leaching. The actual waste samples, pre- and post-leaching, will also be used for mineralogy and Tc speciation characterization. Tc speciation studies would also be conducted under a separate DO/HQ initiative. Details of the processing and waste form characterization tests will be described in the test plan to be developed to guide the actual-waste Cast Stone testing.

The results of the Cast Stone actual-waste testing are expected to demonstrate that Cast Stone specimens prepared with chemical and spiked simulants are representative of the Cast Stone properties expected with actual wastes. The testing will further mature the LAW Cast Stone waste form with respect to the DOE-EM technology readiness assessment (DOE-EM 2008). The testing will address some of the testing needs identified above in Sections 4.4, Land Disposal Restrictions Compliance Testing; 4.5 Cast Stone Physical and Chemical Properties; 4.8, Cast Stone Solid-Phase Characterization; 4.9, Waste Form Leach Testing-PA Support; and 4.11, Physical Stability.

\subsection{Cast Stone Engineering-Scale Demonstration}

After selection of the final nominal LAW Cast Stone formulation, an engineering-scale demonstration of the Cast Stone process and containerized waste form may be conducted. The demonstration will be conducted with prototypic mixing and pumping equipment. One or more LAW simulants determined to be indicative of the range of impactful waste compositions will be used in the engineering-scale-testing along with the nominal LAW Cast Stone formulation. The Cast Stone slurry/paste will be placed in an appropriately sized container to allow for characterization of the pumpability and flowability of the as prepared slurry and to characterize the temperature rise and profile in a larger Cast Stone monolith. Processing properties to be characterized include gelling and hardening time, slurry/paste rheology, residual free liquids and potential for phase separation during setting and hardening.

After curing, the large Cast Stone monolith will be examined for macroscopic inhomogeneities in the waste form block. Samples will be taken for characterization including compressive strength, density, porosity, leachability, and chemical composition. The samples will be taken at selected locations to demonstrate the consistency in properties within the Cast Stone block. Specific details of the process demonstration and resulting waste form characterization will be described in the test plan to guide the engineering-scale demonstration.

The results of the LAW Cast Stone engineering-scale demonstration will confirm the preparation of LAW Cast Stone under more prototypical conditions and will determine scaling factors to be addressed in the design of an operating LAW Cast Stone system. The testing will further mature the LAW Cast Stone waste form with respect to the DOE-EM technology readiness assessment (DOE-EM 2008). This initial 
engineering-scale demonstration will address some of the testing needs identified above in Sections 4.2, Process Control Tests, and Section 4.3, Full-Scale Waste Form Package Tests.

\subsection{Risk Assessment and Performance Assessment Support}

An environmental risk analysis will be conducted to evaluate the environmental impacts of the LAW waste forms being considered as part of TPA Milestone M-062-40ZZ. Additional data on Cast Stone for LAW is needed to support the risk analysis that will be an integral part of the products submitted to meet the milestone. The near-term testing objectives to support this risk analysis and future PAs are to provide contaminant release data for the LAW Cast Stone waste form.

Selected Cast Stone monoliths that are leached during the screening tests, waste loading and WFQ tests, and actual-waste activities described in Sections 6.1 through 6.3 may continue to be leached beyond the 63 day standard time interval used in EPA 1315. The monolith extended leach tests will start with a solution replacement time period of 14 days and the replacement interval will be changed to ever increasing time periods (i.e., $>14$ days) based on making sure that enough mass of the key constituent Tc leaches during each time period that the concentration in the leachate is above detection limit values. The extended leach testing and Tc speciation and characterization analyses are part of a separately funded DOE/HQ initiative. However, those activities will be closely coordinated with the work described in this testing plan and will make use of samples and test specimens prepared as a result of the work described in this plan.

The testing will address some of the testing needs described in Sections 4.8, Cast Stone Solid-Phase Characterization; 4.9, Waste Form Leach Testing-PA Support; and 4.12, Waste Form Release Model. 


\subsection{Quality Assurance}

The WFQ work and testing to support PA analyses outlined in this testing plan will be performed in accordance with a project-specific Quality Assurance Program (QAP). The QAP will be based on the following requirements:

- 10 CFR 830, Subpart A, "Quality Assurance Requirements.”

- DOE Order 414.1D (dated 4/25/2011, supersedes DOE Order 414.1C) (DOE 2011), Quality Assurance.

The QAP will use the following consensus standards:

- ASME NQA-1, Quality Assurance Requirements for Nuclear Facility Applications, Part 1, Requirements for Quality Assurance Programs for Nuclear Facilities.

- ASME NQA-1, Part II, Subpart 2.7, Quality Assurance Requirements for Computer Software for Nuclear Facility Applications.

- ASME NQA-1, Part IV, Subpart 4.2, Guidance on Graded Application of Quality Assurance (QA) for Nuclear-Related Research and Development.

Further, for data collected in support of environmental regulatory activities, the QAP will address the QA/QC requirements specified in the Hanford Analytical Services Quality Assurance Requirements Documents (HASQARD) (DOE/RL 1998). The PNNL document for implementing HASQARD is Conducting Analytical Work in Support of Regulatory Programs (CAWSRP). Data Quality Objectives established in CAWSRP were generated in accordance with HASQARD requirements.

Where appropriate, field experiment and sampling and analysis plans will be based on application of the data quality objectives process in accordance with the Guidance on Systematic Planning Using the Data Quality Objectives Process (EPA QA/G-4) (EPA/240/B-06/001) (EPA 2006).

Subcontractors and suppliers will be required to develop and implement QA programs that meet the QA requirements of the project QAP. 


\subsection{References}

10 CFR 61.56. 2009. "Waste Characteristics.” Code of Federal Regulations, U.S. Nuclear Regulatory Commission, Washington, D.C.

10 CFR 830. 2010. “Nuclear Safety Management." Code of Federal Regulations, U.S. Department of Energy.

40 CFR 261. 2010. "Identification and Listing of Hazardous Waste." Code of Federal Regulations, U.S. Environmental Protection Agency.

40 CFR 268. 2010. “Land Disposal Restrictions.” Code of Federal Regulations, U.S. Environmental Protection Agency.

Albenesius EL. 2001. Computer Modeling of Saltstone Landfills by Intera Environmental Consultants. DPST-83-529, Savannah River Site, Aiken, South Carolina.

Aloy AS, JR Harbour, EW Holtzscheiter, and CA Langton. 2008. "Evaluation of Durability of Mortars and Concretes Used in Ancient Structures." In: Materials Research Society Symposium Proceedings Vol. 1107, Paper \#127, Materials Research Society, Pittsburgh, Pennsylvania.

Angus MJ and FP Glasser. 1985. "The chemical environment in cement matrices.” Mat. Res. Soc. Symp. Proc., 50:547-556.

ANSI/ANS-American National Standards Institute/American Nuclear Society. 1992. Solid Radioactive Waste Processing System for Light-Water-Cooled Reactor Plants;-Appendix B - Testing for Free Liquids in Solidified Matrices. ANSI/ANS-55.1, La Grange Park, Illinois.

ANSI/ANS - American National Standards Institute/American Nuclear Society. 2003. Measurement of the Leachability of Solidified Low-Level Radioactive Wastes by a Short Term Test Procedure.

ANSI/ANS-16.1, La Grange Park, Illinois.

ASME_-American Society of Mechanical Engineers. 2000. Quality Assurance Requirements for Nuclear Facility Applications. NQA-1, Washington, D.C.

ASTM-American Society for Testing and Materials. 1985. Standard Test Method for Thermocycling of Electroplated Plastics. ASTM B553, West Conshohocken, Pennsylvania.

ASTM-American Society for Testing and Materials. 1996. Standard Practice for Determining Resistance of Plastics to Bacteria. ASTM G22, West Conshohocken, Pennsylvania.

ASTM-American Society for Testing and Materials. 2000. Practice for Dissolving Glass Containing Radioactive and Mixed Waste for Chemical and Radiochemical Analysis. ASTM C1463, West Conshohocken, Pennsylvania.

ASTM-American Society for Testing and Materials. 2001. Standard Test Method for Distribution Ratios by the Short-Term Batch Method. ASTM D4319-93 (Reapproved 2001), West Conshohocken, Pennsylvania. 
ASTM-American Society for Testing and Materials. 2007. Standard Practice for Measurement of the Glass Dissolution Rate Using the Single-Pass Flow-Through Test Containing Radioactive and Mixed Waste for Chemical and Radiochemical Analysis. ASTM C1662, West Conshohocken, Pennsylvania.

ASTM-American Society for Testing and Materials. 2008a. Standard Test Methods for Determining Chemical Durability of Nuclear, Hazardous, and Mixed Waste Glasses and Multiphase Glass Ceramics: The Product Consistency Test (PCT). ASTM C1285, West Conshohocken, Pennsylvania.

ASTM-American Society for Testing and Materials. 2008b. Standard Test Method for Accelerated Leach Test for Diffusive Releases from Solidified Waste and a Computer Program to Model Diffusive, Fractional Leaching from Cylindrical Waste Forms. ASTM C1308, West Conshohocken, Pennsylvania.

ASTM-American Society for Testing and Materials. 2008c. Standard Test Methods for Time of Setting of Hydraulic Cement by Vicat Needle. ASTM C191, West Conshohocken, Pennsylvania.

ASTM-American Society for Testing and Materials. 2008d. Standard Test Methods for Determination of the Soil Water Characteristic Curve for Desorption Using Hanging Column, Pressure Extractor, Chilled Mirror Hygrometer, or Centrifuge. ASTM D 6836-02 (Reapproved 2008), West Conshohocken, Pennsylvania.

ASTM-American Society for Testing and Materials. 2009a. Standard Test Method for Compressive Strength of Cylindrical Concrete Specimens. ASTM C39/C39M, West Conshohocken, Pennsylvania.

ASTM-American Society for Testing and Materials. 2009b. Standard Test Method for Measuring Waste Glass or Glass Ceramic Durability by Vapor Hydration Test. ASTM C1663, West Conshohocken, Pennsylvania.

ASTM-American Society for Testing and Materials. 2009d. Standard Practice for Determining Resistance of Synthetic Polymeric Materials to Fungi. ASTM G21, West Conshohocken, Pennsylvania.

ASTM - American Society for Testing and Materials. Standard Test Method for

Temperature of Freshly Mixed Hydraulic-Cement Concrete. ASTM C 1064, West Conshohocken, Pennsylvania.

Bacon DH and BP McGrail. 2001. Waste Form Release Calculations for the 2001 Immobilized LowActivity Waste Performance Assessment. PNNL-13369, Pacific Northwest National Laboratory, Richland, Washington.

Bacon DH, MD White, and BP McGrail. 2000. Subsurface Transport Over Reactive Multiphases (STORM): A General, Coupled, Nonisothermal Multiphase Flow, Reactive Transport, and Porous Medium Alteration Simulator, Version 2, User's Guide. PNNL-13108, Pacific Northwest National Laboratory, Richland, Washington.

Bacon DH, MD White, and BP McGrail. 2004. Subsurface Transport Over Reactive Multiphases (STORM): A Parallel, Coupled, Nonisothermal Multiphase Flow, Reactive Transport, and Porous Medium Alteration Simulator, Version 3.0, User's Guide. PNNL-14783, Pacific Northwest National Laboratory, Richland, Washington.

Bacon DH and BP McGrail. 2005. Waste Form Release Calculations for the 2005 Integrated Disposal Facility Performance Assessment. PNNL-15198, Pacific Northwest National Laboratory, Richland, Washington. 
Bros R, H Hidaka, G Kamei, and T Ohnuki. 2003. "Mobilization and mechanisms of retardation in the Oklo natural reactor zone 2 (Gabon) - Inferences from U, REE, Zr, Mo and Se Isotopes." Applied Geochemistry, 18:1807-1824.

Brown CF, KN Geiszler, and TS Vickerman. 2005. "Extraction and Quantitative Analysis of Iodine in Solid and Solution Matrixes." Analytical Chemistry, 77(21):7062-7066. doi:10.1021/ac050972v.

Brunauer S, PH Emmett, and E Teller. 1938. "Adsorption of gases in multimolecular layers." Journal of the American Chemical Society, 60:309-319.

Cadelli, N., G. Cottone, S. Orlowski, G. Bertozzi, F. Girardi, and A. Saltelli. 1988. Performance Assessment of Geological Isolation Systems for Radioactive Waste (PAGIS). Summary. EUR 11775 EN, Commission of .the European Communities, Luxembourg.

Crow RF and JD Connolly. 1973. "Atomic absorption analysis of Portland Cement and Raw Mix using lithium metaborate fusion." J. Test. Evaluation, 1:382.

CH2M HILL. 2005. Testing Plan to Support Determination of Equivalent Treatment for Bulk Vitrification. RPP-Plan-28064, CH2M HILL Hanford Group, Richland, Washington.

Chen Y, DW Engel, BP McGrail, and KS Lessor. 1995. AREST-CT V1.0 Software Verification. PNL-10692, Pacific Northwest Laboratory, Richland, Washington.

Chen Y, BP McGrail, and DW Engel. 1997. "Source-term analysis for Hanford low-activity tank waste using the reaction-transport code AREST-CT." In: Scientific Basis for Nuclear Waste Management XX, Walter J. Gray and Ines R. Triay, Eds., Proceedings of the Materials Research Society, vol. 465, Pittsburgh, Pennsylvania.

Cherrey, KD, M Flury, and JB Harsh. 2003. "Nitrate and colloid transport through coarse Hanford sediments under steady state, variably saturated flow." Water Resources Research, 39(6):1165-1175. doi:10.1029/2002WR001944, 2003

Cook JR. 2000. Radiological Performance Assessment for the E-Area Vaults Disposal Facility. WSRC-RP-94-0218, Savannah River Site, Aiken, South Carolina.

De Windt L, S Leclercq, and J van der Lee. 2006. "Assessing the Durability of Nuclear Glass with Respect to Silica Controlling Processes in a Clayey Underground Disposal." In: Scientific Basis for Nuclear Waste Management XXIX, Mater. Res. Soc. Symp. Proc. 932, ed P Van Isheghem, September 12-16, 2005, Ghent, Belgium, paper \#10, Warrendale, Pennsylvania.

DOE-U.S. Department of Energy, 1999, Implementation Guide for use with DOE M435.1-1. DOE G435.1, Washington, D.C.

DOE-U.S. Department of Energy. 2000, as amended. WTP Contract, Contract DE-AC27-01RV14136. DOE Office of River Protection, Richland, Washington.

DOE O 414.1D. 2011. “Quality Assurance.” U.S. Department of Energy. Washington, D.C.

DOE-EM-U.S. Department of Energy Office of Environmental Management. 2008. Technology Readiness Assessment (TRA)/Technology Maturation Plan (TMP) Process Guide, Washington, D.C. 
DOE-RL. 1998. Hanford Analytical Services Quality Assurance Requirements Documents.

DOE/RL-96-68, U.S. Department of Energy, Richland Operations Office, Richland, Washington.

Ecology-Washington State Department of Ecology. 2008 as amended. Dangerous Waste Portion of the Resource Conservation and Recovery Act Permit for the Treatment, Storage and Disposal of Dangerous Waste at the Hanford Facility. WA 7890008967, Olympia, Washington.

Ecology, EPA, and DOE (Washington State Department of Ecology, Olympia, Washington; U.S. Environmental Protection Agency, Washington, D.C.; and U.S. Department of Energy, Richland, Washington), 1989, Hanford Federal Facility Agreement and Consent Order, 89-10, as amended, accessed through http://www.hanford.gov/page.cfm/TriParty.

EPA-U.S. Environmental Protection Agency. 1999. Understanding Variation in Partition Coefficient, Kd, Values: Volume I. The Kd Model, Methods of Measurement, and Application of Chemical Reaction Codes. EPA 402-R-99-004A, U.S. Environmental Protection Agency, Washington, D.C. http://www.epa.gov/radiation/cleanup/402-r-99-004.html

EPA-U.S. Environmental Protection Agency. 2000. Toxicity Characteristic Leaching Procedure. SW-846 Method 1311 for VOCs, SVOCs, Chlorinated Pesticides, Herbicides, Metals, and Mercury. Cincinnati, Ohio.

EPA-U.S. Environmental Protection Agency. 2006. Guidance on Systematic Planning Using the Data Quality Objectives Process. EPA QA/G-4, U.S. Environmental Protection Agency, Washington, D.C.

EPA-U.S. Environmental Protection Agency. 2008. Methods for Evaluating Solid Waste, Physical/Chemical Methods. SW-846, U.S. Environmental Protection Agency, Washington, D.C.

EPA-U.S. Environmental Protection Agency. 2009a. Method 1313: Leaching Test (Liquid-Solid Partitioning as a Function of Extract pH) of Constituents in Solid Materials using a Parallel Batch Extraction Test (DRAFT). U.S. Environmental Protection Agency, Washington, D.C.

EPA-U.S. Environmental Protection Agency. 2009b. Method 1314: Leaching Test (Liquid-Solid Partitioning as a Function of Liquid-Solid Ratio) of Constituents in Solid Materials using an Up-Flow Percolation Column (DRAFT). U.S. Environmental Protection Agency, Washington, D.C.

EPA-U.S. Environmental Protection Agency. 2009c. Mass Transfer Rates of Constituents in Monolith or Compacted Granular Materials Using a Semi-Dynamic Tank Leaching Test. Draft Method 1315, Washington, D.C.

EPA-U.S. Environmental Protection Agency. 2009d. Method 1316: Leaching Test (Liquid-Solid Partitioning as a Function of Liquid-to-Solid Ratio) of Constituents in Solid Materials using a Parallel Batch Extraction Test (DRAFT). U.S. Environmental Protection Agency, Washington, D.C.

Freedman VL, ZF Zhang, JM Keller, and Y Chen. 2007. Development of Waste Acceptance Criteria at 221-U Building: Initial Flow and Transport Scoping Calculations. PNNL-16585, Pacific Northwest National Laboratory, Richland, Washington.

Freedman VL and MD White. 2007. STOMP Software Test Plan. PNNL-SA-54022, Pacific Northwest National Laboratory, Richland, Washington. 
Furhmann M, JH Heiser, R Pietrzak, EM Franz, and P Colombo. 1990. Users' Guide For the Accelerated Leach Test Computer Program. BNL-52267, Brookhaven National Laboratory, Upton, New York.

Gasper, KA, KD Boomer, ME Johnson, GW Reddick, Jr., AF Choho, and JS Garfield, 2002, Recommendation for Supplemental Technologies for Potential Mission Acceleration, RPP-11261, Revision 0, CH2MHill Hanford Group, Inc., Richland, Washington.

Giesche H. 2006. "Mercury Porosimetry: A General (Practical) Overview.” Part. Part. Syst. Charact. 23:1-11. DOI:10.1002/ppsc.200601009.

Gin S, A Verney-Carron, and G Libourel. 2009. "Use of Archaeological Glass to Predict the Long-Term Behavior of HLW." In Scientific Basis for Nuclear Waste Management XXXIII, Mater. Res. Soc. Symp. Proc. 1193, ed BE Burakov and AS Aloy, May 24-29, 2009, St. Petersburg, Russia, paper number 239, Warrendale, Pennsylvania.

Grambow B and E Giffaut. 2006. "Coupling of Chemical Processes in the Near Field," in: Scientific Basis for Nuclear Waste Management XXIX, Mater. Res. Soc. Symp. Proc. 932, ed P Van Isheghem, September 12-16, 2005, Ghent, Belgium, paper \#6, Warrendale, Pennsylvania.

Gregg KSW and SJ Sing. 1967. Adsorption, Surface Area and Porosity. Academic Press, Inc. New York, NY.

Horton R, PJ Wierenga, and DR Nielsen. 1982. "A Rapid Technique for Obtaining Uniform Water Content Distributions in Unsaturated Soil Columns.” Soil Sci., 133:397-399.

Jantzen CM and NE Bibler. 2008. The Product Consistency Test (PCT): How and Why It Was Developed, SRNS-STI-2008-00110, Savannah River National Laboratory, Aiken, South Carolina.

Kaplan DI, T Hang, and SE Aleman. 2005. Estimated Duration of the Reduction Capacity Within a High-Level Waste Tank (U). WSRC-RP-2005-01674, Revision 0, Westinghouse Savannah River Company, Aiken, South Carolina.

Koningsberger, D. \& Prins, R. (1988). X-ray Absorption: Principles, Applications, Techniques of EXAFS, SEXAFS, and XANES. Wiley-Interscience Publishing Company. New York, New York.

Krupka KM and RJ Serne. 1998. Performance Assessment of Low-Level Radioactive Waste Disposal Facilities: Effects on Radionuclide Concentrations by Cement/Ground-Water Interactions. NUREG/CR6377, U. S. Nuclear Regulatory Commission, Washington, D. C.

Krupka KM, RJ Serne, and DI Kaplan. 2004. Geochemical Data Package for the 2005 Hanford Integrated Disposal Facility Performance Assessment. PNNL-13037, Rev. 2, Pacific Northwest National Laboratory, Richland, Washington.

Langton CA. 1980. Longevity of Borehole and Shaft Sealing Materials: 2, Characterization of CementBased Ancient Building Material. ONWI -202, Office on Nuclear Waste Isolation, Battelle Memorial Institute, Columbus, Ohio

Lasaga AC. 1998. Kinetic Theory in the Earth Sciences. Princeton University Press, Princeton, New Jersey. 
Lee W and B Batchelor. 2003. "Reductive Capacity of Natural Reductants." Environmental Science Technology, 37:535-541.

Linklater CM, Y Albinsson, WR Alexander, I Casas, IG McKinley, and P Sellin. 1996. "A natural analogue of high-pH cement pore waters from the Maqarin area of northern Jordan: Comparison of predicted and observed trace-element chemistry of uranium and selenium." J. of Contam. Hydrol. 21:59-69.

Mahoney LA and JD Vienna. 2005. Feed Variability and Bulk Vitrification Glass Performance Assessment. PNNL-14985, Pacific Northwest National Laboratory, Richland, Washington.

Mann FM, KC Burgard, WR Root, RJ Puigh, SH Finfrock, R Khaleel, DH Bacon, EJ Freeman, BP McGrail, SK Wurstner, and PE LaMont. 2001. Hanford Immobilized Low-Activity Waste Performance Assessment: 2001 Version. DOE/ORP-2000-24, Rev. 0. DOE/ORP-U.S. Department of Energy Office of River Protection, Richland, Washington.

Mann FM, RJ Puigh, R Khaleel, S Finfrock, BP McGrail, DH Bacon, and RJ Serne. 2003. Risk Assessment Supporting the Decision on the Initial Selection of Supplemental ILAW Technologies. RPP-17675, Rev. 0, CH2M HILL Hanford Group Inc., Richland, Washington.

Matlack KS, I Joseph, W Gong, IS Muller, and IL Pegg. 2007. Final Report Enhanced LAW Glass Formulation Testing. VSL-07R1130-1, Vitreous State Laboratory, The Catholic University of America, Washington, D.C.

Matlack KS, I Joseph, W Gong, IS Muller, and IL Pegg. 2009. Final Report Glass Formulation Development and DM10 Melter Testing with ORP LAW Glasses. VSL-09R1510-2, Vitreous State Laboratory, The Catholic University of America, Washington, D.C.

Mattigod SV, JH Westsik, Jr, CW Chung, MJ Lindberg, and KE Parker. 2011. Waste Acceptance Testing of Secondary Waste Forms: Cast Stone, Ceramicrete and DuraLith. PNNL-20632, Pacific Northwest National Laboratory, Richland, Washington.

McGrail BP, DH Bacon, JP Icenhower, FM Mann, RJ Puigh, HT Schaef, and SV Mattigod. 2001. "Near-field performance assessment for a low-activity waste glass disposal system: Laboratory testing to modeling results." Journal of Nuclear Materials, 298:95-111.

McGrail BP, DH Bacon, RJ Serne, and EM Pierce. 2003. A Strategy to Assess Performance of Selected Low-Activity Waste Forms in an Integrated Disposal Facility. PNNL-14362, Pacific Northwest National Laboratory, Richland, Washington.

McLoughlin SD, NC Hyatt, RJ Hand, and WE Lee. 2006. "Corrosion of Archaeological Model Glasses After 32 Years of Burial at Ballidon.” In: Scientific Basis for Nuclear Waste Management XXIX, Mater. Res. Soc. Symp. Proc. 932, ed P Van Isheghem, September 12-16, 2005, Ghent, Belgium, paper number 162, Warrendale, Pennsylvania.

Mendel JE. 1983. Nuclear Waste Materials Handbook - Waste Form Test Methods, DOE/TIC-11400, Materials Characterization Center, Battelle-Pacific Northwest Laboratories, Richland, Washington. 
Mitsui S, H Makino, M Inagaki, and T Ebina. 2009. "Impact of Silicon Migration Through Buffer Material on the Lifetime of Vitrified Waste." In: Scientific Basis for Nuclear Waste Management XXXIII, Mater. Res. Soc. Symp. Proc. 1193, ed BE Burakov and AS Aloy, May 24-29, 2009, St. Petersburg, Russia, paper number 397, Warrendale, Pennsylvania.

Moore, WJ. 1972. Physical Chemistry, $4^{\text {th }}$ edition, Prentice-Hall Inc., Englewook Cliffs, NJ.

Nichols WE and MD White. 2007a. Project Management Plan for Subsurface Transport Over Multiple Phases (STOMP) Software Maintenance and Development. PNNL-SA-54024, Pacific Northwest National Laboratory, Richland, Washington.

Nichols WE and MD White. 2007b. Software Design Description For Subsurface Transport Over Multiple Phases (STOMP) Software. PNNL-SA-54078, Pacific Northwest National Laboratory, Richland, Washington.

NRC_-U.S. Nuclear Regulatory Commission. 1991. Technical Position on Waste Form, Rev. 1, Low-Level Waste. Division Management Branch, Office of Nuclear Material Safety and Safeguards, Washington, D.C.

Peters MT and RC Ewing. 2007. "A Science-Based Approach to Understanding Waste Form Durability in Open and Closed Nuclear Fuel Cycles." In: Scientific Basis for Nuclear Waste Management XXX, Mater. Res. Soc. Symp. Proc. 985, ed D Dunn, C Poinssot, B Begg, Nov 27-Dec 1, 2006, Boston, Massachusetts, paper number NN07-03, Warrendale, Pennsylvania.

Pierce, EM, BP McGrail, et al. 2004. Waste Form Release Data Package for the 2005 Integrated Disposal Facility Performance Assessment. PNNL-14805, Pacific Northwest National Laboratory, Richland, Washington.

Powers LJ. 2005. Petrographic Studies on Laboratory-Prepared Mortar Sample. WJE No. 2005.2034, Wiss, Janney, Elstner Associates, Inc., Northbrook, Illinois.

Ramsey AA and RA Robbins. 2012. Secondary Liquid Waste Treatment Cast Stone Technology Development Plan, RPP-51790, Washington River Protection Solutions, Richland, Washington.

Rassat SD, LA Mahoney, RL Russell, SA Bryan, and RL Sell. 2003. Cold Dissolved Saltcake Simulant Development, Preparation, and Analysis. PNNL-14194, Rev. 1, Pacific Northwest National Laboratory, Richland, Washington.

Relyea JF, RJ Serne, and D Rai. 1980. Methods for Determining Radionuclide Retardation Factors: Status Report. PNL-3349, Pacific Northwest Laboratory Richland, Washington.

Roberts KA and DI Kaplan. 2009. Reduction Capacity of Saltstone and Saltstone Components. SRNL-STI-2009-00637, Rev 0, Savannah River National Laboratory, Aiken, South Carolina.

Roy DM and CA Langton. 1989. Studies of Ancient Concrete as Analogs of Cementitious Sealing Materials for a Repository in Tuff, LA-11527-MS, Los Alamos Technical Report, Las Alamos, New Mexico. 
Serne RJ, WJ Martin, SB McLaurine, SP Airhart, VL LeGore, and RL Treat. 1987. Laboratory Leach Tests of HFW Grout and Leachate Adsorption Tests Using Hanford Sediment. PNL-6019, Pacific Northwest Laboratory, Richland, Washington.

Serne RJ and JH Westsik, Jr. 2011. Data Package for Secondary Waste Form Down-Selection-Cast Stone. PNNL-20706, Pacific Northwest National Laboratory, Richland, Washington.

Smellie JAT and F Karlsson. 1999. "The use of natural analogues to assess radionuclide transport." Engineering Geology 52:193-220.

Smellie JAT, F Karlsson, and WR Alexander. 1997. "Natural analogue studies: present status and performance assessment implications. "J. of Contam. Hydrol. 26:3-17.

Smith RW and JC Walton. 1993. "The Role of Oxygen Diffusion in the Release of Technetium from Reducing Cementitious Waste Forms." Materials Research Society Symposium Proceedings 1993, pp. 247-253.

Song, KM, J Mitchell and LF Gladden. 2009. "Magnetic resonance studies of hydration kinetics and microstructural evolution in plaster pastes." J Mater Sci. 44:5004-5012. DOI 10.1007/s10853-009-37654.

Sundaram SK, CW Chung, KE Parker, ML Kimura, MM Valenta, CA Burns, SG Pitman, W Um, J Chun, and JH Westsik, Jr. 2011. Secondary Waste Form Development and Optimization-Cast

Stone. PNNL-20159 Rev. 1, Pacific Northwest National Laboratory, Richland, Washington.

Um W, MM Valenta, CW Chung, J Yang, MH Engelhard, RJ Serne, KE Parker, G Wang, KJ Cantrell, and JH Westsik, Jr. 2011. Radionuclide Retention Mechanisms in Secondary Waste-Form Testing: Phase II. PNNL-20753, Pacific Northwest National Laboratory, Richland, WA.

Van Iseghem P, K Lemmens, M Aertsens, S Gin, I Ribet, B Grambow, JLCrovisier, M Del Nero, E Curti, B Schwyn, B Luckscheiter, and T McMenamin. 2006. "Chemical Durability of High-Level Waste Glass in Repository Environment: Main Conclusions and Remaining Uncertainties from the GLASTAB and GLAMOR Projects.” In: Scientific Basis for Nuclear Waste Management XXIX, Mater. Res. Soc. Symp. Proc. 932, P Van Isheghem, September 12-16, 2005, Ghent, Belgium, paper \#7, Warrendale, Pennsylvania.

WAC - Washington Administrative Code. "Dangerous Waste Regulations." WAC 173-303. Available online at: http://apps.leg.wa.gov/wac/default.aspx?cite=173-303. Accessed 06/17/2010.

White MD and BP McGrail. 2005. STOMP, Subsurface Transport Over Multiple Phases, Version 1.0, Addendum: ECKEChem, Equilibrium-Conservation-Kinetic Equation Chemistry and Reactive Transport. PNNL-15482, Pacific Northwest National Laboratory, Richland, Washington.

White MD and M Oostrom. 2006. STOMP: Subsurface Transport Over Multiple Phases, Version 4.0, User's Guide. PNNL-15782, Pacific Northwest National Laboratory, Richland, Washington.

White MD and VL Freedman. 2007. STOMP Software Configuration Management Plan. PNNL-SA54023, Pacific Northwest National Laboratory, Richland, Washington. 
Wierenga PJ, MH Young, GW Gee, RG Hills, CT Kincaid, TJ Nicholson, and RE Cady. 1993. Soil Characterization Methods for Unsaturated Low-Level Waste Sites. PNL-8480, Pacific Northwest Laboratory, Richland, Washington.

Worden, RH. 2006. "Dawsonite cement in the Triassic Lam Formation, Shabwa Basin, Yemen: A natural analogue for a potential mineral product of subsurface $\mathrm{CO}_{2}$ storage for greenhouse gas reduction." Marine and Petroleum Geology 23:61-77.

Yang L and CI Steefel. 2008. "Kaolinite Dissolution and Precipitation Kinetics at $22^{\circ} \mathrm{C}$ and $\mathrm{pH}$ 4." Geochimica et Cosmochimica Acta, 72:99-116.

Zhang ZF, VL Freedman, and MD White. 2007. Requirements for STOMP Subsurface Transport Over Multiple Phases. PNNL-SA-54079, Pacific Northwest National Laboratory, Richland, Washington. 


\section{Appendix A}

\section{Comparison of Specifications Relevant to Low-Activity Waste Cast Stone Waste Form}




\section{Appendix A}

\section{Comparison of Specifications Relevant to Low-Activity Waste Cast Stone Waste Form}

The table that follows provides a comparison of waste form specifications that are relevant to the Low-Activity Waste (LAW) Cast Stone waste form. The sources of the specifications include:

- U.S. Department of Energy. Waste Treatment Contract with Bechtel National Inc. Contract DE-AC27-01RV14136, Section C, Specification 2.

- Integrated Disposal Facility Waste Acceptance Criteria, RPP-8402, Rev. 1, February 23, 2005.

- IDF portion of the Hanford Facility Resource Conservation and Recovery Act (RCRA) Permit. Permit WA 89000 8967, Part III, Operating Unit 11, Integrated Disposal Facility. March 31, 2008.

Table A.1 compares the WTP contract specifications for ILAW based on WTP contract modification M041 with the draft IDF waste acceptance criteria and the IDF permit conditions. The table is organized by the WTP specifications, providing the title and number of each WTP requirement. The table then compares the different sources of requirements and identifies and actions planned or required to resolve discrepancies among the sets of requirements. Generally, the WTP specifications and the draft IDF waste acceptance criteria are essentially equivalent.

See Section 3.1 for further discussion. 
Table A.1. Immobilized Low-activity Waste Specifications and Integrated Disposal Facility Waste Acceptance Criteria Relevant to LAW Cast Stone ${ }^{1}$

\begin{tabular}{|c|c|c|c|c|c|}
\hline Specification & $\begin{array}{c}\text { WTP } \\
\text { Contract } \\
\text { Specification } \\
\text { 2: ILAW } \\
\text { Product } \\
\text { (M152) } \\
\end{array}$ & $\begin{array}{c}\text { IDFWAC } \\
\text { (RPP-8402 } \\
\text { Rev } 1 \text { Draft) }\end{array}$ & $\begin{array}{c}\text { IDF } \\
\text { Operating } \\
\text { Unit } 11 \\
\text { Unit-Specific } \\
\text { Conditions }\end{array}$ & Comparison of Specification & Actions/Comments \\
\hline $\begin{array}{l}\text { Package } \\
\text { Description }\end{array}$ & 2.2 .2 .1 & $\begin{array}{l}4.3 .1 \\
1.5 .2 .1\end{array}$ & $\begin{array}{l}\text { III.11.I } \\
\text { III.11.I.2 }\end{array}$ & $\begin{array}{l}\text { WTP-Sealed stainless steel container } \\
\text { enclosing poured glass waste form. } \\
\text { IDFWAC-Package must be constructed of } \\
\text { metal, concrete, or masonry and meet other } \\
\text { requirements. LAW is immobilized in a } \\
\text { glass matrix. } \\
\underline{I D F P e r m i t-O n l y ~ a c c e p t a b l e ~ I L A W ~ w a s t e ~} \\
\text { form is glass in WTP canisters or bulk } \\
\text { vitrification boxes. }\end{array}$ & $\begin{array}{l}\text { Cast Stone will require permit modification. } \\
\text { Requests for permit modifications will require } \\
\text { analysis to comply with the Washington State } \\
\text { Environmental Policy Act (SEPA), risk } \\
\text { assessment, and groundwater modeling to } \\
\text { show environmental impact. }\end{array}$ \\
\hline Waste Loading & 2.2 .2 .2 & None & None & 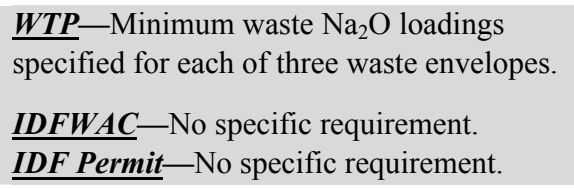 & $\begin{array}{l}\text { Testing program needs to determine limits of } \\
\text { waste loading in the Cast Stone waste form } \\
\text { product. }\end{array}$ \\
\hline $\begin{array}{l}\text { Size and } \\
\text { Configuration }\end{array}$ & 2.2 .2 .3 & 4.3 .2 & None & $\begin{array}{l}\underline{W T P}-304 \text { Stainless Steel, right cylinder } \\
\text { that is } 2.3 \mathrm{M} \text { in height and } 1.22 \mathrm{M} \text { in } \\
\text { diameter. } \\
\underline{\text { IDF } \boldsymbol{W A C} \text {-Several container sizes and }} \\
\text { configurations accepted. } \\
\text { IDF Permit-No specific requirement }\end{array}$ & $\begin{array}{l}\text { Non-standard containers would require } \\
\text { criticality safety evaluation. }\end{array}$ \\
\hline
\end{tabular}

1 Table adapted from Bagaasen, LM, JH Westsik, Jr. and TM Brouns. 2005. Waste Form Qualification Compliance Strategy for Bulk Vitrification. PNNL-15048, Pacific Northwest National Laboratory. 


\begin{tabular}{|c|c|c|c|c|c|}
\hline Specification & $\begin{array}{c}\text { WTP } \\
\text { Contract } \\
\text { Specification } \\
\text { 2: ILAW } \\
\text { Product } \\
\text { (M152) }\end{array}$ & $\begin{array}{c}\text { IDFWAC } \\
\text { (RPP-8402 } \\
\text { Rev } 1 \text { Draft) }\end{array}$ & $\begin{array}{c}\text { IDF } \\
\text { Operating } \\
\text { Unit } 11 \\
\text { Unit-Specific } \\
\text { Conditions }\end{array}$ & Comparison of Specification & Actions/Comments \\
\hline Mass & 2.2.2.4 & None & III.11.H.1 & $\begin{array}{l}\text { WTP-Mass }<10,000 \mathrm{Kgs} . \text { For the required } \\
\text { disposal package, this mass limits the force } \\
\text { exerted by the package to } 796 \mathrm{Kg} / \mathrm{ft}^{2} \text {. } \\
\text { IDF } \boldsymbol{W} \boldsymbol{A C} \text {-No specific requirement. } \\
\text { IDF Permit-Weight of waste, container, } \\
\text { fill material, and closure cover shall not } \\
\text { exceed load-bearing capacity of liner } \\
\left(13,000 \mathrm{lb} / \mathrm{ft}^{2}\right)\left(5,900 \mathrm{Kg} / \mathrm{ft}^{2}\right) .\end{array}$ & $\begin{array}{l}\text { Need to estimate mass and footprint of Cast } \\
\text { Stone disposal package. }\end{array}$ \\
\hline Void Space & 2.2 .2 .5 & $\begin{array}{l}4.1 .4 \\
\text { Appendix D }\end{array}$ & III.11.I.1.a & 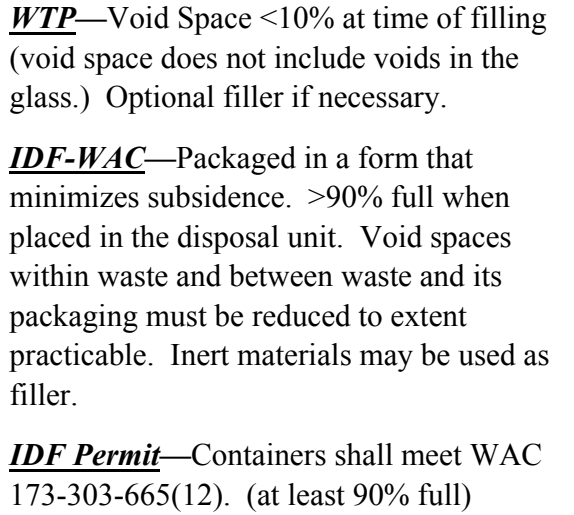 & $\begin{array}{l}\text { Equivalent requirements } \\
\text { No action required. }\end{array}$ \\
\hline
\end{tabular}




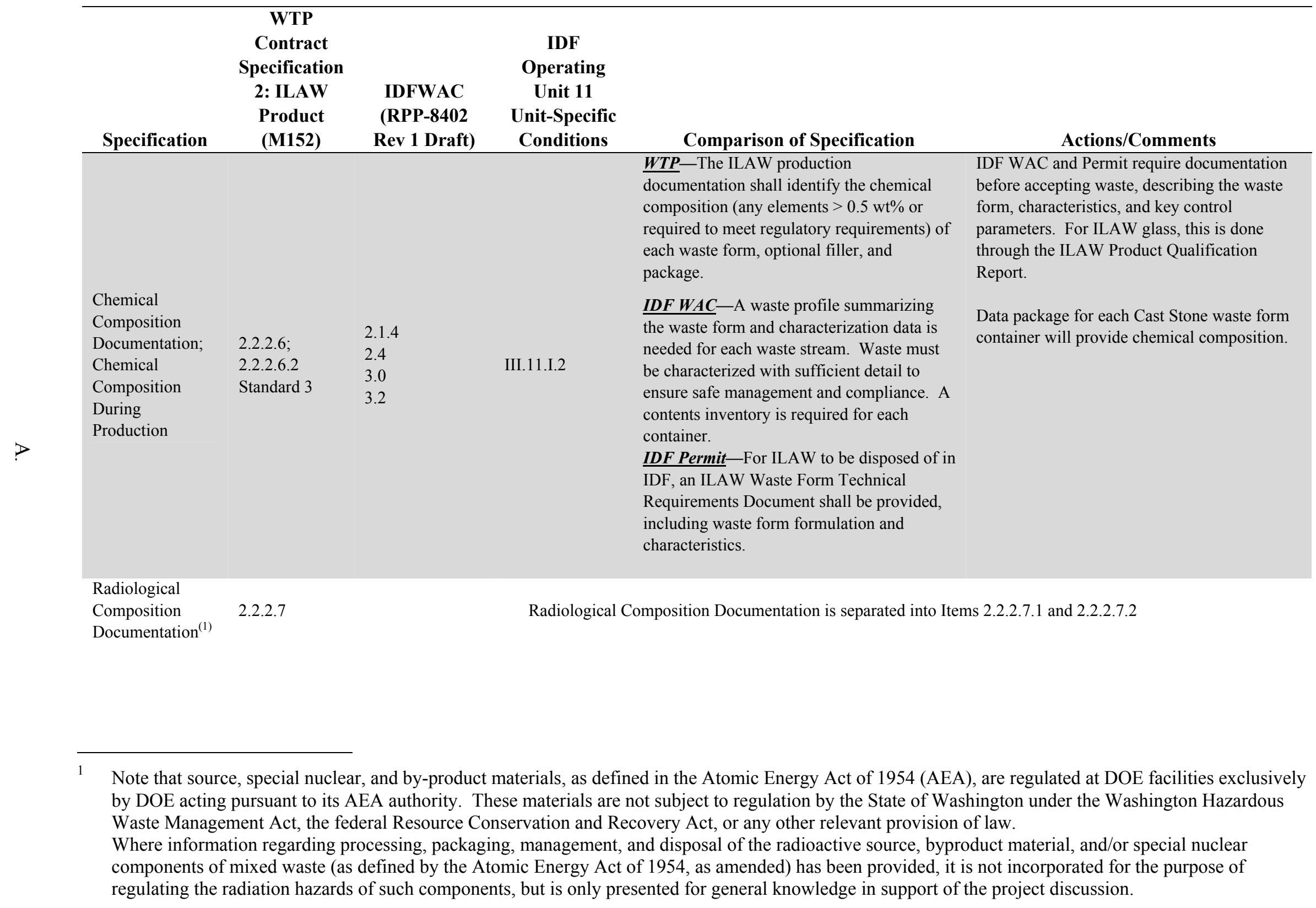




\begin{tabular}{|c|c|c|c|c|c|}
\hline Specification & $\begin{array}{c}\text { WTP } \\
\text { Contract } \\
\text { Specification } \\
\text { 2: ILAW } \\
\text { Product } \\
\text { (M152) }\end{array}$ & $\begin{array}{c}\text { IDFWAC } \\
\text { (RPP-8402 } \\
\text { Rev } 1 \text { Draft) }\end{array}$ & $\begin{array}{c}\text { IDF } \\
\text { Operating } \\
\text { Unit } 11 \\
\text { Unit-Specific } \\
\text { Conditions }\end{array}$ & Comparison of Specification & Actions/Comments \\
\hline $\begin{array}{l}\text { Radionuclide } \\
\text { Composition } \\
\text { Qualification }\end{array}$ & 2.2.2.7.1 & 4.2 .1 & None & $\begin{array}{l}\text { WTP-Estimated radionuclide } \\
\text { concentrations in the waste form shall be } \\
\text { identified in the ILAW Product Qualification } \\
\text { Report. } \\
\text { IDF WAC-A Waste Profile summarizing } \\
\text { the waste form and characterization data is } \\
\text { needed for each waste stream. Waste must } \\
\text { be characterized with sufficient detail to } \\
\text { ensure safe management and compliance. } \\
\underline{\text { IDF Permit-No specific requirements. }}\end{array}$ & $\begin{array}{l}\text { IDF WAC and Permit require documentation } \\
\text { before accepting waste, describing the waste } \\
\text { form and characteristics and key control } \\
\text { parameters. For ILAW glass, this is done } \\
\text { through the ILAW Product Qualification } \\
\text { Report. }\end{array}$ \\
\hline $\begin{array}{l}\text { Radionuclide } \\
\text { Composition } \\
\text { During } \\
\text { Production }\end{array}$ & 2.2.2.7.2 & $\begin{array}{l}2.4 \\
4.2 .1 \\
\text { Appendix A }\end{array}$ & None & 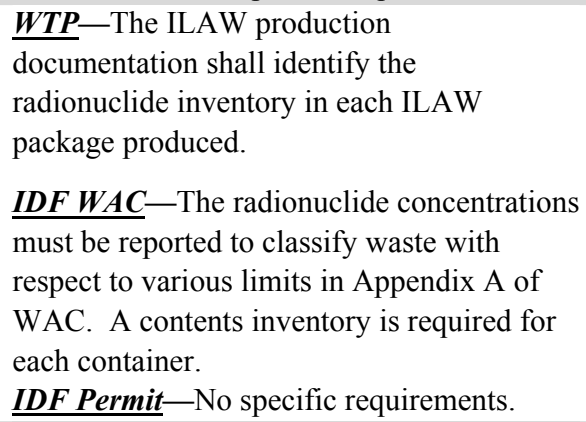 & $\begin{array}{l}\text { Data package for each Cast Stone waste form } \\
\text { container will provide radionuclide } \\
\text { composition and radiological properties. }\end{array}$ \\
\hline $\begin{array}{l}\text { Radionuclide } \\
\text { Concentration } \\
\text { Limitations }\end{array}$ & 2.2.2.8 & $\begin{array}{l}4.2 .1 .1 \\
4.2 .1 .2 \\
4.2 .2 \\
4.2 .3 \\
\text { Appendix A } \\
\text { Appendix F }\end{array}$ & None & 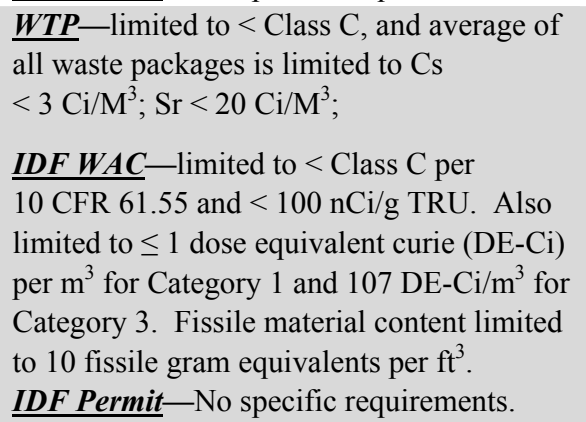 & $\begin{array}{l}\text { The radiological limits in Appendix F of RPP- } \\
8402 \text { are based, in part, on the concentration } \\
\text { limits in the Hanford Immobilized Low- } \\
\text { Activity Waste Performance Assessment: } \\
2001 \text { Version (DOE/ORP 2000-24). The } \\
\text { limits will need to be updated based on any PA } \\
\text { analyses that include the LAW Cast Stone } \\
\text { waste form. }\end{array}$ \\
\hline
\end{tabular}




\begin{tabular}{|c|c|c|c|c|c|}
\hline Specification & $\begin{array}{c}\text { WTP } \\
\text { Contract } \\
\text { Specification } \\
\text { 2: ILAW } \\
\text { Product } \\
\text { (M152) }\end{array}$ & $\begin{array}{c}\text { IDFWAC } \\
\text { (RPP-8402 } \\
\text { Rev } 1 \text { Draft) }\end{array}$ & $\begin{array}{l}\text { IDF } \\
\text { Operating } \\
\text { Unit } 11 \\
\text { Unit-Specific } \\
\text { Conditions }\end{array}$ & Comparison of Specification & Actions/Comments \\
\hline $\begin{array}{l}\text { Surface Dose } \\
\text { Rate Limitations }\end{array}$ & 2.2.2.9 & 4.2 .6 & None & $\begin{array}{l}\text { WTP}- \text { Surface dose } \leq 500 \mathrm{mRem} / \mathrm{hr} . \\
\underline{\boldsymbol{I D F} \boldsymbol{W} \boldsymbol{A} \boldsymbol{C}-\text { Surface dose } \leq 2 \mathrm{milliSieverts}} \\
(200 \mathrm{mRem} / \mathrm{hr}) \text { and } \leq 100 \mathrm{mRem} / \mathrm{hr} \text { at } \\
30 \text { centimeters from the waste package. } \\
\text { IDF Permit - No specific requirements }\end{array}$ & IDF WAC more restrictive. \\
\hline $\begin{array}{l}\text { Surface } \\
\text { Contamination } \\
\text { Limitations }\end{array}$ & 2.2 .2 .10 & 4.2 .4 & None & $\begin{array}{l}\text { WTP-Surface contamination } \leq 367 \mathrm{~Bq} / \mathrm{M}^{2} \\
\text { alpha }\left(202 \mathrm{dpm} / 100 \mathrm{~cm}^{2}\right) \text { and } 3670 \mathrm{~Bq} / \mathrm{M}^{2} \\
\text { beta-gamma }\left(2019 \mathrm{dpm} / 100 \mathrm{~cm}^{2}\right) \text { when } \\
\text { measured with method described in } \\
49 \mathrm{CFR} 173.443(\mathrm{a}) . \\
\text { IDF } \boldsymbol{W A C} \text {-Surface contamination less than } \\
\text { or equal to HNF-5183. These requirements } \\
\text { range from } 20 \mathrm{dpm} / 100 \mathrm{~cm}^{2} \text { to } \\
1,000 \mathrm{dpm} / 100 \mathrm{~cm}^{2} \text { for alpha, beta, and } \\
\text { gamma, depending on the specific isotope } \\
\text { (excluding tritium, which has a limit of } \\
10,000 \mathrm{dpm} / 100 \mathrm{~cm})^{2} \text {. Also, smearable } \\
\text { contamination must not exceed } 0.1 \% \text { of } \\
\text { limits in Table } 7-10 \text { of DOE/ORP-2000-24. } \\
\text { IDF Permit-No specific requirements }\end{array}$ & $\begin{array}{l}\text { IDF WAC reference to HNF- } 5183 \text { may be a } \\
\text { typo. HNF- } 5173 \text { is referenced in the Hanford } \\
\text { Site Solid Waste Acceptance Criteria (HNF- } \\
\text { EP-0063), which in turn may be replaced by } \\
\text { CHPRC-00073. }\end{array}$ \\
\hline Labeling & 2.2.2.11 & $\begin{array}{l}4.3 .5 \\
\text { Appendix C }\end{array}$ & None & 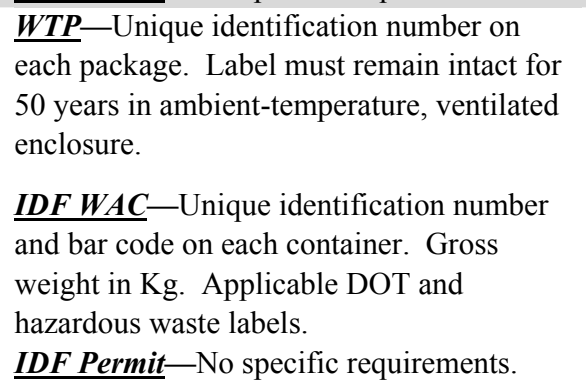 & Part of package design \\
\hline
\end{tabular}




\begin{tabular}{|c|c|c|c|c|c|}
\hline Specification & $\begin{array}{c}\text { WTP } \\
\text { Contract } \\
\text { Specification } \\
\text { 2: ILAW } \\
\text { Product } \\
\text { (M152) }\end{array}$ & $\begin{array}{c}\text { IDFWAC } \\
\text { (RPP-8402 } \\
\text { Rev } 1 \text { Draft) }\end{array}$ & $\begin{array}{c}\text { IDF } \\
\text { Operating } \\
\text { Unit } 11 \\
\text { Unit-Specific } \\
\text { Conditions }\end{array}$ & Comparison of Specification & Actions/Comments \\
\hline $\begin{array}{l}\text { Closure and } \\
\text { Sealing }\end{array}$ & 2.2.2.12 & $\begin{array}{l}4.3 \\
4.3 .1\end{array}$ & None & $\begin{array}{l}\text { WTP} \text {-The full, loaded package shall be } \\
\text { closed and sealed to prevent dispersal of } \\
\text { radioactive material. Closure system shall } \\
\text { be designed to remain intact for a storage } \\
\text { period of } 50 \text { years in an ambient- } \\
\text { temperature, ventilated enclosure. } \\
\underline{I D F W A C} \text { - Containers shall maintain } \\
\text { containment during handling and storage. } \\
\text { Storage period before disposal unspecified. } \\
\text { ILAW glass containers must have welded } \\
\text { lids. } \\
\underline{I D F} \text { Permit-No specific requirement. }\end{array}$ & \\
\hline $\begin{array}{l}\text { External } \\
\text { Temperature }\end{array}$ & 2.2.2.13 & None & III.11.H.1 & 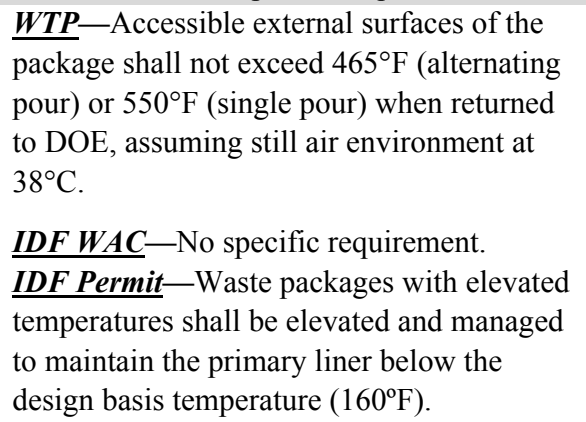 & $\begin{array}{l}\text { Need to dissipate heat of hydration during } \\
\text { curing. }\end{array}$ \\
\hline
\end{tabular}




\begin{tabular}{|c|c|c|c|c|c|}
\hline Specification & $\begin{array}{c}\text { WTP } \\
\text { Contract } \\
\text { Specification } \\
\text { 2: ILAW } \\
\text { Product } \\
\text { (M152) } \\
\end{array}$ & $\begin{array}{c}\text { IDFWAC } \\
\text { (RPP-8402 } \\
\text { Rev } 1 \text { Draft) } \\
\end{array}$ & $\begin{array}{c}\text { IDF } \\
\text { Operating } \\
\text { Unit 11 } \\
\text { Unit-Specific } \\
\text { Conditions } \\
\end{array}$ & Comparison of Specification & Actions/Comments \\
\hline Heat Generation & None & $\begin{array}{l}4.1 .13 \\
\text { Appendix A }\end{array}$ & III.11.H.1 & $\begin{array}{l}\text { WTP}- \text { No specific requirement. } \\
\text { IDF WAC - Waste must not generate excess } \\
\text { heat that would compromise container } \\
\text { integrity of contained waste and nearby } \\
\text { waste. Maximum wattage to the geotextile } \\
\text { layers is } 38 \text { watts per square meter. } \\
\text { IDF Permit-Waste packages with elevated } \\
\text { temperatures shall be elevated and managed } \\
\text { to maintain the primary liner below the } \\
\text { design basis temperature }\left(160^{\circ} \mathrm{F}\right) \text {. }\end{array}$ & $\begin{array}{l}\text { Need to dissipate heat of hydration during } \\
\text { curing. }\end{array}$ \\
\hline Free Liquids & 2.2.2.14 & $\begin{array}{l}4.1 .3 \\
\text { Appendix D }\end{array}$ & None & 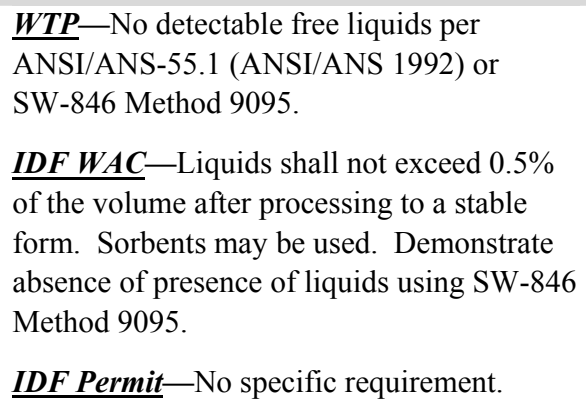 & $\begin{array}{l}\text { Note: DOE G } 435.1-1 \text {, Ch. IV also } \\
\text { recommends use of ANS- } 55.1 \text { for testing of } \\
\text { stabilized waste forms. }\end{array}$ \\
\hline
\end{tabular}




\begin{tabular}{|c|c|c|c|c|c|}
\hline Specification & $\begin{array}{c}\text { WTP } \\
\text { Contract } \\
\text { Specification } \\
\text { 2: ILAW } \\
\text { Product } \\
\text { (M152) }\end{array}$ & $\begin{array}{c}\text { IDFWAC } \\
\text { (RPP-8402 } \\
\text { Rev } 1 \text { Draft) }\end{array}$ & $\begin{array}{c}\text { IDF } \\
\text { Operating } \\
\text { Unit } 11 \\
\text { Unit-Specific } \\
\text { Conditions }\end{array}$ & Comparison of Specification & Actions/Comments \\
\hline $\begin{array}{l}\text { Ignitability, } \\
\text { Pyrophoricity or } \\
\text { Explosivity }\end{array}$ & 2.2 .2 .15 & $\begin{array}{l}4.1 .8 \\
4.1 .9 \\
4.1 .10\end{array}$ & None & 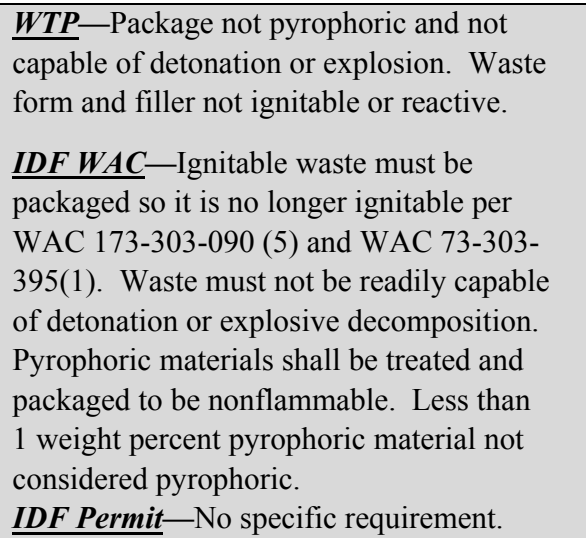 & No action required \\
\hline $\begin{array}{l}\text { Explosive or } \\
\text { Toxic Gases }\end{array}$ & 2.2.2.16 & 4.1 .11 & None & 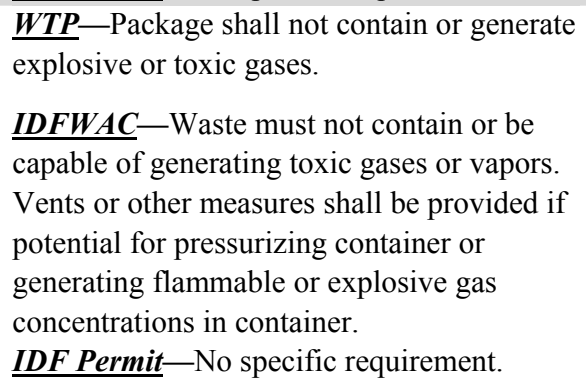 & \\
\hline $\begin{array}{l}\text { Waste Form } \\
\text { Testing }\end{array}$ & 2.2.2.17 & & & is separated into Items 2.2.2.17. & igh 2.2.2.17.3. \\
\hline
\end{tabular}




\begin{tabular}{|c|c|c|c|c|c|}
\hline Specification & $\begin{array}{c}\text { WTP } \\
\text { Contract } \\
\text { Specification } \\
\text { 2: ILAW } \\
\text { Product } \\
\text { (M152) }\end{array}$ & $\begin{array}{c}\text { IDFWAC } \\
\text { (RPP-8402 } \\
\text { Rev } 1 \text { Draft) }\end{array}$ & $\begin{array}{c}\text { IDF } \\
\text { Operating } \\
\text { Unit 11 } \\
\text { Unit-Specific } \\
\text { Conditions }\end{array}$ & Comparison of Specification & Actions/Comments \\
\hline $\begin{array}{l}\text { Leachability } \\
\text { Index }\end{array}$ & 2.2.2.17.1 & 4.2.1.1 & $\begin{array}{l}\text { III.11.1.2 } \\
\text { III.11.1.2.a.i }\end{array}$ & $\begin{array}{l}\text { WTP-This requirement was deleted in } \\
\text { Mod } 041 \text { of the WTP contract. } \\
\text { IDFWAC} \text {-Category } 3 \text { waste stabilized in } \\
\text { concrete or other stabilization agents must } \\
\text { meet leach index criteria in NRC Technical } \\
\text { Position on Waste Form. Leachability index } \\
\text { per ANSI/ANS } 16.1 \text { should be greater than } \\
6 . \\
\text { IDF Permit_-For ILAW to be disposed of in } \\
\text { IDF, an ILAW Waste Form Technical } \\
\text { Requirements Document shall be provided, } \\
\text { including waste form formulation and } \\
\text { characteristics of the waste form that are key } \\
\text { to satisfactory performance (e.g., Vapor } \\
\text { Hydration Test (VHT), PCT, EPA Toxicity } \\
\text { Characteristic Leaching Procedure (TCLP), } \\
\text { and/or other appropriate and necessary } \\
\text { testing methodologies.) }\end{array}$ & $\begin{array}{l}\text { Evaluate need for ANSI/ANS } 16.1 \text { [2003]. } \\
\text { Leachability test for the Cast Stone waste } \\
\text { forms. Also consider EPA } 1315 \text { and ASTM } \\
\text { C1308 methods. }\end{array}$ \\
\hline $\begin{array}{l}\text { Product } \\
\text { Consistency Test }\end{array}$ & 2.2.2.17.2 & None & $\begin{array}{l}\text { III.11.1.2 } \\
\text { III.11.1.2.a.i }\end{array}$ & 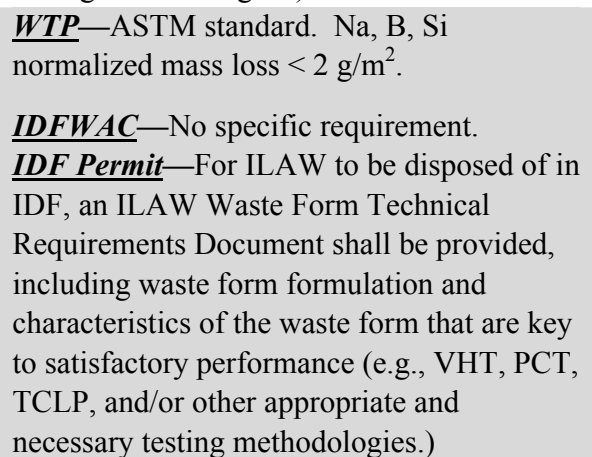 & $\begin{array}{l}\text { Evaluate suitability of PCT for Cast Stone } \\
\text { waste forms. }\end{array}$ \\
\hline
\end{tabular}




\begin{tabular}{|c|c|c|c|c|c|}
\hline Specification & $\begin{array}{c}\text { WTP } \\
\text { Contract } \\
\text { Specification } \\
\text { 2: ILAW } \\
\text { Product } \\
\text { (M152) } \\
\end{array}$ & $\begin{array}{c}\text { IDFWAC } \\
\text { (RPP-8402 } \\
\text { Rev } 1 \text { Draft) }\end{array}$ & $\begin{array}{c}\text { IDF } \\
\text { Operating } \\
\text { Unit 11 } \\
\text { Unit-Specific } \\
\text { Conditions } \\
\end{array}$ & Comparison of Specification & Actions/Comments \\
\hline $\begin{array}{l}\text { Vapor Hydration } \\
\text { Test }\end{array}$ & 2.2.2.17.3 & None & $\begin{array}{l}\text { III.11.1.2 } \\
\text { III.11.1.2.a.i }\end{array}$ & $\begin{array}{l}\frac{\boldsymbol{W T P} \text {-Glass alteration rate }<50 \mathrm{~g} /\left(\mathrm{m}^{2} \mathrm{~d}\right)}{\text { using } 7 \text {-day vapor hydration test at } 200^{\circ} \mathrm{C} .} \\
\underline{\boldsymbol{I D F W A C}} \text {-No specific requirement. } \\
\text { IDF Permit-For ILAW to be disposed of in } \\
\text { IDF, an ILAW Waste Form Technical } \\
\text { Requirements Document shall be provided, } \\
\text { including waste form formulation and } \\
\text { characteristics of the waste form that are key } \\
\text { to satisfactory performance (e.g., VHT, PCT, } \\
\text { TCLP, and/or other appropriate and } \\
\text { necessary testing methodologies.) }\end{array}$ & $\begin{array}{l}\text { Evaluate suitability of VHT for Cast Stone } \\
\text { waste form. }\end{array}$ \\
\hline $\begin{array}{l}\text { Compressive } \\
\text { Strength }\end{array}$ & 2.2.2.18 & $\begin{array}{l}4.1 .4 \\
4.2 .1 .1\end{array}$ & None & 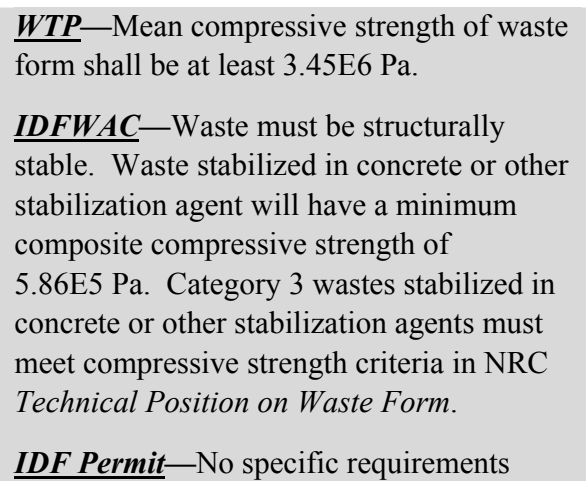 & \\
\hline
\end{tabular}

Radiation,

Biodegradation

Thermal, Radiation, Biodegradation, and Immersion Stability is separated into Items 2.2.2.19.1 through 2.2.2.19.4

and Immersion

2.2.2.19

(Note: this requirement was deleted in Mod 041 of the WTP contract).

Stability 


\begin{tabular}{|c|c|c|c|c|c|}
\hline Specification & $\begin{array}{c}\text { WTP } \\
\text { Contract } \\
\text { Specification } \\
\text { 2: ILAW } \\
\text { Product } \\
\text { (M152) } \\
\end{array}$ & $\begin{array}{c}\text { IDFWAC } \\
\text { (RPP-8402 } \\
\text { Rev 1 Draft) }\end{array}$ & $\begin{array}{c}\text { IDF } \\
\text { Operating } \\
\text { Unit 11 } \\
\text { Unit-Specific } \\
\text { Conditions } \\
\end{array}$ & Comparison of Specification & Actions/Comments \\
\hline $\begin{array}{l}\text { Thermal } \\
\text { Degradation }\end{array}$ & 2.2.2.19.1 & 4.2.1.1 & None & 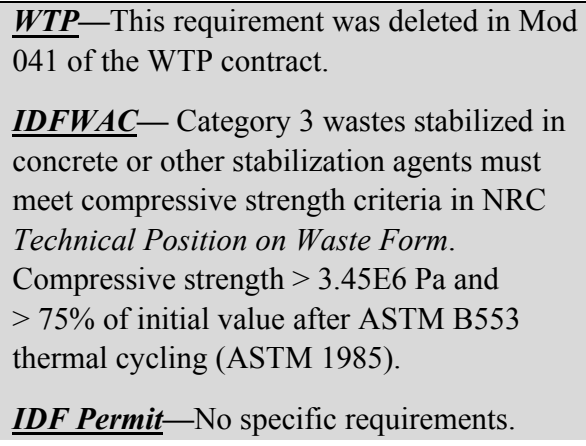 & \\
\hline $\begin{array}{l}\text { Radiation } \\
\text { Degradation }\end{array}$ & 2.2.2.19.2 & 4.2.1.1 & None & 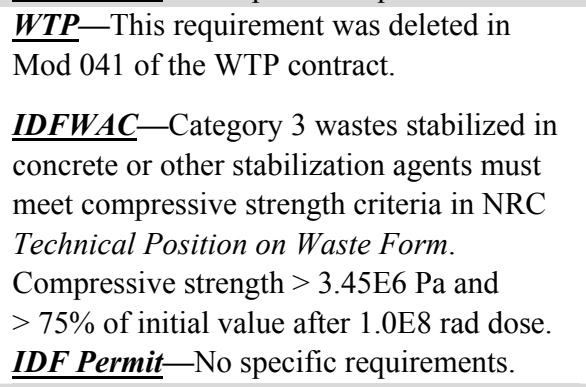 & \\
\hline Biodegradation & 2.2 .2 .19 .3 & 4.2.1.1 & None & 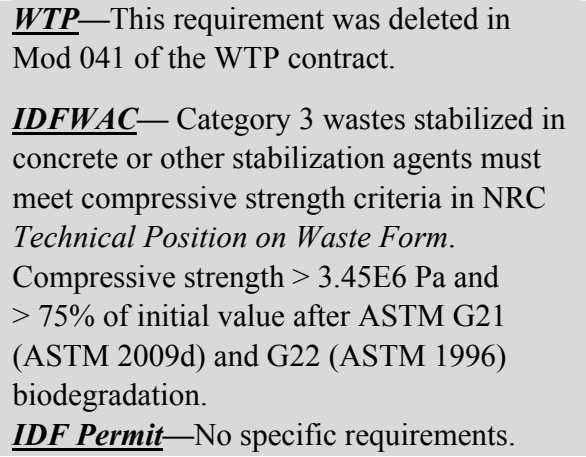 & \\
\hline
\end{tabular}




\begin{tabular}{|c|c|c|c|c|c|}
\hline Specification & $\begin{array}{c}\text { WTP } \\
\text { Contract } \\
\text { Specification } \\
\text { 2: ILAW } \\
\text { Product } \\
\text { (M152) }\end{array}$ & $\begin{array}{c}\text { IDFWAC } \\
\text { (RPP-8402 } \\
\text { Rev } 1 \text { Draft) }\end{array}$ & $\begin{array}{c}\text { IDF } \\
\text { Operating } \\
\text { Unit } 11 \\
\text { Unit-Specific } \\
\text { Conditions }\end{array}$ & Comparison of Specification & Actions/Comments \\
\hline $\begin{array}{l}\text { Immersion } \\
\text { Degradation }\end{array}$ & 2.2.2.19.4 & 4.2.1.1 & None & 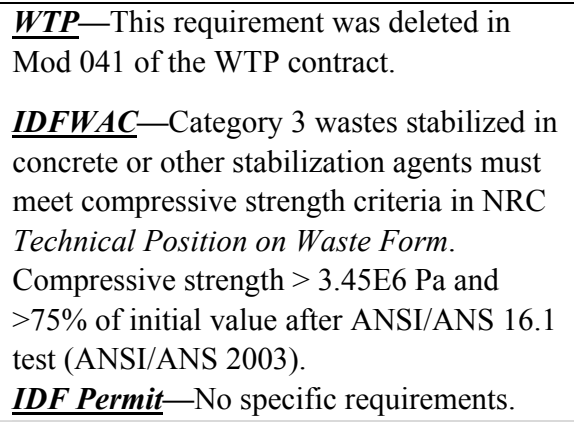 & \\
\hline $\begin{array}{l}\text { Dangerous Waste } \\
\text { Limitations }\end{array}$ & 2.2.2.20 & $\begin{array}{l}4.1 .1 \\
4.1 .2 \\
4.1 .2 .1\end{array}$ & III.11.I.2 & $\begin{array}{l}\text { WTP-ILAW must be acceptable for land } \\
\text { disposal under WAC 173-303 and } \\
40 \text { CFR } 268 . \\
\text { IDFWAC-IDF will accept wastes with } \\
\text { dangerous waste numbers D001, D002, } \\
\text { D003, D004 through D043, state only } \\
\text { (WT01, WT02, WP02, WP03, WSC2 and } \\
\text { W001), and listed waste (F001 through } \\
\text { F012, F019, F028, and F039); and all U and } \\
\text { P dangerous waste numbers. All waste } \\
\text { subject to land disposal restrictions in } \\
40 \text { CFR } 268 \text { and WAC 173-303-140 shall } \\
\text { meet LDR treatment standards. } \\
\text { IDF Permit-The LDR treatment standard } \\
\text { for ILAW is HLVIT (40 CFR 268). }\end{array}$ & $\begin{array}{l}\text { Will require a data quality objectives (DQO) } \\
\text { process and testing to demonstrate the waste } \\
\text { form can meet LDR treatment standards. }\end{array}$ \\
\hline $\begin{array}{l}\text { Compression } \\
\text { Testing }\end{array}$ & 2.2.2.21 & None & None & $\begin{array}{l}\frac{\boldsymbol{W T P}-\text { Package can withstand compression }}{\text { load of } 5 \times \text { the canister. }} \\
\underline{\text { IDFWAC}- \text { No specific requirement. }} \\
\underline{\text { IDF Permit}}-\text { No specific requirement. }\end{array}$ & \\
\hline
\end{tabular}




\begin{tabular}{|c|c|c|c|c|c|}
\hline Specification & $\begin{array}{c}\text { WTP } \\
\text { Contract } \\
\text { Specification } \\
\text { 2: ILAW } \\
\text { Product } \\
\text { (M152) }\end{array}$ & $\begin{array}{c}\text { IDFWAC } \\
\text { (RPP-8402 } \\
\text { Rev } 1 \text { Draft) }\end{array}$ & $\begin{array}{c}\text { IDF } \\
\text { Operating } \\
\text { Unit } 11 \\
\text { Unit-Specific } \\
\text { Conditions }\end{array}$ & Comparison of Specification & Actions/Comments \\
\hline $\begin{array}{l}\text { Container } \\
\text { Material } \\
\text { Degradation }\end{array}$ & 2.2.2.22 & 4.3 .1 & None & $\begin{array}{l}\text { WTP-Container and handling } \\
\text { appurtenances shall be designed for safe } \\
\text { lifting and movement after a storage period } \\
\text { of } 50 \text { years. } \\
\text { IDFWAC-Containers must be made of or } \\
\text { be lined with materials that will not react } \\
\text { with the wastes during handling and storage. } \\
\text { IDF Permit-No specific requirement. }\end{array}$ & Address through container design \\
\hline Manifesting & 2.2 .2 .23 & $\begin{array}{l}2.4 \\
2.5\end{array}$ & None & $\begin{array}{l}\text { WTP_-Shipping manifest consistent with } \\
\text { NUREG/BR-0204 (NRC 1998) and DOE M } \\
\text { 435.1-1 (DOE 2001). } \\
\text { IDFWAC-Uniform Hazardous Waste } \\
\text { Manifest, Land Disposal Restriction } \\
\text { Notification/Certification Form. } \\
\underline{\text { IDF Permit-No specific requirement. }}\end{array}$ & $\begin{array}{l}\text { No action required. All onsite LAW Cast } \\
\text { Stone waste form package transportation will } \\
\text { comply with Hanford requirements. }\end{array}$ \\
\hline $\begin{array}{l}\text { Package } \\
\text { Handling }\end{array}$ & 2.2.3.1 & 4.3 .4 & None & $\begin{array}{l}\text { WTP_Package shall be equipped with } \\
\text { lifting and other handling appurtenances to } \\
\text { allow safe lifting and movement when fully } \\
\text { loaded. } \\
\text { IDFWAC_-Packages must be configured for } \\
\text { safe unloading by forklift, crane, or alternate } \\
\text { means. Packages shall be equipped with } \\
\text { lifting appurtenances for safe handling if } \\
\text { designed for unloading by crane. } \\
\text { IDF Permit-No specific requirement. }\end{array}$ & Address through container design \\
\hline
\end{tabular}




\begin{tabular}{|c|c|c|c|c|c|}
\hline Specification & $\begin{array}{c}\text { WTP } \\
\text { Contract } \\
\text { Specification } \\
\text { 2: ILAW } \\
\text { Product } \\
\text { (M152) } \\
\end{array}$ & $\begin{array}{c}\text { IDFWAC } \\
\text { (RPP-8402 } \\
\text { Rev } 1 \text { Draft) }\end{array}$ & $\begin{array}{c}\text { IDF } \\
\text { Operating } \\
\text { Unit 11 } \\
\text { Unit-Specific } \\
\text { Conditions } \\
\end{array}$ & Comparison of Specification & Actions/Comments \\
\hline $\begin{array}{l}\text { Quality } \\
\text { Assurance }\end{array}$ & 2.3 & 2.1 .1 & $\begin{array}{l}\text { III.11.I.2 } \\
\text { III.11.I.2.a.iii }\end{array}$ & 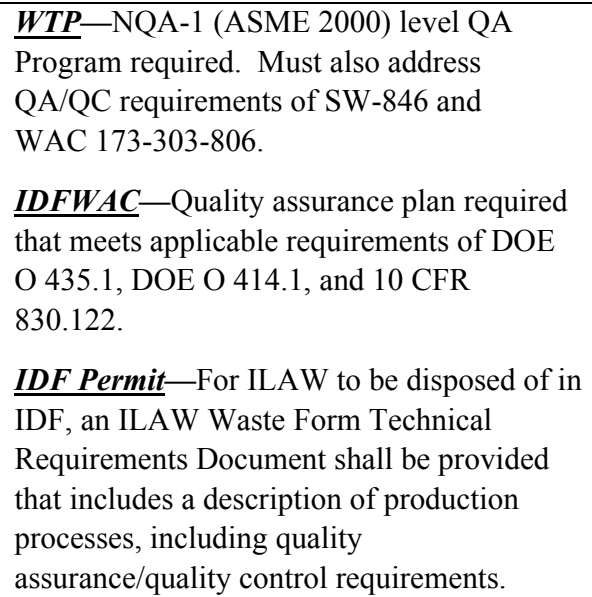 & \\
\hline $\begin{array}{l}\text { Inspection and } \\
\text { Acceptance }\end{array}$ & $\begin{array}{l}2.4 \\
\text { Specification } \\
13\end{array}$ & $\begin{array}{l}2.0 \\
2.1 \\
2.1 .2 \\
2.1 .3 \\
2.1 .4\end{array}$ & III.11.I.3.a & $\begin{array}{l}\text { WTP} \text {-Product inspection and acceptance } \\
\text { process is defined in WTP contract } \\
\text { specification } 13 \text { for the production } \\
\text { operations, referencing the ILAW Product } \\
\text { Compliance Plan. } \\
\text { IDFWAC-Waste acceptance process } \\
\text { includes Waste Certification Program that } \\
\text { includes QA Plan, Implementation } \\
\text { Crosswalk, Waste Certification Officials, } \\
\text { and Waste Profiles. } \\
\text { IDF Permit -Permit to be modified with } \\
\text { inclusion of waste acceptance criteria and } \\
\text { IDF Waste Acceptance Plan. Also requires } \\
\text { ILAW Waste Form Technical Requirements } \\
\text { Document and ILAW Verification Plan. }\end{array}$ & $\begin{array}{l}\text { The waste form qualification (WFQ) Strategy } \\
\text { shall define requirements for a compliance } \\
\text { plan and inspection and acceptance process. }\end{array}$ \\
\hline
\end{tabular}




\section{References}

10 CFR 830. 2010. “Nuclear Safety Management.” Code of Federal Regulations, U.S. Department of Energy.

40 CFR 268. 2010. "Land Disposal Restrictions.” Code of Federal Regulations, U.S. Environmental Protection Agency, Washington, D.C.

ANSI/ANS-American National Standards Institute/American Nuclear Society. 1992. Solid Radioactive Waste Processing System for Light-Water-Cooled Reactor Plants; Appendix B - Testing for Free Liquids in Solidified Matrices. ANSI/ANS-55.1, La Grange Park, Illinois.

ANSI/ANS-American National Standards Institute/American Nuclear Society. 2003. Measurement of the Leachability of Solidified Low-Level Radioactive Waste by a Short-Term Test Procedure. ANSI/ANS-16.1, American Nuclear Society, La Grange Park, Illinois.

ASME_-American Society of Mechanical Engineers. 2000. Quality Assurance Requirements for Nuclear Facility Applications. NQA-1, Washington D.C.

ASTM-American Society for Testing and Materials. 1985. Standard Test Method for Thermocycling of Electroplated Plastics. ASTM B553, ASTM Institute, West Conshohocken, Pennsylvania.

ASTM-American Society for Testing and Materials. 1996. Standard Practice for Determining Resistance of Plastics to Bacteria. ASTM G22, ASTM Institute, West Conshohocken, Pennsylvania.

ASTM - American Society for Testing and Materials. 2009d. Standard Practice for Determining Resistance of Synthetic Polymeric Materials to Fungi. ASTM G21, ASTM Institute, West Conshohocken, Pennsylvania.

DOE_U.S. Department of Energy. 2001. Radioactive Waste Management Manual. DOE M 435.1-1, U.S. Department of Energy, Washington, D.C.

NRC-U.S. Nuclear Regulatory Commission. 1998. Instructions for Completing NRC's Uniform LowLevel Radioactive Waste Manifest. NUREG/BR-0204, U.S. Nuclear Regulatory Commission, Washington, D.C.

WAC - Washington Administrative Code. "Dangerous Waste Regulations." WAC 173-303. Available online at: http://apps.leg.wa.gov/wac/default.aspx?cite=173-303. Accessed 06/17/2010. 


\section{Appendix B}

\section{Low-Activity Waste Cast Stone Waste Form Testing Objectives and Approach Matrix}




\section{Appendix B}

\section{Low-Activity Waste Cast Stone Waste Form Testing Objectives and Approach Matrix}

Table B.1 shows the objectives of the low-activity waste (LAW) Cast Stone test program as outlined in Section 3 of this Supplemental Immobilization Technology Development and Testing Plan. In several cases, the testing objectives in the program plan are further defined to aid in defining the work scope as follows and as discussed in Section 4:

- Provide for Acceptance of Waste Form at the Integrated Disposal Facility (IDF)

- 1.0 Provide for Acceptance of Waste Form at IDF

○ 14.0 Provide Data to Meet Land Disposal Restrictions Requirements

- Optimize Waste Loading

○ 2.0 Optimize Waste Loading

- Demonstrate Waste Form Over Expected Range of Wastes

○ 3.0 Demonstrate Waste Form Over Expected Range of Wastes

- Define and Demonstrate Product Control Strategy

○ 4.0 LAW Cast Stone Waste Immobilization

- Provide Data to Support Risk and Performance Assessments

○ 7.0 Solid-Phase Characterization

○ 8.0 Waste Form Leach Testing

○ 9.0 Waste Package Release Testing

○ 10.0 Physical Stability

- 11.0 Waste Form Release Model

○ 12.0 Batch Adsorption Tests

○ 13.0 Validate PA Predictions

The requirements column in Table B.1 describes the information needed to address the testing objective.

The next three columns in Table B.1 indicate how the LAW should be represented in the testing to address the objective and information requirements. Most of the waste form qualification (WFQ) testing can be conducted with nonradioactive simulants. Some test objectives require some sort of demonstration that the Cast Stone process/waste form is applicable to the entire range of expected waste compositions. Other tests may require only selected representative simulants that highlight or emphasize specific characteristics of the waste that impact the Cast Stone process/waste form. Testing to address land disposal restrictions for the hazardous constituents in the waste, including the Resource Conservation and Recovery Act (RCRA) metals and underlying hazardous constituents and hazardous organic species, need to include simulants with the waste constituents of concern (COCs). Generally, the only testing requiring radioactive simulants is that which addresses retention and release of technetium in the Cast Stone waste 
form. Some testing with actual waste is required for comparison to the simulated waste testing to validate that the simulant tests are representative of the actual wastes.

The Approach/Testing Scale columns in Table B.1 indicate the scale at which the Cast Stone process and waste form testing needs to be conducted.

- Calculation/Analysis: To address the objectives and requirements, calculations and engineering analyses are performed. This may also include literature reviews, design calculations, and computer modeling.

- Laboratory: The Cast Stone waste form is produced on a laboratory scale. Typically 1 to 4 liter batches to prepare smaller test specimens

- Bench/Scale: The Cast Stone product is produced on a bench scale. Typically 4 to 20 liters (1 to 5 gallons) that is then sampled after hardening and curing for characterization

- Pilot Scale: The Cast Stone is produced on a pilot scale. Includes filling scaled to full-size containers

- Full Scale: For this LAW Cast Stone testing plan, "full scale" refers to the production of prototypic Cast Stone waste form packages including any containers. Full-scale testing of the Cast Stone process is not anticipated until system checkout and commissioning of the production facility.

- Production: Some final testing will be required during production operations to complete the Cast Stone WFQ and waste acceptance processes.

Within each of the Approach/Testing columns, the specific tests to be conducted to address the objectives and associated requirements are identified. The characterization tests themselves may be conducted at a laboratory scale, but the materials to be tested need to be produced at the scale indicated. 
Table B.1. Low-Activity Waste Cast Stone Waste Form Testing Objectives and Approach Matrix

\begin{tabular}{|c|c|c|c|c|c|c|c|c|c|c|c|c|}
\hline \multirow[b]{2}{*}{$\begin{array}{l}\text { Activity } \\
\text { ID }\end{array}$} & \multirow[b]{2}{*}{ Objective } & \multirow[b]{2}{*}{ Requirement } & \multicolumn{3}{|c|}{ Waste Type } & \multicolumn{6}{|c|}{ Approach / Testing Scale } & \multirow[b]{2}{*}{ Comments } \\
\hline & & & $\begin{array}{l}\text { Simulant } \\
\text { Non-Rad }\end{array}$ & $\begin{array}{c}\text { Simulant } \\
\text { Rad }\end{array}$ & $\begin{array}{l}\text { Actual } \\
\text { Waste }\end{array}$ & $\begin{array}{l}\text { Calculation/ } \\
\text { Analysis }\end{array}$ & Laboratory & $\begin{array}{c}\text { Bench/ } \\
\text { Engineering }\end{array}$ & Pilot Scale & $\begin{array}{c}\text { Full-Scale } \\
\text { Component } \\
\text { Testing }\end{array}$ & $\begin{array}{l}\text { Production } \\
\text { Hot Operations }\end{array}$ & \\
\hline 1 & Provide fo & r Acceptance of Waste Forr & at IDF & & & & & & & & & \\
\hline 1.1 & & Package Description & & & & & & & & & & $\begin{array}{l}\text { Product/process } \\
\text { description. No } \\
\text { testing required. }\end{array}$ \\
\hline 1.2 & & Waste Loading & $\begin{array}{l}\text { Range of } \\
\text { simulants } \\
\text { representing } \\
\text { variability in } \\
\text { LAW }\end{array}$ & & & & $\begin{array}{l}\text { Determine acceptable } \\
\text { range of dissolved and } \\
\text { undissolved solids in } \\
\text { waste and range of waste } \\
\text { to dry materials }\end{array}$ & $\begin{array}{l}\text { Determine } \\
\text { acceptable } \\
\text { range of } \\
\text { waste to dry } \\
\text { materials }\end{array}$ & $\begin{array}{l}\text { Demonstrate process } \\
\text { control strategy to } \\
\text { achieve waste loading in } \\
\text { Cast Stone waste form }\end{array}$ & & & \\
\hline 1.3 & & Size and Configuration & & & & $\begin{array}{l}\text { Criticality calculation } \\
\text { required for nonstandard } \\
\text { container }\end{array}$ & & & & & & $\begin{array}{l}\text { Product/process } \\
\text { description. No } \\
\text { testing required. }\end{array}$ \\
\hline 1.4 & & Mass & Yes & & & $\begin{array}{l}\text { Calculate maximum } \\
\text { mass using materials } \\
\text { densities. }\end{array}$ & $\begin{array}{l}\text { Measure densities of } \\
\text { waste form and package } \\
\text { materials as needed }\end{array}$ & & Weigh filled containers & $\begin{array}{l}\text { Weigh filled } \\
\text { containers }\end{array}$ & $\begin{array}{l}\text { Weigh filled } \\
\text { containers }\end{array}$ & \\
\hline 1.5 & & Void Space & Yes & & & & & & $\begin{array}{l}\text { Demonstrate control of } \\
\text { fill volume. Examine } \\
\text { filled containers for gross } \\
\text { voids }\end{array}$ & & & \\
\hline 1.6 & & $\begin{array}{l}\text { Chemical Composition } \\
\text { Documentation }\end{array}$ & Yes & & $\begin{array}{l}\text { Chemical } \\
\text { analysis }\end{array}$ & Calculate mass balances. & Chemical analysis & & $\begin{array}{l}\text { Demonstrate process } \\
\text { control of addition and } \\
\text { mixing of waste and dry } \\
\text { materials. Determine } \\
\text { mass balance for } \\
\text { contaminants in Cast } \\
\text { Stone immobilization } \\
\text { system }\end{array}$ & & $\begin{array}{l}\text { Periodic } \\
\text { Chemical } \\
\text { analysis }\end{array}$ & $\begin{array}{l}\text { Details in LAW } \\
\text { Cast Stone Waste } \\
\text { Form Compliance } \\
\text { Plan }\end{array}$ \\
\hline 1.7 & & $\begin{array}{l}\text { Radiological Composition } \\
\text { Documentation }\end{array}$ & & & $\begin{array}{l}\text { Radiochemical } \\
\text { analysis }\end{array}$ & $\begin{array}{l}\text { Calculate mass balances } \\
\text { and inventories using } \\
\text { scaling factors as } \\
\text { necessary. }\end{array}$ & Radiochemical analysis & & $\begin{array}{l}\text { Determine mass balance } \\
\text { for contaminants in Cast } \\
\text { Stone immobilization } \\
\text { system }\end{array}$ & & $\begin{array}{l}\text { Periodic } \\
\text { Radiochemical } \\
\text { analysis }\end{array}$ & \\
\hline 1.8 & & $\begin{array}{l}\text { Radionuclide } \\
\text { Concentration Limitations }\end{array}$ & & & & $\begin{array}{l}\text { Calculate } \\
\text { dose-equivalent curies } \\
\text { and fissile gram } \\
\text { equivalents based on } \\
\text { radiochemical } \\
\text { composition } \\
\text { determination. }\end{array}$ & & & & & & $\begin{array}{l}\text { Compliance } \\
\text { through } \\
\text { administrative } \\
\text { controls and } \\
\text { calculations based } \\
\text { on radiochemical } \\
\text { composition }\end{array}$ \\
\hline 1.9 & & $\begin{array}{l}\text { Surface Dose Rate } \\
\text { Limitations }\end{array}$ & & & & $\begin{array}{l}\text { Calculate maximum } \\
\text { surface dose based on } \\
\text { expected maximum } \\
\text { radionuclide } \\
\text { composition. }\end{array}$ & & & & & $\begin{array}{l}\text { Measure surface } \\
\text { dose of } \\
\text { production } \\
\text { packages }\end{array}$ & \\
\hline
\end{tabular}




\begin{tabular}{|c|c|c|c|c|c|c|c|c|c|c|c|c|}
\hline \multirow[b]{2}{*}{$\begin{array}{c}\text { Activity } \\
\text { ID }\end{array}$} & \multirow[b]{2}{*}{ Objective } & \multirow[b]{2}{*}{ Requirement } & \multicolumn{3}{|c|}{ Waste Type } & \multicolumn{6}{|c|}{ Approach / Testing Scale } & \multirow[b]{2}{*}{ Comment: } \\
\hline & & & $\begin{array}{r}\text { Simulant } \\
\text { Non-Rad } \\
\end{array}$ & $\begin{array}{c}\text { Simulant } \\
\text { Rad }\end{array}$ & $\begin{array}{l}\text { Actual } \\
\text { Waste }\end{array}$ & $\begin{array}{l}\text { Calculation/ } \\
\text { Analysis }\end{array}$ & Laboratory & $\begin{array}{c}\text { Bench/ } \\
\text { Engineering }\end{array}$ & Pilot Scale & $\begin{array}{c}\text { Full-Scale } \\
\text { Component } \\
\text { Testing } \\
\end{array}$ & $\begin{array}{c}\text { Production } \\
\text { Hot Operations } \\
\end{array}$ & \\
\hline 1.10 & & $\begin{array}{l}\text { Surface Contamination } \\
\text { Limitations }\end{array}$ & & & & & & & $\begin{array}{l}\text { Demonstrate control of } \\
\text { container filling to } \\
\text { prevent/minimize } \\
\text { spillage outside } \\
\text { container. }\end{array}$ & & $\begin{array}{l}\text { Swab } \\
\text { production } \\
\text { packages to } \\
\text { determine level } \\
\text { of surface } \\
\text { contamination. }\end{array}$ & \\
\hline 1.11 & & Labeling & & & & & & & & $\begin{array}{l}\text { Demonstrate } \\
\text { label on full- } \\
\text { scale prototypic } \\
\text { container. }\end{array}$ & & \\
\hline 1.12 & & Closure \& Sealing & & & & & & & & $\begin{array}{l}\text { Demonstrate } \\
\text { container } \\
\text { closure and } \\
\text { sealing on full- } \\
\text { scale prototype. }\end{array}$ & & \\
\hline 1.13 & & $\begin{array}{l}\text { Heat Generation and } \\
\text { External Temperature }\end{array}$ & Yes & & & $\begin{array}{l}\text { Calculate radiogenic } \\
\text { heat from maximum } \\
\text { estimated radionuclide } \\
\text { inventory. Calculate } \\
\text { temperature profile from } \\
\text { heat of reactions and } \\
\text { radiogenic heat. }\end{array}$ & $\begin{array}{l}\text { Measure heat of reaction } \\
\text { in calorimeter. }\end{array}$ & & $\begin{array}{l}\text { Measure temperature } \\
\text { profile and cooling curve } \\
\text { of scaled container being } \\
\text { filled and cured. }\end{array}$ & & & \\
\hline 1.14 & & Free Liquids & Yes & & & & $\begin{array}{l}\text { Determine dry materials } \\
\text { and the mix ratios of } \\
\text { waste to dry materials to } \\
\text { minimize free liquids. }\end{array}$ & & $\begin{array}{l}\text { Demonstrate control of } \\
\text { dry materials and the mix } \\
\text { ratios of waste to dry } \\
\text { materials. Examine } \\
\text { filled containers for free } \\
\text { liquids. }\end{array}$ & $\begin{array}{l}\text { Demonstrate } \\
\text { control of dry } \\
\text { materials and } \\
\text { the mix ratios of } \\
\text { waste to dry } \\
\text { materials. } \\
\text { Examine filled } \\
\text { containers for } \\
\text { free liquids. }\end{array}$ & $\begin{array}{l}\text { Examine filled } \\
\text { containers for } \\
\text { free liquids. }\end{array}$ & \\
\hline 1.15 & & $\begin{array}{l}\text { Pyrophoricity or } \\
\text { Explosivity }\end{array}$ & & & & $\begin{array}{l}\text { Engineering analysis to } \\
\text { demonstrate Cast Stone } \\
\text { and inert filler are not } \\
\text { pyrophoric, explosive, or } \\
\text { ignitable }\end{array}$ & $\begin{array}{l}\text { Demonstrate Cast Stone } \\
\text { with organics is not } \\
\text { pyrophoric or explosive }\end{array}$ & & & & & \\
\hline 1.16 & & Explosive or Toxic Gases & & & & $\begin{array}{l}\text { Engineering analysis to } \\
\text { demonstrate that Cast } \\
\text { Stone and inert filler do } \\
\text { not generate explosive or } \\
\text { toxic gases. }\end{array}$ & & & & & & \\
\hline
\end{tabular}




\begin{tabular}{|c|c|c|c|c|c|c|c|c|c|c|c|c|}
\hline \multirow[b]{2}{*}{$\begin{array}{c}\text { Activity } \\
\text { ID }\end{array}$} & \multirow[b]{2}{*}{ Objective } & \multirow[b]{2}{*}{ Requirement } & \multicolumn{3}{|c|}{ Waste Type } & \multicolumn{6}{|c|}{ Approach / Testing Scale } & \multirow[b]{2}{*}{ Comments } \\
\hline & & & $\begin{array}{l}\text { Simulant } \\
\text { Non-Rad }\end{array}$ & $\begin{array}{c}\text { Simulant } \\
\text { Rad }\end{array}$ & $\begin{array}{l}\text { Actual } \\
\text { Waste }\end{array}$ & $\begin{array}{l}\text { Calculation/ } \\
\text { Analysis }\end{array}$ & Laboratory & $\begin{array}{c}\text { Bench/ } \\
\text { Engineering }\end{array}$ & Pilot Scale & $\begin{array}{c}\text { Full-Scale } \\
\text { Component } \\
\text { Testing }\end{array}$ & $\begin{array}{l}\text { Production } \\
\text { Hot Operations }\end{array}$ & \\
\hline 1.17 & & Waste Form Testing & $\begin{array}{l}\text { Selected } \\
\text { representative } \\
\text { simulants }\end{array}$ & Tc Spike & & $\begin{array}{l}\text { Evaluate applicability of } \\
\text { PCT, vapor hydration } \\
\text { test (VHT), MCC-1, } \\
\text { PUF, SPFT, and EPA } \\
\text { methods } 1313,1314, \\
1315, \text { and/or } 1316 \text { to } \\
\text { characterize release of } \\
\text { contaminants from Cast } \\
\text { Stone waste form. }\end{array}$ & & & & & & $\begin{array}{l}\text { Identify one or } \\
\text { more methods } \\
\text { indicative of Cast } \\
\text { Stone waste form } \\
\text { performance and } \\
\text { quality as basis for } \\
\text { waste form } \\
\text { specification }\end{array}$ \\
\hline 1.18 & & Leachability Index & $\begin{array}{l}\text { Selected } \\
\text { representative } \\
\text { simulants }\end{array}$ & Tc spike & $\begin{array}{l}\text { Selected } \\
\text { representative } \\
\text { actual waste } \\
\text { samples }\end{array}$ & & $\begin{array}{l}\text { ANSI/ANS16.1 [2003] } \\
\text { Leachability Index test on } \\
2 \text {-in diameter } \times 4 \text {-inch tall } \\
\text { Cast Stone waste form } \\
\text { cylinders }\end{array}$ & & $\begin{array}{l}\text { ANSI/ANS16.1 } \\
\text { Leachability Index test } \\
\text { on } 2 \text {-in. diameter } \times 4 \text {-in. } \\
\text { tall Cast Stone waste } \\
\text { form cylinders }\end{array}$ & & & $\begin{array}{l}\text { Consider EPA } \\
1315 \text { and ASTM } \\
\text { C1308 as } \\
\text { alternative test } \\
\text { methods }\end{array}$ \\
\hline 1.19 & & Product Consistency Test & $\begin{array}{l}\text { Selected } \\
\text { representative } \\
\text { simulants }\end{array}$ & Tc spike & $\begin{array}{l}\text { Selected } \\
\text { representative } \\
\text { actual waste } \\
\text { samples }\end{array}$ & $\begin{array}{l}\text { Evaluate applicability of } \\
\text { test method }\end{array}$ & $\begin{array}{l}\text { PCT per ASTM C1285 } \\
\text { (2008a) - if applicable }\end{array}$ & & $\begin{array}{l}\text { PCT per ASTM C1285- } \\
\text { if applicable }\end{array}$ & & & $\begin{array}{l}\text { PCT as a } \\
\text { specification for } \\
\text { Cast Stone waste } \\
\text { form needs to be } \\
\text { evaluated }\end{array}$ \\
\hline 1.20 & & Vapor Hydration Test & $\begin{array}{l}\text { Selected } \\
\text { representative } \\
\text { simulants }\end{array}$ & & & $\begin{array}{l}\text { Evaluate applicability of } \\
\text { test method }\end{array}$ & $\begin{array}{l}\text { VHT per ASTM C1663 } \\
\text { (2009b) - if applicable }\end{array}$ & & $\begin{array}{l}\text { VHT per ASTM C1663 - } \\
\text { if applicable }\end{array}$ & & & $\begin{array}{l}\text { VHT as a } \\
\text { specification for } \\
\text { Cast Stone waste } \\
\text { form needs to be } \\
\text { evaluated }\end{array}$ \\
\hline 1.21 & & Compressive Strength & $\begin{array}{l}\text { Selected } \\
\text { representative } \\
\text { simulants }\end{array}$ & & & & $\begin{array}{l}\text { Measure compressive } \\
\text { strength on 2-in diameter } \\
\times 4 \text {-in. tall Cast Stone } \\
\text { waste form cylinders. } \\
\text { ASTM C39/C39M } \\
\text { (2009a). }\end{array}$ & & & & & \\
\hline 1.22 & & $\begin{array}{l}\text { Thermal, Radiation, } \\
\text { Biodegradation, and } \\
\text { Immersion Stability }\end{array}$ & $\begin{array}{l}\text { Selected } \\
\text { representative } \\
\text { simulants }\end{array}$ & & & & $\begin{array}{l}\text { Measure compressive } \\
\text { strength (ASTM } \\
\text { C39/C39M) on Cast Stone } \\
\text { waste form cylinders after } \\
\text { thermal cycling (ASTM } \\
\text { B553 [1985]), } \\
\text { biodegradation (ASTM } \\
\text { G21 [2009d], ASTM G22 } \\
\text { [1996]), irradiation, and } \\
\text { water immersion tests } \\
\text { (ANSI/ANS } 16.1 \text { [2003]) }\end{array}$ & & & & & \\
\hline 1.23 & & Dangerous Waste & & & & & & & & & & $\begin{array}{l}\text { See \#14 Land } \\
\text { Disposal } \\
\text { Restrictions below }\end{array}$ \\
\hline
\end{tabular}




\begin{tabular}{|c|c|c|c|c|c|c|c|c|c|c|c|c|}
\hline \multirow[b]{2}{*}{$\begin{array}{l}\text { Activity } \\
\text { ID }\end{array}$} & \multirow[b]{2}{*}{ Objective } & \multirow[b]{2}{*}{ Requirement } & \multicolumn{3}{|c|}{ Waste Type } & \multicolumn{6}{|c|}{ Approach / Testing Scale } & \multirow[b]{2}{*}{ Comments } \\
\hline & & & $\begin{array}{l}\text { Simulant } \\
\text { Non-Rad }\end{array}$ & $\begin{array}{l}\text { Simulant } \\
\text { Rad }\end{array}$ & $\begin{array}{l}\text { Actual } \\
\text { Waste }\end{array}$ & $\begin{array}{l}\text { Calculation/ } \\
\text { Analysis }\end{array}$ & Laboratory & $\begin{array}{c}\text { Bench/ } \\
\text { Engineering }\end{array}$ & Pilot Scale & $\begin{array}{c}\text { Full-Scale } \\
\text { Component } \\
\text { Testing }\end{array}$ & $\begin{array}{l}\text { Production } \\
\text { Hot Operations }\end{array}$ & \\
\hline 1.24 & & Compression Testing & & & & $\begin{array}{l}\text { Conduct engineering } \\
\text { calculations to } \\
\text { demonstrate compliance } \\
\text { with package integrity } \\
\text { and handling } \\
\text { requirements. }\end{array}$ & & & & & & \\
\hline 1.25 & & $\begin{array}{l}\text { Container Material } \\
\text { Degradation }\end{array}$ & & & & $\begin{array}{l}\text { Conduct engineering } \\
\text { calculations to } \\
\text { demonstrate compliance } \\
\text { with package integrity } \\
\text { and handling } \\
\text { requirements. }\end{array}$ & $\begin{array}{l}\text { Cast Stone interactions } \\
\text { with waste form container } \\
\text { studies }\end{array}$ & & 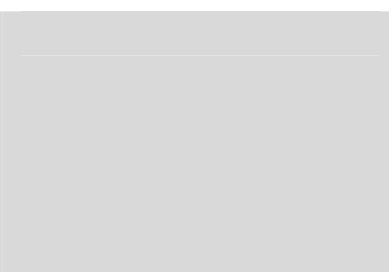 & $\begin{array}{l}\text { Demonstrate } \\
\text { container lifting } \\
\text { and handling on } \\
\text { full-scale } \\
\text { prototype }\end{array}$ & & \\
\hline 1.26 & & Manifesting & & & & & & & & & & $\begin{array}{l}\text { Documentation } \\
\text { activity. No testing } \\
\text { required }\end{array}$ \\
\hline 1.27 & & Package Handling & & & & $\begin{array}{l}\text { Conduct engineering } \\
\text { calculations to } \\
\text { demonstrate compliance } \\
\text { with package integrity } \\
\text { and handling } \\
\text { requirements. }\end{array}$ & & & & $\begin{array}{l}\text { Demonstrate } \\
\text { container lifting } \\
\text { and handling on } \\
\text { full-scale } \\
\text { prototype }\end{array}$ & & \\
\hline 2 & Optimize & Waste Loading & & & & & & & & & & \\
\hline 2.1 & & $\begin{array}{l}\text { Optimize waste loading in } \\
\text { LAW Cast Stone waste } \\
\text { form product }\end{array}$ & $\begin{array}{l}\text { Range of } \\
\text { simulants } \\
\text { representing } \\
\text { variability in } \\
\text { LAW }\end{array}$ & Tc spike & & & $\begin{array}{l}\text { Determine acceptable } \\
\text { range of dissolved and } \\
\text { undissolved solids in } \\
\text { waste and range of waste } \\
\text { to dry materials. } \\
\text { Tc diffusivity using } \\
\text { ANSI/ANS 16.1 [2003], } \\
\text { EPA 1315, or ASTM } \\
\text { C1308 [2008b]. } \\
\text { Compressive strength } \\
\text { using ASTM C39/C39M } \\
\text { (2009a). } \\
\text { Rheology, Heat of } \\
\text { hydration }\end{array}$ & & $\begin{array}{l}\text { Determine acceptable } \\
\text { range of process } \\
\text { parameters for target } \\
\text { Cast Stone formation } \\
\text { Diagnostic leach test (see } \\
1.17 \text { Waste Form } \\
\text { Testing) that compares } \\
\text { leaching of key major } \\
\text { components and mobile } \\
\text { contaminants (Tc) vs. } \\
\text { loading. XRD, } \\
\text { SEM/TEM, other } \\
\text { characterization methods } \\
\text { indicative of Cast Stone } \\
\text { performance } \\
\text { Mixing, pumpability, } \\
\text { flowability into } \\
\text { container. }\end{array}$ & & & \\
\hline
\end{tabular}




\begin{tabular}{|c|c|c|c|c|c|c|c|c|c|c|c|c|}
\hline \multirow[b]{2}{*}{$\begin{array}{l}\text { Activity } \\
\text { ID }\end{array}$} & \multirow[b]{2}{*}{ Objective } & \multirow[b]{2}{*}{ Requirement } & \multicolumn{3}{|c|}{ Waste Type } & \multirow[b]{2}{*}{$\begin{array}{l}\text { Calculation/ } \\
\text { Analysis }\end{array}$} & \multicolumn{3}{|c|}{ Approach / Testing Scale } & \multirow[b]{2}{*}{$\begin{array}{c}\text { Full-Scale } \\
\text { Component } \\
\text { Testing } \\
\end{array}$} & \multirow[b]{2}{*}{$\begin{array}{c}\text { Production } \\
\text { Hot Operations }\end{array}$} & \multirow[b]{2}{*}{ Comments } \\
\hline & & & $\begin{array}{l}\text { Simulant } \\
\text { Non-Rad }\end{array}$ & $\begin{array}{l}\text { Simulant } \\
\text { Rad }\end{array}$ & $\begin{array}{l}\text { Actual } \\
\text { Waste }\end{array}$ & & Laboratory & $\begin{array}{c}\text { Bench/ } \\
\text { Engineering }\end{array}$ & Pilot Scale & & & \\
\hline 3 & Demonstr: & te Waste Form Over Expe & ed Range of W & & & & & & & & & \\
\hline 3.1 & & $\begin{array}{l}\text { Understand how range in } \\
\text { waste compositions affects } \\
\text { Cast Stone process }\end{array}$ & $\begin{array}{l}\text { Range of } \\
\text { simulants } \\
\text { representing } \\
\text { variability in } \\
\text { LAW }\end{array}$ & Tc spike & & & $\begin{array}{l}\text { Diagnostic leach test (see } \\
1.17 \text { Waste Form Testing) } \\
\text { that compares leaching of } \\
\text { key major components } \\
\text { and mobile contaminants } \\
\text { (Tc) vs. loading. XRD, } \\
\text { SEM/TEM, other } \\
\text { characterization methods } \\
\text { indicative of Cast Stone } \\
\text { performance }\end{array}$ & & $\begin{array}{l}\text { Diagnostic leach test (see } \\
1.17 \text { Waste Form } \\
\text { Testing) that compares } \\
\text { leaching of key major } \\
\text { components and mobile } \\
\text { contaminants (Tc) vs. } \\
\text { loading. XRD, } \\
\text { SEM/TEM, other } \\
\text { characterization methods } \\
\text { indicative of Cast Stone } \\
\text { performance }\end{array}$ & & & \\
\hline 3.2 & & $\begin{array}{l}\text { Demonstrate Cast Stone } \\
\text { process sufficiently robust } \\
\text { to handle waste variability }\end{array}$ & $\begin{array}{l}\text { Range of } \\
\text { simulants } \\
\text { representing } \\
\text { variability in } \\
\text { LAW }\end{array}$ & Tc Spike & & & $\begin{array}{l}\text { Diagnostic leach test (see } \\
1.17 \text { Waste Form Testing) } \\
\text { that compares leaching of } \\
\text { key major components } \\
\text { and mobile contaminants } \\
\text { (Tc) vs. loading. XRD, } \\
\text { SEM/TEM, other } \\
\text { characterization methods } \\
\text { indicative of Cast Stone } \\
\text { performance }\end{array}$ & & $\begin{array}{l}\text { Diagnostic leach test (see } \\
1.17 \text { Waste Form } \\
\text { Testing) that compares } \\
\text { leaching of key major } \\
\text { components and mobile } \\
\text { contaminants (Tc) vs. } \\
\text { loading. XRD, } \\
\text { SEM/TEM, other } \\
\text { characterization methods } \\
\text { indicative of Cast Stone } \\
\text { performance }\end{array}$ & & & \\
\hline 3.3 & & $\begin{array}{l}\text { Identify impactful waste } \\
\text { components on Cast Stone } \\
\text { waste form product }\end{array}$ & $\begin{array}{l}\text { Range of } \\
\text { simulants } \\
\text { representing } \\
\text { variability in } \\
\text { LAW }\end{array}$ & $\begin{array}{l}\text { Alpha } \\
\text { radionuclide } \\
\text { spike }\end{array}$ & & & $\begin{array}{l}\text { Diagnostic leach test (see } \\
1.17 \text { Waste Form Testing) } \\
\text { that compares leaching of } \\
\text { key major components } \\
\text { and mobile contaminants } \\
\text { (Tc) vs. loading. XRD, } \\
\text { SEM/TEM, other } \\
\text { characterization methods } \\
\text { indicative of Cast Stone } \\
\text { performance, Alpha } \\
\text { radiation damage }\end{array}$ & & & & & \\
\hline
\end{tabular}




\begin{tabular}{|c|c|c|c|c|c|c|c|c|c|c|c|c|}
\hline \multirow[b]{2}{*}{$\begin{array}{l}\text { Activity } \\
\text { ID }\end{array}$} & \multirow[b]{2}{*}{ Objective } & \multirow[b]{2}{*}{ Requirement } & \multicolumn{3}{|c|}{ Waste Type } & \multicolumn{6}{|c|}{ Approach / Testing Scale } & \multirow[b]{2}{*}{ Comments } \\
\hline & & & $\begin{array}{l}\text { Simulant } \\
\text { Non-Rad }\end{array}$ & $\begin{array}{l}\text { Simulant } \\
\text { Rad }\end{array}$ & $\begin{array}{l}\text { Actual } \\
\text { Waste }\end{array}$ & $\begin{array}{l}\text { Calculation/ } \\
\text { Analysis }\end{array}$ & Laboratory & $\begin{array}{c}\text { Bench/ } \\
\text { Engineering }\end{array}$ & Pilot Scale & $\begin{array}{c}\text { Full-Scale } \\
\text { Component } \\
\text { Testing }\end{array}$ & $\begin{array}{c}\text { Production } \\
\text { Hot Operations }\end{array}$ & \\
\hline 5 & Define \& I & emonstrate Product Contr & Strategy - LA & ast Stone W & Imobiliz: & Process & & & & & & \\
\hline 5.1 & & $\begin{array}{l}\text { Demonstrate Cast Stone } \\
\text { Operating Envelope }\end{array}$ & $\begin{array}{l}\text { Selected } \\
\text { representative } \\
\text { simulants }\end{array}$ & & & & $\begin{array}{l}\text { Determine acceptable } \\
\text { range of mix ratios of } \\
\text { waste to dry materials. Tc } \\
\text { diffusivity using } \\
\text { ANSI/ANS 16.1, EPA } \\
\text { 1315, or ASTM C1308 } \\
\text { (2008b). Compressive } \\
\text { strength using ASTM } \\
\text { C39/C39M (2009a). } \\
\text { Rheology }\end{array}$ & & $\begin{array}{l}\text { Mixing, pumpability, } \\
\text { flowability into } \\
\text { container. } \\
\text { Porosity, pore size, } \\
\text { voids, tortuosity }\end{array}$ & & & $\begin{array}{l}\text { Verify operating } \\
\text { envelope } \\
\text { Validate control } \\
\text { strategy }\end{array}$ \\
\hline 5.2 & & $\begin{array}{l}\text { Identify product control } \\
\text { parameters }\end{array}$ & & & & $\begin{array}{l}\text { Engineering analysis to } \\
\text { determine control } \\
\text { parameters }\end{array}$ & & & & & & \\
\hline 5.3 & & $\begin{array}{l}\text { Determine process } \\
\text { parameter control range } \\
\text { e.g., blend ratios, particle } \\
\text { size distribution and } \\
\text { variability }\end{array}$ & $\begin{array}{l}\text { Selected } \\
\text { representative } \\
\text { simulants }\end{array}$ & & & & $\begin{array}{l}\text { Determine acceptable } \\
\text { range of mix ratios of } \\
\text { waste to dry materials. Tc } \\
\text { diffusivity using } \\
\text { ANSI/ANS 16.1, EPA } \\
\text { 1315, or ASTM C1308. } \\
\text { Compressive strength } \\
\text { using ASTM C39/C39M. } \\
\text { Rheology }\end{array}$ & & $\begin{array}{l}\text { Determine waste form } \\
\text { process parameter } \\
\text { control ranges. } \\
\text { Mixing, pumpability, } \\
\text { flowability into } \\
\text { container. Fill-height } \\
\text { control. } \\
\text { Tc diffusivity using } \\
\text { ANSI/ANS 16.1, EPA } \\
\text { 1315, or ASTM C1308. } \\
\text { Compressive strength } \\
\text { using ASTM C39/C39M. } \\
\text { Rheology } \\
\text { Particle size distribution }\end{array}$ & & & $\begin{array}{l}\text { Temperature, } \\
\text { measure of mixing } \\
\text { effectiveness }\end{array}$ \\
\hline 5.4 & & $\begin{array}{l}\text { Demonstrate mixing waste } \\
\text { and dry materials together }\end{array}$ & $\begin{array}{l}\text { Selected } \\
\text { representative } \\
\text { simulants }\end{array}$ & & & & & & $\begin{array}{l}\text { Demonstrate final waste } \\
\text { form processing on pilot } \\
\text { scale } \\
\text { Mixing, pumpability, } \\
\text { flowability into } \\
\text { container. Fill-height } \\
\text { control. } \\
\text { Porosity, pore size, } \\
\text { voids, tortuosity }\end{array}$ & & & $\begin{array}{l}\text { Dusting, mixing, } \\
\text { waste form control, } \\
\text { pouring, moisture } \\
\text { control, particle } \\
\text { distribution? }\end{array}$ \\
\hline
\end{tabular}




\begin{tabular}{|c|c|c|c|c|c|c|c|c|c|c|c|c|}
\hline \multirow[b]{2}{*}{$\begin{array}{l}\text { Activity } \\
\text { ID }\end{array}$} & \multirow[b]{2}{*}{ Objective } & \multirow[b]{2}{*}{ Requirement } & \multicolumn{3}{|c|}{ Waste Type } & \multicolumn{6}{|c|}{ Approach / Testing Scale } & \multirow[b]{2}{*}{ Comments } \\
\hline & & & $\begin{array}{l}\text { Simulant } \\
\text { Non-Rad }\end{array}$ & $\begin{array}{l}\text { Simulant } \\
\quad \operatorname{Rad}\end{array}$ & $\begin{array}{l}\text { Actual } \\
\text { Waste }\end{array}$ & $\begin{array}{l}\text { Calculation/ } \\
\text { Analysis }\end{array}$ & Laboratory & $\begin{array}{c}\text { Bench/ } \\
\text { Engineering }\end{array}$ & Pilot Scale & $\begin{array}{l}\text { Full-Scale } \\
\text { Component } \\
\text { Testing } \\
\end{array}$ & $\begin{array}{l}\text { Production } \\
\text { Hot Operations }\end{array}$ & \\
\hline 5.5 & & $\begin{array}{l}\text { Determine acceptable cure } \\
\text { time, temperature, } \\
\text { humidity conditions }\end{array}$ & $\begin{array}{l}\text { Selected } \\
\text { representative } \\
\text { simulants }\end{array}$ & & & & & & $\begin{array}{l}\text { Determine waste form } \\
\text { cure parameters and } \\
\text { acceptable cure } \\
\text { conditions. } \\
\text { Tc diffusivity using } \\
\text { ANSI/ANS 16.1, EPA } \\
\text { 1315, or ASTM C1308. } \\
\text { Compressive strength } \\
\text { using ASTM C39/C39M. } \\
\text { Porosity, pore size, } \\
\text { voids, tortuosity }\end{array}$ & & & \\
\hline 6 & \multicolumn{12}{|l|}{ Reserved } \\
\hline 7 & \multicolumn{12}{|c|}{ Provide Data to Support Risk and Performance Assessments - Solid-Phase Characterization (coordinate with HQ initiative) } \\
\hline 7.1 & & $\begin{array}{l}\text { Identify Tc speciation } \\
\text { (REDOX) and location } \\
\text { within Cast Stone solid } \\
\text { and pore-water phases }\end{array}$ & & $\begin{array}{l}\text { Tc spiked; } \\
\text { Selected } \\
\text { representative } \\
\text { simulants }\end{array}$ & $\begin{array}{l}\text { Selected actual } \\
\text { wastes }\end{array}$ & & $\begin{array}{l}\text { Use XAS (XANES, } \\
\text { XAFS), micro-XRF, } \\
\text { STEM-EDS }\end{array}$ & & & & & \\
\hline 7.2 & & $\begin{array}{l}\text { Identify iodine speciation } \\
\text { and location within Cast } \\
\text { Stone solid and pore-water } \\
\text { phases }\end{array}$ & $\begin{array}{l}\text { Stable I spiked; } \\
\text { Selected } \\
\text { representative } \\
\text { simulants }\end{array}$ & & $\begin{array}{l}\text { Selected actual } \\
\text { wastes }\end{array}$ & & $\begin{array}{l}\text { Use XAS (XANES, } \\
\text { XAFS), micro-XRF, } \\
\text { STEM-EDS }\end{array}$ & & & & & \\
\hline 7.3 & & $\begin{array}{l}\text { Determine Cast Stone } \\
\text { product mineralogy }\end{array}$ & $\begin{array}{l}\text { Selected } \\
\text { representative } \\
\text { simulants }\end{array}$ & & $\begin{array}{l}\text { Selected actual } \\
\text { wastes }\end{array}$ & & XRD, SEM-EDS, TEM & & & & & \\
\hline \multicolumn{13}{|l|}{7.4} \\
\hline 7.5 & & $\begin{array}{l}\text { Determine redox capacity } \\
\text { of Cast Stone dry } \\
\text { materials and waste form } \\
\text { product }\end{array}$ & $\begin{array}{l}\text { Selected } \\
\text { representative } \\
\text { simulants }\end{array}$ & & & & $\begin{array}{l}\text { Cerium(IV) oxidant } \\
\text { (Angus and Glasser 1985) } \\
\text { and chromium (VI) } \\
\text { oxidant (Lee and } \\
\text { Batchelor 2003) }\end{array}$ & & & & & \\
\hline 7.6 & & $\begin{array}{l}\text { Determine porosity and } \\
\text { pore size of Cast Stone }\end{array}$ & $\begin{array}{l}\text { Selected } \\
\text { representative } \\
\text { simulants }\end{array}$ & & & & $\begin{array}{l}\text { SEM, microtomography, } \\
\text { Hg intrusion, gas } \\
\text { adsorption BET }\end{array}$ & & $\begin{array}{l}\text { SEM, microtomography, } \\
\text { Hg intrusion, gas } \\
\text { adsorption BET }\end{array}$ & $\begin{array}{l}\text { SEM, micro- } \\
\text { tomography, Hg } \\
\text { intrusion, gas } \\
\text { adsorption BET }\end{array}$ & & \\
\hline 8 & \multicolumn{12}{|c|}{ Provide Data to Support Risk and Performance Assessments - Waste Form Leach Testing (coordinate with HQ initiative) } \\
\hline 8.1 & & $\begin{array}{l}\text { Identify release } \\
\text { mechanisms for waste } \\
\text { components }\end{array}$ & $\begin{array}{l}\text { Selected } \\
\text { representative } \\
\text { simulants }\end{array}$ & Tc spike & & $\begin{array}{l}\text { Use a combination of } \\
\text { solids analysis, results } \\
\text { from various leach tests } \\
\text { on non-rad and } \\
\text { Tc-spiked } \\
\text { simulant-generated Cast } \\
\text { Stone and geochemical } \\
\text { speciation codes. }\end{array}$ & $\begin{array}{l}\text { As applicable, conduct } \\
\text { PCT, VHT, Leachability } \\
\text { Index, ASTM C1308, } \\
\text { MCC-1, PUF, SPFT, } \\
\text { TCLP and EPA methods } \\
1313,1314,1315 \text {, and } \\
1316 \text { to characterize } \\
\text { release of contaminants } \\
\text { from Cast Stone waste } \\
\text { form. }\end{array}$ & & & & & $\begin{array}{l}\text { Applicability of } \\
\text { PCT, VHT, PUF, } \\
\text { and SPFT for Cast } \\
\text { Stone waste form } \\
\text { needs to be } \\
\text { evaluated }\end{array}$ \\
\hline
\end{tabular}




\begin{tabular}{|c|c|c|c|c|c|c|c|c|c|c|c|c|}
\hline \multirow[b]{2}{*}{$\begin{array}{c}\text { Activity } \\
\text { ID }\end{array}$} & \multirow[b]{2}{*}{ Objective } & \multirow[b]{2}{*}{ Requirement } & \multicolumn{3}{|c|}{ Waste Type } & \multicolumn{6}{|c|}{ Approach / Testing Scale } & \multirow[b]{2}{*}{ Comments } \\
\hline & & & $\begin{array}{l}\text { Simulant } \\
\text { Non-Rad }\end{array}$ & $\begin{array}{l}\text { Simulant } \\
\text { Rad }\end{array}$ & $\begin{array}{l}\text { Actual } \\
\text { Waste }\end{array}$ & $\begin{array}{l}\text { Calculation/ } \\
\text { Analysis }\end{array}$ & Laboratory & $\begin{array}{c}\text { Bench/ } \\
\text { Engineering }\end{array}$ & Pilot Scale & $\begin{array}{c}\text { Full-Scale } \\
\text { Component } \\
\text { Testing }\end{array}$ & $\begin{array}{l}\text { Production } \\
\text { Hot Operations }\end{array}$ & \\
\hline 8.2 & & $\begin{array}{l}\text { Determine release from } \\
\text { individual Cast Stone } \\
\text { phases }\end{array}$ & & & & & $\begin{array}{l}\text { SPFT, } \\
\text { XRD, SEM/EDAX }\end{array}$ & & & & & $\begin{array}{l}\text { Applicability of } \\
\text { SPFT for Cast } \\
\text { Stone waste form } \\
\text { needs to be } \\
\text { evaluated }\end{array}$ \\
\hline 8.3 & & $\begin{array}{l}\text { Determine parameters for } \\
\text { kinetic rate-law equation }\end{array}$ & $\begin{array}{l}\text { Selected } \\
\text { representative } \\
\text { simulants }\end{array}$ & Tc spike & & & $\begin{array}{l}\text { SPFT, long-term PCT and } \\
\text { PUF tests }\end{array}$ & & & & & $\begin{array}{l}\text { Applicability of } \\
\text { PCT, PUF, and } \\
\text { SPFT for Cast } \\
\text { Stone waste form } \\
\text { needs to be } \\
\text { evaluated }\end{array}$ \\
\hline 8.4 & & $\begin{array}{l}\text { Determine weathering } \\
\text { process and final state of } \\
\text { the Cast Stone waste form }\end{array}$ & $\begin{array}{l}\text { Selected } \\
\text { representative } \\
\text { simulants }\end{array}$ & & & & $\begin{array}{l}\text { VHT, Short- and } \\
\text { long-term PCT and PUF } \\
\text { followed by solids } \\
\text { characterization (XRD, } \\
\text { SEM-EDS, TEM) }\end{array}$ & & & & & $\begin{array}{l}\text { Applicability of } \\
\text { PCT, VHT, PUF, } \\
\text { and SPFT for Cast } \\
\text { Stone waste form } \\
\text { needs to be } \\
\text { evaluated }\end{array}$ \\
\hline 8.5 & & $\begin{array}{l}\text { Determine transport } \\
\text { parameters of } \\
\text { contaminants Cast Stone } \\
\text { waste form }\end{array}$ & $\begin{array}{l}\text { Selected } \\
\text { representative } \\
\text { simulants spiked } \\
\text { with RCRA } \\
\text { metals and } \\
\text { underlying } \\
\text { hazardous } \\
\text { constituents }\end{array}$ & $\begin{array}{l}\text { Selected } \\
\text { representative } \\
\text { simulants. Tc, } \\
\text { stable I }\end{array}$ & & & $\begin{array}{l}\text { Diffusivity }\left(D_{\text {eff }}\right) \text { using } \\
\text { ANSI/ANS } 16.1 \text {, } \\
\text { EPA 1315, and/or ASTM } \\
\text { C1308. } \\
\text { Porosity, pore size, } \\
\text { hydraulic conductivity }\end{array}$ & & $\begin{array}{l}\text { Tc diffusivity using } \\
\text { ANSI/ANS 16.1, } \\
\text { EPA 1315, and/or ASTM } \\
\text { C1308. } \\
\text { Porosity, pore size, } \\
\text { hydraulic conductivity }\end{array}$ & & & \\
\hline 9 & Provide D & ta to Support Risk and Per & ormance Assessm & ents - Waste Pac & Release & & & & & & & \\
\hline 10 & Provide D & ta to Support Risk and Per & ormance Assessm & ents - Physical S & ity (coor & HQ initiative) & & & & & & \\
\hline 10.1 & & $\begin{array}{l}\text { Determine degradation of } \\
\text { Cast Stone matrix over } \\
\text { time including chemical } \\
\text { and physical changes. } \\
\text { Consider impacts of heat, } \\
\text { radiation, drying, and } \\
\text { reactions with disposal } \\
\text { environment such as } \\
\text { carbonation observed with } \\
\text { cements. }\end{array}$ & $\begin{array}{l}\text { Selected } \\
\text { representative } \\
\text { simulants }\end{array}$ & & & & $\begin{array}{l}\text { Measure compressive } \\
\text { strength (ASTM } \\
\text { C39/C39M) on Cast Stone } \\
\text { waste form cylinders after } \\
\text { thermal cycling (ASTM } \\
\text { B553 [1985]), } \\
\text { biodegradation (ASTM } \\
\text { G21 [2009d], ASTM G22 } \\
\text { [1996]), irradiation, and } \\
\text { water immersion tests } \\
\text { (ANSI/ANS 16.1). } \\
\text { Carbonation. } \\
\text { Solid-phase } \\
\text { characterization (XRD, } \\
\text { SEM, and, } \\
\text { microtomography, Hg } \\
\text { intrusion }\end{array}$ & & & & & \\
\hline
\end{tabular}




\begin{tabular}{|c|c|c|c|c|c|c|c|c|c|c|c|c|}
\hline \multirow[b]{2}{*}{$\begin{array}{c}\text { Activity } \\
\text { ID }\end{array}$} & \multirow[b]{2}{*}{ Objective } & \multirow[b]{2}{*}{ Requirement } & \multicolumn{3}{|c|}{ Waste Type } & \multirow[b]{2}{*}{$\begin{array}{c}\text { Calculation/ } \\
\text { Analysis }\end{array}$} & \multicolumn{5}{|c|}{ Approach / Testing Scale } & \multirow[b]{2}{*}{ Comments } \\
\hline & & & $\begin{array}{r}\text { Simulant } \\
\text { Non-Rad } \\
\end{array}$ & $\begin{array}{c}\text { Simulant } \\
\text { Rad }\end{array}$ & $\begin{array}{l}\text { Actual } \\
\text { Waste }\end{array}$ & & Laboratory & $\begin{array}{c}\text { Bench/ } \\
\text { Engineering }\end{array}$ & Pilot Scale & $\begin{array}{c}\text { Full-Scale } \\
\text { Component } \\
\text { Testing } \\
\end{array}$ & $\begin{array}{c}\text { Production } \\
\text { Hot Operations } \\
\end{array}$ & \\
\hline 11 & Provide D & ta to Support Risk and Pel & formance Asse & ients - Waste & elease $\mathrm{C}$ & tual Model (coordinate w & ith $\mathrm{HQ}$ initiative) & & & & & \\
\hline 11.1 & & $\begin{array}{l}\text { Develop model for waste } \\
\text { form release/radionuclide } \\
\text { source term for PA } \\
\text { modeling }\end{array}$ & & & & $\begin{array}{l}\text { Use all the solid-phase } \\
\text { characterization and } \\
\text { leach data and a } \\
\text { combined kinetic and } \\
\text { thermodynamic physical } \\
\text { (porosity/pore size) and } \\
\text { chemical speciation code } \\
\text { capable of solubility and } \\
\text { sorption modeling. }\end{array}$ & & & & & & \\
\hline 11.2 & & $\begin{array}{l}\text { Add release rates for } \\
\text { dominant phases in Cast } \\
\text { Stone }\end{array}$ & & & & $\begin{array}{l}\text { Use SPFT, long-term } \\
\text { PCT leach results and, } \\
\text { basic } \mathrm{K}_{\mathrm{sp}} \Delta \mathrm{C}_{\mathrm{p}} \\
\text { measurements on pure } \\
\text { end-member minerals } \\
\text { representative of the } \\
\text { Cast Stone waste form. }\end{array}$ & & & & & & $\begin{array}{l}\text { Applicability of } \\
\text { PCT and SPFT for } \\
\text { Cast Stone waste } \\
\text { form needs to be } \\
\text { evaluated }\end{array}$ \\
\hline 11.3 & & $\begin{array}{l}\text { Add thermodynamic data } \\
\text { for key phases }\end{array}$ & & & & $\begin{array}{l}\text { Use experimental results } \\
\text { from above and add } \\
\text { necessary reactions, } \\
\text { basis species into } \\
\text { geochemical speciation } \\
\text { code. }\end{array}$ & & & & & & \\
\hline 11.4 & & $\begin{array}{l}\text { Add impacts of common } \\
\text { ion effects }\end{array}$ & Yes & $\begin{array}{l}\text { Tc, stable I } \\
\text { and RCRA } \\
\text { TM Tc }\end{array}$ & & $\begin{array}{l}\text { Run SPFT and long-term } \\
\text { PCT tests with leachants } \\
\text { containing key macro } \\
\text { constituents } \mathrm{Al} \text { and } \mathrm{Si} \\
\text { over range expected } \\
\text { (dilute to near saturation } \\
\text { in respect to key } \\
\text { secondary minerals). }\end{array}$ & & & & & & $\begin{array}{l}\text { Applicability of } \\
\text { PCT, VHT, PUF, } \\
\text { and SPFT for Cast } \\
\text { Stone waste form } \\
\text { needs to be } \\
\text { evaluated }\end{array}$ \\
\hline 11.5 & & $\begin{array}{l}\text { Add mass transport effects } \\
\text { of monolith }\end{array}$ & & & & $\begin{array}{l}\text { Use results of EPA } 1315 \\
\text { or ANS16.1 monolith } \\
\text { leach tests to add } \\
\text { diffusion constraints to } \\
\text { the source-term } \\
\text { algorithm. }\end{array}$ & & & & & & \\
\hline 11.6 & & $\begin{array}{l}\text { Validate model for waste } \\
\text { form release/radionuclide } \\
\text { source term }\end{array}$ & & & & $\begin{array}{l}\text { Look for natural analog } \\
\text { data sets or make a } \\
\text { prediction for select } \\
\text { waste package/leach } \\
\text { environment and then } \\
\text { run a laboratory test to } \\
\text { compare observed } \\
\text { results vs. predicted } \\
\text { results. }\end{array}$ & $\begin{array}{l}\text { Characterize mineralogy } \\
\text { of weathered natural } \\
\text { analogs. } \\
\text { XRD, SEM/EDS }\end{array}$ & & & & & \\
\hline
\end{tabular}




\begin{tabular}{|c|c|c|c|c|c|c|c|c|c|c|c|c|}
\hline \multirow[b]{2}{*}{$\begin{array}{l}\text { Activity } \\
\text { ID }\end{array}$} & \multirow[b]{2}{*}{ Objective } & \multirow[b]{2}{*}{ Requirement } & \multicolumn{3}{|c|}{ Waste Type } & \multicolumn{6}{|c|}{ Approach / Testing Scale } & \multirow[b]{2}{*}{ Comments } \\
\hline & & & $\begin{array}{l}\text { Simulant } \\
\text { Non-Rad }\end{array}$ & $\begin{array}{l}\text { Simulant } \\
\quad \operatorname{Rad}\end{array}$ & $\begin{array}{l}\text { Actual } \\
\text { Waste }\end{array}$ & $\begin{array}{l}\text { Calculation/ } \\
\text { Analysis }\end{array}$ & Laboratory & $\begin{array}{c}\text { Bench/ } \\
\text { Engineering }\end{array}$ & Pilot Scale & $\begin{array}{l}\text { Full-Scale } \\
\text { Component } \\
\text { Testing }\end{array}$ & $\begin{array}{l}\text { Production } \\
\text { Hot Operations }\end{array}$ & \\
\hline 12 & Provide D & ata to Support Risk and Pe & formance Assessm & ents - Batch Ad: & orption Tests (cc & rdinate with $\mathrm{HQ}$ initiative & & & & & & \\
\hline 12.1 & & $\begin{array}{l}\text { Develop } \mathrm{K}_{\mathrm{d}} \text { adsorption } \\
\text { data for Cast Stone waste } \\
\text { form leachates to support } \\
\text { fate and transport } \\
\text { modeling }\end{array}$ & $\begin{array}{l}\text { Use available } \\
\text { leachates from } \\
\text { lab leach tests }\end{array}$ & $\begin{array}{l}\text { Use available } \\
\text { leachates from } \\
\text { lab leach tests }\end{array}$ & $\begin{array}{l}\text { Use available } \\
\text { leachates from } \\
\text { lab leach tests }\end{array}$ & & $\begin{array}{l}\text { Perform batch Kd tests } \\
\text { with Hanford formation } \\
\text { sediments (sand and } \\
\text { gravel facies). Do a few } \\
\text { flow-through sediment } \\
\text { column adsorption tests to } \\
\text { confirm Kds for mobile } \\
\text { contaminants }\end{array}$ & & & & & \\
\hline 13 & Provide D & ata to Support Risk and Pe & formance Assessm & ents - Validate I & A Predictions (c & ordinate with $\mathrm{HQ}$ initiativ & & & & & & \\
\hline 13.1 & & $\begin{array}{l}\text { Develop information to } \\
\text { validate PA model } \\
\text { predictions for the Cast } \\
\text { Stone waste form using } \\
\text { laboratory testing, } \\
\text { lysimeter testing, and } \\
\text { natural analog studies. }\end{array}$ & & & & & $\begin{array}{l}\text { Perform a few total } \\
\text { near-field flow-through } \\
\text { tests with crushed } \\
\text { monolith material (spiked } \\
\text { COC Cast Stone) } \\
\text { sandwiched in sediment. } \\
\text { PUF system and } \\
\text { unsaturated column; } \\
\text { consider need for field } \\
\text { lysimeter tests }\end{array}$ & & & & & \\
\hline 14 & Provide D & ata to Meet Land Disposal & estrictions Requir & ements & & & & & & & & \\
\hline 14.1 & & $\begin{array}{l}\text { Demonstrate Cast Stone } \\
\text { waste form passes TCLP } \\
\text { test for RCRA metals and } \\
\text { underlying hazardous } \\
\text { constituents }\end{array}$ & $\begin{array}{l}\text { Selected } \\
\text { representative } \\
\text { simulants spiked } \\
\text { with RCRA } \\
\text { metals and } \\
\text { underlying } \\
\text { hazardous } \\
\text { constituents }\end{array}$ & & $\begin{array}{l}\text { Selected } \\
\text { representative } \\
\text { actual waste } \\
\text { samples }\end{array}$ & & $\begin{array}{l}\text { TCLP on spiked simulants } \\
\text { and a few select actual- } \\
\text { waste generated waste } \\
\text { packages }\end{array}$ & & EPA TCLP & & & \\
\hline 14.2 & & $\begin{array}{l}\text { Demonstrate Cast Stone } \\
\text { process retains organic } \\
\text { contaminants }\end{array}$ & $\begin{array}{l}\text { Selected } \\
\text { representative } \\
\text { simulants spiked } \\
\text { with organics }\end{array}$ & & $\begin{array}{l}\text { Selected } \\
\text { representative } \\
\text { actual waste } \\
\text { samples }\end{array}$ & & $\begin{array}{l}\text { Measure organic species } \\
\text { in final waste form }\end{array}$ & & & & & \\
\hline 14.3 & & $\begin{array}{l}\text { Provide data and analysis } \\
\text { to demonstrate the waste } \\
\text { form will meet LDR } \\
\text { treatment standards }\end{array}$ & $\begin{array}{l}\text { Selected } \\
\text { representative } \\
\text { simulants spiked } \\
\text { with RCRA } \\
\text { metals and } \\
\text { underlying } \\
\text { hazardous } \\
\text { constituents }\end{array}$ & & $\begin{array}{l}\text { Selected } \\
\text { representative } \\
\text { actual waste } \\
\text { samples }\end{array}$ & $\begin{array}{l}\text { Demonstrate that } \\
\text { corrosivity characteristic } \\
\text { is deactivated by Cast } \\
\text { Stone. }\end{array}$ & $\begin{array}{l}\text { TCLP tests on samples } \\
\text { from pilot-scale and full- } \\
\text { scale containers }\end{array}$ & & $\begin{array}{l}\text { Demonstrate Cast Stone } \\
\text { process designed and will } \\
\text { be operated to } \\
\text { consistently produce } \\
\text { compliant waste form. } \\
\text { Mass balance to } \\
\text { demonstrate retention of } \\
\text { inorganic hazardous } \\
\text { waste constituents in } \\
\text { waste form. } \\
\text { TCLP }\end{array}$ & $\begin{array}{l}\text { Cast Stone } \\
\text { waste form for } \\
\text { testing. } \\
\text { TCLP }\end{array}$ & & \\
\hline
\end{tabular}




\begin{tabular}{|c|c|c|c|c|c|c|c|c|c|c|c|c|}
\hline \multirow[b]{2}{*}{$\begin{array}{c}\text { Activity } \\
\text { ID }\end{array}$} & \multirow[b]{2}{*}{ Objective } & \multirow[b]{2}{*}{ Requirement } & \multicolumn{3}{|c|}{ Waste Type } & \multicolumn{6}{|c|}{ Approach / Testing Scale } & \multirow[b]{2}{*}{ Comments } \\
\hline & & & $\begin{array}{l}\text { Simulant } \\
\text { Non-Rad }\end{array}$ & $\begin{array}{c}\text { Simulant } \\
\text { Rad }\end{array}$ & $\begin{array}{l}\text { Actual } \\
\text { Waste }\end{array}$ & $\begin{array}{l}\text { Calculation/ } \\
\text { Analysis }\end{array}$ & Laboratory & $\begin{array}{c}\text { Bench/ } \\
\text { Engineering }\end{array}$ & Pilot Scale & $\begin{array}{l}\text { Full-Scale } \\
\text { Component } \\
\text { Testing }\end{array}$ & $\begin{array}{l}\text { Production } \\
\text { Hot Operations }\end{array}$ & \\
\hline 14.4 & & $\begin{array}{l}\text { Provide data and analysis } \\
\text { to demonstrate the waste } \\
\text { form will meet LDR } \\
\text { treatment standards }\end{array}$ & $\begin{array}{l}\text { Selected } \\
\text { representative } \\
\text { simulants spiked } \\
\text { with RCRA } \\
\text { metals and } \\
\text { underlying } \\
\text { hazardous } \\
\text { constituents }\end{array}$ & & $\begin{array}{l}\text { Selected } \\
\text { representative } \\
\text { actual waste } \\
\text { samples }\end{array}$ & & $\begin{array}{l}\text { TCLP tests on Cast Stone } \\
\text { waste form samples }\end{array}$ & & $\begin{array}{l}\text { TCLP tests on samples } \\
\text { from full-scale containers }\end{array}$ & & & \\
\hline
\end{tabular}




\section{References}

Angus MJ and FP Glasser. 1985. "The Chemical Environment in Cement Matrices." Mat. Res. Soc. Symp. Proc., 50:547-556.

ANSI/ANS-American National Standards Institute/American Nuclear Society. 2003. Measurement of the Leachability of Solidified Low-Level Radioactive Wastes by a Short Term Test Procedure.

ANSI/ANS-16.1, La Grange Park, Illinois.

ASTM-American Society for Testing and Materials. 1985. Standard Test Method for Thermocycling of Electroplated Plastics. ASTM B553, West Conshohocken, Pennsylvania.

ASTM-American Society for Testing and Materials. 1996. Standard Practice for Determining Resistance of Plastics to Bacteria. ASTM G22, West Conshohocken, Pennsylvania.

ASTM-American Society for Testing and Materials. 2008a. Standard Test Methods for Determining Chemical Durability of Nuclear, Hazardous, and Mixed Waste Glasses and Multiphase Glass Ceramics: The Product Consistency Test (PCT). ASTM C1285, West Conshohocken, Pennsylvania.

ASTM-American Society for Testing and Materials. 2008b. Standard Test Method for Accelerated Leach Test for Diffusive Releases from Solidified Waste and a Computer Program to Model Diffusive, Fractional Leaching from Cylindrical Waste Forms. ASTM C1308, West Conshohocken, Pennsylvania.

ASTM-American Society for Testing and Materials. 2009a. Standard Test Method for Compressive Strength of Cylindrical Concrete Specimens. ASTM C39/C39M, West Conshohocken, Pennsylvania.

ASTM-American Society for Testing and Materials. 2009b. Standard Test Method for Measuring Waste Glass or Glass Ceramic Durability by Vapor Hydration Test. ASTM C1663, West Conshohocken, Pennsylvania.

ASTM-American Society for Testing and Materials. 2009d. Standard Practice for Determining Resistance of Synthetic Polymeric Materials to Fungi. ASTM G21, West Conshohocken, Pennsylvania.

Lee W and B Batchelor. 2003. "Reductive Capacity of Natural Reductants." Environmental Science Technology 37: 535-541. 


\section{Appendix C}

Solution and Solid-Phase Analysis Techniques 


\section{Appendix C}

\section{Solution and Solid-Phase Analysis Techniques}

This appendix gives brief descriptions of the various analytical techniques/instruments that are used to analyze the leachate solutions generated in the various waste-form- and waste-package-release laboratory tests and the initial solid phases subjected to the leach testing or the final weathered (leached) solid phases.

\section{C.1 Solution Analysis}

The following instruments are used for analyzing leachants and leachates from the various leach tests to identify the elements/species present and to measure the concentrations of identified constituents.

Inductively coupled plasma-optical emission spectroscopy/-mass spectroscopy (ICP-OES/ICP-MS): In optical emission spectroscopy (OES), all elements in a solution sample are thermally excited in the core of an inductively coupled plasma, which can reach temperatures up to about $8000^{\circ} \mathrm{C}$, and give off light at their characteristic wavelengths. The emitting light is collected by the spectrometer, resolved into a spectrum of its constituent wavelengths, and converted to an elemental concentration by comparison with calibration standards. The ICP-OES is sometimes referred to as ICP-AES (-atomic emission spectroscopy). In mass spectroscopy (MS), the plasma is also used to generate ions that can be separated, collected according to their mass-to-charge ratios, and analyzed by the mass analyzer. The ICP-OES instrument is widely used to analyze concentrations of major and minor generally cationic constituents in liquid samples. The ICP-MS instrument is widely used to analyze concentrations of trace elements such as the RCRA metals but including long-lived radioisotopes such as ${ }^{99} \mathrm{Tc}$ and ${ }^{129} \mathrm{I}$ in liquid samples with great sensitivity (low detection limits). Although the ICP-OES emission spectra can be complicated because of the interelement interferences, and the ICP-MS mass spectra can exhibit complex (two elements bound together) interference from the common matrix elements, the two instruments used in concert can analyze at least 70 elements in a single solution sample, from major components to those in very low concentrations (detection limits close to sub-ppb), with high accuracy and precision.

Ion chromatograph (IC): The IC is typically used for measuring concentrations of major anions, but can as well measure cations in solutions at concentrations from hundreds of ppm down to the ppb range. The ionic species are separated in packed columns based on their different electrical interactions (charge) and size. The separations are aided by the use of pressurized chromatographic columns. After injection of the sample, an eluent solution is passed through the column wherein the absorbed ions begin separating from each other and eluting from the chromatography column. Generally, the eluent is continuously monitored for conductivity, and the retention time (time that species reaches the conductivity probe) of different species determines the identity of the species. The height or area of the conductivity peak indicates the concentration of the identified species. Complex mixtures of known standards and several different chromatographic columns are used to calibrate the IC for measuring unknown solutions.

pH and Eh (Redox Potential): Most leachates are also characterized for $\mathrm{pH}$ and Eh using standard probes and meters. 


\section{C.2 Solid Analysis}

The following instruments are typically used for identifying elements, minerals, solid-phase morphology, chemical composition of solid surfaces, chemical bond structures and lengths, and the oxidation state of elements in the solids.

Carbon Content: The total carbon concentration of the solids is measured with a Total Organic Carbon Analyzer. At Pacific Northwest National Laboratory (PNNL), a Shimadzu TOC-V CSN instrument with an SSM-5000A Total Organic Carbon Analyzer is used that relies on combusting the solids at approximately $900^{\circ} \mathrm{C}$. The procedure is based on the ASTM Method, "Standard Test Methods for Analysis of Metal Bearing Ores and Related Materials by Combustion Infrared Absorption Spectrometry" (ASTM 2001). Samples are placed into a precombusted, tared, ceramic combustion sample holder and weighed on a calibrated balance. After the combustion sample holders are placed into the furnace introduction tube, an approximately 2 minute waiting period is allowed for the ultrapure oxygen carrier gas to remove any carbon dioxide $\left(\mathrm{CO}_{2}\right)$ introduced to the system from the atmosphere during sample placement. After this sparging process, the sample is moved into the combustion furnace, and the combustion begins. Carrier gas then transfers combustion products to the cell of a nondispersive infrared gas analyzer where the $\mathrm{CO}_{2}$ is detected and measured. The amount of $\mathrm{CO}_{2}$ measured is proportional to the total carbon content of the sample. Adequate system performance is confirmed by analyzing known quantities of a calcium carbonate standard.

Solid samples will also be analyzed for inorganic carbon content by placing a small aliquot of oven-dry solid into a ceramic combustion boat. The combustion boat is placed into the sample introduction tube where it is sparged with ultrapure oxygen for 2 minutes to remove atmospheric $\mathrm{CO}_{2}$. A small amount (usually $0.6 \mathrm{~mL}$ ) of $3 \mathrm{M}$ phosphoric acid is then added to the sample in the combustion boat. The boat is moved into the combustion furnace where it is heated to $200^{\circ} \mathrm{C}$. Samples are completely covered by the acid to allow a full reaction to occur. Ultrapure oxygen sweeps the resulting $\mathrm{CO}_{2}$ through a dehumidifier and scrubber into the cell of a nondispersive infrared gas analyzer where the $\mathrm{CO}_{2}$ is detected and measured. The amount of $\mathrm{CO}_{2}$ measured is proportional to the inorganic carbon content of the sample.

The organic carbon content is determined by the difference between the inorganic carbon and total carbon concentration.

X-ray Diffraction (XRD): XRD is a rapid analytical technique primarily used to identify crystalline solid materials and can provide information on unit-cell dimensions for the study of crystal structures and atomic spacing. XRD is based on constructive interference of monochromatic X-rays generated by a cathode ray tube $\left(\mathrm{Cu} \mathrm{K}_{\alpha}\right.$ radiation $\left.=0.5418 \AA\right)$ with a crystalline sample. The interaction of the incident rays with the sample produces constructive interference (or diffracted X-rays) when conditions satisfy Bragg's Law (Moore 1997). These diffracted X-rays are detected, processed, and counted by scanning the sample through a range of $2 \theta$ angles (usually from $\sim 5^{\circ}$ to $70^{\circ}$ ). Conversion of the diffraction peaks to $\mathrm{d}$-spacings allows identification of the mineral because each mineral has a set of unique d-spacings. Peak positions occur where the X-ray beam has been diffracted by the crystal lattice. Comprehensive databases of the d-spacings for known standard (reference) minerals are available in software packages that can quickly perform peak matching of unknown spectra to identify likely minerals in the spectra. Based on the XRD patterns and comparison with standard references, identification of minerals associated with the secondary waste forms can be identified, and the average bulk composition of minerals is also determined 
semiquantitatively based on the height of the identified peaks. In addition, use of a small-angle X-ray scattering device in combination with XRD can also reveal more information on the particle size distribution and pore size distribution of the samples.

X-ray Fluorescence (XRF): XRF is a nondestructive technique that is used to quantify the elemental composition of solid and liquid samples. XRF measures the emission of characteristic "secondary" (or fluorescent) X-rays from a sample that is being bombarded with high-energy X-rays or gamma rays. As photon energy (or an electron) is absorbed, a state of the target element changes from the ground state (lowest energy state) to an excited state (higher energy state). The excited state of the element then returns back to the normal ground state with the emission of a photon (fluorescence) or an electron in the outer shell of the orbital. Detection of the intensity and energy of emissions, which are characteristic of each element, is used for chemical elemental analysis. XRF is capable of detecting elements from aluminum to uranium in concentrations from $\mathrm{ppm}$ to $100 \mathrm{wt} \%$. Through the use of appropriate reference standards, XRF can accurately quantify the elemental composition of both solid and liquid samples (Couture et al. 1993). XRF can analyze areas as small as $30 \mu \mathrm{m}$ with a sampling depth as great as $10 \mu \mathrm{m}$. However, no elements lighter than Al can be measured by XRF without special thin window detectors. The XRF technique is generally part of an attachment to scanning electron microscopes (SEM) to allow chemical analysis of small regions of mounted solids. When combined with SEM, the common acronym is SEM-EDS (scanning electron microscopy-energy dispersive spectroscopy).

Microscopes: Scanning electron microscopy rasters across a sample surface using a focused electron beam that provides high-resolution images of the sample surface. Transmission electron microscopy (TEM) and scanning transmission electron microscopy (STEM) are related techniques that use an electron beam to image a sample surface at even greater resolution (smaller sizes/areas probed). Using microscopes such as SEM, TEM, and STEM, the high-resolution images of surface morphology and particle size analysis in the solid waste form can be obtained. Analysis of surface morphology can be used for detecting cracks or any fractures that may develop in the waste forms. Compared to SEM, both TEM and STEM have better spatial resolution, even though they require significantly more sample preparation time and effort. However, in addition to outstanding image resolution, it is also possible to characterize crystallographic phase and crystallographic orientation by use of the diffraction mode in TEM.

SEM-EDS: Energy-dispersive X-ray spectroscopy (EDS or EDX) is an analytical technique used for the elemental analysis or chemical characterization of a sample. It is one of the variants of X-ray fluorescence spectroscopy that relies on the investigation of a sample through interactions between electromagnetic radiation and matter, analyzing X-rays emitted by the matter in response to being hit with charged particles. Its characterization capabilities are due in large part to the fundamental principle that each element has a unique atomic structure, allowing X-rays that are characteristic of an element's atomic structure to be identified uniquely from those of other elements.

To stimulate the emission of characteristic X-rays from a specimen, a high-energy beam of charged particles such as electrons or protons, or a beam of X-rays, is focused into the sample being studied. At rest, an atom within the sample contains ground-state (or unexcited) electrons in discrete energy levels or electron shells bound to the nucleus. The incident beam may excite an electron in an inner shell, ejecting it from the shell while creating an electron hole where the electron was. An electron from an outer, higher-energy shell then fills the hole, and the difference in energy between the higher-energy shell and the lower-energy shell may be released in the form of an X-ray. The number and energy of the X-rays 
emitted from a specimen can be measured by an energy-dispersive spectrometer. Because the energy of the X-rays is characteristic of the difference in energy between the two shells and of the atomic structure of the element from which they were emitted, the elemental composition of the specimen can be measured.

There are four primary components of the EDS setup: the beam source, the X-ray detector, the pulse processor, and the analyzer. A number of freestanding EDS systems exist; however, EDS systems are most commonly found on scanning electron microscopes (SEM-EDS) and electron microprobes. Scanning electron microscopes are equipped with a cathode and magnetic lenses to create and focus a beam of electrons, and since the 1960 s, they have been equipped with elemental analysis capabilities. A detector is used to convert X-ray energy into voltage signals; this information is sent to a pulse processor, which measures the signals and passes them onto an analyzer for data display and analysis.

Fourier Transform Infrared Spectroscopy (FTIR): FTIR provides specific information about chemical bonding and molecular structures, making it useful for analyzing organic materials and certain inorganic materials. Because chemical bonds vibrate at characteristic frequencies, a vibrational spectrum is also characteristic of a given sample, and individual vibration peaks are associated with the presence of particular structural groups within the sample, which can be used to infer the presence of particular phases or molecular groups. Vibrational spectra can be easily obtained for crystalline or amorphous solids, liquids, or gases and can be easily applied to systems involving elements of low atomic weight. Since a vibrational spectrum is dependent on the interatomic forces, temperature, and composition in a particular sample, it is a sensitive probe of the microscopic structure and bonding within the material. When the chemicals are exposed to infrared radiation, they absorb the radiation at frequencies that match their vibration modes. Measuring the radiation absorption as a function of frequency produces a spectrum that can be also used to identify functional groups and compounds.

Raman Spectroscopy: Raman Spectroscopy also determines the chemical structure of a sample and identifies the compounds present by measuring molecular vibrations, similar to FTIR. However, the Raman method yields better spatial resolution and enables the analysis of smaller samples. Raman is a good technique for the qualitative analysis of organic and/or inorganic mixed materials and can also be employed for semiquantitative and quantitative analysis. It can be used to identify inorganic compounds both in the bulk and in individual particles to 1) map the distribution of components in a sample through Raman imaging and depth profiling, 2) investigate the presence of different carbon types and their relative proportions, 3) determine inorganic oxides and their valence states, and 4) measure the stress and crystalline structure in weathered waste forms and other materials.

X-ray Photoelectron Spectroscopy (XPS): XPS is based on the photoelectric effect. When materials are bombarded with X-rays strong enough to eject electrons from the inner shell of atoms, the difference between the incoming photon energy and electron binding energy is converted to kinetic energy in the escaping photoelectron (Hochella 1988). A chemical shift, defined as the difference in binding energy between a particular line and the binding energy for the same line in a reference compound, can distinguish between two different oxidation states of an element in a given sample or between different coordination environments. Alternatively, XPS can be used to perform depth profiling of elemental composition to study alteration or dissolution of mineral (or waste form) surfaces. XPS is a surface-sensitive technique because it is based on detection of photoelectrons that have undergone no inelastic collisions, and this can only happen near the surface. The depth of analysis is therefore typically between 10 and $50 \AA$. Because every element has a unique atomic structure, and the low-energy X-rays 
used can only excite a few atomic levels from each element, elements can be identified unambiguously in most cases. A wide-energy-range "survey" scan can be used to identify the elements present in the surfaces of solids, but it is not used for quantification of elemental composition because it lacks resolution.

X-ray Absorption Spectroscopy (XAS): X-ray photon energy is used to eject a photoelectron from the core shell of an atom in the target material at the time of X-ray absorption. X-ray absorption occurs when an X-ray photon travels through solid matter. The intensity of the incident X-ray photon decreases by passing through the material, and the absorption coefficient is determined by the thickness of matter and the difference in intensities between incident and transmitted X-rays. As the energy of the photon increases, the absorption coefficient generally decreases until the incident energy reaches the threshold energy at which the absorption coefficient increases abruptly. The threshold energy is the minimum energy required to eject an electron from a core shell of an atomic orbital in the material. This sharp increment in the absorption coefficient is attributed to the photoelectron ejection and is referred to as the absorption edge. The absorption coefficient as a function of incident photon energy is used for the analysis of XAS. The photoelectron emitted by X-ray absorption is partially backscattered with the neighboring atoms before the ejection occurs (Teo 1986). Multiple scattering of ejected photoelectrons is used as the measuring technique in X-ray absorption near-edge structure (XANES), while a single scattering mainly occurs in extended X-ray absorption fine structure (EXAFS) measurement techniques. Both XANES and EXAFS spectroscopy probe only the local environment because of the low energy of photoelectrons. Both techniques are element selective and yield molecular local environmental information such as oxidation state, element identity, and bonding information (coordination numbers and bonding distance between the central and the nearest neighboring elements). The advantage of XAS is that most elements (except hydrogen) in the periodic table can be studied in all types of phases (crystalline, amorphous solids, liquids, gases, or mineral-water interfaces), even at low concentration levels (approximately 1 to $10 \mathrm{ppm}$ ). XAS is an in situ technique that does not need any special sample preparation like drying or vacuum conditions (Brown et al. 1988, Koningsberger and Prins 1988). The disadvantage of XAS techniques is that high-intensity X-ray sources (i.e., a synchrotron radiation facility) are required, and the data collection and analysis processes are quite complicated/time consuming and expensive. Even though XAS is a short-range-order probe (approximately 4 to $6 \AA$ from the absorber) as compared to XRD, it provides remarkably unique information on the local structural environment in most materials so that it complements information from other spectroscopic methods to increase our understanding of binding and leaching mechanisms of contaminants in waste forms.

Gas Adsorption Analysis: Because the transport or diffusion processes of contaminants through porous materials are closely related to the specific surface area and the pore structure of the material, these physical characteristics need to be determined for waste forms/packages. The specific surface area is the amount of available surface area per unit weight of the solid material and can be measured at liquid nitrogen temperature (approximately $77 \mathrm{~K}$ ) using the $\mathrm{N}_{2}$-BET method (Brunauer et al. 1938, Gregg and Sing 1982, Webb and Orr 1997). Pore information, including average pore diameter and pore volume (or area) distribution as a function of pore diameter, can be also obtained from the complete adsorption isotherm using the Barrett-Joyner-Halenda (BJH) method (Barrett et al. 1951). 
Hg Porosimetry: The following web page has a good introduction:

http://micromeritics3.reachlocal.com/coupon/?scid $=1558580 \& \mathrm{cid}=598524 \& \mathrm{tc}=100902202702072$

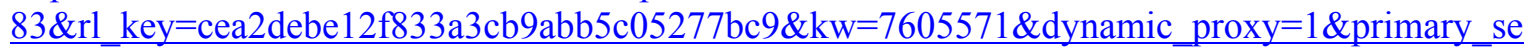
$\underline{\mathrm{rv}=\text { micromeritics3.reachlocal.net\&pub cr } \mathrm{id}=4701462369}$

Vertical Scanning Interferometry (VSI): VSI is an optical light technique in which minute changes in surface height can be detected (nanometer range), and the change in height can be correlated with a dissolution rate (Lüttge et al. 1999, Lasaga and Lüttge 2001, Lüttge and Conrad 2004, Green and Lüttge 2006, Koyuncu et al. 2006). Before a dissolution test is run, a small portion of the test material is coated with a waterproof substance that protects the surface from reaction with water. During the test, the unprotected portion of the surface is subjected to dissolution, and the surface dissolves and retreats in height. After the test, the protective material is removed, and the protected area is used as a reference surface to which the height of the dissolved surface is compared. The difference in height is proportional to the dissolution rate. This technique is especially useful for quantifying dissolution rates of insoluble minerals, such as many glasses. In traditional dissolution tests, the test specimen is placed in a reactor filled with aqueous solution. Aliquots of solution are periodically collected, and the dissolution rate of the specimen is proportional to the concentration of dissolved elements released from the specimen. Because of the slow release of dissolved material to solution, concentrations of elements in solution that would normally quantify dissolution rates are very low, presenting analytical difficulties. However, by analyzing the change in height between the reference and reactive surface using the VSI technique, dissolution rates of sparingly soluble solids in solution can be easily quantified. Presently, the VSI technique is only available for use on nonradioactive samples.

X-ray Microtomography (XMT): Different components of the solid lead to different X-ray absorption, such as denser elements showing the stronger absorption. A visible-light image is generated by a fluorescent screen and then projected by an optical microscope onto a charge-coupled-device (CCD) camera. The shadow projections of the object are recorded with a high-resolution CCD-based camera system. After correction and normalization of the projections, the tomograms can be reconstructed for two- and three-dimensional (3-D) images using the filtered back-projection technique. Incoming X-ray energy of the synchrotron radiation is also controlled very precisely with the help of a double crystal monochromator set below and above the absorption edge of an element to be investigated. Only the distribution of the particular element becomes visible using this setup because the absorption of all other elements stays practically constant across the absorption edge (Tricart et al. 2000). The synchrotron-based XMT apparatus achieves spatial resolutions of 3 to $5 \mu \mathrm{m}$ and can determine attenuation coefficients to about $5 \%$ accuracy for single voxels while the conventional tomography technique has 10-200 $\mu \mathrm{m}$ spatial resolution, depending on the size of the specimen and X-ray source. Because the brightness differences in the reconstructed tomograph slice are normally a replica of the material's density distribution, chemical compositions can be distinguishable by creating image contrasts, which then allow specific elements to be distinguished. Use of this behavior also allows development of 3-D elemental distribution maps of the sample. Three-D images of the internal microstructure of mixed solids and pore structure characteristics of the Cast Stone are the key uses planned for XMT.

Nuclear magnetic resonance (NMR) spectroscopy: NMR spectroscopy is a technique to study the static structure and dynamic behavior of condensed phases because it directly examines the properties of specific elements located in solid matrices and often offers significant advantages over diffraction methods and vibrational spectroscopy (Kirkpatrick 1988). The nuclei of many elemental isotopes have 
characteristic spins, such as integral spin, fractional spin, and zero spin. In the presence of an external magnetic field, two spin states exist in nuclei, $+1 / 2$ and $-1 / 2$, and the magnetic field causes the spin system to tip with respect to the applied magnetic field. Irradiation of a sample with radio frequency energy corresponding exactly to the spin state separation of a specific set of nuclei will cause excitation of those nuclei in the $+1 / 2$ state to the higher $-1 / 2$ spin state. An NMR spectrum can be acquired by varying or sweeping the magnetic field over a small range while observing the radio frequency signal from the sample (Stebbins 1988). Coordination information of species, bonding arrangements, and the diffusion coefficient of hydrogen in the waste forms can be determined using the NMR spectra, including chemical shift, chemical exchange, and nuclear spin relaxation.

Mössbauer Spectroscopy: Mössbauer spectroscopy involves the resonant emission and absorption of gamma radiation by specific atomic nuclei in solids (Hawthorne 1988). Mössbauer spectroscopy is similar to NMR spectroscopy. In Mössbauer spectroscopy, a solid sample is exposed to a beam of gamma radiation, and a detector measures the intensity of the beam transmitted through the sample. The atoms in the source emitting the gamma rays must be of the same isotope as the atoms in the sample absorbing them. A significant fraction of the emitted gamma rays will not lose energy to recoil and thus will have approximately the right energy to be absorbed by the target atoms. In the resulting spectra, gamma-ray intensity is plotted as a function of the source velocity. At velocities corresponding to the resonant energy levels of the sample, some of the gamma rays are absorbed, resulting in a drop in the measured intensity and a corresponding dip in the spectrum. The number, positions, and intensities of the peaks provide information about the chemical environment of the absorbing nuclei and can be used to characterize solids. Because of extremely fine energy resolution, Mössbauer spectroscopy can detect even subtle changes in the nuclear environment of the relevant atoms, identify the presence of particular compounds and phase transformations (e.g., the ratio of $\mathrm{Fe}^{2+}$ to $\mathrm{Fe}^{3+}$ ), and provide the crystallite size and grain structure of a material.

Reduction Capacity Procedures: See Angus and Glasser (1985) and Lee and Batchelor (2003).

\section{C.3 References}

Angus MJ and FP Glasser. 1985. "The Chemical Environment in Cement Matrices." Mat. Res. Soc. Symp. Proc., 50:547-556.

ASTM-American Society for Testing and Materials. 2001. Standard Test Methods for Analysis of Metal Bearing Ores and Related Materials by Combustion Infrared Absorption Spectrometry. E1915-01, West Conshohocken, Pennsylvania.

Barrett EP, LG Joyner, and PP Halenda. 1951. "The Determination of Pore Volume and Area Distributions in Porous Substances. I. Computations from Nitrogen Isotherms." J. Am. Chem. Soc., 73:373-380. DOI:10.1021/ja01145a126.

Brown GE, G Calas, GA Waychunas, and Petiau. 1988. "X-ray Absorption Spectroscopy and Its Applications in Mineralogy and Geochemistry." In: Hawthorne, FC (ed.), Spectroscopic Methods in Mineralogy and Geology, Reviews in Mineralogy, 18:431-512. Mineralogical Society of America, Washington, D.C. 
Brunauer S, PH Emmett, and E Teller. 1938. “Adsorption of Gases in Multimolecular Layers.” Journal of the American Chemical Society, 60:309-319.

Couture RA, MS Smith, and RF Dymek. 1993. "X-ray fluorescence analysis of silicate rocks using fused glass discs and a side-window $\mathrm{Rh}$ source tube: accuracy, precision and reproducibility." Chemical Geology, 110:315-328.

Gregg SJ and KSW Sing. 1982. Adsorption, surface area, and porosity. 2nd edition. Academic Press, Inc., Orlando, Florida.

Green E and A Lüttge. 2006. "Incongruent Dissolution of Wollastonite Measured with Vertical Scanning Interferometry.” American Mineralogist, 91:430-434.

Hawthorne FC. 1988. "Mossbauer spectroscopy." In: Hawthorne, FC (ed.) Spectroscopic Methods in Mineralogy and Geology Reviews in Mineralogy, 18:573-637. Mineralogical Society of America, Washington, D.C.

Hochella MF, Jr. 1988. “Auger electron and X-ray photoelectron spectroscopies.” In: Hawthorne, FC (ed.), Spectroscopic Methods in Mineralogy and Geology Reviews in Mineralogy, 18:573-637.

Mineralogical Society of America, Washington, D.C.

Kirkpatrick RJ. 1988. "MAS NMR spectroscopy of minerals and glasses.” In: Hawthorne, FC (ed.), Mineral-water Interface Geochemistry. Reviews in Mineralogy 18:341-403. Mineralogical Society of America, Washington, D.C.

Koningsberger DC and R Prins. 1988. X-ray Absorption: Principles, Applications, Techniques of EXAFS, SEXAFS, and XANES. Wiley, New York.

Koyuncu I, J Brant, A Lüttge, and MR Riesner. 2006. "A Comparison of Vertical Scanning Interferometry (VSI) and Atomic Force Microscopy (AFM) for Characterizing Membrane Surface Topography." Journal of Membrane Science, 278: 410-417.

Lasaga AC and A Lüttge. 2001. "Variation of Crystal Dissolution Rate Based on a Dissolution Stepwave Model.” Science, 291(5512):2400-2404.

Lee W and B Batchelor. 2003. "Reductive Capacity of Natural Reductants." Environnemental Science Technology, 37:535-541.

Lüttge A and PG Conrad. 2004. "Direct Observation of Microbial Inhibition of Calcite Dissolution." Applied and Environmental Microbiology, 70:1627-1632.

Lüttge A, EW Bolton, and AC Lasaga 1999. "An Interferometric Study of the Dissolution Kinetics of Anorthite: The Role of Reactive Surface Area.” American Journal of Science, 299: 652-678.

Lüttge A and PG Conrad. 2004. "Direct Observation of Microbial Inhibition of Calcite Dissolution." Applied and Environmental Microbiology, 70:1627-1632. 
Moore DM and RC Reynolds, Jr. 1997. X-Ray diffraction and the Identification and Analysis of Clay Minerals. 2nd Ed., Oxford University Press, New York.

Stebbins JF. 1988. "NMR spectroscopy and dynamic process in mineralogy and geochemistry." In: Hawthorne, FC (ed.), Mineral-water Interface Geochemistry, 18:431-512. Mineralogical Society of America, Washington, D.C,.

Teo BK. 1986. "EXAFS: Basic Principles and Data Analysis." Inorganic Chemistry Concepts. Springer-Verlag, New York.

Tricart JP, M Van Geet, and A Sasov. 2000. "Using Micro-CT for 3D characterization of geological materials." Microscopy and Analysis, 65:31.

Webb PA and C Orr. 1997. Analytical Methods in Fine Particle Technology. Micromeritics Instrument Corporation, Norcross, Georgia. 


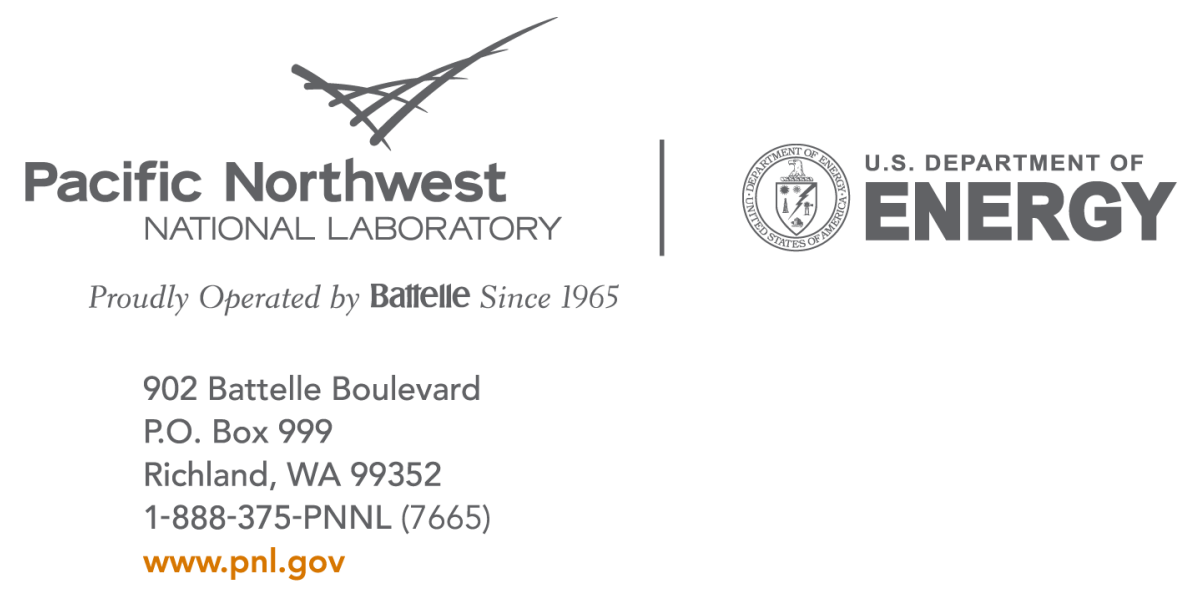

